\title{
THE CEO ROLE IN NEW ZEALAND: PERCEPTIONS AND INTERPRETATIVE SCHEMA - TENSIONS AND PARADOXES
}

Beverley McNally

A thesis submitted in fulfilment of the requirements for the degree of Doctor of Philosophy

Victoria University of Wellington 2009 


\section{Dedication}

For my Dad, Mick, who was the feminist in our family, the man who complained "even the cat is a woman". His philosophy was his 'girls could do anything'. What 'his girls did' was not the issue. That they tried as hard as they could and were the best they could be was what was important to him. His belief in 'his girls' gave me the strength to complete a process that required tenacity and a level of commitment that was beyond any imagining. Dad, I salute you and thank you for your faith in me. I love you. Who you were; your origins as a man, your sense of justice and its importance, is what gave me the strength to achieve what I have in my life.

For Heather C, Paul S and Di O-K, Graham H, Pat C, Wayne T and Wally the horseman, who, in their own very special and sad way demonstrated to me that life is not a dress rehearsal, it is the main event.

And for those who may choose to follow in the footsteps created by this work, some thoughts:

“But I don't want to go among mad people,” said Alice.

"Oh, but you can't help that," said the Cheshire Cat. "We're all mad here. I'm mad. You're mad." "How do you know I'm mad?" asked Alice.

"You must be," said the Cat, "or you wouldn't have come here".

Lewis Carroll, as reported in (Corace 2001) 


\section{Acknowledgements}

Firstly, I acknowledge all those unnamed individuals who made such heartfelt contributions to this study. It was your willingness to share your experiences, concerns; hopes and dreams that made this research project a reality and kept it alive. Your preparedness to trust a comparative stranger with so much of your precious time, to be open with your feelings and to provide such valuable information resulted in this study taking on a life that was not previously envisaged. I salute your passion and commitment.

To express my thanks to you for your passion and commitment, I turned to President Václav Havel, who made the following comments upon receiving the Open Society Prize at the Central European University in Budapest in 1999:

There are no exact guidelines. There are probably no guidelines at all. The only thing I can recommend at this stage is a sense of humour, and ability to see things in their ridiculous and absurd dimensions, to laugh with others and at ourselves, to have a sense of irony regarding everything that calls out for parody in this world. In other words, I can only recommend perspective and distance. Have an awareness of all the most dangerous kinds of vanity, both in others and in ourselves. Possess a good mind and a modest certainty about the meaning of things. Have gratitude for the gift of life and the courage to take responsibility for it. Maintain a vigilance of spirit.

Paul Wilson (Trans) as cited in (Patton, 2002, p. 588) 
A very important thank you to the following people:

For John Davies: Who, in your own words, have been both my mentor and tormentor. Thank you for your support in various forms throughout my association with Victoria University of Wellington. You were at the start of my journey as a business student, ending as my supervisor in the latter part of this project. Your calm considered approach played a vital role in the successful completion of all my studies.

For Sally Riad: Your willingness to step into the role as co-supervisor while still on sabbatical was greatly appreciated and words cannot express my thanks. Your knowledge and skills and professionalism have taught me great deal and I will never forget your collegiality and support.

Professor Brad Jackson, who became my supervisor in an environment that was dynamic and changing, despite this you always remained calm and considered, your knowledge and skills in leadership played a large part in making this thesis a reality. Also a special note of thanks for Associate Professor Dai Gilbertson who stepped into the breach after Professor Parry and Professor Jackson departed for pastures new. Your humour and help negotiating the processes within PhD land was gratefully received.

To my colleagues at the Centre for the Study of Leadership, at the Victoria University of Wellington, both past and present my heartfelt thanks for your support, encouragement and advice over the years. My Masters degree and this project would not have been possible without you. A special vote of thanks goes to, Professor Ken Parry, now of Bond University Australia, who was the inaugural director of the Centre. His support during the completion of my Master's dissertation and passion for leadership provided the initial impetus and supervision for this work.

To Adrienne McGovern-Wilson, your trustworthiness and support played a large part in my keeping going when the going got tough. Janet Keilar, the Commerce Librarian, your skill at seeking out even the most obscure of citations was much appreciated. To Tricia Lapham, thanks for your support and assistance throughout and for Pat Cumming (RIP), whose motherly advice and kindness was welcome on those occasions we drove to work together. 
Betty, Wally (RIP) and the people of Bayly's Beach - a community that understands what life is all about and how important it is to pause and reflect on one's own journey, to live life and live it to the full - the sound of the ocean, the smell of salt air, the horse and I with the wind in our faces and the speed taking my mind to different places, letting me construct a different set of realities for the world in which I dwell.

For my family and personal friends, thank you for reminding me with monotonous regularity and in your own inimitable way, that celebrations are not held for incomplete PhDs. Your love and support was a rock on which I leant on many occasions.

John Woods, PG, Doug, Peter, Andrea, David W, Biddy Welch and Paul Geraghty, and the rest of my colleagues at the Open Polytechnic, (you know who you are) thank you for your ongoing support.

Richard, Ann and Alan, my Henley MBA friends, whose help, support and encouragement via the regular "Glee Club" meetings helped sustain me throughout an arduous, trying, yet satisfying process.

Helena, Samantha, Amelia, Lara and Richard, your neighbourly support, love, laughter, and help with various household chores aided greatly in the completion of this project.

Finally, to the Wine Club, the conviviality and the monthly tastings provided me with a welcome relief from the papers, books, computer and an isolated, paper-filled $\mathrm{PhD}$ study. 


\begin{abstract}
This thesis examines the perceptions of the CEO role in large New Zealand organisations. The study is a response to calls from scholars for more empirical work on executive leadership specifically, as it pertains to the CEO role, which scholars have identified as an under-researched and less clearly understood construct. A modified grounded theory approach was utilised to establish the research participants' perceptions of the CEO role. Specifically, this thesis focuses on how the participants interpret and construct meaning from the interactions occurring within their context.
\end{abstract}

The sample for the study comprised 30 participants, 22 CEOs and 8 executives in nonCEO roles. The criteria for selection related to the position an individual held in an organisation. The individual was, or had been, a CEO in a large New Zealand organisation or was directly involved with the CEO role, for example, a board chairperson. The primary data were collected from semi-structured interviews of between one to two hours in duration. Informal interviews, company publications and documentation, and the relevant research literature supplemented the primary data. The concurrent data collection and analysis identified two interpretative schemas that guide and inform the CEO role. These were the leadership interpretative schema and the institutionalised interpretative schema. The participants in this study articulated the enactment of their leadership within the frame of the leadership interpretative schema. However, the predominant schema informing the CEO role was the institutionalised interpretative schema. The contact between the two schemas represented collisions. Such collisions, in turn, created a set of tensions and paradoxes for the CEO. In seeking a clearer explanation of these tensions and paradoxes, the study identified the basic social structural process of the CEO role as a social institution.

This thesis re-conceptualises the CEO role as a social institution. As such it is a multifaceted construct with its own set of social norms that create, guide and sustain a social order governing the behaviour of the CEO. Situated within this social structural process the study identified the social psychological process balancing the tensions and paradoxes. The study identified that the CEOs perceived the need to be able to balance the tensions and paradoxes within their context if they are to enact their role effectively. In other words, an effective CEO is perceived as acting as a mediator, successfully 
mediating between the dualities created by the conflicting expectations of the two interpretative schemas.

Establishing context as a primary factor within the study allowed the contextual factors that enhanced or inhibited the enactment of the CEO role in New Zealand to receive their due emphasis. Such a focus was responsible for allowing the social, cultural, legal and economic forces, within the context of the CEO, to be brought to the fore. These, in turn, were perceived by the participants as having their genesis within in the religious, economic and historical traditions of New Zealand's European colonialism, and in their responses to it. In this study, context is embraced as a means for allowing the voices of the participants to be brought forward and be heard, whereas, the concept of voice has been traditionally ascribed to the weak, minorities, and disadvantaged (Baez, 2002). Paradoxically, this research identified that CEOs perceive themselves as having little voice. This despite the perception, both within society and within organisations, that CEOs have considerable power and status and therefore have the ability to voice their 'true feelings'. The analysis identified that they perceive constraints and silencing with regard to certain aspects of their role, suggesting further research on the CEO responses to such constraints is required.

The outcomes of this study have implications for research and practice. In terms of the former, there are opportunities for researchers to build on the findings of the study thereby, contributing to the body of knowledge. With regards to practice, the study raises implications for those involved in the governance function, policy-makers and those having responsibilities for the development of individuals to fill the CEO role. 


\section{Table of Contents}

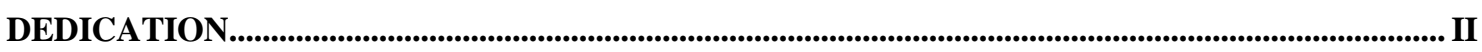

ACKNOWLEDGEMENTS...........................................................................................................

ABSTRACT ............................................................................................................................................................... VI

TABLE OF CONTENTS ..................................................................................................................

TABLE OF FIGURES ............................................................................................................................

CHAPTER 1: INTRODUCTION................................................................................................................ 12

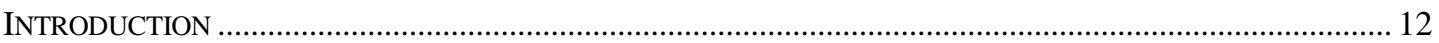

THE ROLE OF THE CEO AND ITS ASSOCIATION WITH ORGANISATIONAL SUCCESS ..................................... 13

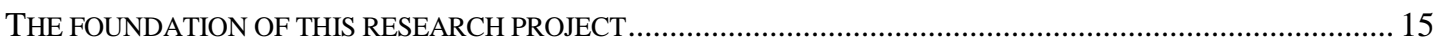

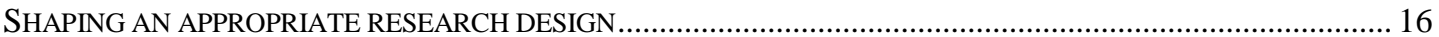

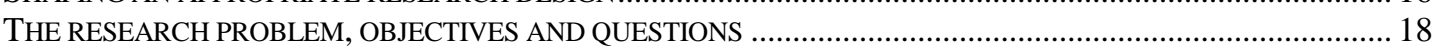

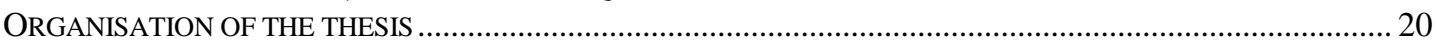

OPERATIONAL DEFINITIONS OF KEY TERMS ...................................................................................... 22

PART I ........................................................................................................................................................................ 25

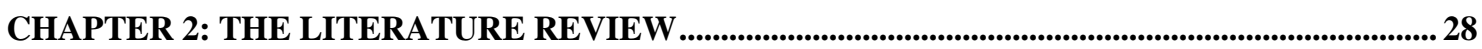

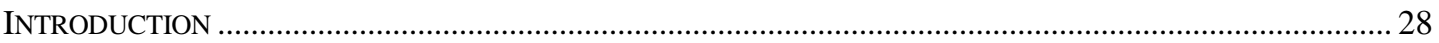

INTRODUCTION TO THE A PRIORI CONCEPTS OF THE CEO RESEARCH LITERATURE ……………………...... 29

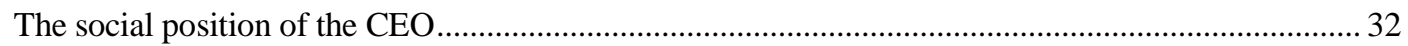

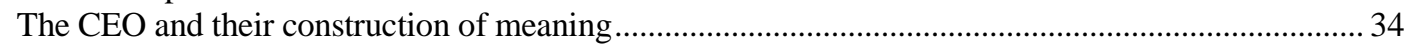

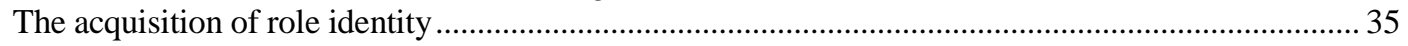

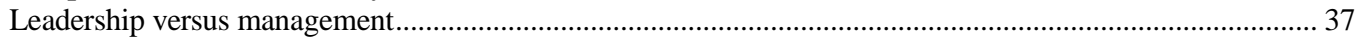

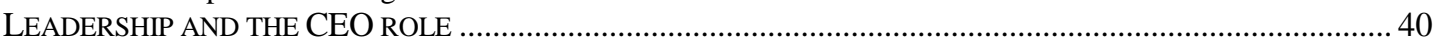

The CEO role as a formal, assigned executive leadership function ...................................................... 43

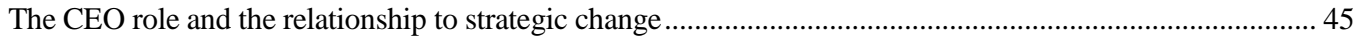

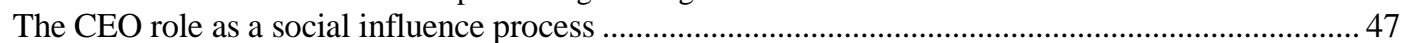

The CEO role as a function of context ........................................................................................ 49

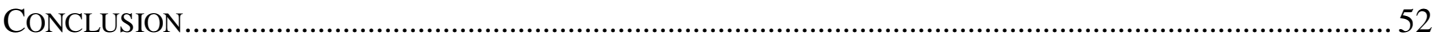

CHAPTER 3: THE METHODOLOGICAL FOUNDATIONS OF THE THESIS ................................53

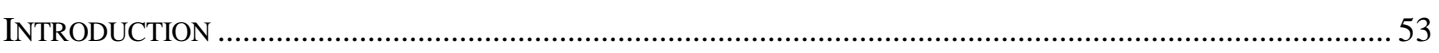

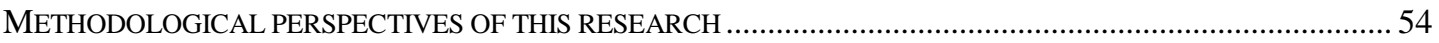

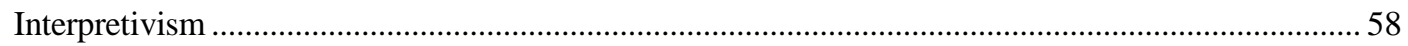

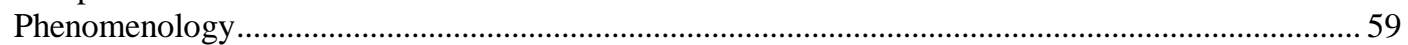

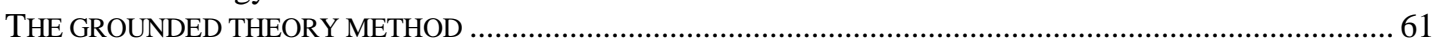

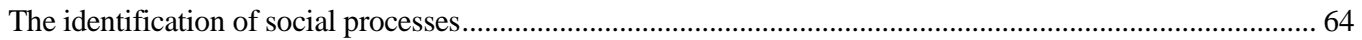

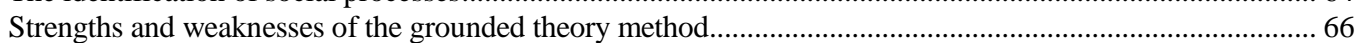

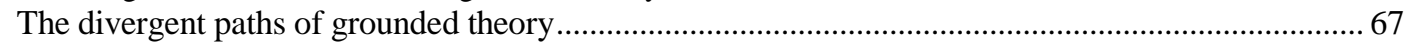

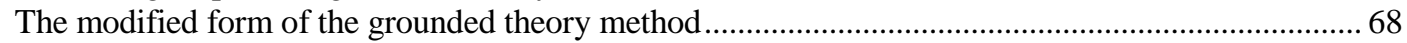

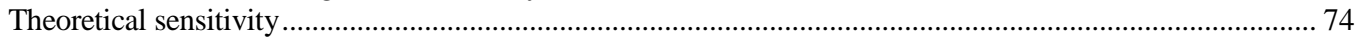

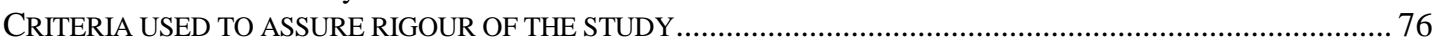

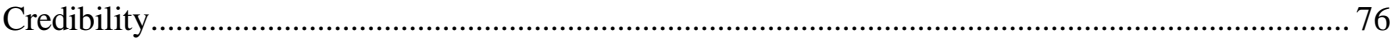

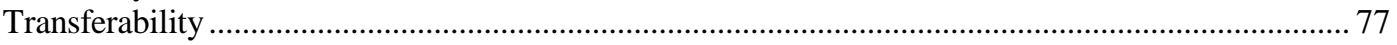

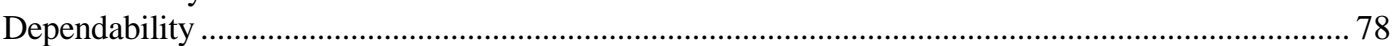

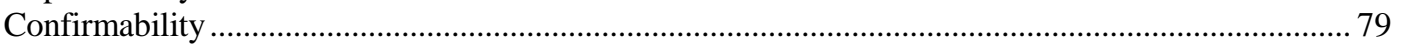

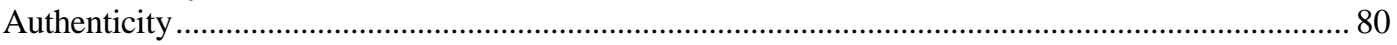

Achieving academic rigour in grounded theory studies................................................................ 81

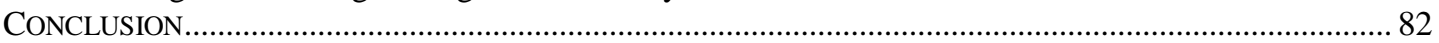

CHAPTER 4: THE RESEARCH METHODOLOGY .................................................................................... 84

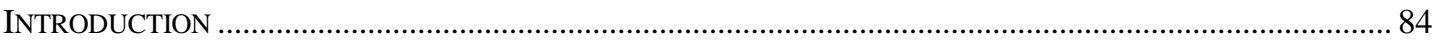

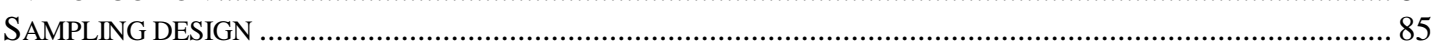

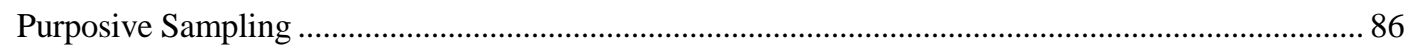

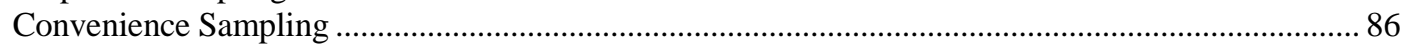




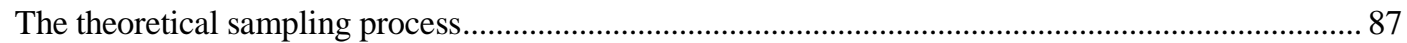

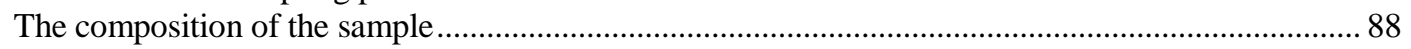

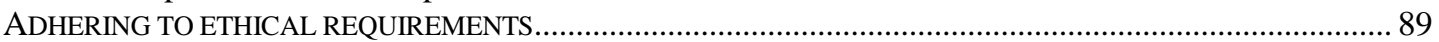

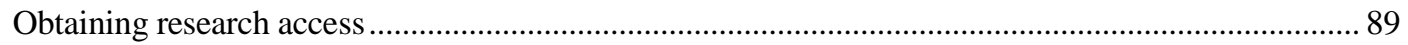

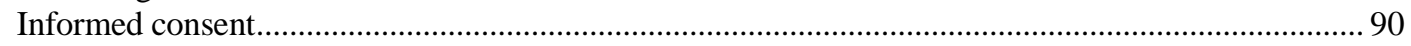

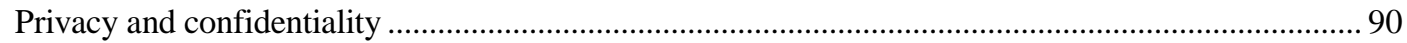

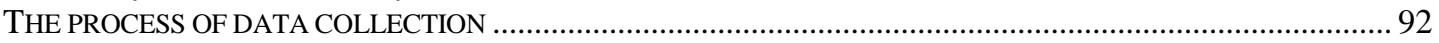

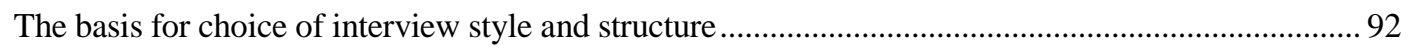

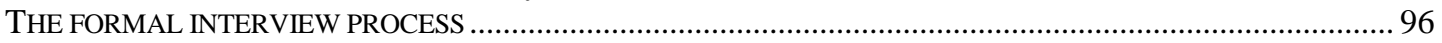

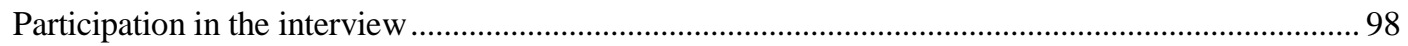

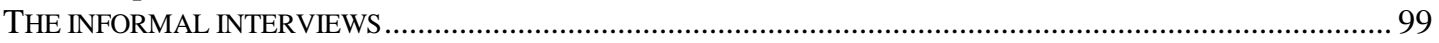

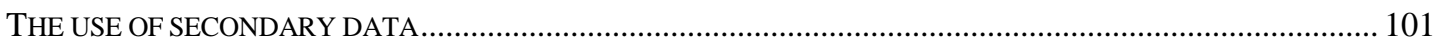

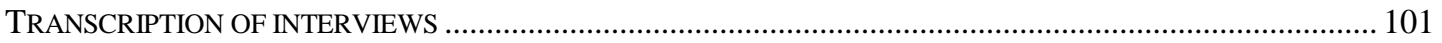

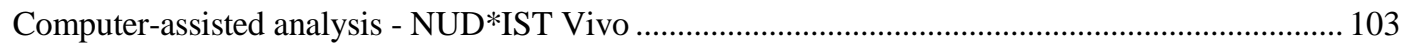

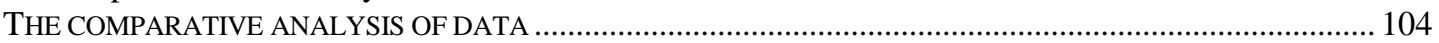

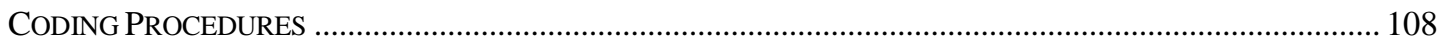

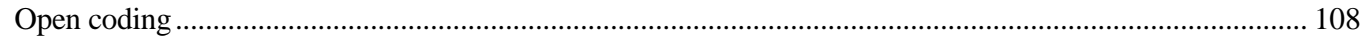

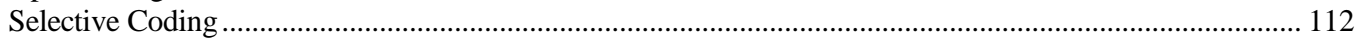

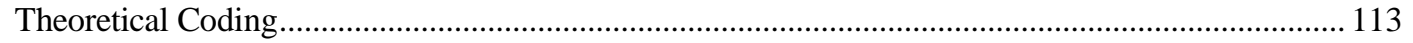

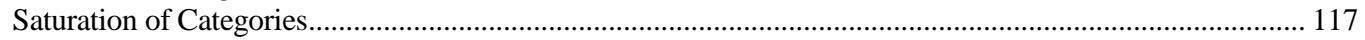

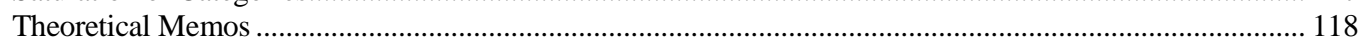

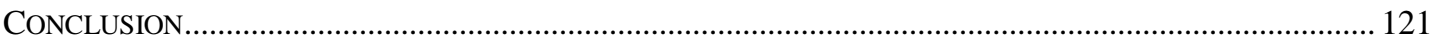

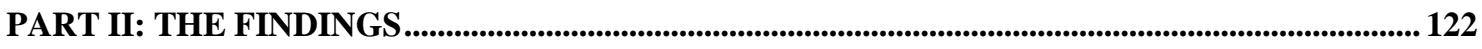

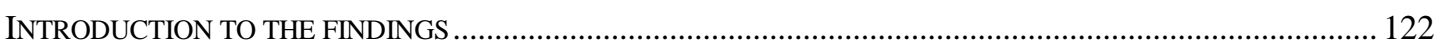

The acquisition of leadership constructs within the CEO role..................................................... 124

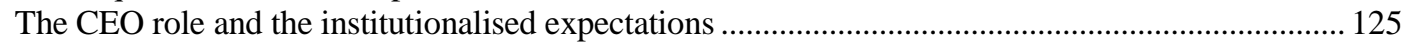

THE RESEARCH CONTEXT ...................................................................................................... 126

CHAPTER 5: THE ACQUISITION OF LEADERSHIP CONSTRUCTS IN THE CEO ROLE..... 130

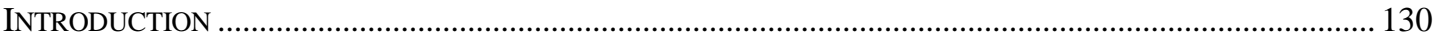

ROLE MODELS AND DEVELOPING PERCEPTIONS OF THE CEO ROLE....................................................... 131

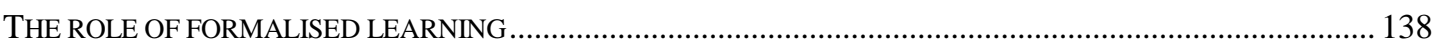

Influence of school learning upon business leadership................................................................... 139

Formal executive leadership programmes and the CEO role ....................................................... 145

DEVELOPING AN EXCITEMENT AN EMPATHY FOR THE CEO ROLE ....................................................... 152

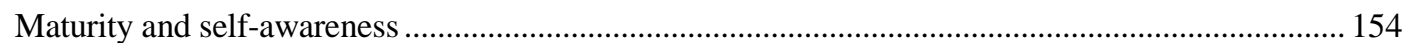

Developing confidence and commitment to the CEO role ............................................................... 164

The CEO role and the passion for challenge .............................................................................. 170

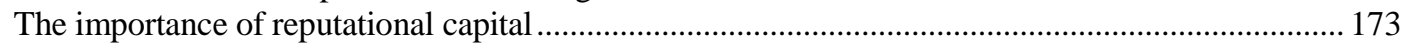

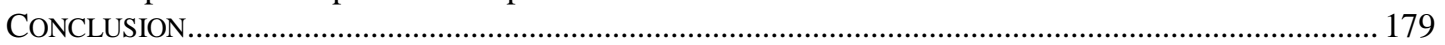

CHAPTER 6: CONFRONTING INSTITUTIONALISED EXPECTATIONS .................................... 181

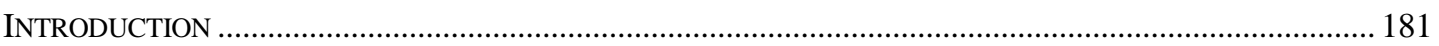

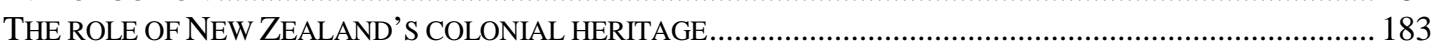

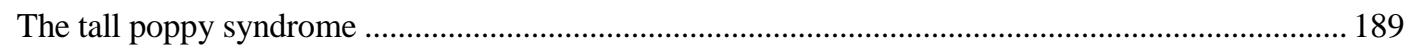

The relationship between "No 8 fencing wire" and the CEO role.................................................. 194

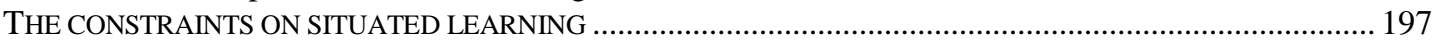

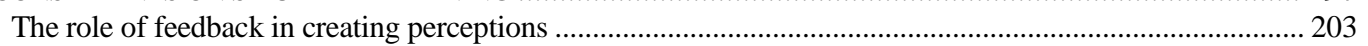

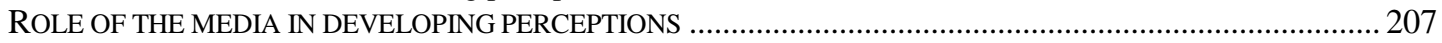

THE INFLUENCE OF POLITICAL ACTIVITY ON THE CEO ROLE.......................................................... 212

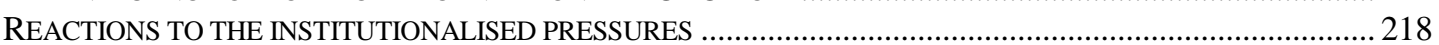

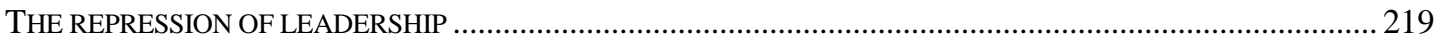

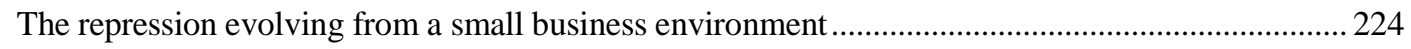

The interrelationship between the CEO role and remuneration....................................................... 227

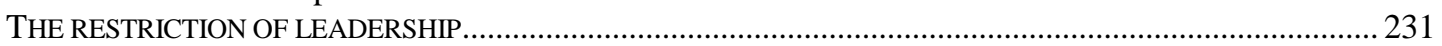

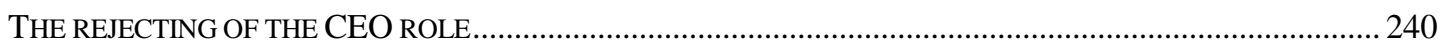

Relationships between boards of directors, policy-makers and the CEO........................................ 246

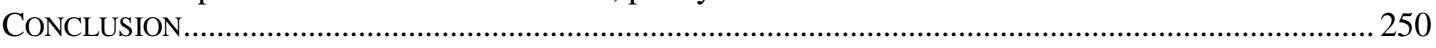

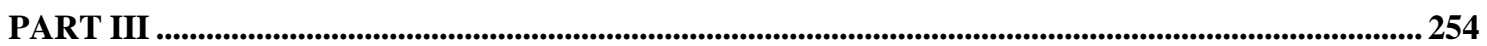




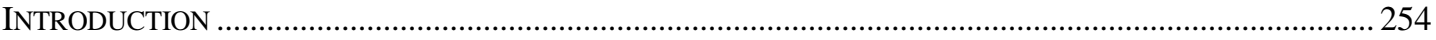

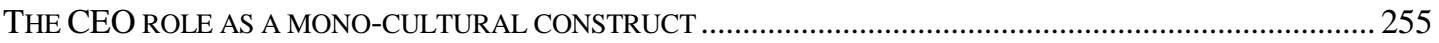

CHAPTER 7: WEAVING THE THEMES TOGETHER ................................................................................ 258

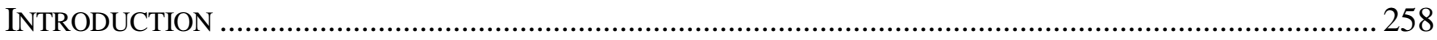

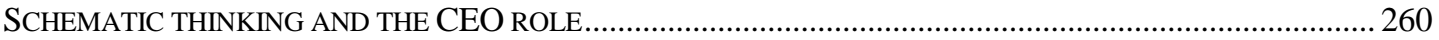

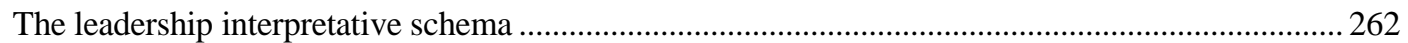

The institutionalised interpretative schema .................................................................................. 266

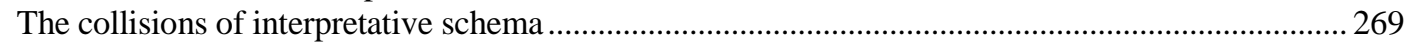

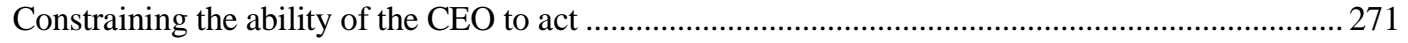

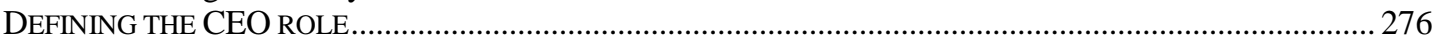

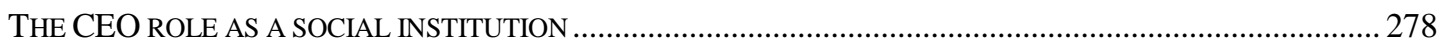

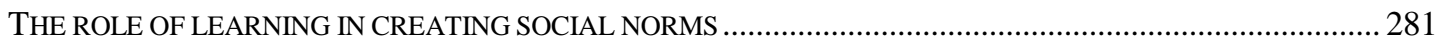

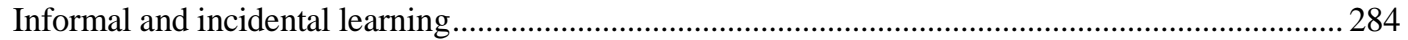

Situated learning experiences and the development of a community of practice .............................285

BALANCING THE TENSIONS AND PARADOXES ….......................................................................... 288

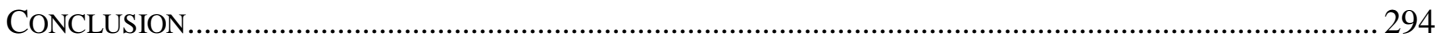

CHAPTER 8: RECAPITULATION, REFLECTIONS, AND FUTURE DIRECTIONS.................. 299

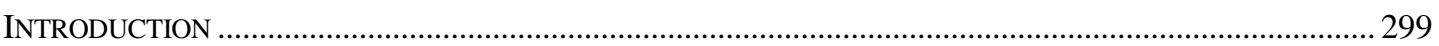

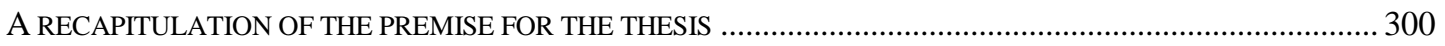

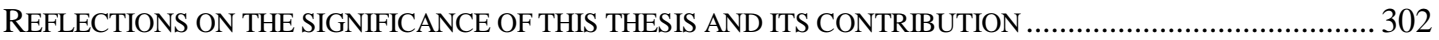

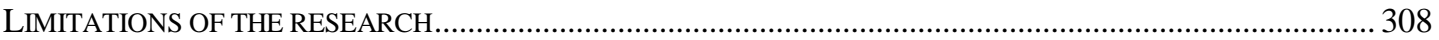

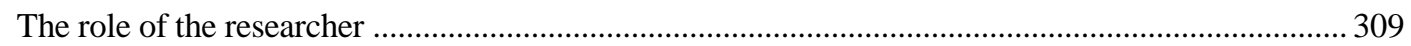

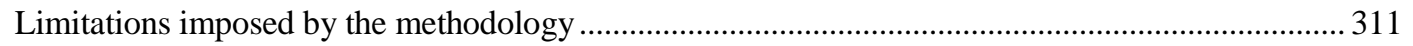

THE IMPLICATIONS OF THE RESEARCH FOR PRACTITIONERS ......................................................... 314

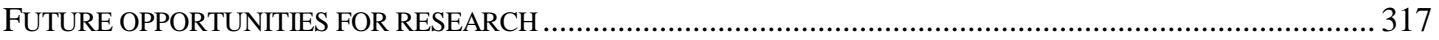

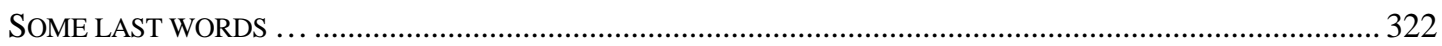

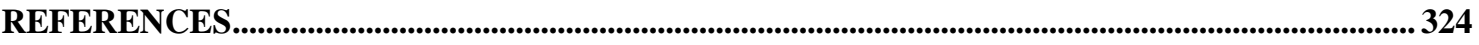

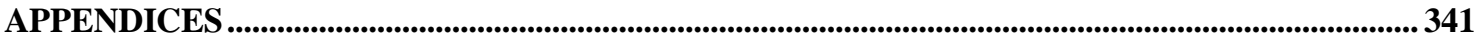

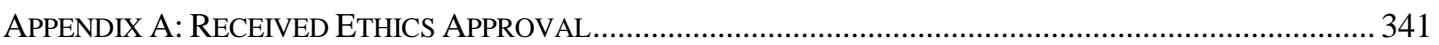

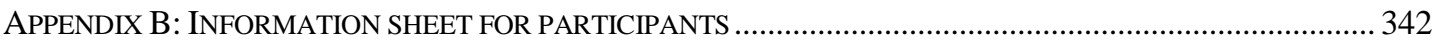

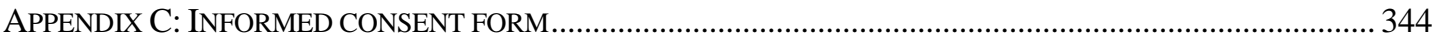

APPENDIX D: PRELIMINARY RESEARCH QUESTIONS .......................................................................... 345 


\section{Table of figures}

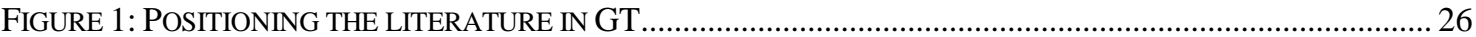

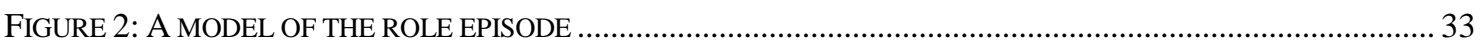

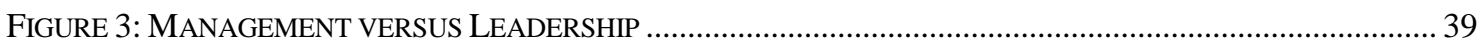

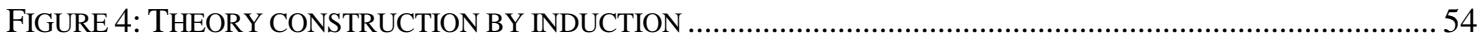

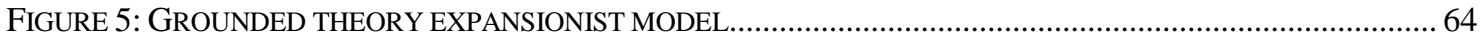

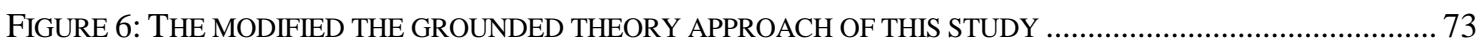

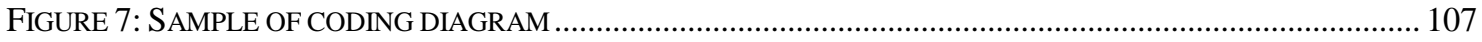

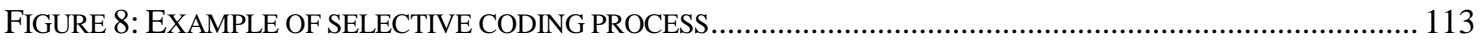

FIGURE 9: A SAMPLE OF DIAGRAMMING PROCESS CONDUCTED THROUGHOUT THE ANALYSIS ..................... 116

FIGURE 10: A DIAGRAMMATIC REPRESENTATION OF THE FINDINGS OF THE STUDY …................................ 123

FIGURE 11: A DIAGRAMMATIC REPRESENTATION OF THE THEMES DISCUSSED IN CHAPTER FIVE ................. 180

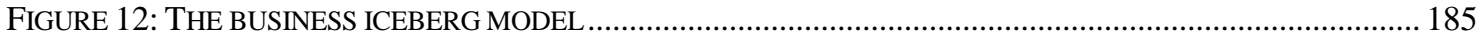

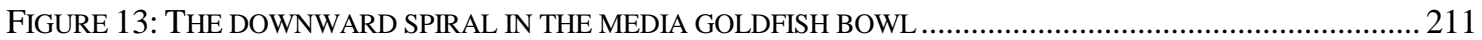

FIGURE 14: DIAGRAMMATIC OUTLINE OF THE THEMES DISCUSSED IN CHAPTER SIX (PART I) ...................... 252

FIGURE 15: DIAGRAMMATIC OUTLINE OF THE THEMES DISCUSSED IN CHAPTER SIX (PART II) ...................... 253

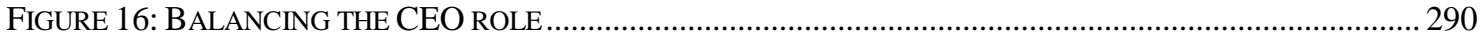




\section{Chapter 1: Introduction}

There is an element of spirituality in this leadership journey, and by spirituality I mean ... at the end of the journey what is the gift that you bequeath to the organisation as a result of your leadership?

A CEO participant

\section{Introduction}

Max DePree (1998) contends that "When a chief executive officer (CEO) departs an organisation, they should leave behind them both assets and a legacy" (p.130). However, if the CEO role and the impact and effectiveness of an individual in that role is not fully understood, it makes it difficult to determine what, if any, gift or legacy is bequeathed (Finkelstein \& Hambrick, 1996). Consequently, an in-depth knowledge of the various facets of the CEO role is imperative if the assets and legacy that a CEO bequeaths the organisation are to be assessed. The purpose of this chapter is to introduce the subject of this thesis. It commences by providing an operational definition and an introduction to the CEO role. The chapter then goes on to provide an introduction to the theoretical foundations of the study and to the identified gaps in the current body of knowledge. It then proceeds to outline the research problem and the research objective and questions that were developed as a result. The chapter concludes with an outline of the remainder of the thesis, and a glossary of the key operational definitions used within this thesis. 


\section{The role of the CEO and its association with organisational success}

Finkelstein and Hambrick (1996) contend that if a CEO has overall responsibility for the management and the results of an organisation, then the characteristics and actions of that individual are vital to both the organisation and its stakeholders. Within the context of this study, the operational definition of a CEO is that provided by Hambrick (1998) who states that a CEO is the individual who has responsibility for the conduct and performance of an entire organisation as opposed to a sub-unit of an organisation. As such it encompasses an executive leadership role. Thus, if the role of the CEO is critical to the success of the organisation, then it is imperative that the role is clearly understood. In addition to understanding more about the role per se, there is also a requirement to acknowledge and understand the context in which the role is situated.

Bartlett and Ghoshal (2000) argue that even in the most stable of times, the world is complex, volatile and filled with uncertainty. Therefore, for a CEO to be successful, they contend that he or she has to be capable of identifying and interpreting the forces existing within his or her environment. Prior to this, Bartlett and Ghoshal (1989) had also stated that the CEO has to be accomplished in leading the new and diverse organisational forms that were emerging in order to be able to deliver coordinated action to ensure organisational success. This, in turn, has led to demands for CEOs who are multi-skilled, multi-talented, multi-cultural and have strong ethical reputations (Gregersen, Morrison, \& Black, 1998; Talkington, 2001).

Not only are CEOs required in greater numbers than are currently available (Michaels, Handfield-Jones, \& Axelrod, 2001), but there are also increasing demands for them to 
provide new and varied styles of leadership (Perkins, 2000). As early as 1992, Adler and Bartholomew expressed concern that the acquisition and development of capable executives is not keeping pace with the need for competent CEOs. DePree (1998) argues that the current CEOs have a responsibility for developing the future leaders of their organisation. Such an argument presupposes that these CEOs are sufficiently skilled and knowledgeable about their role, and the future demands of their role, so that they can be deliberate and proactive in the development process. The CEO talent shortage (Michaels, et al., 2001) has meant that many organisations are grappling with the problem of how to retain and develop their existing executive leadership capacity, in order to ensure the achievement of the organisation's strategic objectives. Unless organisations are able to recruit, develop and retain CEOs who are highly skilled and knowledgeable, such organisations may not be able to respond appropriately to these challenges (Adler, 2002).

This latter situation is not only exacerbated by the limited number of studies that provide insight about the CEO role in general, or outside of the European or North American environments, but also the limited number of studies related to specific geographical or socio-economic contexts, like New Zealand or specific aspects of the CEO role, for example, leadership. Not only is there a limited number of context-specific studies conducted outside the European and North American research environments (De Cieri \& Dowling, 1997; Tsui, 2004), an evaluation of the available empirical leadership research identified that less than 5\% has focused on executive leadership (Zaccaro and Horn 2003 as cited in Storey 2005). This thesis acknowledges the importance of extending the body of knowledge and focuses its research on executive leadership, specifically the perceptions of the CEO role within a New Zealand context. 


\section{The foundation of this research project}

Situated within the qualitative paradigm, this research examines the CEO role, from the perspective of the CEO, in the substantive research environment of large New Zealand business organisations. Parry (1997, p. 27) argues that research in this field has tended to be overly descriptive, somewhat inhibiting the development of a theoretical base. Scholars, in the main (Grint, 2005; Rost, 1993), have failed to theorise on the social processes inside an organisation or within a society, as research studies have, in the main, comprised of descriptive studies answering the whom, when and where questions. Parry (2001) asserts that a study addressing the how and why questions can lead to a more systematic theorised examination of the CEO role. This view supports that of Finkelstein \& Hambrick (1996) who state the majority of writings examining the CEO role have focussed upon the whom, when and where questions rather than on the nature of the interrelationships occurring between the $\mathrm{CEO}$ and society, or on the influence that this interplay may have on the individual CEO's perceptions of their role. In response, this thesis examines how the CEO constructs meaning from the interactions within their context. According to Ospina and Schall (2001), that means an emphasis on how they make sense of, and bring order to, their role. By asking questions of a how or why nature, this thesis aims to extend the knowledge base by examining the perceptions of the CEO role, as perceived by CEOs and others closely involved with the role. 


\section{Shaping an appropriate research design}

Over the latter part of the twentieth century and the early part of the twenty-first century, as the CEO role has changed, there have been repeated calls for a change in what some consider a common approach related, for example, to executive leadership research (Bryman, 1987; Hollenbeck, 2001; Ireland \& Hitt, 1999; Ospina \& Schall, 2001). The theories emanating from the traditional forms of research are dominated by methods derived from the scientific approach (Norburn, 1989), and the field has been driven by causal theory testing, in particular, rather than theory development, in general (Grint, 2005; Irurita, 1990, 1996; Jackson, 2001; Kan, 2002; Ospina \& Schall, 2001; Parry, 1998; Rost, 1993). This has happened to some extent because the "body of knowledge" has had many restrictions placed on it by the need to be able to demonstrate the causality of variables, the replication of a specific study and the generalisation of theory (Bryman, 1987; Bryman \& Stephens, 1996; Parry, 1998).

Bryman and Stephens (1996) go on to assert that this narrow focus has led to a lack of critical analysis about why much of the existing theory fails to effectively explain the CEO role. Despite this stated gap in the literature, and despite recent efforts to increase the amount of qualitative research, "qualitative studies remain relatively rare" (Conger \& Kanungo, 1998, p. 107; Irurita, 1996; Kan, 2002; Ospina \& Schall, 2001). It may not be surprising then, that there have been calls for more research, for example, focussing on the executive leadership dimension of the CEO role and the use of a broader range of epistemologies and ontologies (Conger, 1999; Hunt, 1991; Irurita, 1996; Kan, 2002; Ospina \& Schall, 2001; Parry, 1996; Rost, 1993). This problematic situation has been compounded by the study and development of theory having been strongly influenced by 
a cultural predisposition toward North America (Muczyk \& Adler, 2002). Col (1993) contends that the majority of organisational theories have the label "Made in the USA" stamped on them. Therefore, perceptions of the CEO role are likely to have been framed by North American and European cultural pre-dispositions.

This thesis draws on the grounded theory (GT) method as outlined by Charmaz (2000)) as opposed to the objectivist form of the method (Glaser, 1978, 1998; Locke, 2001; Strauss \& Corbin, 1994). Charmaz's (2000) GT method allows the researcher to emphasise the emergent elements of the method, using them as flexible heuristic strategies, rather than adhering to a formulaic procedure as can be the case with what is known as objectivist grounded theory. (A full discussion of GT is contained in Chapter Three and the GT analysis process in Chapter Four). The aim of grounded research is to gain an understanding of how people create meaning from their environment and the events occurring within that environment (Guba \& Lincoln, 1998). In particular, the aim is to determine how they develop the frameworks that inform their perceptions ${ }^{1}$. These are known as 'schemas', a term used to describe how a stimulus activates frameworks relating to the features of the role. Past knowledge and experience contained in a particular schema affects how the current stimulus and information received by an individual is encoded, thereby providing meaning for that individual within a role (Bartlett, 1932).

1 Within the context of this study a perception is defined as a psychological function that enables individuals to receive and process information obtained from the external environment (Tregoe \& Tobia, 1990). 
The modified form of grounded theory developed by Charmaz facilitates the interactive relationships between the researcher and participants, and allows the documentation of such interactions. In doing so, it brings the centrality of the researcher as an author to the forefront (Mills, Bonner, \& Francis, 2006b). This is in contrast to the tabula rasa approach of objectivist grounded theory (Bryant, 2003; Charmaz, 2000, 2003; Glaser, 1978; Glaser \& Strauss, 1967). Within this study the use of this modified form of the grounded theory method allows the researcher to focus on the perceptions and interpretations held by the research participants about the subject of the study, in this case, the CEO role.

\section{The research problem, objectives and questions}

New Zealand business organisations are part of a highly competitive, turbulent, globalised world. This environment has created a demand for talented CEOs who have the ability to successfully lead organisations that comprise increasingly diverse groups of stakeholders. However, there is a limited empirical research base examining the contextspecific aspects of the CEO role. Where research has been conducted it has been predominately situated in the North American or European contexts. The consequence of this, is that the CEO role in New Zealand is relatively poorly researched, compared to other forms of organisational roles. One of the ramifications is that organisations may not have the knowledge or the ability to attract, develop or retain appropriately skilled CEOs. The identification of this research problem led to the development of the research objective and questions. The purpose is to increase the body of knowledge of the CEO role, specifically, its definition, enactment and the impact on the acquisition and retention of executive leadership within organisations. 
Building on the prior discussion the following research objective was developed:

\section{To identify the CEOs' perceptions of their role and the interpretative schemas}

\section{informing that role}

In particular, the study aims to generate a substantive theory of the CEO role. A substantive theory comprises a set of propositions or questions that furnish an explanation for an area of inquiry consisting of a set of concepts and their interrelationships (Vakkari \& Kuokkanen, 1997), and is considered relevant only to the specific topic under investigation, in order to provide an explanation for certain phenomena (Grover \& Glazier, 1986). To generate the substantive theory the following research questions were developed:

1. How does the context in which CEO role is situated influence the perceptions of the research participants as to the definition and enactment of that role?

2. Why is an individual attracted to the CEO role and why do they choose to remain in or leave the role?

The remaining parts to this chapter offer an overview of the thesis, followed by a Glossary of the operational definitions. 


\section{Organisation of the thesis}

This thesis is organised into three parts across eight chapters. Part I sets out the theoretical foundations of the thesis. Chapter Two commences with a review of past and current research on the topic and of its relevance to this thesis. Chapter Three outlines the ontological and epistemological foundations of the research design and methodology. Chapter Three also provides discussion of the grounded theory method and surfaces the reasoning underpinning use of the modified grounded theory approach in this study. It ends with a discussion of the processes undertaken to ensure the academic rigour of the study. Chapter Four presents the research methodology of the thesis. The chapter commences with a discussion of sample design and strategy, and then proceeds to outline the ethical considerations and how the research participants' rights and privacy were protected within this thesis. The chapter summarises the method of data collection, and includes a discussion of the interview process and the transcription of the data gathered. In particular, the chapter explains the grounded theory method processes of concurrent data collection and analysis, the theoretical sampling, coding and memoing.

Part II of the thesis covers the findings of the thesis. It commences with an introduction to the research context. Chapter Five proffers a discussion of the CEO role and the nature of the factors present contributing to the development of CEO leadership. This also examines the forces that were identified as attracting an individual to executive leadership and the CEO role in particular. Chapter Six discusses the factors that create the institutionalised expectations of the CEO role. This chapter also examines the social structural processes that cause the repression and restriction of leadership and the social psychological process - the rejecting of the CEO role. Part III provides the summary 
chapters of the thesis. In addition, it discusses an identified gap in the findings. The purpose of Chapter Seven is to weave together the themes and provide a substantive theory of the CEO role. Chapter Eight concludes the thesis with a précis of the work, including reflections on the research process, a summary of the key conclusions, an outline of the limitations of the thesis and suggestions for the future directions for both practitioners and scholarly research. 


\section{Operational Definitions of Key Terms}

Constant Comparison - is the process within the grounded theory method of concurrently gathering and categorising data, and comparing them with data and categories obtained previously (Glaser and Strauss, 1967, p.41).

Forces - are defined as where a person or thing exerts influence on somebody or something (Pearsall, 1999).

Formal theory - relates to a formal, conceptual, and generalisable areas of sociological inquiry (Glaser \& Strauss, 1967, p. 32).

Grounded theory - is a research methodology in which theory emerges from and is grounded in the data (Glaser \& Strauss, 1967, p. 4).

NUD*IST - Non -numerical, unstructured Data; Indexing, Searching, Theorising (Richards \& Richards, 1997, p. 146).

Perception - is defined as a psychological function that enables strategic leaders to receive and process information obtained from the external environment (Tregoe \& Tobia, 1990).

Saturation (of themes) - relates to the use of theoretical sampling to gain data on a category until the research can be sure of the existence and nature of a theme (Glaser \& Strauss, 1967, p. 61). 
Schema - is a term used to describe how a stimulus activates frameworks relating to the features of a particular role. Past knowledge and experience contained in a particular schema affects how the current stimulus and information is encoded, thereby providing meaning (Bartlett, 1932).

Social Influence - refers to the psychological explanation of the process of influence of one person on another (Yukl, 2002, p. 195).

Social Process(es) - provide for the development and definition of roles and role expectations, including how individuals and groups impact upon one. This is done by examining the socially constructed meanings and behaviour patterns that emerge from the interactions of individuals with each other (Barker, 2001, p. 352).

Social relationship - is based upon a set of role expectations that are understood by the participants in the relationship. Relationships in society tend to be contractual, with performance standards and evaluations (Barker, 2001, p. 352).

Substantive theory - is theory deriving from research that relates to a substantive or empirical, area of sociological inquiry (Glaser \& Strauss, 1967, p. 32).

Theoretical sampling - is a grounded theory process of data collection whereby data are intentionally collected to develop theory as it emerges (Glaser \& Strauss, 1967, p. 45). 
Theoretical Sensitivity - is the sensitivity of the research to existing theory which applies to the topic being investigated (Glaser \& Strauss, 1967, p. 46). 


\section{Part I}

Part One of this thesis provides a discussion of the theoretical foundations. It comprises three chapters, Chapter Two, 'The Literature Review,' Chapter Three, 'The Theoretical Foundations' and Chapter Four, 'The Research Methodology'. Here, I offer a brief note on the use of the literature within grounded theory studies more broadly and in this study, specifically.

Glaser, as early as 1978, argued that in grounded theory studies, the literature is less likely to be used to set the scene for the research and should be used in a manner so that it does not direct the questions or propositions that are posited by the researcher. In his 1998 work, Glaser reiterated this position and further strengthened it by making the following two points:

First, do not do a literature review in the substantive area and related areas where the research is done. Second, when the grounded theory is nearly completed during sorting and writing up, then the literature search on the substantive area can be undertaken and woven into the theory as another source of data in the constant comparison process (Glaser, 1998, pp 360 -367)

Glaser's (1998) reasoning was that it is important for the researcher to be as free from influences that could compromise theoretical discovery and development. Rather, the literature review should supplement or facilitate the findings of the research (Denzin \& Lincoln, 2000; Mills, Bonner, \& Francis, 2006a). Charmaz (2000) argues such an approach is to prevent any presumed cause-and-effect relationship between what may be emergent themes. Accordingly, many grounded theory studies report minimal literature, if any at all, as a basis for study (Gilbert, 2008; Gordon, 2008; Goulding, 1999; Goulding, 
2002b; Kelsey, Weeks, \& Terry, 2002; Parry, 1997). Glaser (1998) recommends that the researcher should constantly consult the literature in contiguous substantive areas, in order to build awareness of, or increase their theoretical sensitivity (this is discussed further in Chapter Three). In addition, the researcher reviews both the convergent and divergent literature in order to address the emergent themes and substantive theory. Klenke (2008) reinforces Glaser's position, arguing that using the literature too early in the research might condition or predetermine the development of preconceptions on the part of the researcher for what to find. She provided the following outline of the grounded theory process and the recommended situating of the literature within a study:

Figure 1: Positioning the literature in GT

\section{Data collection}

Field notes

Saturation

Coding

Meomoing

Revising codes followed by additional data collection

LITERATURE REVIEW

Writing up theory

Source: Klenke (2008, p188)

Conversely, others, for example, Schreiber (2001) argue that approaching a study without delving into the relevant literature is not only unwise, but also unrealistic: "Although there may be merit for a researcher to approach a study in a tabula rasa fashion, it is not 
likely to be realistic or feasible to do so" (p. 59). This view supports that of Eisenhardt (1989) who states that process-oriented studies similar to this thesis generate vast amounts of data. Her recommendation is to use a priori concepts from the literature to guide data collection and analysis. This aids in focussing the research and prevents the researcher from becoming lost in the data.

This study acknowledges the latter view, and as such I have engaged with the literature from the beginning of the study weaving it through the work as another voice contributing to the development of the substantive theory (Mills, et al., 2006b). Acknowledging the existence of a priori concepts, the literature in this thesis is used in three different ways, firstly as a structure within which to situate the study and to guide the initial stages of the research. The analogy is one of animal tracks, the researcher following the tracks through only partially familiar territory (Massey, 1996). Secondly, the literature is used to provide signposts. Massey (1996) argues the purpose of such signposts is to indicate to the researcher new or alternative directions to explore. Thirdly, the literature acts as a surrogate mentor/supervisor, a constant companion to whom the researcher could refer throughout the research (Massey, 1996). Therefore, references are found throughout this thesis supporting the findings and assisting with the establishment of the substantive theory. In the literature review, the literature is reviewed and presented as a structure on which to base the remainder of the study. 


\section{Chapter 2: The Literature Review}

Every path we take leads to fantasies about the path not taken

Halcolm as cited in Patton (2002)

\section{Introduction}

The purpose of this chapter is to provide an introduction to the literature that has significance to this study. The chapter commences with a discussion of the CEO research pertinent to this thesis. Subsequently, a discussion of role theory and its significance to this study is provided. The review clarifies the nature of the CEO role, and expands on the definition provided in Chapter One. Further discussion of how meaning is constructed in general, and by the research participants specifically, precedes a discussion of how the CEO participants acquire role identity. This discussion provides a synopsis of the debate on the difference between leadership and management. The chapter concludes by examining the interrelationship between the CEO role and executive leadership and the three core components that comprise the role within the context of this thesis. 


\section{Introduction to the a priori concepts of the CEO research literature}

Concern has been expressed in relation to the paucity of research focussing on executive leadership, especially that relating to the CEO (Finkelstein \& Hambrick, 1996; Harrison \& Pelletier, 1997; Storey, 2005). While there has been much written about leadership as a discipline, it is only in the middle of the twentieth century that there has been a focus upon executive leadership within business organisations (Finkelstein \& Hambrick, 1996; Hitt, Keats, \& Yucel, 2003; Ireland \& Hitt, 1999). This situation does not appear to have improved during the three year period of this study. For example, a search of the Proquest database at Victoria University in August 2008 using the keywords chief executive officers, and the search using the parameters of full text and scholarly peer reviewed journals published in the past twelve months gave a response of 345 documents. A search using the keywords chief executive officers and leadership with the same search parameters gave a search result of 11 articles. This is not to say that chief executive officers have not been involved in research or that the previous studies have not provided important insights into the strategic choice and decision-making of CEOs. Rather it is to argue that in-depth empirical studies are not as common in the literature as might be expected for such an important role. Furthermore, the majority of prior research has focused on top executives' backgrounds and personal characteristics (Hagen, Hassan, \& Amin, 1998; Norburn, 1989; Pye, 2002). Much of this has led to research that has emphasised the traits, styles and situational factors that influence CEO behaviour (Caldwell, Bischoff, \& Karri, 2002), rather than studies of how meaning is constructed about the interactions and social processes that influence the CEO role (Grint, 2005; Kan, 2002; Pye, 2002). Thomas, Clark \& Gioia (1993) argue that prior research has focussed primarily on the need to understand the CEO's perspective with regard to the 
interpretation of information and organisational success. There has been little attention given to understanding how meaning is constructed with respect to the CEO role, its definition and enactment and the social processes that influence the role. This despite evidence as early as Barnard's (1938) study, which identified that CEOs operate in a social context that spans organisational boundaries (Geletkanycz \& Hambrick, 1997). Some researchers assert that the context in which the CEO role is situated has largely been ignored or overlooked in many studies (Hitt, Lee, \& Yucel, 2002; Hunt \& Dodge, 2000). Hunt \& Dodge (2000) provocatively argue that studies examining the CEO role are unlikely to be of any additional value until they take into account both the external and organisational context and their influence on the role.

The nature of this situation is not unique to studies of CEOs. A search of the literature identified that inductive studies examining the construction of meaning and sense making since Weick's (1995) work, were conspicuous by their absence (Parry, 2003). For the purposes of this study, the construction of meaning is deemed to encompass: "those processes of interpretation and meaning production whereby individuals and groups reflect on and interpret phenomena and produce inter-subjective accounts" (Brown, 2000, pp. 45-46). DePree (1998) claims that a CEO who is able to assess accurately the dynamics within his or her environment is better able to create a successful plan for their organisation's success, thereby honouring their obligations to their stakeholders (DePree, 1998).

Therefore, building an understanding of how a CEO develops his or her perceptions may be critical to evaluating the effectiveness of an individual in the role. For the purposes of this study, a perception is defined as a psychological function that enables strategic 
leaders to receive and process information obtained from the external environment (Tregoe \& Tobia, 1990). Lord, Harvey and Hall (2001) argue that a CEO's perceptions of his or her social, cultural, task and interpersonal environments may constitute a significant part of their cognitive boundaries when making strategic choices. This, then, may impact upon strategy formulation and the enactment of their role as a CEO (Anderson \& Paine, 1975). It is of concern that determinants of perception development and the CEO's responses to different contexts have not been thoroughly explored (Cheng, 1994; Schneider \& De Meyer, 1991; Tsui, 2004).

Lord and Smith (1999) are of the opinion that developing an understanding of how a CEO constructs his or her perceptions will assist in providing additional insights into the strategic choices made by the CEO and how this may enhance or inhibit their effectiveness. Lord et al., (2001) go on to argue that roles such as that of the CEO are constructed via the social norms that are present within a specific context, and it is the resulting perceptual constructs (frameworks) that embed the role in a flexible task and social system. As a multifaceted construct, it may or may not be surprising that the CEO role has many nuances and subtleties which make it difficult to codify easily (Sorcher \& Brant, 2002) as cited in Hitt \& Ireland (2002). In Chapter One, Hambrick’s (1998) definition of the CEO role was offered as an operational definition, that is; "the individual who has responsibility for the conduct and performance of an entire organisation as opposed to a sub-unit of an organisation and as such it encompasses an executive leadership role". To provide a conceptualisation of the actions of the CEO as an executive leader it, is considered that "the individual CEO has the ability to influence others to voluntarily make day to day decisions that enhance the long-term viability of the organisation, while maintaining its short-term financial stability"(Rowe, 2001, p. 83). Therefore, the role is a formal assigned role; is deemed to 
have influence; and is situated within a particular context. The next section of this chapter explores the CEO role by providing a discussion of how the role is formed.

\section{The social position of the $\mathrm{CEO}$}

Merton (1957) stated each social position is associated with a group of role-specific behaviours that, when brought together, comprise a role set. This role set can be defined as a set of requirements and expectations attributed to the incumbent of a particular position, both by the person in that position and by the role-senders (those who provide feedback to the role incumbent) with whom the incumbent must deal in order to fulfil the obligations of the position (Banton, 1965). Figure 2 on the next page outlines the features of the feedback loop relating to the interrelationships between the participants involved in a role, and how the various features are linked together. 


\begin{tabular}{|c|c|c|c|}
\hline \multicolumn{2}{|c|}{$\begin{array}{l}\text { Role senders } \\
\text { Those who provide feedback }\end{array}$} & \multicolumn{2}{|c|}{ Role incumbent } \\
\hline $\begin{array}{l}\text { Experience } \\
\text { Role } \\
\text { Expectations }\end{array}$ & $\begin{array}{l}\text { Response } \\
\text { Role } \\
\text { Pressures }\end{array}$ & $\begin{array}{l}\text { Experience } \\
\text { Psychological } \\
\text { Conflict }\end{array}$ & $\begin{array}{l}\text { Response } \\
\text { Coping efforts }\end{array}$ \\
\hline $\begin{array}{l}\text { Perception of } \\
\text { focal person's } \\
\text { behaviour } \\
\text { Evaluations }\end{array}$ & $\begin{array}{l}\text { Objective, } \\
\text { role conflict }\end{array}$ & $\begin{array}{l}\text { Experienced } \\
\text { ambiguity } \\
\text { Perception of } \\
\text { role and role } \\
\text { senders }\end{array}$ & $\begin{array}{l}\text { Compliance } \\
\text { Symptom } \\
\text { formation }\end{array}$ \\
\hline
\end{tabular}

Source: Kahn, Wolfe, Quinn, Snoek \& Rosenthal (1964)

In the literature, role has been identified as a manifestation of a continual cycle of interactions between the role senders and the role incumbents (Kahn, et al., 1964), with a high level of importance placed on the strength and continual nature of this cycle. When Bauer \& Simmons (2000) scrutinised the dynamics involved in the role episode they discovered that most of the studies to date had focussed upon the role incumbent, the person in a particular role rather than examining the part played by the role senders. Bauer and Simmons (2000) established that a minimal amount of empirical research has been conducted examining the part that role senders external to the organisation play in developing a CEO's perceptions. Kahn et al., (1964) contend that the role incumbent is dependent upon interactions and messages received from the role sender in order to comprehend how the role is to be enacted. Therefore, how they construct meaning from 
their context, and how the CEO role identity is formed, is a critical part of coming to know and understand the CEO role more fully. This is explored in the next sub-section.

\section{The CEO and their construction of meaning}

Hitt (1996) asserts that every individual has a desire to make sense of the world and their place in that world, and therefore, the search for meaning may be a person's most important quest. Drath \& Palus (1994) describe this in terms of the ability and hunger to make sense of the environment in which an individual is situated:

Creating meaning is the process of arranging the understanding of an experience so an individual can come to know what has happened and what is happening, in order to be able to predict what will happen; it is constructing knowledge of ourselves and the world (Drath \& Palus, 1994, p. 2).

Louis (1980) made the point that an individual's construction of meaning is a recurring process whereby conscious rational thought is used to bring order to surprise and in Festinger's (1957) terms to minimise cognitive dissonance.

The CEO role, like any other role, is socially constructed through interaction (Berger \& Luckmann, 1971). Smircich and Morgan (1982) suggesting that the CEO role emerges as a result of the constructions and actions of both the leader and the led. Consequently, the individual may acquire a set of assumptions that enables them to interpret information and plan accordingly (Drath \& Palus, 1994). The CEO role is not simply a process of acting or behaving, nor is it a process of manipulating rewards. In Smircich and 
Morgan's (1982) terms, it is a process of power-based reality construction and thus needs to be understood in these terms. Drath \& Palus (1994) consider that the construction of meaning is never solitary, stating that what an individual constructs internally is contingent on the nature and form of the interactions that occur between and among individuals. While people individually construct meaning of their own personal experience at various periods in their lives, they also construct meaning socially. That is, they construct their experiences with others so they can cooperate and agree about what is happening (Drath \& Palus, 1994). Indeed, Drath and Palus (1994) go on to state that an individual learns the expectations and requirements of the $\mathrm{CEO}$ role, how it is to be defined, acquired and enacted, as a result of their constructing meaning from the interactions they experience within their context.

\section{The acquisition of role identity}

Drath and Palus (1994) argue that the acquisition of role identity, whether it is the CEO role or any other role, results in the way an understanding of that role is attained. That is, we arrange our understanding of our experiences in such a manner so that we can seek to know what has happened, what is happening and what we can predict will happen. In doing this, we construct knowledge of ourselves, our role and the world (Drath \& Palus, 1994). This results in the development of a schema. To reiterate, Bartlett's (1932) definition, a schema is: a term to describe how a stimulus activates frameworks relating to the features of the role. Past knowledge and experience embedded within a particular schema affects how the current stimulus and information is encoded, thereby providing meaning (Bartlett, 1932). To be effective a CEO has a) to be attuned to their environment and surroundings, and b) to have the flexibility to adjust their behaviour in 
response to changes in that environment (Lord et al., 2001). However, the perception of what constitutes an effective CEO can vary between individuals and contexts; this is referred to as implicit leadership theory. Ritter and Lord (2004) contend that implicit leadership theory suggests that a fundamental part of the CEO role involves the process of being perceived by others as a leader. Implicit leadership theory addresses the evaluations that other people make about leaders, and the cognitive processes underlying these evaluations (Lord, Binning, Rush, \& Thomas, 1978). According to the theory, if an individual enacts the role behaviours required of a leader they would still not be regarded as a leader unless they were perceived as a leader by their stakeholders. Implicit leadership theory examines the perceptions of the leader by groups that can be considered to be followers. Inferences are then made as to the effectiveness of that individual in the role (Hunt, 1984). Implicit beliefs can be developed over time and are refined as a result of actual experiences, exposure to the media and literature, and other social-cultural influences. Such beliefs are also influenced by the personality traits of others and by the cultural values and assumptions they hold about leaders (Gerstner \& Day, 1994; Keller, 1999; Yukl, 2002).

Harrison and Pelletier (1997) contend that these implicit evaluations are present in the environment and often result from the unavoidable cognitive biases that exist below the threshold of awareness. They may also be deliberate choices, reflecting a conscious preference towards a particular outcome. Ranson, Hinings and Greenwood (1980) assert that this happens through a process of constructing meaning. As a result the individual develops an interpretative schema that defines those provinces of meaning that map their experiences of the world, identifying their schema's constituents and its relevancies to their experiences and how they are to come to know and understand them. Bartunek 
(1984) goes on to argue that the development and use of interpretative schema by those involved with a role, permits the explanation of the shared fundamental assumptions about why events happen as they do and how people, for example, CEOs, are to act in different situations. The process of constructing meaning about the shared fundamental assumptions of the CEO role now leads to a discussion about the difference between leadership and management in the next section of this chapter.

\section{Leadership versus management}

An ongoing debate over the difference between management and leadership stems from the use of 'management' and 'leadership' as synonymous terms (Rost, 1991). Graen \& Hui (1999) argue that this ambiguity can be traced back to pioneering leadership studies such as the Ohio and Michigan studies conducted in the early part of the twentieth century. That research examined supervision within organisations. However, rather than require that a 'leadership' relationship exist, the studies only needed the presence of a ‘supervisory’ relationship. Thus, supervision unwittingly became leadership because it assumed supervision subsumed leadership and the definition of the word 'leader' has come to include only the job title and not the trust, respect and obligation that exist between a leader and follower (Graen \& Hui, 1999). The debate over what is leadership and what is management has ranged from the view that leadership and management cannot occur in the same person (Bennis \& Nanus, 1985; Zaleznik, 1977), to the view that successful management in an organisation by definition involves leadership in some form (Grint, 2005; Yukl, 2002). 
A similar but different view is that the leader creates and changes cultures while managers/administrators live within them (Schein, 1992). Zaleznik (1977) maintains that management is represented by individuals who, in order to get people to accept solutions, continually coordinate and balance processes in order to negotiate conflicting values, whereas a leader creates excitement in work and develops choices that give substance to metaphors that excite people. Some researchers state that whilst managers maintain a low level of emotional involvement, by contrast, leaders have empathy with people, and also give attention to interpreting events and actions (Kotter, 1996; Mullins, 1993; Rost, 1991; Selznick, 1957; Yukl, 2002; Zaleznik, 1977).

An underpinning assumption of this study is that management and leadership can be differentiated in terms of their core functions and intended outcomes (Kotter, 1990) and that they are able to be found in the same person (Yukl, 2004). A distinction is often made between leadership and management because in some situations, especially those involving complexity and change, leadership is of paramount importance, and in other situations management should be the focus (Gioia \& Chittipeddi, 1991; Kanter, 1985; Kotter, 1990; Rost, 1991). Steel (1997) contends that many managers do not understand the difference between commitment and compliance, and often leadership is equated with merely holding a senior or higher job title and giving orders. He goes on to state that if the fundamentals of strong effective management have not been established, it will be difficult for leaders to excel. Therefore, as Rost (1991) contends, the view held by some that management is inherently bad and leadership is inherently good is invalid (Rost, 1991). A summary of Kotter's distinctions between leadership and management is provided on the next page. 


\section{MANAGEMENT}

- Planning and budgeting:

Establishing detailed steps and timetables for achieving needed results, then allocating the resources necessary to make it happen

- Organizing and staffing:

Establishing some structure for accomplishing plan requirements, staffing that structure with individuals, delegating responsibility and authority for carrying out the plan, providing policies and procedures to help guide people, and creating methods or systems to monitor implementation

- Controlling and problem solving:

Monitoring results, identifying deviations from plan, then planning and organizing to solve these problems

Produces a degree of predictability and order and has the potential to consistently produce the short-term results expected by various stakeholders (e.g. for customers, always being on time; for stockholders, being on budget)

\section{LEADERSHIP}

- Establishing direction:

Developing a vision of the future - often the distant future - and strategies for producing the changes needed to achieve that vision

- Aligning people:

Communicating direction in words and deeds to all those whose cooperation may be needed so as to influence the creation of teams and coalitions that understand the vision and strategies and that accept their validity

- Motivating and inspiring:

Energizing people to overcome major political, bureaucratic, and resource barriers to change by satisfying basic, but often unfulfilled needs

Produces change, often to a dramatic degree, and has the potential to produce extremely useful change (e.g. new products that customers want, new approaches to labour relations that help make a firm more competitive)

Source: Kotter (1990, p.139)

In order to conceptualise any difference between leadership and management, Rost

(1993) states "firstly, one must determine if the phenomenon is management. Second,

can it then be determined if the relationship is effective or ineffective, good or bad.

Similarly, the same statement can be made about leadership" (Rost, 1993, p. 111). This

thesis addresses the leadership aspect of the CEO role rather than dwell on the managerial

functions. The next section of this chapter provides an overview of the relationship

between the CEO role and leadership. 


\section{Leadership and the CEO role}

As stated in Chapter One, and again in the previous section the CEO role in this study can be regarded as a leadership function as opposed to solely a management one. Therefore, this section provides a discourse about the literature that informs the leadership component of the role. When Northouse (2004) wrote that there is a multitude of ways to finish the sentence "Leadership is ..." he was echoing the words of leadership scholars over the past fifty years. As early as 1948, Barnard, ( as quoted in Northouse, 2004, p. 81), argued that the understanding and defining of leadership was a challenge and problematic. This view was endorsed by Stogdill (1974, p. 7) who contends that there are almost as many definitions of leadership as there are people who have tried to define it. There are estimated to be around 35,000 definitions of leadership in the academic literature (DuBrin, 2000), a situation that has been created, in part, by the use of the term leadership as both as a state (the state of 'being a leader') and a process (the actions that a leader takes). That is, the CEO role is a process and/or an action conducted amongst people, but the task and roles of the CEO are established through position, designation or role. This duality has been credited with creating a confusion that results from double meanings and multiple implications (Barnard, 1948; Burns, 1978; Pye, 2002). In addition, the term leadership is:

... a relatively new addition to the English language; it first appeared approximately 200 years ago in writings about political influence in the British Parliament. However, from Egyptian hieroglyphics we know symbols for 'leader' existed as early as 5,000 years ago ... leaders have existed in all cultures throughout history (Fondas, 1997, p. 270). 
The issues surrounding CEO leadership are further complicated by a belief that, while we know a great deal about leaders, who they are, and what they do, we know very little about leadership (Burns, 1978; Grint, 2005; Northouse, 2004). The difficulty in providing a succinct meaningful definition of leadership has been delightfully described as follows:

Conceptualising leadership presents a challenge which is akin to capturing the ethereal qualities of 'the moon on the water'. You know it when you see it, but it defies capture (Pye, 2002, p. 2).

We may infer that Pye (2002) is referring to those subtle personal qualities that leadership relies upon, qualities that are hard to observe and yet are powerful, for example, enthusiasm, integrity, courage, and humility (Daft, 2002). While we may intuitively know what is meant by such words, they may have dissimilar meanings for different people (Northouse, 2004).

The attention given to leadership has led to what may be described as a more sceptical view, for example that of Barker (2001), who has asserted somewhat cynically that leadership is an industry. Much of the research in the field is undertaken to provide support for products and processes that focus on the industry of leadership development. Therefore, many of the definitions of leadership have been created in order to support these products and processes. Alvesson (1996) believes that the quest for an allencompassing definition is further complicated by the use of the term leadership in a manner that has sought to cover many different forms of leadership within many different contextual situations. He goes on to state that the term leadership has been applied to leaders across a diversity of organisations and industries, for example, churches and 
universities, SS officers, gang leaders, politicians, and non-violent civil rights leaders. He proceeds to argue that seeking an inclusive definition with universal application may not only be difficult, but may explain little of the richness and complexity of the phenomenon of leadership.

When undertaking a research project, Barker (1997) contends that a differentiation must be made between the terms leader and leadership. However, whilst there may be a plethora of definitions, it is also common for some research projects not to provide a definition at all. Rost, as cited in Barker (1997) examined a total of 587 works on leadership and found 366 did not offer any definition of leadership as part of their discussion. The generic non-specific use of the term leadership, to cover multiple facets of the construct, has made it critical for the term leadership to be defined within the context of a particular research study in order to provide rigour and a framework upon which to base the findings and discussion (Clark \& Clark, 1990). Clark \& Clark (1990) recommend that the terms, leaders and leadership, be used as generic terms only. When data or research results are being discussed, the methods by which the leadership qualities are measured should be specified and the way in which the subjects, called leaders, are selected should also be described. More importantly, where possible some specific word should be used instead of the generic term leader, for example, senior executive, elected officer, CEO or middle manager.

As discussed earlier in this chapter, many studies have focussed on the managerial component of the role. This study, by accepting that the CEO role includes a leadership function thus seeks to broaden the lens examining the CEO construct. This, in turn, led 
to the following three criteria as contributing to the essence of the CEO role, in as much as the role:

- encompasses a formal assigned executive leadership function,

- is constituted within a social influence process, and

- exists within, and as part of a contextual relationship.

These three points are now dealt with in turn.

\section{The CEO role as a formal, assigned executive leadership function}

The focus of this thesis will be on the CEO role embracing an assigned formal leadership role. Smircich and Morgan (1982) argue that a formal organisation is one that is based upon the existence of shared meanings that define roles and authority relationships. An individual's behaviour is embedded within those roles and authorities. This, in turn, determines how relationships and practices regarding a particular role occur within an organisation and how the experiences of organisational members are to be structured (Smircich \& Morgan, 1982). The role of the CEO within a formal organisational structure is a strategic function and a leadership process by which the CEO influences the attitudes, behaviours and values of others (Vecchio, 1995).

Chief executive officers are executive leaders (Finkelstein \& Hambrick, 1996; Hagen, et al., 1998; Harrison \& Pelletier, 1997). Executive leadership encompasses the ability to anticipate, envision, maintain flexibility and empower others to create strategic change as necessary (Byrd, 1987) as cited in (Hagen et al., 1998). Hagen et al., (1998) go on to 
state the responsibility for effective executive leadership rests with the CEO and is unable to be delegated. In addition, Northouse (2004) states that the CEO role is deemed to be an assigned role as opposed to an emergent role. An emergent leadership role is acquired through acceptance by others of an individual as a leader. This usually occurs by virtue of their behaviour rather than by appointment through a formal recruitment and selection process.

However, CEO leadership is more than the traits and behaviours of the individual (Hitt \& Ireland, 2002). Hagen et al., (1998) argue that focussing solely on the traits and behaviours of the CEO, and on the consequences of their behaviours, results in other characteristics and functions of the CEO role being excluded from consideration. The acknowledgment of the CEO role as an assigned executive leadership role presupposes that it is a dynamic role involving leading and managing interactions with people. This results in CEO leadership being an interactive process between leader and followers that extends beyond formal organisation and leadership boundaries (Northouse, 2004). It also lessens the importance of the CEO's characteristics, abilities and traits (Barker, 2001) and focuses more upon their actions, interactions, perceptions and feelings (Hagen et al., 1998). That is, the CEO role is a multi-faceted social process of dynamic collaboration. At the heart of the CEO role, Kotter (1982) asserts, is the management of resources. An essential aspect of the resources, for which the CEO as a leader is responsible, is the social capital (people) of the organisation (Hitt \& Ireland, 2002). The relationships between the CEO's leadership and social capital involves networks of interactions between individuals and organisations, and is underpinned by a variety of norms, values and obligations (Adler \& Kwon, 2002). In addition to the internal social capital, the CEO is also concerned with the social capital external to the organisation (Hitt, Lee, \& Yucel, 
2003). Increasing global competition and more dynamic external relationships have placed pressure on CEOs to build mutually beneficial relationships with those external to the organisation (Gulati, Nohria, \& Zaheer, 2000). This, in turn, has created a need for a greater depth of knowledge of the CEO's understanding of their context in which the CEO role is situated, and his or her perception of the dynamics within that context. Kotter (1990) argues that as a result of the dynamic complexities confronting CEOs, one of their key responsibilities is the leadership of change. Therefore, the next section of this chapter provides a discussion about the relationship of the CEO role to the initiation and implementation of strategic change.

\section{The CEO role and the relationship to strategic change}

Inherent to understanding the CEO role is attaining an understanding of the relationship between the CEO role and the initiation and leadership of strategic change. Leading change is one of the more important and difficult leadership responsibilities of the CEO (Nadler, Shaw, \& Walton, 1995; Yukl, 2002), and the leadership of change is considered to be a key differentiator between leadership and management (Kotter, 1990). A common finding is that when the success of a particular change initiative is evaluated, effective leadership is critical to its success (Hackman \& Johnson, 1996; Kanter, 1992; Yukl, 2002). The increasingly turbulent and complex organisational environments have created a need to understand why some organisations are successful, yet others are far from being so. In addition, complexity and uncertainty resulting from the failure to maintain competitiveness can create stressful operating conditions for the CEO. 
Graen and Hui (1999) suggest that the leadership of radical change will be one of the key global themes of twenty-first century leadership, and the role of the CEO will be crucial to the success of an organisation in these changing environments (Burns, 1978; Kanter, 1985; Kotter, 1996). The CEO and, according to Gioia and Chittipeddi (1991), ultimately the top management team, can be seen as the architects, assimilators, and facilitators of strategic change. Robbins, Millet, Cacioppe and Waters-Marsh (1999) observe that:

During times of change, there is uncertainty, confusion and risk; leaders must have two qualities that are vital during this period. First, they are able to understand the need for change and to identify what needs to be done in order for organisations and people to successfully deal with the change. Second, they must have the ability to motivate people to do what is necessary for the new direction to be successful (p.395).

The role of the CEO in any strategic change initiative is also considered to be one of creating meaning for others in the organisation. It is contended that the CEO needs to firstly understand how the intended change makes sense or fits into some revised interpretative schema or system of meaning (Bartunek, 1984; Ranson, Hinings, \& Greenwood, 1980). Then it is considered that they must be able to communicate this to others. Thus, the CEO must develop a sense of all aspects of the organisation's environments (Kotter, 1996). Indeed, when leading change, the role of the CEO is acutely context-sensitive and the actions of a CEO in deciding what to change and how to go about it are bounded by the context both within the firm and within the external environment (Pettigrew \& Whipp, 1991). Ireland and Hitt (1999) also argue the mind of the CEO must be agile, flexible, quick, innovative and strategic, enabling them to identify and competitively exploit opportunities as they emerge. This, in turn, will allow their organisations to prosper and remain competitive within the boundaries and schema imposed by their environment. 
The work of Gioia and Chittipeddi (1991) has focused on the symbolic role of the CEO during a period of strategic change and they conclude it goes beyond being an expression of values, beliefs and actions. They contend it enables the accomplishment of change. Such symbolism helps create meaning for others and contributes to and can be fundamental to the success of change initiated by the CEO. As stated earlier in this chapter the role of the CEO involves the construction of meaning and a degree of influence on people. The next section of this chapter discusses the role of the CEO as an influence process.

\section{The CEO role as a social influence process}

If the CEO's role is one of leadership within an organisation, then it needs to be considered as part of a social influence process, that is the process, whereby one person exerts intentional influence over others. Yukl (2002) contends that this allows the CEO to guide structure and facilitate activities and relationships in a group or organisation and influence the attitudes, behaviours, and values of others (Daft, 2002; Vecchio, 1995). In turn, this helps create a relationship between people that is both active and interactive (Daft, 1999). Accordingly, it is possible to understand CEO leadership as being more than a linear, one-way event. It is shaped through the interaction of at least two points of reference: that is, of leaders and the led (Smircich \& Morgan, 1982). In other words, without individuals or groups to influence, leadership cannot occur (Kan, 2002). In order to possess influence, the CEO must make sense of all facets of their context and provide meaning and direction for their followers (Zaccaro \& Banks, 2001). Incorporating 
'influencing' within the operational definition of a CEO role adds a temporal (chronological) dimension to the CEO role and further supports the understanding of it as a process (Kan, 2002; Parry, 1998).

Barker (2001) argues that a social process is much broader than a social relationship. Considering leadership as something that is processual brings more depth and context to the study. A social relationship is based upon a set of role expectations that are understood by the participants in the relationship. Baker (2001) suggests that relationships in society tend to be contractual, with performance standards and evaluations. While social processes include social relationships, they also provide for the development and definition of roles and role expectations, including how individuals and groups impact upon one. That is, the meaning of leadership as enacted in roles such as the CEO's can be uncovered by examining the socially constructed meanings and behaviour patterns that emerge from the interactions of individuals with each other (Barker, 2001, p. 352).

Wright (1996), in linking role expectations to role effectiveness, sounds a cautionary note when assessing role effectiveness in different contexts. For if effectiveness is defined solely in terms of the degree of influence then, for example, if the CEO influences his or her followers to pursue a disastrous course of action, it would be fundamentally wrong to consider that individual as being effective (Wright, 1996). Some people (Yukl, 2002) believe that anything that influences behaviour is leadership. However, many sources of influence are not examples of leadership, and do not achieve the forms of risk-taking and commitment that Dunnette (1966) says are characteristic of true leadership. Influence, without leadership, for example, can be apparent where the followers develop a childlike dependency upon the leader, exhibiting an unreflective acceptance and unconscious 
compliance with authority that occurs in cult groups, for example, Jim Jones and the People's Temple (Gemmill \& Oakley, 1992). Daft (1999) maintains that inherent in the use of influence is an assumption that leadership is multi-faceted and non-coercive, resulting in the enhancement of follower self-esteem and faith in the leader (Howell \& Avolio, 1992). This thesis heeded the call by Rost (1993) for researchers to investigate the phenomenon of the CEO role more broadly by examining the dynamic processes by which the various groups involved with a specific role develop their perceptions about that role:

Leadership scholars have spilled much ink on the peripheral elements surrounding leadership and its content, instead of on the nature of leadership as a process and leadership viewed as a dynamic relationship (Rost, 1993, p. 4).

At that time, Rost's (1993) call arose from his belief that the scope of research into all facets of leadership and leadership roles must be broadened if the construct is to be better understood. This provides the context within which the CEO role is situated that is relevant to this study.

\section{The CEO role as a function of context}

As stated in Chapter One, the development of leadership theory has resulted in a de facto cultural predisposition toward North America (Muczyk \& Adler, 2002). Col (1993) asserts that the majority of organisational theories have the label "Made in the USA" stamped on them. He argues this is the consequence of the theories having been shaped by the political, economic and cultural context of the USA in the twentieth century. 
Similar concerns have also been expounded and expanded to include the impact of European research and scholarship on organisational theories (De Cieri \& Dowling, 1997; Wright, Lane \& Beamish, 1988). Such theories relating to organisations have been further influenced by the predisposition towards democratic individualism found in North American culture (Muczyk \& Adler, 2002) - a predisposition that according to some does not encourage the recognition of differing styles of leadership, especially those from other cultural contexts (Muczyk \& Adler, 2002). As Muczyk and Adler (2002, p. 3) contend, such theories have been assimilated consciously or otherwise because the scholars involved in the development of leadership theory were also academics with strong predispositions toward the collegial model of leadership.

As a result, there have been implications for leadership studies conducted in contexts outside the USA or Western Europe. For example, an exploration of cross-cultural leadership theories conducted by Pfeifer (2005) showed that theories, developed in contexts other than the USA, do reveal that alternative conceptualisations of leadership exist. This suggests that the supposedly dominant or prevalent leadership theories may not cover the full range of leadership behaviours. Therefore, if the frameworks and scripts that inform a leadership role in New Zealand are developed solely from western models and theories, then indigenous forms and styles may not be recognised as leadership behaviours.

Smith (2005) argues that much of the early research conducted in New Zealand has been informed by western models which have been described as perceiving indigenous models as second class. Furthermore, Pfeifer (2005) contends where studies have been conducted, for example Hines (1973), Kennedy (2000) and Parry and Proctor-Thomson 
(2000), they have "treated" everyone as one cultural group rather than identifying different ethnicities within the sample.

The view that North American and European leadership theories and models may not be relevant to other parts of the world is becoming more widespread (Adler, 1982, 2002; Cheng, 1994; Hessling, 1971; Hofstede, 1980; Hofstede \& Kassem, 1980; Maruyama, 1974; Muczyk \& Adler, 2002; Tsui, 2004). As a result, there have been calls for leadership research to be undertaken within the specific institutional, situational and societal contexts in which a particular leadership role occurs - for example, the specific institutional, situational and societal context of the CEO (Alvesson, 1996; Biggart \& Hamilton, 1987; Bryman \& Stephens, 1996; Muczyk \& Adler, 2002).

Adler (2002) has commented on the paucity of research examining how leadership theories can be adapted to a wider range of organisational types and across different cultures. She argues that not enough is known about management and leadership practices in indigenous contexts outside the USA or about their consequent impact upon organisational effectiveness. It has been claimed that context has to become central to the research rather than remaining a marginal issue (Bryman, Gillingwater \& McGuinness, 1996). Thus, the context within which the role is situated becomes vital to determining how that role should be enacted:

If leadership is considered to be a relationship and a social process then leadership is acutely context sensitive. The limits of the strategic leader's discretion are bounded by the internal and external contexts of the firm (Pettigrew \& Whipp, 1991, p. 165). 
Tsui (2004) also argues there is a need for more context-specific and context-bound research in order to enhance the knowledge of executive leadership. She proposes three approaches to examining context. The first is, context-free research that produces models applicable to any social, cultural or political context, the second is context-bound research where the models are applicable to some contexts and not others. The third type is context-specific research where models or knowledge are substantive only to a particular context. As there are only a limited number of context-bound and context-specific research studies (Cheng, 1994; Tsui, 2004), there are still many gaps in the field of CEO research to be filled. This thesis, as a context-specific study, acknowledges the importance of the CEO's environment and how they construct meaning within that environment.

\section{Conclusion}

The purpose of this chapter was to use the literature to introduce the topic of the thesis. In doing so, it identified the a priori concepts relevant to this thesis. The chapter provided a discussion of role, in this case, the CEO role, the development of role identity and how interpretative schemas contribute to the definition and the subsequent enactment of the role. For the purposes of this thesis, the CEO role is defined as an assigned executive leadership function, a social influence process and an integral part of the context within which it is situated. The introduction to the literature also selectively discusses the interrelationship between the CEO role and executive leadership, and how meaning is constructed from the ongoing interactions that are experienced. In the next chapter, the ontological and epistemological bases for the study are outlined and the reasoning for the decisions made regarding the choice of research methods is provided. 


\section{Chapter 3: The Methodological foundations of the thesis}

The idea of acquiring an "inside" understanding - the actors' definitions of the situation - is a powerful central concept for understanding the purpose of qualitative inquiry.

Thomas A. Schwandt (2000, p. 102)

\section{Introduction}

The purpose of this chapter is to provide the reader with an overview of the theoretical foundations of this thesis. To address an often claimed or identified weakness of the grounded theory method, the chapter commences by providing an overview of the theoretical paradigms that underpin the study. It then outlines the grounded theory method, including a discussion of the origins of the method, its strengths and weaknesses. The chapter then proceeds to summarize the divergent paths taken by Glaser and Strauss in developing the method. Following on from this, a commentary is provided on the modified form of the method developed by Charmaz (2000, 2003). The chapter concludes with a discussion of the processes that were undertaken to ensure the academic rigour of the research. 


\section{Methodological perspectives of this research}

This research study is an inductive study as opposed to a deductive study. Deductive research starts with a theory and a resultant hypothesis, and then gathers observations in order to seek confirmation, or otherwise, of the theory, whereas inductive research could be considered to be a bottom-up approach where the theory is developed as a result of the analysis of the data which is obtained by studying the social world (see Figure 4).

Figure 4: Theory construction by induction

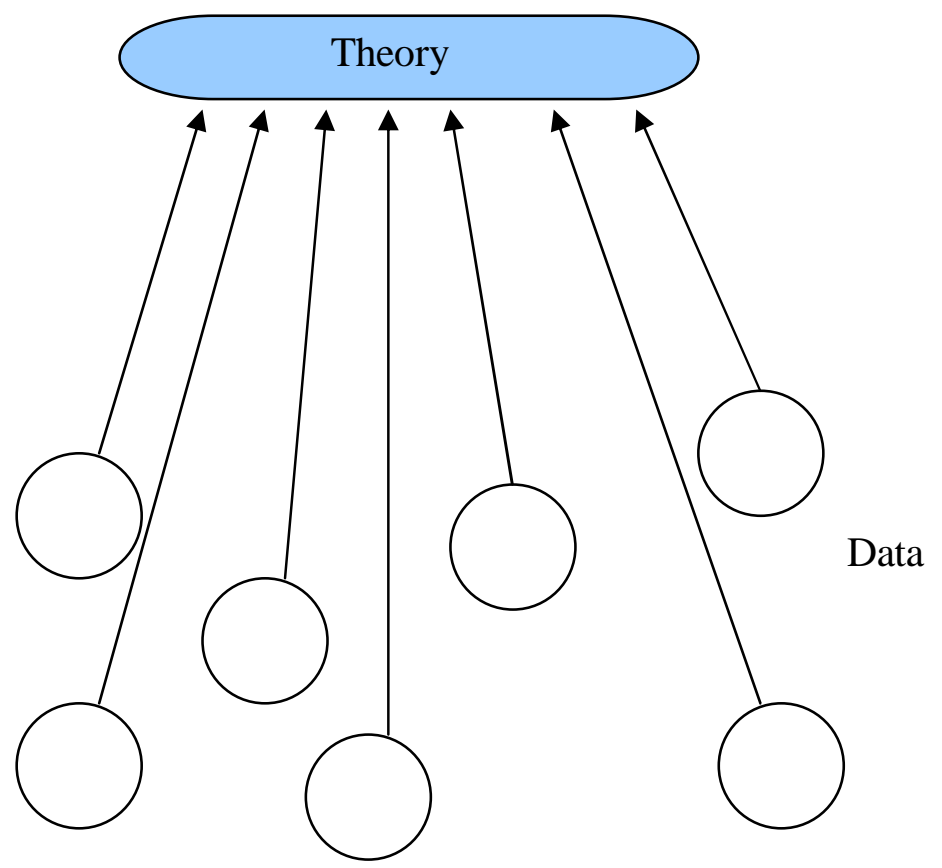

Source: (Gilbert, 2008, p. 27) 
That is, in inductive research, the researcher commences with a research problem pertaining to the social world and then creates a research design that studies that social world and that allows the researcher to generate a theory of that social world (Gilbert, 2008). The choice of research design approach for this thesis is linked to the perceived value and anticipated benefits arising from mutual discovery and interaction between the research participants and researcher. Such a choice enabled the depth, richness and complexity of these mutual interactions to be explored (Carr, 1994). This led the study to be situated within the qualitative paradigm. Leininger (1985) and Munhall (1989) argue that the use of the methodological tools situated within this paradigm permits a researcher to explore the participants' perceptions and experiences and identify the social processes within a context that might affect those perceptions and experiences. In fact, Ebbs (1989) has stated that qualitative methods do not silence the voices of the research participants. Rather they support and celebrate them for the contributions they make to organisations, communities and society.

Munhall and Boyd (1993) assert that in any qualitative study, there are two commonalities; the first, is an acknowledgement and acceptance that reality changes over time and reflects the perceptions of an individual, thereby creating a different reality for each person. The second commonality is that an individual's knowledge is specific to a given situation or context, thus leading to the existence of a diversity of "realities". Crotty (1998) argues that when setting out a research project, any researcher will hold a set of beliefs with regard to the nature of reality, a particular view of the world, and also a perspective on how a particular research project should investigate that world. These beliefs, views and perspectives are influenced by the individual's history and cultural context and have shaped his or her view of the world. This in turn influencing his or her 
construction of meaning (Mills, et al., 2006b). Mingers and Brocklesby (1997) state that these can be distinguished in terms of three philosophical dimensions; the ontology, that is the types of entities assumed to exist. The second is the epistemology that is, the possibilities of, and limitation on, our knowledge of the world. The third is the methodology that is how we gain knowledge of the world. A methodology is a structured set of guidelines or activities to assist people in undertaking research or intervention.

Within the context of this research, the ontology is pluralist and relativist (Schwandt, 1994). That is, realities are in the form of multiple mental models or constructions: reflecting realities that are socially and experientially based and local and specific in nature (Denzin \& Lincoln, 2000). The form and content of these constructions depend on the individual persons or groups holding them (MacDonald \& Schreiber, 2001). Epistemology provides the philosophical grounding for deciding what kinds of knowledge are possible and how we can ensure that they are both adequate and legitimate (Maynard, 1994). Within the context of this thesis, the epistemological assumption is that knowledge is subjectivist, arising from and reflecting the interaction between the researcher and the research participants. The findings of the research are created as the investigation proceeds (Denzin \& Lincoln, 2000). Thus, the researcher is part of the context of the phenomenon that is being explored and brings his or her own personal experience and perspectives to the investigation in the creation of knowledge (Speziali \& Carpenter, 2003).

As a qualitative study, the methodology results in the study being positioned in the field as opposed to within a laboratory. As recommended by Mingers (2003), the principles and processes of the grounded theory method were used as a set of structured methods or 
techniques to carry out the research. The primary data was obtained by conducting indepth, face to face interviews at the participants' place of work. The interviews were semi-structured and designed to elicit and refine the individual interviewee's perceptions about the CEO role (Guba \& Lincoln, 1994). The interview strategies are discussed in Chapter Four.

Cresswell (1994) argues that there are two additional influences related to the values and language within qualitative studies and are defined as, the axiological and rhetorical. Axiological issues deal with the role that values play in a study. Within qualitative research, the researcher admits to the value-laden nature of the study and actively reports on those values and biases as well as the value-laden nature of the information that is gathered. Rhetorical relates to the language of the research paradigm within which the researcher chooses to operate. The rhetoric within a qualitative study recognises and reflects the lexicon of the social scientists. Cresswell (1994) states that the language of qualitative research is quite distinct from that of quantitative research; words such as understanding, discover, and meaning featuring strongly in the vocabulary of the qualitative researcher, but not always in quantitative research. Within the context of this research, axiological and rhetorical issues were relevant to informing the philosophical perspectives underpinning this study, in as much as the language constructions of both the researcher and the participants in this study are value laden, and therefore language used throughout this thesis is value-laden. One of the identified weaknesses of grounded theory research is that the philosophical underpinnings of a study are not often clearly explained. The next section of this chapter outlines methodological foundations applicable to this research. 


\section{Interpretivism}

Interpretivism is often described as a canvas that provides a naturally occurring, unforced view which is open for the researcher's interpretation (Schwandt, 1994). Interpretivism has evolved from the Verstehen tradition in sociology and the phenomenology of Alfred Schultz and provides an alternative to positivism in the effort to obtain richer, deeper meanings from the research outcomes (Guba, 1990). Vrasidas (2001) argues that while those working in the positivist tradition aim to describe people's actions, the interpretivist endeavours to identify the reasons for, and the meaning behind, those actions. That is, they are attempting to answer the how and why questions:

The emphasis of interpretive research is on the meanings in action of the actors involved. To understand these meanings the researcher has to study them in naturally occurring settings, not in highly controlled laboratory settings (Vrasidas, 2001, p. 3).

The natural sciences have been defined as nomothetic, and the human and social sciences as ideographic (Crotty, 1998). This distinction also places an emphasis on the description (Erklähan) of human behaviour (the positivist paradigm) and the understanding (Verstehen) of human behaviour (interpretivist paradigm) (Bryman, 2001; Patton, 1990).

Interpretivism requires a researcher to be able to grasp the subjective meaning of social action (Bryman, 2001). Therefore, if we want to understand people's actions we have to first understand those actions in the way the participants do. Grounded theory has been linked to Verstehen which considers understanding on two tiers (Kan, 2002). Bryman (1988) contends, at the first tier, it supports the achieving of an understanding of the causes and effects of people's actions, while at the second, it allows for clarification of 
the underlying motivational or explanatory understanding of the behaviour of the individual, that is the how and why of an individual behaves in the manner they do.

In this study, these two tiers of understanding occurred through the analysis of the interview transcripts and the actions and statements of the research participants and the factors that caused those reactions. Often, this was as basic as recognising the tone of an interviewee's voice, distinguishing aspects of his or her body language or noting a momentary emotional reaction to a question or statement made in the interview. On some occasions, the analysis necessitated further deeper questioning, the searching of news and other media or even additional interviews, both formal and informal, in order to achieve an understanding of how the participants create meaning. As stated earlier in this chapter, the epistemological stance encompasses how social reality is created by the identification of phenomena. The next section outlines the part phenomenology took in this thesis.

\section{Phenomenology}

Crotty (1998) states that phenomenology has been identified as one of the main intellectual traditions responsible for the development of the post-positivism. Crotty (1998) further asserts that phenomenology focuses on the manner in which human experiences are examined, exploring how an individual understands their everyday experiences articulating them in everyday terms (Cresswell, 1994). Cresswell (1994) goes on to state that it invites us to engage with the phenomena in our world and make sense of them directly and immediately. This allows the subjective nature of the data not to be compromised as it is collected and analysed (Crotty, 1998). 
Within the context of this thesis, a phenomenon is recognised as a problem, an issue or an event that is defined as being significant to the participants. When seeking to identify phenomena, the researcher looks for repeated behaviours or actions which may represent what people do or say, alone or together, in response to the situations in which they find themselves (Strauss \& Corbin, 1998). Phenomenological considerations within the context of this thesis focused not only on the importance of a particular phenomenon in itself, it also examines the research participants' perceptions of that phenomenon and how they understood and constructed meaning regarding the nature and reasons for its existence or occurrence.

The utilisation of a phenomenological perspective means the researcher is able to use interviews to find out how people experience and interpret the phenomenon under study. An alternative is for the researcher to actually experience the phenomenon by taking the role of a participant observer (Parry, 1997). However, this was not deemed practical in this study. This led to the selection of interviewing as the principle data gathering method in order determine how CEOs and those closely involved with the role experienced and interpreted the phenomenon of the CEO role. Eichelberger (1989) writes that a critical dimension of phenomenology is that the experiences of people are analysed, compared and bracketed to determine the essence of the experience under investigation. Therefore, the commonality of the experiences of people is critical to phenomenology. This commonality is also methodologically important to the modified grounded theory approach used in this study. Parry (1998) argues that one of the primary requirements of grounded theory is that the research determines core themes with a core social process that explains the phenomenon being analysed. The determination of the core social 
process is, in effect, the determination of the phenomenological essence of the experience of the subjects of the research (Parry, 1997). The next section of this chapter provides a discussion of the grounded theory method and its development as a qualitative research tool. A full outline of the concurrent data analysis and collection is provided in Chapter Four.

\section{The grounded theory method}

As stated in the previous section, the purpose of grounded theory is to identify a core social process (Glaser \& Strauss, 1967; Parry, 1998). This purpose led the grounded theory method to be at the forefront of what some regard as the qualitative revolution (Denzin, 1994; Fisher, Schonfeldt, \& Shaw, 1999). Glaser and Strauss (1967) developed the method at a time when quantitative social science studies were the dominant form of social scientific inquiry (Charmaz, 2003). The impetus behind its development was the desire to avoid highly abstract sociology, and to bridge the "gap between theoretically uninformed empirical research and empirically uninformed theory by grounding the theory in the data" (Goulding, 1999; Goulding, 2002a). Glaser \& Strauss (1967) stated that grounded theory involves the systematic collection and analysis of data, the objective being the discovery of theory as opposed to traditional sociological methods, which are concerned with obtaining accurate facts and rigorous theory testing. Chenitz and Swanson (1986) argued that the process of theory generation involves the gathering of data in a systematic manner, then analysing that data in order to gain increased understanding of the social and psychological phenomena. The ultimate aim is the generation of a substantive theory, which includes abstracting the concepts and the relationships between these concepts. (See definition contained in Chapter One). 
Grounded theory does not involve the testing of theory or of hypotheses (Goulding, 2002a). Rather it involves the qualitative analysis of qualitative data until theory emerges (Glaser \& Strauss, 1967; Goulding, 2002a; Parry, 1997). Data collection, analysis and theory generation are conducted concurrently (Strauss \& Corbin, 1990). Glaser and Strauss (1967) called this concurrent process, the constant comparative method of analysis, stating that it is central to the conducting of grounded theory. Glaser (1978, p. 16) described the conceptual grounded method from data collection to a finished written report as a process of double-back steps. As the researcher moves forward, they are also going back to previous steps in order to clarify and add meaning to themes that are surfacing from the data. This is in keeping with the arguments contained in the literature about the development of theory within the qualitative paradigm (Bonoma, 1985; Eisenhardt, 1989; Gilmore \& Carson, 1996). Clarification and creation of meaning is critical, especially when taking into consideration the complex relationships and the processes involving people and organisations. Therefore, this process must be dealt with as rigorously as possible (Perry, Riege, \& Brown, 1999).

Some authors state that when assembling the concepts and driving the analysis, the researcher must maintain rigour, ensuring that the theory is grounded in the data, while at the same time displaying both critical and creative thinking (Locke, 2001; Milliken \& Schreiber, 2001). Glaser (1978) and Strauss and Corbin (1998) contend this is an essential element of the naming of themes - as the researcher must ask critical, stimulating questions in order to make valid comparisons that result in innovative, integrated and realistic theory. Inherent within all forms of grounded theory is the 
requirement that the analysis will progress past the descriptive stage and that a theory will be generated (Glaser \& Strauss, 1967).

Glaser $(1978, p .6)$ proceeds to argue that an additional advantage of the grounded theory method is that, not only is it uniquely suited to qualitative research and fieldwork, it can also be used as a general method of data analysis with any form of data collection methods, such as experiments, surveys and case studies. This includes the analysis of secondary data, for example, company documents and news media reports as used in this study.

This results in grounded theory taking on an expansionist stance with regard to the generation of theory (Glaser \& Strauss, 1967). In contrast to the reductionist position which reduces the investigation to a small number of clearly defined variables, the expansionist standpoint will seek description and understanding of phenomena as a whole (Parry, 1997). Figure Five on the following page outlines the principles of the expansionist approach. During the analysis, incidents are identified and are then coded into a concept. The researcher returns to the incident seeking explanation about how and why the incident occurs. As the concurrent analysis continues, these concepts coalesce to become themes that act to explain the identified phenomena. 


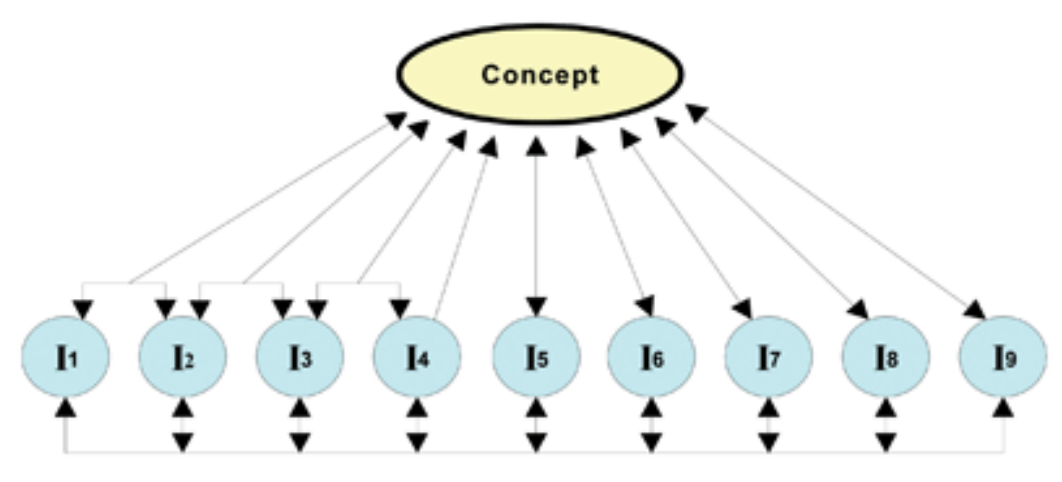

Source: Glaser (1978 p. 62)

Retrieved from, http://epress.anu.edu.au/info_systems/images/fig5.4.gif Accessed on 01/12/08.

Parry (1997) goes on to state that expansionists enter a field of inquiry and build outward from the entry point with each additional inquiry step based on the sum of the insights from the previous steps. This expansionist approach allows the identification of the social processes associated with the development of a theory grounded in the data.

\section{The identification of social processes}

As outlined in the Literature Review, the CEO role is deemed to be constituted as part of a social influence process. Therefore, this thesis examines the CEO role from a processual perspective. That is, how the social processes existing within a specific context can influence the perceptions of the CEO role. This means that the study is concerned with the interrelationships between human beings. Within the grounded theory method, themes are deemed to be social processes if they involve change over time (Fagerhaugh, 1986). Glaser and Strauss (1967) stated that a social process can be either a 
basic social structural process (BSSP), for example bureaucratisation, routinisation, centralisation or decentralisation, whereas a basic social psychological process (BSPP), is as becoming, highlighting and personalising, the gerund 'ing' indicating a process (Schreiber \& Stern, 2001, pp. 75-76). The logical relationship between the processes is that a basic social structural process abets, facilitates or is the social structure within which the basic social psychological process occurs (Glaser, 1978, p. 102).

Schreiber (2001) maintains that there has been insufficient work completed in the area of the basic social structural processes and their relationship to and impact on, an organisational role. This is because the majority of work has concentrated on the basic social psychological processes (Gordon, 2008; Irurita, 1990; Kan, 2002; Locke, 2001; Millett, 1994; Parry, 1997; Schreiber, 2001). Schreiber (2001) goes on to state that the wider social context has been largely neglected in grounded theory studies, and it is only recently that an appreciation of the ways in which social forces impact on individual action has begun to develop. Whilst Glaser and Strauss (1967) discussed the role of social structural processes in the sixties, as Schreiber (2001) argues, little has been done since to expand on this notion. This thesis recognises the presence of social structural processes and seeks to determine their impact on the individual CEO and the enactment of their role. In doing so, this study accepts and accommodates Barker's (2001) distinction that process, not structure is the vessel of leadership. 


\section{Strengths and weaknesses of the grounded theory method}

Grounded theory has been established and developed over an extended period of time (Chenitz \& Swanson, 1986; Glaser, 1978; Glaser \& Strauss, 1967; Strauss, 1987; Strauss \& Corbin, 1990). One of the primary contributions of the method is in fields where little prior research has been completed and where the method supports the emergence of theory (Chenitz \& Swanson, 1986). Morse (2001) describes another as being the ability to apply the method of analysis to both primary and secondary data, in informal situations, and to other materials such as media reports, in order to utilise evidence from a variety of sources. Morse, (2001) goes on to state that one of the major challenges that grounded theory presents is for the researcher to 'actively seek and include variation in the study in order to provide a more balanced and well-rounded description of the topic' (p.11). This ability to seek variation creates a situation where it is possible to develop theory, and not merely to describe phenomena (Chenitz \& Swanson, 1986). This creates the need for a researcher to ensure the research sample is representative of the study population and to include both primary and secondary data.

One of the major criticisms levelled at the grounded theory method is that its epistemological assumptions are often not clearly articulated (Charmaz, 1990), and that constant comparison, as on ongoing feature of the process, is not adhered to throughout the study (Goulding, 2002a). She goes on to express concern as to the danger of emphasising the identification of codes as an exclusive feature of the process, without identifying how the various codes relate to one and other. The result may be that the researcher can become more descriptive than theoretical; the core themes may not be explained fully and an overarching social process may not be derived (Glaser, 1978, 
1992; Goulding, 1999; Goulding, 2002a; Stern, 1994; Strauss \& Corbin, 1990). An additional espoused weakness of the methodology is that an over familiarity with the study area is a threat to the researcher's theoretical sensitivity (Backman \& Kyngas, 1999; Skodol-Wilson \& Ambler-Hutchinson, 1996). The need for the researcher to maintain an appropriate level of theoretical sensitivity within this thesis led to the modified form of grounded theory, as theorised by Charmaz (2000), to be used. This approach to the method allows the researcher and research participants to create meaning from their interactions with each other. While a discussion of theoretical sensitivity and the modified approach is provided later in the chapter, at this stage, it is appropriate to provide a brief overview of and the reasoning behind the divergent paths the method has taken.

\section{The divergent paths of grounded theory}

Since its inception in 1967, grounded theory has taken differing and at times opposing paths. Charmaz (2003) contends that this divergence has created a need for a debate about what grounded theory is, what it has become and what it should be. Therefore, it was deemed relevant at this point in the thesis to provide an overview of the divergent paths and then proceed to explain why the modified approach, as proposed by Charmaz (2000), was chosen for this thesis. Since the publication of their book, The Discovery of Grounded Theory, Glaser and Strauss (1967) have separately refined and developed the grounded theory method. Glaser believed that the method should focus on the emergent nature of the theory from the data, while Strauss, in association with Corbin, preferred a more technically rigorous approach. These different paths have been labelled the 
Glaserian and Straussian models. Of the two, the Straussian approach to technical rigour leads it to be more prescriptive in its methods of procedure. The Glaserian approach stresses the importance of allowing the theory to emerge from the data, and not be "forced" into a framework by some pre-prescribed coding protocol (Charmaz, 2000). Goulding (1999) argues that this divergence has occurred because Strauss modified the description of grounded theory from its original concept of emergence to one which involved a densely codified operation.

However, Lee (1999) argues that since the underlying assumption of grounded theory is that social phenomena are complex, therefore the steps taken to study these complex social phenomena need to be flexible. Lee (1999) goes on to argue that there should be no hard and fast rules about how to conduct grounded theory. Instead, Lee proposed there should be general guidelines that allow the researcher to choose the most appropriate theoretical approach for a specific study in order to answer the research question. It is this proposition that led to the choice of a modified form of grounded theory for this thesis.

\section{The modified form of the grounded theory method}

The modified grounded theory approach as proposed by Charmaz (2000) resulted from her belief that a researcher should be able to use grounded theory in a more inductive interpretative manner than either the Glaserian or Straussian forms of the method. An aim of this study is to gain an understanding of the social processes that are present within the research context and their influence upon the perceptions of the CEO role. 
Consequently, adopting an interpretivist ontology allowed the thesis to address the contextual and processual elements, as well as the actions of the participants. In keeping with the recommendations of Patton (2002), this thesis begins with the premise that the human world is different from the natural, physical world; therefore it must be studied differently. Extending from this is the presumption that the underlying purpose of qualitative studies is to reveal and understand how people construct meaning with regard to their environment and the events occurring within it (Guba \& Lincoln, 1998). Researchers working in the qualitative paradigm focus upon the role of ideas, norms, knowledge, culture and argument (Finnemore \& Sikkink, 2001), and how the individual human subject engages with the objects in the world and creates meaning from them (Crotty, 1998). Indeed, Crotty (1998) argues that basic tenet of the researcher's world is that meaning is not discovered by the mind, but constructed by the individual from the interactions they experience within their environment.

Charmaz (2000), when proposing her modified approach, stated that the aim was to facilitate the researcher being able moving away from the objectivist/positivist form of grounded theory. This will allow them to take into account the various ways in which the individual human subject engages with objects in their environment and makes sense of them (Crotty, 1998). Charmaz (2000) contended that this will allow researchers to reclaim grounded theory tools from their positivist underpinnings and to form a more open-ended practice of grounded theory, stressing the emergent elements of theory. As stated previously, Charmaz (2003) stresses that within this modified grounded approach the methods should be used as adaptable, heuristic tools as opposed to mechanical procedures. Therefore, her argument is that modifying the approach to the study of people in their natural settings redirects grounded theory research away from any 
tendency towards positivism, allowing the researcher to enter the worlds of those being studied in order to observe the context of the participants, and the interactions and interpretations that occur within it (Barker, Wuest, \& Stern, 1992; Goulding, 1999).

Charmaz's $(2000,2003)$ view echoes that of Rost (1993), and has been supported by Ospina and Schall (2001), who consider that one of the primary requirements for a researcher is to be sensitive to the forces present within a specific context. Ospina and Schall (2001) and Rost (1993) are of the view that it is important for researchers to recognise that, as members of society, we construct our social world together and that human behaviour must be understood by taking the point of view of those experiencing it. This is essential if a greater degree of executive leadership theory and research is to be based within the qualitative paradigm. Therefore, the modified grounded theory approach is an appropriate method by which to examine the CEO role as: "something that emerges as people make sense out of their everyday lives, rather than merely observing the individual who is given or takes the role of leader" (Ospina \& Schall, 2001, p. 2).

Charmaz (2003), when distinguishing between the objectivist and the modified approaches to grounded theory, was adamant that her modified approach does not constitute the only valid form of the method. Her argument is that the objectivist approach, as theorised originally by Glaser and Strauss (1969), assumes the reality of an external world and that it takes for granted the notion of the neutral researcher viewing categories derived from the data in a tabula rasa fashion. By contrast, assuming an interpretivist ontological perspective it is recognised that the researcher plays a significant role in creating and analysing the data in interaction with the participants (Bryant, 2003). 
Indeed, in a modified grounded theory study, the interview is often context-bound or context-specific and the relationship between the interviewer and interviewee is one of reciprocity; people giving and taking in the construction of knowledge (Mills, et al., 2006a). As such, the views and values of the researcher become relevant and need to be given voice in the study. The study eschews predetermined data categories allowing the data to speak for itself (Bryant, 2003; Charmaz, 2000; Mills et al., 2006b). Therefore, the use of this form of grounded theory allows the researcher to surface and describe the feelings and emotions of individuals as emergent phenomena, and also means that "gathering data without forcing either preconceived questions or frameworks upon it" becomes a major priority (Charmaz, 2000, p. 512).

Paraphrasing these latter points, it may be stated that that utilising the modified grounded theory method provided the researcher with a means to analyse the data rather than apply a set of prescriptive processes that might analyse the data , allowing an in-depth and holistic discussion of the emergent themes (Bryant, 2003). Charmaz (2000) contends that using the grounded theory method in this way lets the data analysis remain interpretative, allowing the emergent themes to be established via constant comparison, and not via the preconceptions imposed upon the researcher nor by pre-ordained coding families as proposed by Glaser and Strauss (1967). Mills et al., (2006b) consider the outcome of such an approach is that studies retain an ability to harness rich context-specific information from the data, developing patterns and theories that help to explain the phenomena. The change in the role of the researcher then leads to the need for a discussion about the debate that surrounds the writing up of research within this paradigm. 
Historically, the writing up of the results of grounded theory has been silently authored (Charmaz, 2003). Mills et al., (2006a) contend in the modified grounded approach where the researcher plays an interactive role in the study, silent authorship is problematic. As an active participant in the research, the method makes it permissible for the author to use his or her voice in the writing of the research, allowing them, as Mills et al., (2006b) state, to present themselves as a human being. Mills et al., (2006b) assert that when using this grounded theory approach, the researcher openly acknowledges their role in authoring the story of shared experiences. The writing needs to be evocative of the experiences of the participants and the researcher should not transcend experience, but re-envisage it (Charmaz, 2003; Mills et al., 2006b). This thesis records these views and follows an interpretivist approach to the writing up or constructing narratives of emergent themes and of the substantive theory, rather than adhere to the hierarchical silent approach of the Glaserian and Straussian forms.

The modified grounded perspective in this study necessitates that one should build an understanding of how the phenomena identified in the research are interrelated and why (Finnemore \& Sikkink, 2001). Finnemore \& Sikkink (2001) liken this interrelatedness to one achieving an understanding of how the structure of the double-helix molecule is constituted, which in turn allows an understanding of genetics and disease. In this study, this interrelatedness occurred as a result of the CEO constructing meaning of their environment and then interacting with the researcher. By examining this interrelatedness in an explicit manner, the study aims to broaden the knowledge base of the CEO role. Utilising an interpretivist approach to the study supports a subjective view of reality with an emphasis on the individual's perceptions of that reality. Figure Six on the next page provides a diagrammatic representation of the interrelatedness of the modified grounded 
theory method. The diagram shows the circular interactive nature of the approach taken in this study as opposed to the more linear hierarchical process of objectivist grounded theory. A guide to the terms is contained in the glossary in Chapter One. Chapter Four contains a full outline of the processes and procedures outlined in Figure Six.

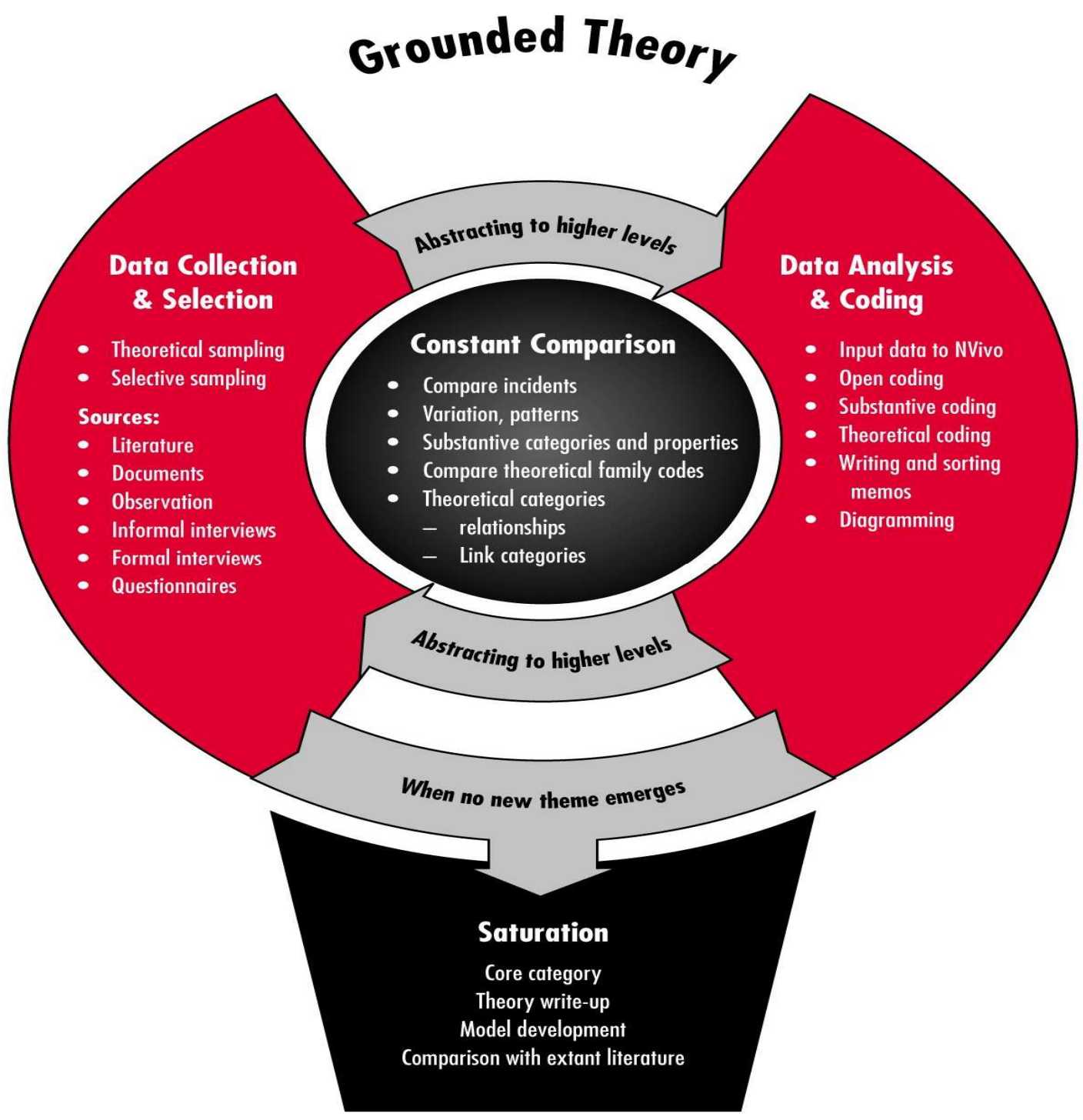

Source: Adapted from Kan (2002) 


\section{Theoretical sensitivity}

Within grounded theory, theoretical sensitivity is a multidimensional concept that focuses on the researcher's insight about the research area. Strauss and Corbin (1990) defined theoretical sensitivity as follows:

Theoretical sensitivity refers to the personal qualities of the researcher. It indicates an awareness of the subtleties of meaning of data. One can come to the research situation with varying degrees of sensitivity depending upon previous reading and experience with or relevant to that area... from a number of sources ... literature ... including reading, research and documents ... professional experience ... if the researcher is fortunate enough to have had this experience (pp 41-42).

Mills and Bonner (2006b) assert that theoretical sensitivity deals with the researcher's insights and how attuned they are to the nuances and complexities of the participant's realities and actions and their ability to reconstruct meaning from the data generated with the participant (Mills, et al., 2006b). Objectivist grounded theory asks researchers to enter the field of inquiry with as few pre-determined thoughts as possible: as a tabula rasa (Clarke, 2005; Glaser, 1978; Glaser \& Strauss, 1967). However, MacDonald and Schreiber (2001) note that even a grounded theorist beginning with an atheoretical stance remains open to the possibility that a priori concepts might be found in the data. By an atheoretical stance, MacDonald and Schreiber (2001) mean that the researcher has no specific idea of what the results will be. They go on to argue that a researcher can not abandon the notions, for example, that race, gender and social-structural conditions may be important themes in the analysis of the data. However, at the same time, they stress that a balance must be struck between cultivating the necessary theoretical sensitivity and avoiding the imposition of prior theoretical conceptualisations on the data. This is 
achieved by the constant comparative method of grounded theory (MacDonald \& Schreiber, 2001).

As a result of my prior business and academic experience, it was not possible for me to enter the research with an atheoretical stance; rather I acknowledge the presence of $a$ priori concepts. The adoption of the interpretivist perspective created an opening for my voice in the research. This in turn, permitted my personal experiences to be recognised as a contribution to the interactions that took place in the study. Strauss and Corbin (1990) go on to state;

It is theoretical sensitivity that allows one to develop a theory that is grounded, conceptually dense and well integrated - and to do this more quickly than if this sensitivity were lacking ... theoretical sensitivity represents an important creative aspect of grounded theory ... acquired during the research process through continual interactions with the data (pp 42,46).

Mills et al., (2006a) contend that within studies where a priori concepts exist, the researcher must "locate the participant as a vessel containing precious liquor in which the researchers will immerse themselves in order to become more theoretically sensitive. The immersion commences with the very first idea and does not end until the final word is written" (p. 4). Establishing and recognising the level of my theoretical sensitivity was a contribution to ensuring the academic rigour of the research. In the next section of the chapter, the processes undertaken within this study to ensure the trustworthiness and authenticity of the study are outlined. 


\section{Criteria used to assure rigour of the study}

Bryman (2001) argues that within qualitative studies, it is critical that the researcher is able to demonstrate rigour to ensure the findings are developed from a methodologically and analytically sound base (Guba, 1990). It is the presence of rigour that adds value to the findings (Le Compte \& Goetz, 1982). Lincoln and Guba (1985) have proposed two primary criteria to determine the rigour of a qualitative study, trustworthiness and authenticity. The first, trustworthiness, has four sub-criteria; credibility, transferability, dependability, and confirmability (Bryman, 2001). Each of these sub-criteria is dealt with in turn.

\section{Credibility}

When discussing the credibility of the findings, the researcher ensures the research is carried out according to the canons of good practice for submitting research (Bryman, 2001). Credibility is attained when the participant's causal maps, cognitive schema or worldview are successfully captured by the researcher (Lee, 1999). In this research study, a robust research design, combined with appropriate sampling tools and interviewing techniques were identified as essential pre-conditions to ensure the confirmability of the findings. The use of both primary and secondary forms of data collection, and the constant comparative approach of grounded theory to identify the themes and their elements, all assisted in achieving the credibility of the findings. The credibility of the account that a researcher arrives at determines its acceptability to others (Bryman, 2001). The descriptions, transcripts and quotes used in the study have been checked by the participants, by colleagues and have been recognised as credible. Glaser 
(1978) and Lincoln and Guba (1985) state that if a researcher has direct ongoing contact with the research participants, learns about their culture and environment, and is able to build trust and also test for misinformation, the research will likely provide more credible findings.

\section{Transferability}

Bryman (2001) contends that qualitative findings are best oriented to the contextual uniqueness and significance of the social world being studied. The transferability of the findings of a research project depend upon the degree of congruence between the sending context within which the research is conducted and the receiving context to which it is to be applied (Ritchie \& Lewis, 2003). In order to strengthen the transferability of the research findings, Lincoln \& Guba (1985) propose that by providing a thick description of a culture, the researcher can provide others with a reference point or database for making judgements about the transferability of the findings to other contexts. Thick description requires the researcher to provide sufficient detail of the original observations or commentaries, and the environments within which they occurred (Geertz, 1973).

In order to increase the transferability of the research findings, the sampling process was designed to gather a representative sample of individuals across a variety of industry sectors and organisational contexts. It is acknowledged that application of the findings to other contexts may not be possible without increasing the representativeness or size of the sample selection. Chapter Four provides a full outline of the concurrent data collection and analysis process. The purpose of this process is to increase the likelihood of the 
transferability of the research findings; in order to enable fellow researchers to use the findings to undertake comparative studies of the CEO role in different contexts.

\section{Dependability}

Bryman (2001) contends that maintaining academic rigour within qualitative research is difficult as the unique natural settings cannot easily be reconstructed precisely. Examples include the difficulty in replicating the exact setting of an interview; the business and/or political environment may have changed, or the individual may have experienced significant life or career changes in the interim or even be unavailable for interview. The use of a different interviewer conducting the interview may change the dynamics of the interview situation and therefore the nature of the responses. This is overcome by the use of the criterion of dependability. Dependability within the context of qualitative research relates to the efforts made by the researcher to establish the merit of the research by adopting a rigorous auditing approach. This approach involves the keeping of complete records, for example, data, findings, interpretations and recommendations (Bryman, 2001; Lincoln \& Guba, 1985). By providing an explanation of the methodology, this study enhances the ability of other researchers to examine similar problems, albeit within different settings.

One of the criticisms made of qualitative findings stems from the lack of well-formulated methods of analysis, or clear conventions for the researcher to follow (Miles, 1979). This can lead external reviewers to become suspicious of the dependability of such studies (Yin, 1994, p. 97). This research study is designed to address these criticisms via the use of the grounded theory method of data analysis. Glaser (1978) and Strauss (1987) 
argue that a full outline of the grounded theory method should be provided in sufficient detail to overcome previously identified problems. Dependability in this research study was further enhanced through digital recording and handwritten interview notes, the immediate transcribing of interviews, the use of diary notes, and memoranda that allowed the researcher to compare interviews and check the information obtained.

\section{Confirmability}

Bryman (2001) maintains that confirmability requires the researcher to have a plan of action that ameliorates the personal biases that may occur in qualitative research. However, complete objectivity is impossible in social research so the researcher must be shown to have acted in good faith (Lincoln \& Guba, 1985). Ensuring confirmability in this study was assisted by using both primary and secondary sources of data in tandem. The inclusion in the sample of people who were not CEOs but who were closely involved with the CEO role also ensured confirmability, as these people were able to reflect and provide commentary on issues that were raised by the CEO. In addition, as recommended by Perry \& McPhail (2000), interview data were compared with one another and with other sources of information, such as journal and media articles, further strengthening the confirmability process. Yin (1994) has stated that qualitative research that uses multiple sources of evidence and interpretation is rated more highly, in terms of overall quality, than those relying on single sources of information or interpretation.

Within the context of this study, confirmability was ensured by obtaining data from a variety of industry sectors and organisations and through the concurrent comparison and 
coding processes carried out as part of the grounded theory method. While Glaser (1998) discouraged the use of tape recordings and computerised qualitative data management systems, in this study, it was decided that the interviews would be taped and the analysis and coding stored in the Nvivo software programme to aid in the confirmability process. This was a tactic designed to allow the researcher the opportunity to reflect on the interviews over an extended period of time and to enhance the accuracy of the interview notes and memos. In addition, manual analysis of the interviews, memos and notes was undertaken. These actions were all designed to strengthen the confirmability of the research. The findings have been reviewed by key participants and colleagues, as well as having been accepted for presentation as peer-reviewed academic conference papers, the feedback from which was used as part of the confirmability process.

\section{Authenticity}

In addition to the four trustworthiness criteria, Guba \& Lincoln (2001) propose two further criteria to establish the authenticity that engenders the hallmarks of authentic, trustworthy, and rigorous grounded inquiry. These are the following:

- Fairness: Fairness is a quality of balance, where all stakeholder views are apparent in the text. Omission by the researcher of any of the stakeholder or participant voices reflects a methodological bias. Fairness has been achieved by the inclusion of all interviews in the data analysis processes. The researcher attempted to obtain a diversity of participants in the sample and ensured that the views from all have been included and discussed in the findings. The use of the 
grounded theory method, the identification of themes and the subsequent saturation of these themes in keeping with the research guidelines supported the inclusion of all the voices of the participants.

- Ontological and educative authenticity: This occurs when the research provides the stakeholders and participants with an opportunity to reflect on their social milieu, especially when the purpose of the research is to raise awareness of both the research participants and those who surround them (Lincoln \& Guba, 2000). This form of authenticity was achieved by the use of a semi-structured interviewing approach and the use of open-ended questions of a how and why nature, both to encourage the research participants to be self-reflective about their perceptions and views and how they construct meaning from the dynamics surrounding their role.

\section{Achieving academic rigour in grounded theory studies}

In addition to the above criteria for determining the academic rigour of grounded theory studies, Glaser (1978) contends the following five elements should be present in all grounded theory studies, and these are briefly commented on below:

- Grab: Grounded theories should have grab and be interesting. People should remember them and use them. 
- Fit: The categories of the theory must fit the data. Data should not be forced to fit pre-conceived or pre-existent categories or discarded in favour of keeping an extant theory intact.

- Work: A theory should be able to explain what happened, predict what will happen and interpret what is happening in an area of substantive or formal inquiry.

- Relevance: Grounded theory demonstrates relevance when and because it allows core problems and processes to emerge.

- Modifiability: Generation of the theory is an ever modifying process and nothing is sacred if the researcher is dedicated to giving priority to the data.

\section{Conclusion}

The purpose of this chapter was to introduce the reader to the research methodology of the study and to comment on its strengths and weaknesses. To mitigate one of the criticisms of grounded theory, the epistemological, ontological and methodological underpinnings of the study were outlined. An outline of the discovery and development of the method by Glaser and Strauss (1967) was then provided. This includes a discussion of the strengths and weaknesses of the method. Over a period of time, Glaser and Strauss have developed the method along different paths and this has resulted in a vigorous debate especially with regard to the coding processes. This led to Charmaz (2000) developing an alternative approach in an attempt to provide alternative directions for researchers. As discussed, consideration of the researcher's theoretical sensitivity determined that it was not possible to enter the research as a tabula rasa, therefore the 
modified grounded approach as outlined by Charmaz (2000, 2003) and subsequently developed by Bryant (2003) and Mills et al., (2206a, 2006b), was utilised in this study. This decision necessitated a distinction to be made between the objectivist form of grounded theory as outlined by Glaser and Strauss (1969) and Strauss and Corbin (1990) and Glaser (1978) and the form posited by Charmaz (2000; 2003; 2005) and Mills et al., (2006a; 2006b). Awareness of the requirements for theoretical sensitivity on the part of the researcher, and by following the recommendations for the writing up of a grounded study where $a$ priori concepts were present, augmented the confirmability and transferability of the findings. The chapter concludes with the conditions required of a grounded theory for it to achieve academic rigour.

The next chapter will provide further discussion of the research methodology including the concurrent data collection and analysis, a process that is an integral part of the grounded theory method. 


\section{Chapter 4: The Research methodology}

People who are insiders to a setting being studied often have a view of the setting and any findings about it that are quite different from that of the outside researchers who are conducting the study.

Bartunek \& Louis, 1996

\section{Introduction}

In the previous chapter, an explanation of the methodological underpinnings of the thesis was provided. The purpose of this chapter is to explain the research methodology. The format is in keeping with the recommended standards for the reporting of grounded theory studies and with the recommendation of Geertz (1973) for 'thick description' to be provided in qualitative studies. The chapter begins with a description of the sample design and the selection of the sample population. The chapter then proceeds to provide a salient discussion of how the ethical considerations were identified and adhered to. The chapter then proceeds to provide a justification for the decisions made as to the nature of interview process and of the concurrent data collection and data analysis. In doing so, examples of the memoing and coding practices that were undertaken are provided 


\section{Sampling design}

As stated in Chapter One, the aim of this grounded theory study is to develop a substantive theory of perceptions of the CEO role and identify the over-arching social processes, rather than the generalisability of the findings to other groups. Therefore, it was important that the sample design would enable this to occur through the answering of the identified research questions. Strauss and Corbin (1998) state that when building theory inductively, as in grounded theory, the focus is not upon the representativeness of the sample, rather it is the representativeness of concepts and how these concepts vary dimensionally that is important. This resulted in the use of convenience and purposive sampling. This means that the projection of the findings, results and developed theory beyond the actual research sample is statistically inappropriate (Zikmund, 2000). Therefore, the findings of this research are applicable only to the organisations and contexts under investigation. In this thesis, three forms of sampling were used:

- Purposive sampling

- Convenience sampling

- Theoretical sampling

These are now dealt with in turn. 


\section{Purposive Sampling}

Purposive sampling is a non-probability sampling technique that involves the selection of participants according to the sample members' possession of an appropriate characteristic (Zikmund, 2000). Participants were selected according to the level of position they held in an organisation; that is, the individual was or had been a CEO in a large New Zealand organisation with global connections, or in the case of the non-CEO participants, it was that they had held a position that was directly involved with the CEO role, for example, as a board chair, an executive search consultant, or an executive coach whose speciality was CEO leadership.

\section{Convenience Sampling}

Convenience sampling is a sampling technique where a member or part of the research sample is available to the researcher by virtue of accessibility (Bryman, 2001). Initially, the research participants were approached as a result of the researcher's existing business networks. In addition, the networks of colleagues were also utilised as a source of potential participants. As the study progressed, deliberate attempts were made, to gain access to people outside these networks and spheres of influence in order to broaden the sample. For example, news media, professional publications and the New Zealand Business Who's Who, were searched for potential participants. If the individual fitted the required profile for either the non-purposive and theoretical sampling, they were approached and asked if they would participate. 


\section{The theoretical sampling process}

Theoretical sampling is a tool employed within the grounded theory method to increase the robustness of the identified themes (Chenitz \& Swanson, 1986; Glaser, 1978). The process involves the researcher sampling on the basis of concepts that have proven theoretically relevant to the emerging theory. Gordon (2008) writes that the term theoretically relevant means that certain concepts become significant in the data because they are repeatedly present or absent when comparing incident after incident. As the substantive theory emerges, the researcher selects theoretically relevant concepts and data sources in order to build the theory (Locke, 2001). These theoretically relevant concepts are identified by the coding and analysis procedures that are part of the grounded theory method. The purpose of this approach is to seek variation within the data and to allow the researcher to pursue specific issues. This, in turn, provides a greater depth of meaning for the developing themes and to identify any new elements of the themes or social processes that are identified as arising from the data (Glaser, 1978).

An example of theoretical sampling undertaken in this study pertained to the emergent theme, the impact of political scrutiny. In the initial stages of the research project, this theme was identified as a result from the comments made by several CEOs of public sector organisations. A referral to a former CEO who had extensive contacts within both the public and private sectors, led to enquiry and then confirmation that this individual could provide a broader, historical perspective on the nature of political scrutiny, and the implications for the private sector. 


\section{The composition of the sample}

The purpose of this section of the chapter is to outline the composition of the research sample. The sampling strategies resulted in a sample consisting of 30 individuals. These individuals comprised 22 CEOs and 8 others who were closely involved with the CEO role. A total of 40 formal interviews of between one and two hours duration were conducted. Informal interviews were conducted when additional information was required and a formal interview was not warranted. There were 20 informal interviews, 10 of these were with people outside the main participant group. An effort was also made to ensure that there was a gender/ethnic mix in the research sample. However, this effort was constrained by the gender/ethnic mix of the people holding positions that fit the specified criteria. In order to attain a gender mix, organisations that had women CEOs, or women who had worked with CEOs either as a board member or a consultant, were targeted. This process resulted in a sample containing 10 females and 20 males. There were no CEOs that identified themselves as non-European.

In order to enhance the confirmability and transferability of the study, the principles outlined by Yin (1994) were followed when selecting the sample. The individual research participant was the unit of analysis. The selection of individuals across a range of industry sectors created multiple units of analysis. These industry sectors comprised the knowledge/high-tech, retail, distribution/logistics, manufacturing, technology based, agriculture, service and transport sectors. Miles and Huberman (1994) contend that a research finding that occurs in more than one comparable setting enhances the robustness of the findings. 
As with any research study, there were ethical considerations that had to be observed. In this study, the position of the participants and the sensitivity of the information they were imparting, resulted in extra care being taken with handling the information. The next section outlines these processes.

\section{Adhering to ethical requirements}

Whatever the form a particular research project takes, ethics and ethical principles are always present (Orb, Eishauer, \& Wynaden, 2001). This research study abided by the ethical principles for the conducting of research involving human subjects in accordance with The Victoria University of Wellington statutes. Ethical approval was sought and granted before research commenced (see Appendix A).

\section{Obtaining research access}

Research access to an organisation refers to how the first contacts were made and the establishment of relationships for the purpose of gaining entry into an organisation, and also the ability of the researcher to maintain these relationships to ensure continued access (Chenitz \& Swanson, 1986). In the first instance, each CEO's office was approached by telephone. On some occasions, the initial phone call immediately resulted in an appointment for an interview. On other occasions, if the initial contact generated a 
positive indication of interest, an email or letter of explanation with the confidentiality agreement was sent to the CEO (see Appendix B). This information included statements of the purpose of the research and assuring the confidentiality of the participants. On all occasions, this information was restated at the commencement of the interview.

\section{Informed consent}

All informants in this study were advised that their participation was voluntary and that they could withdraw at any time during the research. Each participant was provided with an outline of the purpose of the research and their rights within the Human Ethics Committee Guidelines of Victoria University of Wellington. Each participant signed a formal permission document consenting to participation in the research (see Appendix C). All research participants had the right to withdraw their consent (either verbally or in writing) at any time. None did.

\section{Privacy and confidentiality}

Anonymity and confidentiality was considered to be critical to the success of this research. In qualitative research, it is difficult to achieve anonymity as the researcher knows the identities of the participants (Streubert \& Carpenter, 1999). Therefore, procedures were instituted to ensure the participants' privacy was respected and promoted; in addition to the confidentiality form, a verbal outline of the confidentiality processes was given. Verbal permission was also obtained from each informant to record 
the interview on a micro-cassette. At times, the researcher became aware that the direction of the interviews had a disquieting effect on the participant. If it was felt that a participant was uncomfortable with any aspect of the interview, he or she was reminded that the interview could be terminated at any time. On one occasion, it did become clear that the participant was uncomfortable continuing while the tape recorder was still in operation. As a result, the recorder was turned off. The participant then spoke freely and was quite happy for written notes to be taken. At an appropriate point, the individual was asked if they were comfortable with the tape being turned back on. When permission was given, the interview proceeded as previously. Memoranda were made from these handwritten notes immediately after the interview, and the taped interview replayed in order to record key points.

In addition, care was taken not to reveal the identity of the research participants during transcription of the interviews or in any subsequent discussions. As interviews were transcribed, any identifying names were either deleted or given codes in order to maintain anonymity. All transcripts were stored in a locked filing cabinet in a locked room, and any computers holding notes and analysis were password protected. The thesis and any subsequent publications and reports were, and will be, written so that participants remain unidentified.

An example of confidentiality concerns arose with regard to the ease with which a participant could be identified in a small business community. While the purpose at the beginning of this research was to produce a report comprising two to three cases, it soon became clear that to ensure total anonymity of the participants, a change in strategy was required. The need to report the results openly and explicitly meant that there was a risk 
of a specific person being identified. Therefore, changes were made to the research strategy to prevent this occurring. For example, the sample size was expanded by increasing the number of participants and broadening the range of organisational types. This strategy helped the voices of the participants to emerge without compromising the confidentiality of the participants or the rigour of the study. In the next section the data collection process is outlined.

\section{The process of data collection}

\section{The basis for choice of interview style and structure}

Tellis (1997a) contends that one of the most important sources of data in qualitative research is the interview. Therefore, the first priority for a researcher is to ensure that the most appropriate form of interview for a particular study is chosen and that the interview style is appropriate to their level of expertise. Goulding (1999) contends that the grounded theory method requires a form of interview that is not structured, as a structured interview may merely be a vessel containing the researcher's own expectations. At the other end of the continuum, a totally unstructured interview can cause confusion and result in meaningless data (Lee, 1999). The challenge for this study lay in finding a balance between allowing the participant to feel comfortable enough to expand on their experiences, while not overly directing the course the interview should take (Goulding, 1999). Therefore, a semi-structured format was chosen, the basis of which can be summarised as follows: 
Semi-structured interviews usually have an overarching topic, general themes, targeted issues, and specific questions, with a pre-determined sequence for their occurrence. While interviewers have a pre-determined interview schedule they are able to freely pursue emergent topics and themes and to probe more deeply than the initial planned questions ... the semi-structured interview requires strong interviewer skills (Lee, 1999, p. 62).

Tellis (1997b) argues that one of the main reasons the interviewer needs high level skills is that he or she must be free to pursue matters as the circumstances dictate, being able to probe more deeply and to follow a particular line of questioning should it be necessary. While this is an advantage, it can also make the semi-structured interview more difficult to conduct. Within this study, it was judged that semi-structured interviews would produce the depth and richness of data needed for a successful project. Concerns regarding the level of interviewer skills were further allayed as the researcher has had in excess of ten years training and experience in structured, semi-structured and unstructured interviewing techniques. The researcher had also gained training and experience in the following forms of interviews: counsellor and needs revealing interviews (a tool used in a variety of industries, for example, sales) and behaviour-based interviewing (a human resources selection tool). This experience allowed the researcher to move comfortably between interviewing formats and styles while at the same time not compromising the dependability and confirmability of the study. The following principles are an integral part of the process of conducting of semi-structured interviews. The interviewer should always:

- make minimal use of questions prepared in advance

- use open-ended questions 
- engage in empathetic listening to hear meanings, interpretations and understandings

- consciously silence his or her concerns, preoccupations and judgements

- uses prompts to pursue/clarify the participant's line of reflection and allow the participant to elaborate, provide incidents, clarifications and, maybe, discuss events at length (Ashworth \& Lucas, 2000).

Adhering to these principles maintained the researcher's ability to create environments that facilitated the emergence of the voices of the participants. The semi-structured interview also supported the theoretical sampling process by allowing me to confirm emerging themes and issues as they arose. Keeping these principles at the forefront a list of indicative questions was prepared (see Appendix D), to be used at the start of the interview to initiate the discussion. The consequent direction of the interview and the responses of interviewees determined the precise wording of these questions, and the wording of intervening and supplementary questions. For example, as a CEO the participants were inclined to speak of "big picture" issues. While this provided informative data for the researcher, and the participants were allowed to continue in this vein, there were naturally occurring points where it was deemed important to refocus the interview. At this point, the researcher utilised a question designed to refocus the interview, the choice of question was dependent on the topic under discussion at the time. On occasions more than one focussed question was necessary to achieve the specificity required. For example, when one $\mathrm{CEO}$ had spoken at some length about how the media had too great an influence on business in New Zealand, the question that was asked was, "why do you think this is a problem specific to New Zealand?" The next question was "How do you think this differs to countries such as the USA?" 
Another illustration relates to how interviews were initiated, for examples, at the start of one interview, the CEO was very direct. His first words to me were 'Ok shoot', therefore once I had explained the interview process and the confidentiality form had been signed, the first question asked was 'what are the major challenges facing you and your role as a CEO at the current time'. In contrast, an interview with a Board Chairperson was less direct and more conversational. More time was spent in the initial phase. There came a juncture where it was considered appropriate to start the formal stage of the interview. At this moment, the initial conversation had led to a point where it was appropriate to ask the question, 'please think of a CEO who you deem to be effective. What attributes or qualities do they have that enhances their effectiveness'? Once this question had been answered, the interviewee was then asked to reflect on a CEO who was less than effective, and what contributed to their less than effective behaviour'.

No matter how the interview progressed, there was always an effort to introduce a 'counter question'- that is a question designed to cause the participant to reflect on both the positive and negative aspects of the topic under discussion. This interviewing technique was designed to encourage critical reflection on the part of the participants. 


\section{The formal interview process}

The 30 formal interviews lasted between one and two hours. They began with the researcher providing an outline of the interview purpose and procedure and completion of the research consent form. The interviews were recorded using a small tape recorder and hand-written notes were made during the interviews. The interview questions were finalised after conducting three pilot interviews. The objective of these pilot interviews was to aid in the defining of the topic area in more detail. The transcripts were also examined for themes that might guide future interviews. The transcripts and tapes were also examined by my supervisor and recommendations made as to how the researcher's interviewing techniques could be improved. These pilot interviews were also discussed with colleagues, theses discussion leading to a decision as to the most appropriate format for the interviews. The questions were designed to maintain equilibrium between a freeflowing and a directed conversation (Lee, 1999). Care was taken to ensure that the responses received were not led by the questions themselves. That is, the questions were open-ended and of a how and why nature in an effort to elicit the quality of information required in a study of this nature. An example of how questions were introduced at this stage is given in the following vignette, where there had been a discussion about the criticisms received by business people about the level of salaries paid to executives. At this point, the question was designed to focus the interviewee, for example, on what is specific about the New Zealand context that results in such criticisms. On another occasion, after the interviewee had been discussing, at some length, an individual they admired greatly, they were then asked to reflect on 'what, if any, shortcomings this individual may have'. 
However, questions must be structured in a way that reminds the researcher of the data to be collected and its possible sources (Tellis, 1997b). It is possible within a modified grounded theory approach to adapt the semi-structured format to enable the interviewer to elicit the required information and have a free-flowing conversational interview. When taking an interactive approach, the researcher has to remember that they are not studying their own awareness and reflections, but those of their subjects (Marton, 1994). With this warning in mind, the interviews were regarded as a conversational partnership, a dialogue, where the interviewer assisted a process of reflection by the interviewee (Ashworth \& Lucas, 2000). This allowed me to paraphrase responses back to the interviewee and to re-address issues later in the interview if points made needed clarification.

Following the recommendation of Ashworth \& Lucas (2000), colleagues subjected the researcher's interviewing technique to review and when necessary changes were made to interview techniques. The two key reasons for these changes were a need to follow through on a participant response, or lack of response, more fully; and a need to reframe some of the questions in order to make them more meaningful to the interviewee. Once the research had progressed to a point where it was felt the initial problems were overcome, continual self-review was undertaken. However, research colleagues were consulted when an interview had "not gone so well" or the questions did not elicit the quality of information that was expected. When this occurred, the researcher returned to the participant to clarify the points and to ensure that there had been no misunderstanding of the comment made. This ongoing reflection became an integral part of the process known as theoretical sampling, assisting in the development of additional research 
questions and the identifying of additional people to be interviewed in the quest to add deeper meaning to the data already obtained.

\section{Participation in the interview}

Participation in the study was voluntary, and no difficulties were encountered in meeting with the research participants. What was significant was the willingness of busy senior executives to become involved in the research and their ease in freely supplying information on issues that were clearly important to them. As part of the grounded theory coding process, this ease of access to the CEOs and their participation was integrated into the emergent themes, for example, a commitment for the CEO role. This theme was identified as evolving from the excitement the participants had for the CEO role and the importance accorded by them to the need for a deeper understanding of the role. It was also directly related to the participants' expressed concern about the repression of leadership that they perceived the New Zealand business community to be facing. One of the expressed reasons for participating in this research was that it was one way an individual could help to help improve the knowledge about the CEO role. It was also a sign of the desire of individuals to make a difference, which later contributed to the emergent theme, the excitement for the CEO role. This excitement was exhibited by the participants, in the manner in which they spoke about their role, their body language, voice, intonation and facial expressions. It is not always possible to capture the tone, or tenor of these nuances in the transcriptions; therefore, annotated interview notes and memos made during and immediately after the interview played a vital role in the data analysis. An example of such a memo is as follows: 
When talking about how important people were to the organisation and people skills being a critical part of leadership, AAA sat forward and became very intense in voice tone, also his eyes lit up and began to smile along with his facial expression - it was clear this was a subject he was very passionate about.

When memos such as the above were made, the researcher returned to the matter either during the same interview or in a second interview, so that the content of the memo could be confirmed or otherwise by the participant. Charmaz (2006) contends that language plays an important part in the coding process. Therefore, it is important that the researcher examines the hidden assumptions and meanings behind the participants' actions, responses and use of language. The modified grounded theory approach, utilised in this study, meant that every aspect of the research process had the potential to contribute to the creation of meaning and understanding of the CEO role. The nature and structure of the interview, the interactions and processes occurring throughout the interview, and how they were transcribed and analysed, all contributed to how the voices of the participants surfaced from the data.

\section{The informal interviews}

Informal interviews were used when the need to clarify certain points or obtain a deeper understanding of a particular situation or emergent theme was identified. In addition to the formal interviews 20 informal interviews were conducted. Of these, 10, were with people who were not part of the main sample group. These interviews lasted between 10 minutes and $1 \frac{1}{2}$ hours. They were primarily unstructured and could be likened to everyday conversations if observed by others (Lee, 1999). They were conducted in a 
variety of ways. On some occasions it was for "a coffee and a catch up", on others it was a scheduled meeting where the length of the interview and the place where it was conducted varied, for example, in the interviewee's office or in a café. Lee (1999) asserts that the advantages of the informal unstructured interview include their ad hoc nature and their seeming lack of specific themes or specific planned questions. Therefore, the themes, issues and questions resulting from the interactions between myself and the interviewees resulted in informal interviews being conducted in order to add meaning to the data already obtained.

Often, the time and place of an informal interview made the recording of the interview problematic, not only because the intrusion of a tape recorder could lessen the rapport between interviewer and interviewee, but also because the public profile of many interviewees made it unwise to undertake what was obviously a recorded meeting in a public place. On these occasions, a diary or a PDA was used to make notes during the meeting, which were then formally 'written-up' immediately thereafter.

In addition, numerous conversations, relating to the research project, were held during business functions, networking events and private social functions. These conversations acted as a barometer of the general issues confronting the CEO in the enactment of their role. These were recorded as diary notes and used to guide the theoretical sampling process. 


\section{The use of secondary data}

Secondary data was used to support the primary data and was obtained from document analysis. Documents relevant to the present study included annual reports, strategic plans, web-based information, and HR policy documents and media reports. This secondary data was coded concurrently with the primary data to identify explanatory themes. One example of how secondary data was used was early in the study when the role of the media was identified as influencing the perceptions of CEO leadership. Therefore, the theme the influence of the media was created and the researcher consulted the news media on a daily basis. Consultation included conducting on-line searches of newspapers throughout New Zealand for information on CEO leadership.

\section{Transcription of interviews}

The interviews were transcribed verbatim immediately after completion and prior to analysis. Early in the interviewing process, the researcher conducted a number of interviews within a short period of time and help was sought with transcription of a small number of them. It became evident during this phase of the study that the researcher had to be proactive in the interview process, diligent in examining the transcriptions and conducting the analysis. For example, when analysing the interviews transcribed by another individual, as a precursor to analysis, the researcher noted that words were sometimes misheard, emotions were not conveyed accurately and that the nuances of some aspects of the interviews were not captured by the transcriptions. 
When working within the qualitative paradigm, it is important to include within the transcription, as an annotation, anything that is likely to affect the interpretation of meaning (Svensson \& Theman, 1983), especially when the researcher is seeking to identify the perceptions of the participants and how they create their realities. When another person had transcribed an interview, the researcher, as soon as practicable, reviewed the interview, listening to the tape, utilising the memos and hand-written notes to annotate the transcript. For example, one interviewee made the comment "the local member of parliament was very supportive”. However, when subsequently listening to the tape of the interview and consulting the interview memo, it was clear that the interviewee had been somewhat cynical and sarcastic. The memo note was then confirmed with the participant during an informal interview. This new information was noted as a memo and coded accordingly. In addition, all the tapes were listened to several times during the analysis process, writing appropriate memos when necessary. This process enhanced the understanding of the participants' perceptions by highlighting aspects such as voice tone and manner of speech, both formal and colloquial. Again, any memos made regarding non-verbal data, gestures, tone etc, and their possible impact on the interpretation of verbal data, resulted in a further interview with the participant to confirm, or otherwise, the interpretation made by the researcher, or the comments recorded by the transcribers. 


\section{Computer-assisted analysis - NUD*IST Vivo}

Analysis of the interviews was undertaken both manually and through the use of a computer software programme, the Non-numerical Unstructured Data, Indexing Searching and Theorising (NUD*IST Vivo or Nvivo), a programme specifically designed to support the analysis of unstructured qualitative data (Richards \& Richards, 1997). The use of Nvivo enables computerised management and retrieval of digitised research data, allowing the researcher to explore and search documents, and link ideas and coding in interviews with memos written during the analysis process (Fraser, 1999). The programme aids the researcher in collating and retrieving information quickly and efficiently. Prior to the availability of computer-assisted analysis of qualitative data, qualitative analysis often involved time-consuming manual cutting and filing of data such as interview transcripts (Richards \& Richards, 1997). The ability to retrieve information quickly was of considerable advantage in this study given the number of interviews conducted, the resultant memos and amount of secondary data consulted. The fully transcribed interviews were imported into the computer software. In addition, all memos were written up at the time of the interview, or shortly thereafter, imported into Nvivo, analysed and coded.

One identified advantage of the Nvivo programme is its ability to print out the interviews with a large right-hand margin. The researcher was able to use this margin to manually code for themes that reflected the content of the data. This manual analysis was important to overcome one identified weakness of the NUD*IST software, that is, its sensitivity to coding errors (Chetty, 1996). The manual analysis permitted time for reflection and checking before the code was entered in the computer programme, thereby 
enhancing the coding accuracy. It also allowed me to make notes more effectively, especially regarding voice tone and intonation while listening to the tapes again.

A related weakness can be an overdependence on the software, that is an over-reliance on the "black-box" analysis of data, and that the research data is not treated holistically. Rather it is seen as blocks of variables or chunks in which the sequence of information given in the interview, the informant's assumptions and the causal links between the information and assumptions can be lost (Chetty, 1996). The manual analysis undertaken in conjunction with the computerised analysis overcame this problem, allowing the links between interviews and the sequencing of information to be identified more accurately.

While the use of Nvivo played a beneficial and critical part in the analysis of the data and retrieval of information, the manual analysis helped the researcher achieve a more indepth appreciation of the richness of the data. Utilising both approaches in tandem enabled a wider and more holistic appreciation of the totality of the research data than would have been achieved by relying solely upon software analysis of the data. This procedure also contributed to enhancing the academic quality of the research.

\section{The comparative analysis of data}

Yin (1994) asserts that when undertaking qualitative research, there should be a general analytic strategy. That strategy should encompass a method where themes are identified and classified, and the interrelationships between those themes are revealed (Perry et al., 1999). The process undertaken to identify the major themes meant the analysis and coding of the data began as soon as the data were collected (Charmaz, 2000), and 
occurred continuously and concurrently with the data-gathering process (Streubert \& Carpenter, 1999). Glaser and Strauss (1967) outline four stages of comparative analysis as the development of emergent theory progressed:

1) comparing incidents applicable to each theme

2) integrating the themes and their elements

3) delimiting the theory

4) writing the theory.

In the first stage, phenomena were compared to other phenomena occurring in the same interview or across different interviews. At this stage, the researcher was examining the data continually for similarities and differences. For example, a comment made about the negative perceptions of business and business leadership within New Zealand, was compared with similar comments made in other interviews. These comments were then compared with commentary obtained from news media articles. The emergent theme was named as the influence of the media.

A second stage is where the researcher is continually deciding what theme, or property of a theme, the phenomenon being analysed belongs to, and then naming this theme. In doing so, the researcher ensures the generation of themes and their elements emerge from the data (Glaser, 1992). Themes and elements were integrated during this phase of the analysis. For example, subsequent to the identification of the theme, the influence of the media, the continual, concurrent, constant comparison led to the higher level integration of this theme into an over-arching theme, the CEO role and the institutionalised expectations. 
Chenitz \& Swanson (1986) claim that the use of this iterative and mutually interactive approach permits the researcher to progressively focus with the data, the end result being the "theory" which characterises the behaviour of the research participants. The third stage involved more elaboration than modification as the theory began to solidify. In this study, the influence of school learning was further integrated into the theme of the role of formalised learning that also included the theme, the formal executive leadership development. Glaser and Strauss (1967) noted that this is the point where several themes are subsumed into a core theme, and is the basis for the emergent theory (Goulding, 1999). An example of the coding undertaken in this study is provided in Figure Seven on the next page. The diagram explains the integration of themes from the open and selective coding processes through to the commencement of the theoretical coding via the identification of the major theme the acquisition of leadership constructs in the CEO role. Immediately following the diagram, the chapter outlines the grounded theory coding process undertaken in this study. 
Figure 7: Sample of coding diagram

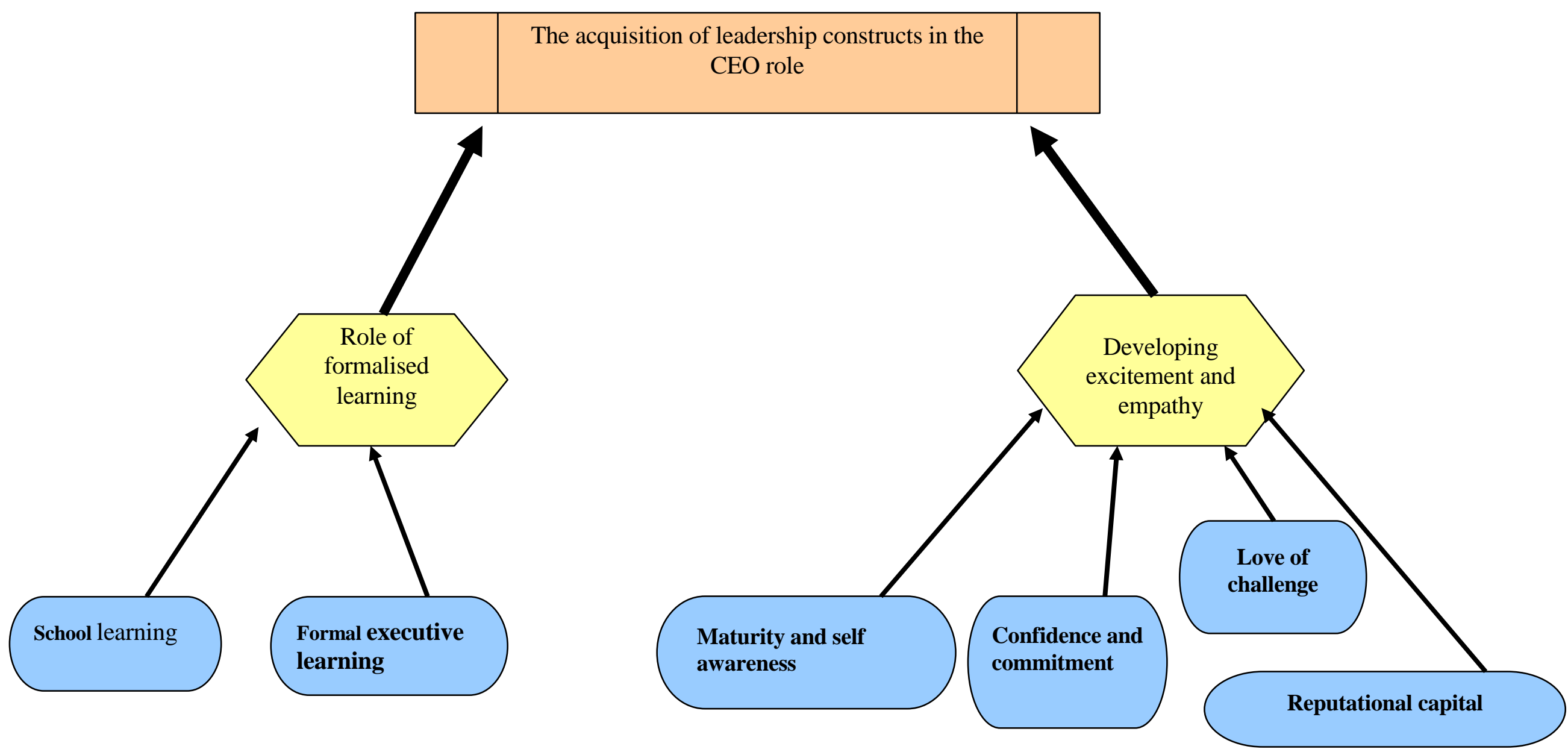




\section{Coding Procedures}

Within the grounded theory method there are two forms of coding, level one and theoretical coding, that are used to generate theory from the data (Glaser, 1978; Glaser \& Strauss, 1967). The first level of coding includes both open and selective coding of the data by which the conceptualisation of the empirical substance of the area is formed. Level one coding generally dominates the earlier stages of analysis. Theoretical coding involves the conceptualisation of relationships between the level one codes, thus generating theory (Glaser \& Strauss, 1967). Although the first level of coding must occur initially in order to generate theory, theoretical coding must also occur and as Glaser (1978) notes that these two types of coding often occur simultaneously. The open and selective coding and theoretical coding processes are now described in more detail.

\section{Open coding}

Open coding is the initial process of breaking down, examining, conceptualising, and categorising data (Glaser, 1992; Strauss \& Corbin, 1990). During this phase of the research, the data is carefully examined and individual phrases, words or stories that contain a single unit of meaning are selected and highlighted (Schreiber, 2001). During the early stages of coding the identified incidents were coded into more than one theme if that was appropriate (Charmaz, 2000; Glaser, 1978; Turner, 1983).

As discussed previously, open coding involved the process of first entering the transcribed interview into the Nvivo software programme, reading the interview and 
making memos, notes and the initial manual codes. The interview was then coded via Nvivo. After the computerised coding, both manual and computerised forms of coding were compared, the researcher noted discrepancies as memos and notes, some of which were used in the theoretical sampling process. When necessary, interviews were re-read and re-coded to ensure the elements of each theme were correctly assigned.

An example of the coding conducted as part of this research follows below. The interview transcript is in the left-hand column and the open coding in the right-hand column. The nuances of the coding processes were indicated by the use of italics, bolding and capitalising. For example, the words in bold indicate how the selective coding processes created the theme, the formal learning of leadership.

That's a good thing. In theory, start as a XXX and end up here.
(points to himself) But in any event certainly, it's a succession
plan and that is important. I attended an induction programme of
twelve new managers who we just appointed down in
Christchurch last week, and I was totally up front with them. I
said 'We do not pay in terms of money top dollars. If you want
to earn top dollars go down the road". But what we will do, is
you and we'll give you a succession plan, we'll give you a career
path, you can have access to Southern Cross, get training on the
job. They know that we'll send them on some course next year
on blah, blah and they know that we'll encourage the better ones
to do an extra mural degree or whatever.

That's a good thing. In theory, start as a XXX and end up here. (points to himself) But in any event certainly, it's a succession twelve new managers who we just appointed down in Christchurch last week, and I was totally up front with them. I to earn top dollars go down the road". But what we will do, is you and we'll give you a succession plan, we'll give you a career

\section{Learning \\ Work up to CEO/succession \\ Succession planning}

Formal induction, learning the role Development induct

Lack of resources

Career plan/succession

Formal development/succession

Remuneration/lack of resources

On the job training

Remuneration/benefits

Formal education/tertiary

Supportive formal learning

Formal learning 
This next example shows the results of a manual coding exercise that incorporated the notes and memos that were made at the time of the interview. It provides an example of the notes made after listening to the tape of the interview and reviewing the manual analysis.

\begin{tabular}{|c|c|}
\hline $\begin{array}{l}\text { Well it's not easy. I mean we, this course I } \\
\text { talked to you about what we're doing with } 20 \\
\text { people, we had } 50 \text { people apply. We actually } \\
\text { could only get to ten that were in any way } \\
\text { remotely effective, or would be useful. There's } \\
\text { still a lack of understanding in my view at the } \\
\text { school level of the importance and what you } \\
\text { can get from ... I mean some of these young } \\
\text { XXX that were great XXX on our property, } \\
\text { guys mid thirties. }\end{array}$ & $\begin{array}{l}\text { Very focussed upon formal development- } \\
\text { based upon on-the job training and bemoaned } \\
\text { the lack of available talent - very concerned re } \\
\text { the lack of appreciation at the school level- } \\
\text { very emotive about this } \\
\text { Influence of school learning } \\
\text { Talent shortage /lack of skills } \\
\text { Relevant skills lacking } \\
\text { Lack of awareness in the education system } \\
\text { Cynicism displayed here as was a level of } \\
\text { anger as to the lack of value placed on the xxx } \\
\text { sector and the ability to generate wealth } \\
\text { certain roles are undervalued }\end{array}$ \\
\hline
\end{tabular}

After the coding process a memo was created to provide additional meaning for the interviewer. The following memo was created as a result of the coding, which followed from the interview above:

The CEO spoke at length of the lack of talent and people, especially young people being prepared to take on a role in his sector and the sector's inability to attract people to it, the inability to pay high salaries. He was aware of the lack of resources and substituted the advantages of a career path in the organisation and the formal development that an individual could access if they had the potential. There was still a strong emphasis upon on-the-job training (situated learning experiences) as the primary means by which an individual learned the role and the managerial skills necessary ... he also displayed anger at the lack of appreciation of the value the sector adds to the New Zealand economy and the wealth generation (he smacked his hand on the arm of the chair) ... spoke passionately about the inability to pay internationally competitive remuneration in order to retain top talent ... this impacts upon the learning of people who may wish to take on a CEO role and the available talent pool. 
Again, when coding note and memos such as the one above highlighted words, for example, 'anger' or 'passion', and similar notations that could impact on the interpretation of the verbal comments or transcribed words, the meaning and interpretations of such comments were confirmed with the participant. For example, notes made during the interview emphasised 'appeared angry'. As a result, the researcher in the latter stage of the interview queried of the participant that he appeared to be quite angry about the lacked of recognition the industry received. He agreed. He also reiterated his comments stating, "It will be the country's loss".

Glaser and Strauss (1967) stress that as the coding progresses; care should be taken not to create too many or too few themes. Using the grounded theory method, it is often found that too many themes tend to 'clog' the system and stifle the emergence of higher-level themes. However, Glaser and Strauss (1967) warn that too few categories could pre-empt or 'force' the emergence and conceptualisation of higher level categories, leading to what they suggest is a major methodological mistake. In this thesis, such problems were averted by two procedures. First, as proposed by Strauss and Corbin (1998), properties were created for each theme. In this way, themes could become progressively more abstract by the incorporation of new properties, rather than the creation of new themes of equally low levels of abstraction (Strauss \& Corbin, 1998). The second procedure was to compare the themes generated by open coding from the very first interview transcript. Each subsequent datum was coded, and that coding was compared to previously generated themes. If the elements were found to be a part of a previously generated theme, the item was allocated to that theme. If the new item was conceptually different from the themes generated previously, a new theme was created. Glaser and Strauss (1967) believe that if theoretical sampling occurs concurrently with the analysis, then the 
theory is more likely to emerge by itself. During this research project, the integration of themes occurred as data analysis progressed. As a result, the number and integration of emergent themes did not become a methodological issue.

\section{Selective Coding}

Selective coding involves "examining and collapsing codes into categories or higher level concepts" (Schreiber \& Stern, 2001, p. 70). Selective coding involves the delimitation of codes to those themes that support a core theme. Delimitation occurs in selective coding when the analyst can see prospects for a theory that copes with the open codes (Glaser, 1978). The other themes are not lost, rather they are considered subordinate to the core themes. The researcher selects themes that relate to the core themes in order to develop the grounded theory. Referring to the coding chart on page 112, one code was on-the-job training (OJT) and the memo referred to it as part of the situated learning process that occurred within organisations. After taking into account the coding and the memos together, all the data coded as on-the-job training, induction and work experiences and the memos referring to these forms of learning, were combined into the newly created higher level code situated learning experiences. See Figure Eight below that outlines the process explained above. 


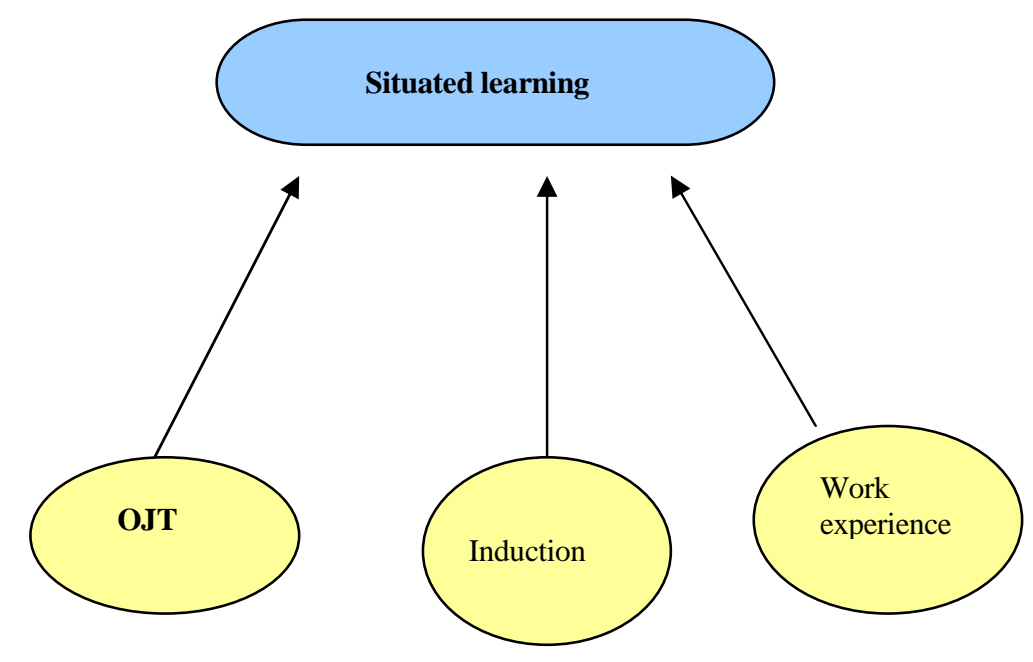

Theoretical Coding

Theoretical coding is the next stage in the coding process and occurs concurrently with the substantive coding. Theoretical codes emerge from the conceptualisation of substantive codes and their relationship to each other (Glaser, 1978). As the substantive themes became saturated, the researcher then examines the relationships and the characteristics of themes that allow them to relate to others in some way. The investigation of the relationships among themes is known as theoretical coding because the discussion of the relationships between the identified themes forms the basis of the grounded theory being developed (Glaser and Strauss, 1967) - that is, the theory is grounded in the themes, and the themes are grounded in the codes etc.

As the theoretical coding progressed, substantive codes such as influence of role models; the presence of maturity and self-awareness, and influence of education systems, were 
combined to create the code of the acquisition of leadership constructs in the CEO role, which became a major theme, explaining the development of the perceptions of leadership of the CEO and of an individual's enactment of the role. As the analysis became more conceptual, this theme became subsumed by the overarching theme, the leadership interpretative schema. This theme was identified as providing a theoretical explanation for sub-themes and the resultant social structural processes. These social structural processes were identified as having an influence on how the participants believed the CEO role was defined, and its subsequent enactment, and on the acquisition and retention of executive leadership.

In addition to the coding processes, diagrams were developed via mind-mapping processes to assist in the identification of the relationships between themes. As these relationships clarified the mind-maps were formalised in an attempt to show the relationships more effectively. An example of one of these diagrams is shown in Figure Nine on page 115 . The diagram is one that was completed during the analysis process. It shows how the emergent themes are linked with the context and how this interrelationship creates perceptions about leadership. When a diagram such as this was completed, the researcher then commenced further searches of the literature and secondary data in order to provide deeper explanations for these themes. While the names of the various themes may have changed during the theoretical coding and writing process, the properties have, of course, stayed the same.

For example, education became learning as the research progressed, just as mindset became excitement and commitment. Figure Nine on page 115 shows the progress towards the themes that were initially labelled as what we say we have to do and what we 
are actually doing. The researcher then undertook further relevant searches of the literature, using such research as a signpost to guide the theory development. This resulted in the properties of the two themes, what we say we have to do and what we actually $d o$, being identified as, and existing as interpretative schema. The next stage of the theoretical coding process was, then, to identify the specific elements pertaining to each schema and assign them appropriately. Once these interpretative schemas were identified further theoretical sampling and analysis was undertaken to confirm the findings of the analysis. 
Figure 9: A sample of diagramming process conducted throughout the analysis

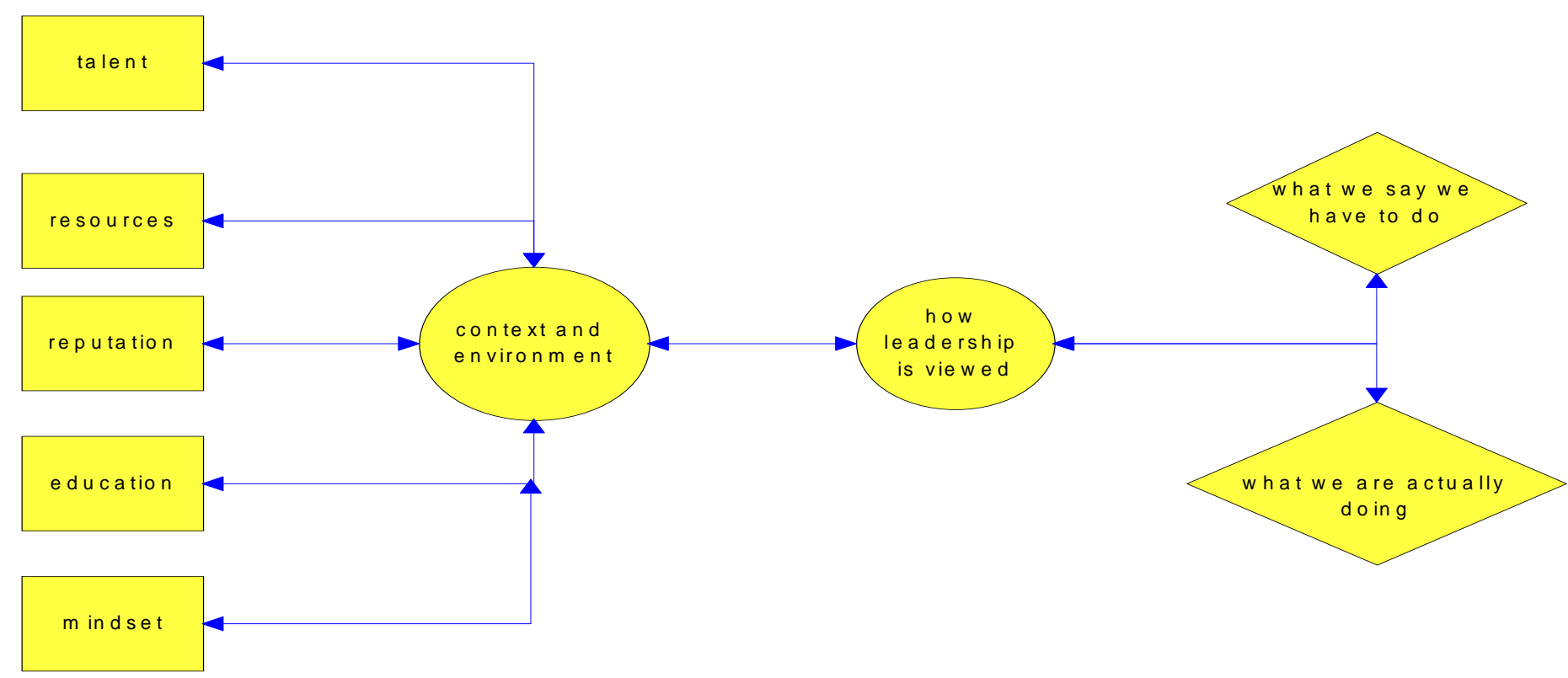




\section{Saturation of Categories}

Within the grounded theory method, coding would continue until saturation occurs, that is, no new data or no new conceptual information is available to indicate new codes or the expansion of existing codes (Glaser and Strauss, 1967; Strauss and Corbin, 1998).

Saturation represents a sense of closure, whereby all data fit into existing themes, and behaviour within the context of the theme can be predicted, such that no further data gathering is required and the theme can be closed (Hutchinson, 1986).

Saturation is reached in any study when any additional data does not contribute to the generation or clarification of a theme, that is, when research participants appear to be saying similar things about the same phenomena. For example, in this case, a minor theme, lack of leadership development, became saturated very early in the research project. However, other themes were created when examining the causes of the perceived lack of leadership development occurring within organisations. The themes, the lack of resources and impact of SME economy, were identified as being linked to this lack of development. Lack of resources was identified as one of the major causes of the perceived low levels of leadership development, which, when considered in conjunction with the theme, the impact of SME economy, was deemed to have a negative moderating influence on many of the emergent themes. While these themes were not able to be abstracted to the level of core themes or social processes, in themselves, they did underpin the findings of the research, and were perceived by the research participants as having a moderating influence upon the enactment of the CEO role. 
By the time the researcher had completed the analysis of 40 formal interviews and 20 informal interviews, all obvious themes had become saturated. That is, no new themes had appeared, no new properties of the themes were apparent and no new relationships between themes were forthcoming. Therefore the themes were "closed".

\section{Theoretical Memos}

As themes and relationships are developed during coding, the ideas generated are written in memos, which lead to abstraction and theorising. These memos are fundamental to the generation of theory (Glaser \& Strauss, 1967). The goal of theoretical memos is to aid the development of ideas and codes. There are three features of theoretical memos, first, they are written with complete freedom, second, they are accumulated, and third, they are highly “sortable" (Glaser, 1978).

Memo writing and diagramming (Chenitz \& Swanson, 1986; Glaser, 1978; Glaser \& Strauss, 1967; Strauss \& Corbin, 1998) were ongoing procedures through all stages of the data analysis in this thesis. Glaser (1978) believes that it is important that memos are written without such constraints such as the necessity for good prose. What is more important was that the idea is recorded. The memos were used as a basis and means to raise the detailed description to theoretical levels by facilitating the drawing of connections between themes, thus abstracting lower-order themes to be re-conceptualised as, or within higher-order themes (Kan, 2002). In addition, guidelines were written for further data collection; sources of information that were deemed useful were recorded as they were identified as contributing to the theory-generating process. As the research progressed, theoretical memos were recorded on an ongoing basis, during observations, 
after conducting an interview, and at any time that the researcher was reflecting on the research process.

Memos were as short as a sentence or as long as the example below. In order to facilitate the use of theoretical memos the researcher kept a diary (an exercise book) readily available, and whenever a thought or an idea was identified, recorded it in the diary. Often this was in the form of mind-maps, which had the effect of linking ideas and leading towards another concept or source of information. The use of a hand-held portable computer (PDA) enabled informal conversations to be recorded, with permission, easily and unobtrusively, and then replayed at a later date. The PDA also allowed me to make memos and notes quickly. This flexibility ensured that appointments and diary notes could be synchronised with material on my main computer on a regular basis. On other occasions, handwritten notes and memos were transcribed and entered in Nvivo and coded them as part of the analysis. This procedure also resulted in the retention of memos in situations that under normal circumstances may have been lost.

An example of a memo that was written after one particularly stimulating interview, related to the theme of the institutionalised schema, and the role of situated learning in developing perceptions of the CEO role. The memo demonstrates the thought processes, the asking of questions and conceptualisation occurring throughout data analysis and theory generation.

Many people being interviewed see on-the-job training as being a critical part of the leadership development process within New Zealand business organisations. One respondent stated, "The best learning happens on the job". There appears to be a formula of 70/20/10: $70 \%$ of learning happens on the job, $20 \%$ with peers and $10 \%$ on courses. At the same time there was recognition that the learning was very much an individual thing rather than a company initiative - it is seen as very ad hoc if it is done at all. It 
became obvious that many New Zealand organisations suffer from a lack of resources to establish the quality of leadership development programmes that are needed. There was also recognition that the most cost-effective way of teaching people their roles was "on the job".

After each memo writing exercise, the researcher reflected on what had been written and why it was necessary to record a memo such as the above. This reflective behaviour resulted in the memos such as the following being created from the above.

This memo raised questions as to how do we know the person involved in learning on-the job is actually learning the "right stuff". How can we be sure that the "masters" from whom the new generation of leaders learn their stuff actually have the required knowledge? Are these the skills managerial skills rather than leadership skills? Are the universities providing the knowledge required? How can New Zealand organisations find the resources to establish the programmes that are needed? What other mechanisms are in place to enable a high potential individual to learn about the role of being a CEO?

Ideas, questions, tentative answers and considerations for further sampling were written as memos throughout the study. For example, after examining the above memo and others written throughout the study the following memo was written.

There appear to be different views existing as to what is leadership. Is there a difference between what is expected of a 'manager' in New Zealand and by New Zealand? Is this different to what is expected from a 'leader'?

These examples are representative of the ongoing analysis processes conducted throughout the research. 


\section{Conclusion}

The purpose of this chapter was to outline the processes that were undertaken in collecting and analysing the data. Geertz (1978) recommends that qualitative research exercises be accompanied by a full description of the analytic processes in order to ensure academic rigour. Therefore it is important that the framework within which these processes are conducted is outlined. Throughout this discussion, the researcher has provided examples of the processes undertaken and the responses to the various challenges encountered throughout the concurrent data collection and analysis processes. Examples of memos and journal note production are also provided. Included in the chapter are examples of the coding processes and the formation and later saturation of themes. The purpose of this first part of the thesis has been to outline the challenges related to the choice of method and the researcher's responses to these challenges. From this point onwards, the thesis discusses the findings of the research in full. 


\section{Part II: The findings}

\section{Introduction to the findings}

The purpose of this section is to provide the reader with a preliminary introduction to the findings of the thesis and the context within which the study took place. In doing so, it provides a foundation for the two chapters that discuss the findings in detail. As the data collection and analysis progressed, two major themes were identified from the data analysis that acted to form the substantive theory of the perceptions of the CEO role. The reporting of the substantive theory is contained in Part III. The themes discussed in this part of the thesis are:

- The acquisition of leadership constructs within the CEO role

- Confronting the institutionalised expectations

Figure Ten on the next page provides a diagrammatic representation of the data analysis indicating the major themes that were identified. As discussed in Chapter Four, the grounded analysis and coding proceeds in a manner to assign incidents into themes, these are then coded to form major themes, the analytical processes leading to the identification of the overarching social processes. In this study, the analytical processes contributed to the conceptualisation of two interpretative schemas, the leadership interpretative schema and the institutionalised interpretative schema. These, in turn, led to the identification of the social structural process, the CEO role as a social institution, and the social psychological process, balancing the tensions and paradoxes. 
Figure 10: A diagrammatic representation of the findings of the study

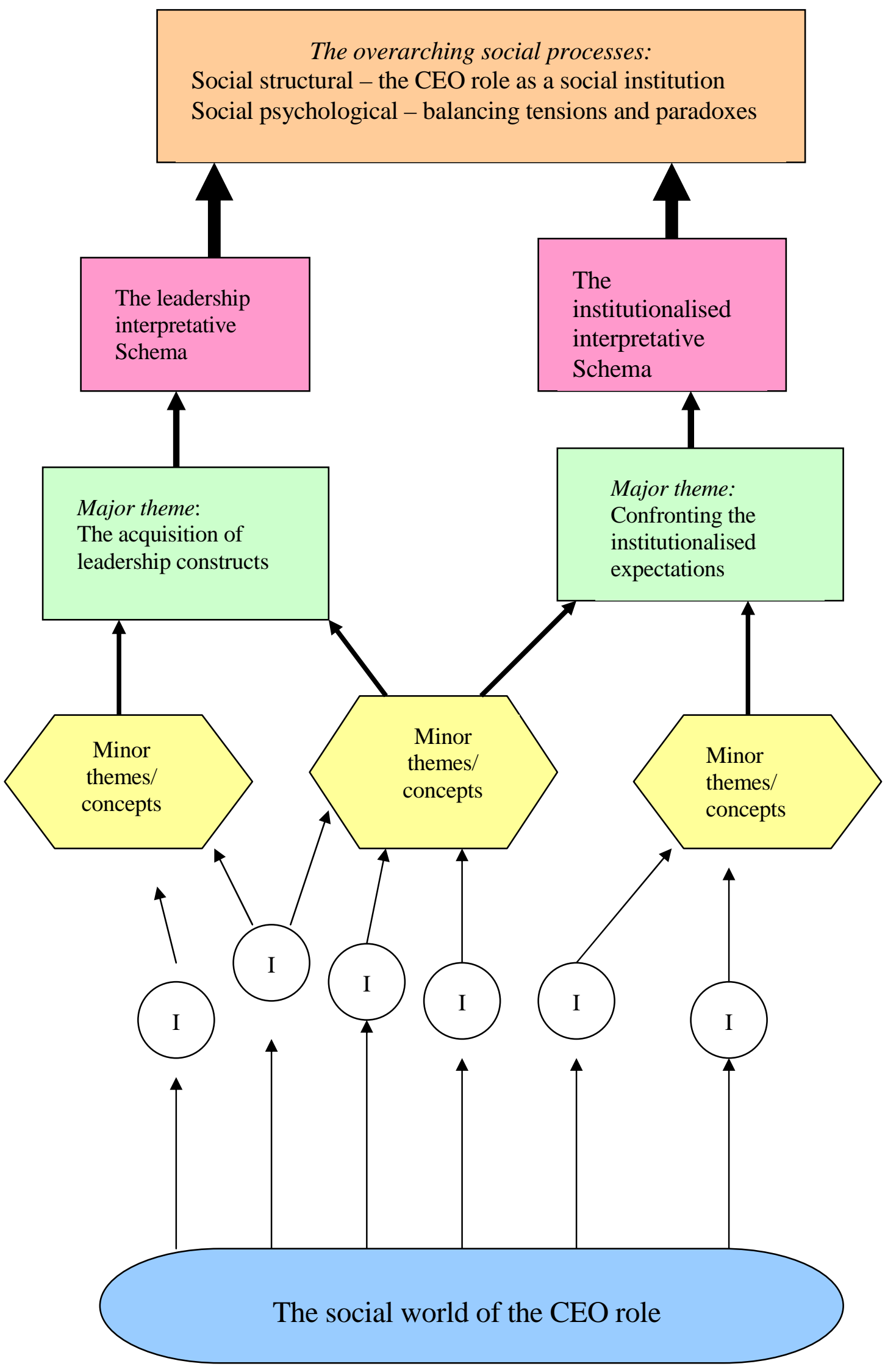




\section{The acquisition of leadership constructs within the $\mathrm{CEO}$ role}

The first major theme identified as a result of the grounded theory analytical processes, described as the concurrent data collection and analysis, captured the participants' perceptions as to how the acquisition of leadership constructs within the CEO role transpired. This theme provides an explanation of the forces within the CEO's context that are responsible for the formation of a set of expectations that contribute to the definition and subsequent enactment of the role. These, in turn were identified as influencing the self-selection of individuals to the CEO role and the retention of capable individuals within the role. The acquisition of leadership constructs provides an interpretative filter to examine the perceptions of social processes from an early stage in an individual's life and, within the different contexts, contribute to the formation of their knowledge about the CEO role. Acquisition, in this sense, is defined as the self-reflective process of individuals to take on or fill a CEO role. The interrelationships between the CEO and the context in which their role is situated, was identified as responsible for providing a diverse range of learning experiences from which the individual constructed their understanding about the role. Surfacing from the data analysis were statements highlighting the participants excitement and empathy for the CEO role, the love of challenge, the importance of a strong self-image and sense of self, a balanced ego, and love for and commitment to people, the organisation and industry. These sub-themes contribute to the explaining how and why an individual may seek to attain a CEO role and then choose to remain in that role. 


\section{The $\mathrm{CEO}$ role and the institutionalised expectations}

This section provides an introduction to the themes that encapsulate the nature of the institutionalised expectations of the CEO role. To the participants, these institutionalised expectations were perceived as so deeply embedded that they have become as a convention within their context. The institutionalised expectations were deemed by the participants to have been formed in part by New Zealand's colonial history, and New Zealanders' responses to it. The theme also provides a framework for the CEO participants' views about why their potential was not always maximised, or why an individual makes a conscious decision not to assume the role of a CEO, or subsequently to leave the role.

To reiterate the point made in Chapter Three, within the grounded theory method, themes are deemed to be social processes if they involve change over time (Fagerhaugh, 1986). Glaser and Strauss (1967) identified two forms of social processes. The first is the basic social structural process (BSSP), for example repression, restriction, or institutionalisation. The second is the basic social psychological process (BSPP), involve rejecting, learning and balancing (Schreiber \& Stern, 2001, pp. 75-76). Glaser (1978, p. 102) states that the logical relationship between the social psychological and social structural processes is that a basic social structural process abets, makes possible or is the social structure within which the basic social psychological process occurs. The analysis identified the participants' interpretations of the interactions, and these were able to be categorised into three sub-themes. These are as follows: 
- The repression of leadership: This theme explains the social structural processes within the external context that cause the repression of leadership.

- The restriction of leadership development: This theme discusses the social structural processes that place a restriction on the development of CEO leadership within the organisation.

- Rejecting the CEO role: In contrast to the prior two themes, this theme describes the social psychological processes that trigger the rejecting of the $\mathrm{CEO}$ role, both by capable executives and the CEOs themselves.

As the research proceeded, it became evident that the participants deemed that the context, in which their role is situated, has a significant impact on the enactment of their role. As a result, an overview of this context is now provided to provide a frame in which to situate the major findings of the thesis.

\section{The Research Context}

As outlined in Chapter Three, the research is situated within large organisations in New Zealand. The country is geographically isolated, situated in the lower part of the South Pacific Ocean, and comprising three main and a number of smaller islands. These islands are some of the most recently inhabited by people (Kennedy, 2000). This results in the potential for business activity to be costly, creating a resultant demand for highperforming capable leadership as one way to control or minimise these costs. However, 
the geographic isolation also contributes to a low population density, which at August 31, 2008 was 4,276,169 (Stats-NZ), this limiting the people resources available to large organisations.

The indigenous people of New Zealand are the Māori, who migrated from Polynesia approximately one thousand years ago. New Zealand then remained virtually isolated until colonised by Britain just less than two hundred years ago. Garrison (1998) argues that:

Experiences such as "war, revolution and colonialism, shape the public consciousness in such a manner they dictate long-chain behaviours and attitudes which are hard if not impossible to demolish" (p.42)

These factors, the events and responses to them, have been identified as having a role in the development of the perceptions of the CEO role. Belich (1996) writes that colonial immigration occurred in waves as migrants arrived, primarily from Britain, to establish settlements. The legacies of this early immigration have moulded the culture of the country. Belich (1996) provides one example of the paradoxes that this colonial heritage has created. For example, the 1840's gold rush developed a negative attitude to wealth. While the gold diggers were initially treated with contempt and considered a dangerous breed, this contempt dissipated as their wealth was redistributed to the community through their commercial endeavours. He believes that this has created a complex set of contradictory attitudes to the creation of wealth within the country

Phillips and Hearn (2008) contend that the make-up of the early immigrants to New Zealand included individuals who were resourceful and determined to make the most of 
the opportunities afforded them in the young colony. One such group were the early whalers and sealers who have been identified as being responsible for introducing a strong egalitarian base to New Zealand society (Belich, 1996). This base combined with the desire of some of the early colonists to escape the restrictive class structures of their "home country", Britain, has embedded egalitarian principles deeply within society. King (2004) has stated that New Zealand was envisaged as a country that would allow an individual to achieve wealth and success no matter what their social origins.

As well as having a relatively small population density, New Zealand's businesses are also comparatively small in a global sense (Statistics-New-Zealand, 2002). Kennedy (2000) contends that the focus upon individualism and the relatively small size of New Zealand enterprises has led to a belief that New Zealand business executives have developed a wide range of generalist skills and abilities rather than the specialist areas of expertise that may have been demanded and that they would have developed in larger companies. The relative smallness of New Zealand organisations is considered to have created implications for the development of CEO talent in New Zealand. Fujita (1994) contends that one of the most critical resource constraints in smaller organisations relates to the ability to provide developmental opportunities for people. This ability has been further hindered by the limited level of empirical research and resultant published work examining executive development and the human resource function in such organisations (Fujita, 1994; Industry-Regional-Development, 2001).

New Zealand companies in every industry sector have been forced to compete with large multi-national corporations (Labour-Market-Policy-Group, 2001). Paradoxically, the unique source of competitive advantage for these organisations is their people. 
Manolova, Brush, Edelman and Greene (2002) argue that a firm's human capital is one means by which to compensate for inadequacies in other resources. Therefore, an assumption can be made that the limited availability and development of management and leadership skills in a country such as New Zealand may be one of the major constraints on the global success of business organisations (Labour-Market-PolicyGroup, 2001). Consequently, it is considered that a more innovative, critical and proactive approach to leadership development is needed as opposed to the approaches that have been taken in the past (Ger, 1999)

Chetty (2001) contends that many New Zealand organisations, in order to meet the challenges presented by the globalisation processes, have entered the international arena by collaborating with other firms. This has enabled these organisations to accelerate the internationalisation process and to achieve success in areas that may otherwise have been inaccessible. Collaboration has also allowed these firms to gain knowledge, skills and economies of scale at a higher level than would be the norm (Chetty, 2001). This, in turn, has created the demand for skilled people, especially skilled executive leadership. This demand may not be met if there is not an understanding of the factors that either inhibit or enhance the acquisition and development of that leadership. The next section of this part of the thesis is Chapter Five reports on the findings that create the theme the acquisition of leadership constructs in the CEO role. 


\section{Chapter 5: The acquisition of leadership constructs in the CEO role}

The CEOs are people who want to learn, who want to improve themselves and learn from their experiences and develop and grow. They are usually people who have some level of awareness about themselves and how they want to improve.

A Board Chair participant

\section{Introduction}

As discussed in Chapter Two, The Literature Review, the CEO role is an ascribed formal, executive leadership role. When an individual is ascribed the CEO role, they can bring with them a set of expectations that have been developed from the social interactions that they have experienced throughout their lifetime. This chapter provides a discussion of the social interactions that contribute to the development of the constructs and scripts that inform the CEO role, especially as an executive leadership role. Analysis of the interviews identified four key themes that contribute to the creation of leadership constructs as perceived by the participants. These are the following:

- The importance of role models,

- The role of formalised learning,

- The Development of empathy and excitement for the CEO role.

- The importance of reputational capital

The next section of this chapter discusses the first of these, the importance of credible role models in developing insights about the CEO role, whilst subsequent sections will provide discussion of the remaining themes. 


\title{
Role models and developing perceptions of the CEO role
}

\author{
All participants, at some point during the research process, spoke of the importance of \\ credible role models in the development of individuals as effective CEOs. A role model \\ within the context of this study is defined as:
}

a cognitive construction on the part of an individual, this cognitive construction based upon the attributes of people in social roles, which the observing individual perceives to be positive and similar to them to some extent and desires to increase the perceived similarity by emulating those attributes (Gibson, 2004, p. 136).

When asked to reflect on their own careers, the interviewees spoke of how, at vital points in their lives, and not solely in their business life, they had the advantage of working with people they considered to be key role models. However, when they were asked what the characteristics of these role models were, no one consistent factor was identified.

However, those participants involved with executive coaching or human resources were emphatic about the importance of role models to the CEO development process. One example of the comments received is: “...those CEOs who have taken part in robust mentoring and coaching events are generally more successful than those who don't..."

Furthermore, one retired CEO when reflecting on his career spoke of how good role models appear to come about more by good luck than by good planning:

I've always been lucky, or whether it's part good management or being in the right place at the right time, to have people around me that I've respected and in the XXXX situation, that was very important ... an older man who, I got on with very, very well. He was 
always able to guide me through some of those [critical] bits and pieces and there was always respect for him.

The role models and mentors were spoken of with affection, respect and fond memories. For example:

He taught me to appreciate music, opera and introduced me to new community activities. It was not until I became a CEO that I realised how much networking is conducted at events such as the symphony and the ballet

These positive relationships were spoken of as motivating the interviewee to strive for, or continue in, an executive leadership role. The presence of appropriate role models was deemed by the respondents as imperative to encouraging an individual "to take on the role". The ability to recognise observe how a CEO should [enact, or] "be in a role", is what Mead (1934) has long identified as a role-taking process, that is, a situation where an individual can imagine how they appear to others in a particular role. As a result, they practise role-taking, enacting the role in a manner that allows them to become an accepted member of the group (Mead, 1934; Stryker, 1962). Cast (2004) argues that role-taking influences not only how individuals behave with their peers and colleagues; it also helps initiate the changes that individuals have to make to their behaviour to enact their role.

While the CEOs spoke with enthusiasm about their own role models, they also acknowledged a belief that there was dearth of positive role models within the business environment. Comments were made about the erstwhile promotion of sports stars as appropriate role models in preference to those from the business community - this occurring whenever high achievement is discussed by role senders, the media or other 
groups in society. However, there was a desire on the part of the participants for role models to be available from a varied range of organisations and sectors. A comment typical of those received was: “There's XXX, and there's XXX [both internationally famous sports stars], there's many other sporting people. Then you go and you look at people in business, and who have you got?" ... "None"”.

The semi-structured nature of the interview process provided opportunities to ask followup questions about the espoused preference for sports stars. The responses of the participants highlighted the manner in which sports stars are thought to have gained their fame and subsequent wealth, for example, their wealth and fame have been achieved as a result of their own talent and hard work as opposed to the effort of others. Participants' reflections highlighted the apparent influence of New Zealand's colonial history; also the links to New Zealand's professed fervour for sport. While there was a consensus view about the desirability of having a broader cross-section of role models, there was agreement that little progress had been made: "We always go on and on about how we've got to get some business heroes positioned down alongside the sporting heroes". One reason given for the lack of appropriate role models is that New Zealand still does not place a high value on business, that is, the egalitarian mores do not necessarily lead to favourable recognition of those involved in the accumulation of conspicuous wealth through business endeavours. One comment received pertaining to the supposed negativity towards the business environment and specifically to the CEO role, related to the impact of the New Zealand's colonial past:

Maybe it's linked to nineteenth century or even seventeenth century England, when if you were a businessman you were looked down upon basically. There is an element of that, like somehow if you are a businessman and you're making money you are ripping other 
people off. It's funny really, isn't it? We don't still value (business) people ... however, there's an extraordinary fixation on politicians and sportspeople".

It is noted that the negative perceptions of the CEO role were deemed to have arisen in part from New Zealand's colonial heritage. However, such perceptions were considered to be an integral or defining aspect of New Zealand society. As discussed in the literature review implicit leadership theory focuses on the attributions and perceptions ascribed to a leader by others and how these influence the perceived effectiveness of that leader (Calder, 1977; Hunt, 1984; Lord \& Aditya, 1997; Lord, et al., 1978). It was a topic that many CEOs had not become aware of until they were established in the role. The CEO participants considered, however, that the majority of the attributions they were aware of, had originated from their external context, and had shaped how their role was defined and had influenced how it is subsequently enacted. When asked for reasons why this occurred, the relative smallness of the country's business environment surfaced as a reason.

The interviewees spoke of how the business context assisted in sustaining the negative perceptions of the CEO role. The observation was that these negative perceptions were not as extreme in larger business communities as they are in smaller environments. An example, provided on more than one occasion, referred to how these negative views arise, for example, where a CEO through inappropriate behaviour, or business failure or selfpromotion, achieved notoriety. Notoriety is where a CEO gains extensive recognition, usually in an unsavoury or unfavourable manner. This notoriety can often obscure the positive and effective behaviours of other CEOs who are 'doing a good job'. Often the public notoriety renders the day-to-day realities of the CEO role invisible. Some respondents blame this situation on the innumerable publications and training resources 
that focus, for example, on the activities of a specific CEO. These publications, whilst often useful, did provide some valuable insights for the CEOs themselves. Often, it contributed to the confusion about the CEO role. One concern the interviewees had, was that a book on leadership may only be written because an event or business activity has resulted in a level of notoriety that may aid sales. As a consequence, they believed that the CEOs or the events profiled were not illustrative of strong, capable or genuine CEO leaders. Consequently, it is a common perception that less than desirable characteristics relevant to the CEO role have been validated. For example, one retired CEO and board chair expressed his concern in the following manner:

... And I see that people think that leadership, is a god-given [attribute] and they don't need to know about it [learning what leadership is]. There is an awful lot written about it as you know ... and there are all these books on leadership such as XXX's [an individual who became famous as a result of a major event] book on leadership. I haven't looked at it but I saw him interviewed and I thought "Oh dear".

This comment was reinforced by others during the informal interviews even to the extent that the particular book and its author were mentioned by other CEOs on several occasions. Reference was also made to the number of negative images of the CEO role that have emanated from North America and Europe, with the interviewees stating that these did not provide positive representations of the CEO role in New Zealand. The interviewees were emphatic that such images bore little, if any, resemblance to the reality of business life in New Zealand.

However, paradoxically, some more experienced CEOs (those with over 15 years experience) also spoke of the advantages that negative role models provide. They considered that even negative role models can add to the learning process, but provided a 
caveat that their influence was conditional on there being available positive role models that would make reflective and favourable comparison possible. This may, of course, provide a prospective executive with the opportunity to evaluate the appropriateness or otherwise of a specific leader's behaviour. It was also suggested that the ability for an individual to critically reflect on positive and negative role models was imperative if learning experiences were to be maximised. However, they recognised that this ability was a skill that took time to develop and was a vital part of an individual's overall capability set:

Well the role models in business, if you struck a good one that was fine, but you have to have enough "nous" and knowledge and have developed a point of view in order to work out what guy is pretty awful and what guy's great, and what the reasons are for the difference.

What concerned the more experienced CEOs was that many talented young people do not have the opportunity to observe a diversity of leadership forms and styles. Therefore, they are never able to compare and contrast the different experiences in order to determine what is appropriate and what is not. One stated outcome is that these younger executives are unable to acquire [role-taking] appropriate behaviours which may enhance their effectiveness as a CEO. The make-up and size New Zealand's business environment was identified as having an influence on the nature of role models and therefore the availability of essential developmental experiences. One retired CEO reflected on some of the situations that he had observed over his lengthy and varied career: 
I mean, if you think of somebody, a young person who works in the same company for ten years, he might think that that's the way life is, like kids who are in a family where it is dysfunctional and there's violence, they know no other life.

He continued to reflect on how often the only business role models that are available are those displaying the "heroic" or "slash and burn" forms of leadership, thereby generating "inappropriate" notoriety for the CEO concerned. Indeed, a statement was made that these images do not accurately reflect the day-to-day realities of the CEO's world. This view was discussed during the informal interviews and it was confirmed that images occurred repeatedly, contributing to the distortion of reality. As a result, individuals with the potential to become CEOs have had their "views coloured", resulting in conflicting perceptions of how the role should be enacted. As a result, some CEOs came to the view that the CEO role was not an appropriate career option for them. These opinions were in keeping with the argument of Markus and Nurius (1986) who contend that if an individual does not have a positive view of him or herself in a role, then their potential to undertake that role, their growth and development into and within the CEO role, may be limited. Concern was expressed, by a former CEO, now a board-chair, about the ease with which an individual could assume the role in an inappropriate manner. This was especially so if the individual did not have a varied range of role models, and were not able to engage in reflective behaviour. Akin (1987) similarly claims that a person with a misplaced sense of self in a role could adapt (role-take) their behaviour in an inappropriate manner and as a result become less effective in that role (p.40)

In summary, the existence of both positive and negative role models is perceived to be important for effective behaviour in the CEO role. What is of concern to those taking 
part in this research is the scarcity of credible positive role models in the New Zealand business community. As the data collection and analysis within this study progressed, the importance of formal developmental opportunities was identified as the primary means by which a CEO learnt or could learn the expectations of them in taking on the CEO role. The next section of this chapter discusses the nature of these formal experiences, and their role in developing the participants' perceptions of the CEO role.

\section{The role of formalised learning}

The importance afforded to formal developmental experiences was identified early in the research process. This led to a definition of learning that would provide a frame for the findings being developed. The researcher turned to the Concise Oxford Dictionary (1999) where learning is defined as: "the knowledge or skills acquired through experience or study or by being taught" (Pearsall, 1999). However, the findings necessitated a broader perspective of the concept of learning. Therefore, Marsick and Watson's (2001) definition of formal learning that is “institutionally sponsored, classroom-based and highly structured", was used. The context-specific nature of this study decreed that an even broader definition be provided. Therefore, Hein's (1991) view of learning as a highly contextualised social process that focuses on the whole person in relationship to their environment, as opposed to a single aspect of the individual or event, was used in conjunction with the above two definitions. Within the context of this thesis, learning is defined as a social activity that cannot be divorced from the whole person as a learner, what else the learner knows and whatever their prejudices and fears may be (Hein, 1991; Lave \& Wenger, 1991). Utilising this broader perspective of learning 
allowed the informal and situated learning experiences to be identified. These are discussed further in Chapter Six. Here, the focus of the chapter is on the formal learning experiences identified, by the participants, as formulating their perceptions of the CEO role. The two modes of formalised learning are those occurring within the school system and those taking place within the organisation itself.

\section{Influence of school learning upon business leadership}

All the participants spoke positively of the importance of their school learning experiences in developing their affinity for business and executive leadership. One characteristic of this theme was that in general the participants' school experiences were identified as being highly structured and formal. Lave \& Wenger (1991) write that the school learning environment is based upon the belief that knowledge and the gaining of that knowledge can be decontextualised. That is, the school environment has been built on a supposition that learning, and the beliefs and attitudes of the learner can occur independently of each other. The approach utilised in this study emphasises that the school environment and the learning processes are unable to be decontextualised. This is in keeping with Lave and Wenger's (1991) argument, and that of Hein (1991), who contend that the school environment is highly contextualised and that the beliefs and attitudes of the learner are inseparable from the environment within which the learning takes place. Lave and Wenger (1991) go on to state that the nature and structure of the school environment creates and sustains a social institution in which contextual influences are unable to be ignored. A typical comment resonating with this view is provided below: 
I went to a private boy's school and we all had to conform ... didn't matter what ethnic group you came from ... you all had to be the same. If you came home to my house we were totally different ... how we acted, how we spoke.

It is not the intention of this study to support a comparison of education systems, nor to provide a measure of the quality or effectiveness of the New Zealand education system. However, the perceptions of the research participants raised questions about the effectiveness of the education system in contributing to, or supporting the development of future executive leadership, specifically CEOs:

I think schools can play a much bigger part whereas there are some good things happening ... and just thinking about my experience and now with my son. There are some things which are fantastic but it is very much a socio-economic thing... and schools need to do more to break the cycle

When reflecting upon their school experiences, interviewees invariably spoke of them in a favourable light. Everyone reminisced about people who had influenced them positively during their school years. These positive encounters providing them with the motivation to strive harder in their particular field of expertise.

However, voices of caution moderated these positive views, stating that whilst there were some opportunities available during their schooling to develop, for example, a competitive or entrepreneurial spirit, these were not always available to every student. It was accepted that students with sporting potential were more likely to be provided with opportunities to exercise competitive drive and to learn what being competitive meant in terms of effort, commitment, success etc. 
When I was at school it was the culture of the first fifteen ... the sports heroes ... they seem to get everything ... it was not so easy for other students

There was a consensus that the development of competitive, risk-oriented, visionary leadership behaviours was in many instances actively discouraged within their school settings. The rewarding and encouragement of low risk, conformist behaviours had been the norm for some interviewees. A female CEO who had attended a girls' only school expressed strong views about the less than positive influences of her school experiences and education on her career. While she acknowledged that attendance at a single sex school provided more leadership opportunities "for a woman of her generation" than she would have had at a co-ed school, she still felt her school experiences repressed high potential leadership behaviours. She stated that while there has 'been some progress in the intervening period', that is, schools have introduced programmes that provide students with experiences with a business orientation, yet an individual is still: ... "taught low risk behaviour and the school environment encourages that ... very little is being done within the school system that encourages risk behaviour".

This comment typified several received throughout the study. As stated earlier in this section, the initial reaction from the majority of the participants was that their school experiences were in the main very positive. However, after being asked to reflect on the good, and the not so good, the forthcoming observations suggested that there were constraining forces operating at the time. When asked what they considered the critical competencies for effective CEOs in the future were, the participants spoke of the ability or willingness to take a risk, albeit a calculated and considered risk. One CEO spoke of the need to be able to take risks while at the same time maintaining key relationships with 
people. These were judged to be vital areas where the participants felt the 'base learning' was not being provided early enough in an individual's life. One CEO explained the required competencies as follows:

Well, one of them is thinking about people ... a really strong focus upon people. The second I think was risk-taking. We have had to take some big risks. The ability to take risks is critical.

The interviewees, when they were asked to reflect on statements such as the one above, reflected on the risk averse environment and the constraints imposed on the development and nurturing of leadership potential. This, in turn, was deemed responsible for creating negative attitudes of those experiences related to business and business leadership. One participant's reflections [summarised] is representative of those made throughout the study:

My theory on the education system ... it is fundamental, here at XXX our people cover all sectors and levels in the education system. A sound education which provides a deep level of people development is critical if the management development systems are to work at a later stage ... it is very risk-averse [the school system] and does not provide the necessary skills which are needed in business.

The grounded theory analysis identified that an unwillingness to take a risk was manifest, as were the demands for conformity, and the perceived failure on the part of the school to nurture a strong competitive spirit. This is a somewhat paradoxical view running counter to prior comments regarding the supposed competitive fervour in New Zealand for sport. Some suggested that the perceived lack of enthusiasm for competition resulted in a lack of the "sharp edge or toughness", considered critical for business success. One person referred to it as, "not having enough of the mongrel in them". This was the only 
comment of this nature received during the research. When asked to explain what he meant, he softened the explanation to "the ability to be tenacious and focussed". The consensus was that ability of an individual to display tenacity, especially in trying times, was perceived as an essential attribute of an effective CEO, and that failure to display such characteristics in turn hindered the effectiveness of the CEO.

The analysis of the interview transcripts indicated an accord in perceptions and recollections of the school system suggesting they were a reasonable reflection of the New Zealand school setting. The common view was that the school system could and should do more to support the development of tenacity and competitive spirit at all levels and across a wider scope of subject areas, not just in sport.

A senior CEO and board chair, who had experience in both the business and education sectors, summarised the views of the participants concerning the interrelationship between schools and the learning of leadership:

Well, if we are going to do that, we need to focus on leadership and we need to take it as part of the curriculum and start in the secondary schools, focus on it, make a real focus of it ... and it's about leadership and excellence and competition and winning and all those things.

Interviewees, spoke of the need for an immediate change in the way business and executive leadership is valued if there is to be any genuine benefit in the short to medium term. Business oriented projects, for example, the Business Enterprise Programme, were spoken of. However, the consensus was that they were not far-reaching or widespread enough to ensure efficacy. 
Adding to these comments was an expressed concern about the level of the basic skills, (for example, the lack of appropriate literacy and numerical skills), or are at an insufficient level for even 'front-line' leadership. The data analysis identified a belief that failure to acquire a high level of basic skills, both scholastic and personal, early in one's life, has a cumulative negative impact on the individual's potential for leadership in any sphere, but specifically business. One CEO who had a long involvement with the New Zealand education system commented:

When we get into the bowels of our leadership ... to our front line leaders, their ability to write, read, arithmetic, the basic stuff, is really, really poor and I think that is a reflection on the New Zealand education system.

Research conducted by Fredrick and Carswell (2001) has offered a similar view stating that the New Zealand education system has a responsibility to be more supportive of business enterprise, if there is to be a sustainable healthy business environment in the future. They go on to argue that the education system should be responsible and accountable for ensuring that the primary skills needed for enterprise and business success are inculcated early in an individual's schooling. They also contend that the school system should be "shouldering the responsibility to train our students for successful and prosperous futures. This means enterprise education". The authors defined enterprise education as the acquisition of entrepreneurial, innovation, business skills and competencies (Frederick \& Carswell, 2001, p. 33).

An observation made by the private-sector respondents reflected on the need for young people, no matter what their culture, ethnicity or economic background, to leave the 
education system with a positive view of business and executive leadership. This would enable young people to make informed choices regarding tertiary and/or vocational education, especially that oriented towards business. The private sector participants' argument was that for the CEO role to be perceived as an attractive career option, the value of positive viewpoints, visions and examples of business leadership could not be underestimated. The consensus across all the research participants was that while their specific schooling experiences were positive and played a significant developmental role in their career choices, there was potential for an even greater contribution to be made. As the analysis progressed, a second channel of formalised learning was identified. This was the learning undertaken in organisations through the provision of executive development programmes. The next section of this chapter outlines the characteristics of the theme: formalised executive leadership programmes and the CEO role.

\section{Formal executive leadership programmes and the $\mathrm{CEO}$ role}

Formalised leadership development programmes and experiences were perceived by the participants as the primary means by which the requirements of the CEO role were learnt. Organisations that provided high level development programmes were judged to be leading the way in executive leadership development. Analysis of the interviews identified a perception that the preparedness of an organisation to send people to offshore executive development programmes demonstrated the organisation's commitment to executive leadership development. One participant comment was thus: 
Spending money and putting people on courses. There was quite a lot of internal development, so we'd get our own internal development programme and we'd go to North America for a week and mix with other CEOs and the various boards and international execs.

The preparedness to invest money on executive development was judged a significant contributor in enhancing an executive's effectiveness in their role. It was also deemed to be evidence of an organisation's long-term thinking. The following two comments typify those concerning the value of formalised learning:

All XXX's direct reports, at least every second or third year would go to INSEAD or Harvard or Stanford ... so we were reasonably progressive.

I have to say that, in terms of the XX company, we were really very farsighted in terms of executive development ... this would be a generalisation, but about every four years senior executives would go on a 2-week or month-long, development programme.

The consensus was that New Zealand's geographic isolation presented both advantages and disadvantages for the provision of developmental opportunities. A key disadvantage was deemed to be the inability of New Zealand organisations to provide high-level developmental experiences. The principal reason offered by the participants was a lack of resources and the size of organisations relative to international organisations. These factors precluded the provision of learning experiences at a level deemed essential by the CEOs for their development. They went on to speak about how important it was for the organisation to motivate people to want to improve their skills. The formalised development programmes were one means by which this could happen as explained by one CEO: 
I think there are people who are intrinsically motivated and there are others [for whom] you can create an environment where their natural levels of motivation are enhanced. I guess that is what you are trying to do when you put them into some sort of learning experience, is to lift their level of motivation to the point where they will engage, because you can't force them.

Across the interviews, there was agreement about the importance off-shore executive development programmes and the ability to keep sending capable executives to such programmes. The CEOs spoke of the personal value they had attained during these experiences and how they were believed to have assisted in developing the required capabilities for successful enactment of the CEO role.

Leadership development, that is, our pure development programs, to build leadership capabilities. So one is identification and individual planning around a group of top talent and the other is a programme of development opportunities, solutions, and programmes

Experience achieved in the offshore programmes was perceived as a fundamental part of CEO's development. The executive was better able to understand the changing expectations and requirements of the role as a result of attendance at such programmes. This also reduced the negative impact of New Zealand's geographic isolation, allowing the CEOs to gain a more global perspective of their role. One individual with over 25 year's global experience expressed this in the following way:

I think the traditional way of developing leaders is to send them offshore to an advanced management programme somewhere. It has its advantages ... one is to meet and work, the second is to actually give CEOs confidence so they can mix it with the best in the world. Before attending they think, we're not that good because we're at the bottom of the South Pacific and we're not up to date. And then they realise of course that they, especially in the generalist sense, that they are okay. 
The participants indicated that individuals who engaged in critical reflection were better able to maximise the benefits gained from these offshore programmes. This occurred as a result of the comparison of the knowledge gained with their existing schemas thereby providing them with the opportunity to gauge its relevance to their role.

The participants were asked to reflect on the difference between the international and domestic programmes they had attended. Whilst their immediate responses addressed the value accorded the development of generalist managerial capabilities in domestic programmes, they believed, in contrast, offshore programmes had more of a strategic visionary focus. When participants were asked to expand on why this occurred, New Zealand's geographic isolation was identified as having created the need for the development of high-level generalist managerial skills, and a preference for professional and technical abilities that have taken precedence over the development of specialist leadership skills.

When the interviewees were asked for a more in-depth explanation, there was a consensus that for an individual to be considered ready for management they must be proficient in a professional or technical sphere, that is, be considered highly competent in a generalist sense. When the ' $w h y$ ' question was asked, the preference for technical and professional skills, was spoken of as having its genesis in New Zealand's colonial history, the colonists being in an environment where people had to be 'Jacks of all Trades' in order to survive and create a new life. The observation was made, that even today, someone who possesses technical expertise at a high level is more likely to be recruited to an executive leadership role than an individual who does not: 
Whether they have the ability to move into another field in the company, and we think that they could go into another specialist role. So they might go into marketing or into XXX business. Whether they've got the ability to go into a higher level management role, or whether they've got the ability to do both, to go up and across. That's how we've defined potential.

This emphasis on the technical and professional qualifications and competence of an individual, and their related abilities as a generalist manager, led to a variety of comments, for example the following:

... and also I think there's this academic debate around what does management mean, and its use of leadership, mean, and I think that confused the shit out of everybody, it's such rubbish.

These comments centred on the differences between leadership and management and specifically on the differing expectations and requirements for role enactment. One CEO laughingly reported back on one conversation he had, commenting: "It is still continuing and I doubt we will get a resolution anytime soon".

Again the observation was made that the limited resources of New Zealand organisations relative to those available globally has resulted in a concentration on developing people who have high levels of generalist abilities as opposed to specialist leadership. One person reflected on their experiences in North America, where there is a supposed emphasis upon "differentiating the professional, technical expertise from the specialist leadership role" and proactively identifying people who are considered to have "high potential for leadership roles" as opposed to those who are "highly skilled members of a professional group" or "top flight generalist managers". It was perceived, somewhat 
paradoxically, that the globalisation process has streng7thened these preferences rather than diminish them. One CEO, for example stated:

Where you're part of a large global company, they want people, who will just provide the numbers and tick the boxes, manage the policy-type stuff. So the more they say "yes we want you just to follow what our requests are, meet those numbers," the more we are going to ask how we are going to lead our companies to do that. Do we want comfort zones? Do we want really good professionals in there or do we need people who can think outside the square and the box?

There was concern expressed by respondents, where, if companies are recruiting for specialist CEO capability, and the expectation for performance is of a generalist managerial nature, then tensions will be created for the CEO. Participants also believed that parent companies' located off-shore from New Zealand are restricted in their ability to provide high-level formal development programmes and that has been particularly noticeable over the last 10-15 years. One comment that summarised the overall feeling was:

There was enormous investment. If I look back historically, maybe seven years, even ten years or more, there was huge investment from companies into people ... but not just in a leadership role, also preparing them for leadership roles.

When the "what happened" question was asked, the participants referred to the turbulent change period of the latter part of the twentieth century when mergers and acquisitions and global takeovers resulted in the cancellation of many development initiatives. Only recently, in the first half of the twenty-first century, has leadership and leadership development experienced something of a renaissance. There was a sense of "there is much catching up" to do, especially with regard to "the young ones coming through". 
Concern was expressed about the lack of a long-term perspective to leadership development. This applied to both the availability of executive development programmes and the fast-tracking of younger capable people. The concern is that the current environment encourages development at a too fast a pace, as expressed by a CEO with more than twenty years experience:

One of the issues we've had with graduates over the last couple of years is that they expect to get too far too quickly, and unfortunately some of them do. Some of them have been given some wonderful opportunities far too early and others expect the same sort of thing, and really they haven't got the maturity yet to fill some of the roles that they've been thrown into.

Appropriately designed formalised programmes were one identified means by which the true realities of an executive leadership role could be conveyed. These need to be deliberate and structured, to involve long-term planning and to ensure the stair-casing of these experiences, one leading naturally to another. Participants were adamant that executive development could not be left to the individual but should be accepted as an organisational responsibility. An executive coach, who had previously held an executive leadership role, when reflecting on some of his experiences with less than successful CEOs, commented:

It would be nice if they are [people developing him or her selves] but they're not, so why don't we deal with that reality ... they are not planning, they are not taking responsibility. Yes there are things that we can try and do to push them in that direction. But in the meantime we may as well accept that there is a gap, and do what we can to fill it. Otherwise we are going to pay the price for their failures as much as they are. 
The identified challenge was to attract, retain and develop capable young people to an executive leadership role. This challenge has become even greater because of the smaller number of graduate programmes that are currently conducted. A situation phrased as further "decimating the pool" by one participant. Another, reflecting on the importance placed on formalised leadership development “in earlier times," commented:

Well, I think there are a number of reasons ... if you think about what was happening politically, think about what decisions were made around something as simple as apprenticeships. If I think about what happened, especially within a lot of government organisations, things tightened overnight. No longer did you have the room to actually spend the time and the money growing people. And then I look at private industry. The same thing is happening.

Despite this situation, the necessary developmental experiences were considered to be at a level where the individuals were able to develop positive attributions of the CEO role. As the data analysis progressed, evidence of the CEO developing an excitement and empathy for the CEO role was identified. The next section discusses the theme identified as developing an excitement and empathy for the CEO role.

\section{Developing an excitement an empathy for the CEO role}

The theme developing an excitement and empathy examines those characteristics of a CEO that were perceived as evidence of high levels of enthusiasm for the role. These characteristics contributed to the CEO's ability to continue within the role. In examining these characteristics, the value of the sample structure, including direct CEO experience and those with board experience, and consultants closely involved with the CEO was 
reinforced at this point in the study. For example, non-CEO participants reflected on their experience of a $\mathrm{CEO}$ who happened to be a participant in this research. Comparing these incidents during the analysis contributed to the confirmability of the findings (see Chapter Three, Maintaining the academic rigour).

The interviews during this phase involved a mixture of emotions, initially cynical and pessimistic, as the individual spoke of the fears and frustrations that the role engendered. Then faces and conversations were often suddenly illuminated with humour, wry observations, witticisms and insightful comments. In general, the interviewees' remarks revealed agreeable personalities, an enduring enthusiasm and empathy for the CEO role, and commitment to their organisations and the industry sector they were involved with.

Throughout the interviews, words, such as challenge, commitment, self-awareness, people, excitement, maturity, and adult behaviour, were used by the participants. The enthusiasm, dedication and willingness to accept the challenges of the role were on occasions almost palpable. There were four sub-themes comprising the theme developing an excitement and empathy. They were identified as:

- The presence of maturity and self-awareness

- Developing confidence and commitment to the $\mathrm{CEO}$ role

- The CEO role and the love of challenge

- The importance of reputational capital

Each of these is now dealt with in turn. 


\section{Maturity and self-awareness}

As discussed in Chapter Four, one of the tools used during the interviews were 'counter questions'. For example, the interviewees were asked to reflect on a CEO whom they considered to be effective in his or her role and comment on what the characteristics were that individual contributed to their effectiveness. They were then asked to reflect on a less than successful CEO, and to identify the characteristics that contributed to their lack of success. The observations drawn from the interviewees focused on the fact that effective CEOs were deemed to be more mature and possess a stronger sense of self than ineffective CEOs. Utilising the literature as a sign-post, and as a "mentor", within this phase of the study, the researcher turned to the work of Gergen (1971) who contends that there are four essential criteria for assessing the level of an individual's self-awareness. These criteria are:

1. An individual's knowledge of who he or she is; their identity, and how they grasp the meaning of their past and their potential for the future.

2. The concern with self-evaluation and the value an individual places upon themselves, establishing their level of self-love and self-esteem.

3. A concern about the conflict between the individual and society and the core feelings and perceptions an individual has about himself or herself that distinguishes them from others in society.

4. A concern for the restrictions and limitations the knowledge of the self and selfperceptions can place upon an individual. 
The level at which any one of the above criteria is present is an indicator of the level of maturity and self-awareness of an individual. The grounded analysis identified continual and explicit reference to all of the above throughout the research. The consultant participants stated that the ability of a CEO to understand who they are as a person, where they come from, and the predispositions created by their upbringing and environment, were of significance. Examples of the environmental forces that impacted the development of maturity and self-awareness included the nature of schooling that an individual had experienced, for example, single-sex or co-educational, religious or secular. One female CEO commented:

I feel that I have achieved what I have because I went to an all girls school that set very high expectations ... but this also hindered me at times ... as many of these expectations were all form and no substance ... and when you are in jobs like these then substance is important.

Family background, clubs and groups that an individual had belonged to at different stages in their life were spoken of as contributing to the development of an individual's characteristics and leadership potential. Throughout the study, participants referred to the importance of the CEO having the ability to reflect on these experiences and how they shaped attitudes and behaviours. This awareness was fundamental to the CEO achieving the ability to modify their behaviour and style of leadership, if and when necessary.

One CEO spoke of a selection process for a board appointment that he was being considered for. Each prospective appointee had had to undergo a process of psychometric testing. He spoke of how initially he felt somewhat insulted that someone of his experience had to undergo such an 'invasive process' and profiling. After a period 
of reflection he decided to take part in the process. He made the point that it was not until he had sat on the board that he realised how important the 'fit of personalities' was to effective governance. He referred to the experience as a one of the more 'growing ones' he had experienced in his lengthy career. In a subsequent interview, this incident was revisited. His perception was that the rigour and intensiveness of such a process was one of the more effective development tasks that he had undertaken and that the feedback was provided in a manner that enabled him to learn a great deal about himself. He said he was still in the habit of reflecting back on the findings to guide him in his current CEO role. The former CEOs and board members in the study also made the point that if the CEO's self-awareness was not fully developed, then the ability to adapt their behaviour was hindered, as would be their effectiveness. One example which the researcher observed whilst attending a staff briefing was that a CEO, in order to illustrate a point he was making, acted a comical role in front of his staff, subsequently making the following comment: "I could not do that unless I was comfortable inside my own skin".

Such an observation symbolises the notion of "balance", in the sense that the level of maturity and self-awareness of the individual was balanced in a manner that precluded a CEO becoming arrogant or indulging in self-aggrandisement. This balanced outlook was evident not only in the CEO's work environment, it was apparent in all spheres of their life. A balanced approach was a quality much admired by those who were involved in the study. Often a degree of wonderment was expressed as people spoke of a peer's ability to manage their life in this manner. This included their personal relationships, for example, friendships and marriage. One comment made by a board member that typified those received was: "When I say successful, truly successful, they have this quite holistic approach to their particular job, their organisation, their role, their life". An individual's 
ability to create and sustain strong, long-term committed interpersonal relationships was judged to be an attribute of a mature, self-aware person.

When one non-CEO participant was asked to describe the characteristics of a CEO whom they deemed successful, the word "adult" was used almost instantly. Displays of adult behaviour based on equality and respect were a necessity, as opposed to parent-child relationships based on power and authority. A senior executive search consultant, when reflecting on a CEO that they had just placed in a role, concurred:

... to be an adult ... I really like that, and I think that I would absolutely agree, and reflecting upon when I first met her, she was adult then. She had a personal discipline. That's actually something that's very evident in her.

Demonstrating personal discipline or adult behaviour was perceived as contributing to the creation of positive, inclusive cultures and the forming of trusting reciprocal relationships, illustrated by comments such as "people have to trust you and believe in you ... if they don't then you can not do this job". The observation made by the majority of the participants was that the diverse and dynamic context within which a CEO operates demands this.

The analysis suggests that these changing demands are not only driven by globalisation, they are also driven by generational factors (Generation X versus Generation Y) requiring changes from hierarchical command and control environments to more flexible and autonomous relationships (Hitt, et al., 2002). One comment was quite emphatic about "the young people asking questions and wanting to be part of the decision making process". Hitt et al., (2002) also states that not only have the changing environments necessitated a 
change in the enactment of the $\mathrm{CEO}$ role, however, there are also changing expectations from organisations with regard to employees' behaviour and performance. One person described these changing demands in the following manner:

It is a much more grown-up world and we all have to live in the world and we all have to be self-managing individuals and we all have to live and work together. It's a much more grow- up place to work now ... it is about where we are in terms of our maturity.

Gergen (1971) asserts that in order to reconcile the conflicting messages received from their context, an individual constructs meaning in a way that supports a set of positive core feelings and perceptions of themselves. This, in turn, permits the individual to develop a set of multiple beliefs about whom and what they could become within the CEO role (Gergen, 1991; Markus, 1977).

The concept of balance appeared frequently throughout the analysis in different guises. For example, it was stated that a "balancing act" is required to ensure that the CEO did not succumb to negativity or compromise elements of their essential self when enacting their role. The iterative analysis, described in grounded theory as concurrent theoretical coding lead to a conclusion that in order to prevent role conflict the CEO had to be 'true to themselves'. It was perceived that a CEO with a well-developed sense of maturity and self-identity has a greater ability to balance the conflicting demands as opposed to those who do not. In addition, those participants who had held a board position stressed the importance of the CEO's awareness of how their behaviour is perceived by others. One person who had been involved with CEO leadership over a period of 20 years expressed this: 
The key thing here is you have a self component. If you take away your business acumen and your capability as a businessperson, it is your ability with people that is the key ... business and people, and it is very much to do with yourself.

Markus (1977) contends that an individual's sense of self and their ongoing development assists them to form a cognitive structure (a schema) about themselves (a self-schema) just as they do about any other phenomenon. An individual's self-schema is selfperpetuating. Once it has been developed, there is a tendency for it to be maintained by the individuals preconception of what they are prepared to accept as being true about themselves (Markus, 1977). In attempting to provide an explanation about how his past influenced who he is today, one CEO said:

Any blockages that you may have as a result of experiences that go right back to childhood can leave you not quite an integrated personality as you need to be. This is then reflected in the way you behave, for example, why you can be over controlling or why you cannot trust people.

A common perception or judgement was that effective CEOs possessed an awareness of how their leadership behaviours and style are influenced by forces within their context. As a result, they are better able to respond to the demands of their context. Failure to do so results in a less than effective CEO.

One issue that was mentioned repeatedly was the perceived inability of some CEOs to transfer their leadership successfully between one context and another. One case in point was provided by a CEO participant who spoke of a colleague (A) who had a very short tenure in their new organisation. Previously, A had been a successful CEO and he was recruited for this reason. A's previous organisation had a hierarchical bureaucratic 
culture. The new organisation was a sales-oriented one. The political environment and the industry sector dynamics demanded that the CEO adjust his style of leadership rather than the reverse. The comment made was to the point:

He was jealous of these top-line salespeople making a lot of money because they could ... it's commission driven and they had to be out there doing the business. It was like he didn't want any salesperson earning more than him. He missed the point ... he would look successful if the business was successful ... he didn't want them to be seen as bigger and better as and brighter than him.

When this scenario was raised with other participants, they were all able to recollect similar incidents where a lack of self-awareness prevented an individual from meeting the expectation of their role sender groups. As one CEO explained, "the self-awareness, the knowledge of the self, maturity, and integrity, all combine to provide positive and successful leadership".

The conclusion reached by the participants involved in this phase of the research was that being a successful CEO in one context does not necessarily guarantee success in another. They suggested that a combination of self-awareness, maturity and ego all had to be in balance to ensure the individual could adapt to differing situations and expectations. However, when the discussions turned to leadership development, only one CEO spoke of the inclusion of self-awareness training in their organisation's leadership development programme and that, in that organisation, developing a consciousness of self-awareness and maturity were an integral part of the programme. This development programme was dedicated to providing opportunities for people to explore their own strengths and weaknesses and how their personal self-schemas were developed and how they influence their career choices: 
So we had them work specifically with a trained psychologist in taking them through a journey of self. Where were you? Where are you now? This involved an interview of two hours and then feedback and then doing some one-on-one work to deal with those issues that were holding them back internally.

One successful outcome of this programme was that some participants made the decision not to follow a career in executive leadership. Rather, they chose to focus on a high-level technical or specialist role. This was deemed a successful outcome because an aim of the programme was to ensure an individual's decisions were in keeping with their skills, qualities and intrinsic preferences and enthusiasm. Self reflection and awareness were developed to a level where the individual understood their potential for success in an executive leadership role or they ought to choose an alternative career role.

There was recognition that the development of self-awareness and maturity supports the CEO in projecting a confident image and establishing a positive rapport with people. One non-CEO participant referred to them "warm, cuddly people", who were able to be approached without fear. They could engender respect, yet at the same time, they were firm, and not perceived as "an easy target". Again, the word balance came to the fore. Maturity, self-awareness and an understanding of the expectations of a specific context and the people within it, provided a foundation for this. One CEO, during his last week in his then current organisation, reflected on his tenure with the comment:

So, building that rapport ... I see that as the biggest challenge in the new role ... When people say 'you know you've done a great job and you have been effective', I know I am doing something to help the company out. Now how did that come about? What kind of activities did I do? 
The analysis identified that opportunities to engage in reflective practices do not happen as often as people may think, nor are they a habitual process. One senior CEO provided an indicator of the views of many, when he said during one of the first interviews conducted: "You are making me very reflective and it is good to be able to sit and think about such things". Similar comments were made throughout the research; for example, the following was received during one of the final interviews, "It was good to stop and think about these kinds of issues ... it doesn't happen very often”. These comments were made in direct response to open-ended questions such as: "Why do you think that is?" or "What do you think caused that to happen?" The comment was made by more than one CEO that this was the first time they had taken part in a study that necessitated their stopping and reflecting upon their own feelings and perceptions about the nature of their role. The CEOs commented that they were familiar with survey research or studies focussing upon the business operations of the firm, but experienced few opportunities to participate in research that focussed upon how they personally felt about their role.

It was noted from the comments that unless a catalyst was provided, reflective practices did not routinely happen. Again, reference was made about the importance of robust feedback processes and the responses received as a result of positive leadership practices enhancing critical reflective practices. One executive coach when speaking of CEOs he worked with stated: "few of them have had the required levels of feedback for them to do their job properly".

Leadership was recognised when it was enacted, and there was a perception that people did respond to positive leadership behaviours which in turn enhanced mutually beneficial 
relationships. One human resources executive, when reflecting on the behaviour of a high-performing effective CEO, commented:

... because if you think about all the things he does ... he's pleasant, he speaks to them, he communicates with them ... leadership and communication, it appears to be a very equal opportunity, egalitarian organisation.

The analysis identified a conviction about the importance of the CEO's ability to communicate and form healthy reciprocal relationships. This was considered, by the interviewees, to be attributable to high levels of maturity, and self-awareness on the part of the CEO, a situation enhanced by the opportunity to engage in reflective practices, for example: "taking the time to sit and have a coffee with someone and bounce ideas off them" or "need to go for a walk around the block so that you can think through issues".

In summary, the collective perceptions of the research participants were that an effective CEO demonstrates high levels of maturity and self-awareness, is able to interpret interactions within their environment and can adapt their behaviour accordingly. In addition, a failure to operate in this manner is expected to impact on the ability of an individual to achieve a sufficiently high level of commitment and the self-confidence necessary to ensure the successful enactment of the role. The next section of this chapter examines the outcomes of the coding processes that formed the theme, developing confidence and commitment to the CEO role. 


\section{Developing confidence and commitment to the $\mathrm{CEO}$ role}

This theme includes those factors that contribute to the development of self-confidence and commitment to the role of the CEO. When the CEO participants spoke of colleagues they admired, they talked of their confidence, commitment, positive self-image and the strong interpersonal skills. These characteristics were perceived as being fundamental to a CEO being able to meet the challenges created by complexity within their context. It was accepted that if a person has been ascribed a CEO role, then it is almost certain they already have a degree of self-assurance and tenacity. However, high levels of commitment do not develop automatically. Rather, it is an attribute that develops over time, becoming stronger as the individual gains a deeper appreciation of the realities of the role. For this to be achieved, it is believed that specific learning experiences have to be gained or designed to encourage and refine an individual's commitment to the role. These experiences were specifically designed to foster the individual's sense of identity, self-confidence and commitment and were delivered as part of the formalised programmes referred to earlier. One example provided was:

And each morning we spent time together, the whole concept of the programme was if you were a chief executive ... you need to look like one and you need to act like one. And what does maturity look like, what does confidence look like? What techniques do you use? ... When you made a speech he talked to you about where you took your breaths and so on and so forth.

The rationale behind these activities was the development of an individual's awareness of his or her own strengths and weaknesses, assisting him or her as a CEO to overcome their insecurities about essential features of their role. The phrase used to describe these experiences was that: "they felt the part": 
Being a chief executive meant that there was somehow magic to that ... it's going to sound a bit pathetic when I say it, but if you went into a room you're somehow part of the magic of being a leader. People respected you, they looked at you, you were confident, you were well dressed, you carried yourself with style, you were appropriate in your behaviour and you were a positive sort of person.

It was stressed by research participants that it was important these experiences occurred within a short period of time of an individual commencing their executive leadership career. It was considered equally important that these experiences take place in unthreatening environments if the development of self-confidence was to be achieved. The aim was to 'ease the pressure', thereby, allowing the CEO to concentrate more effectively on other leadership tasks and to do so with a greater degree of self-assurance. The CEOs who had the benefit of the constructive feedback, as a result, were adamant that they were extremely effective in assisting the development of self-confidence. These experiences were tough and often "one's ego was truly kept in check". The CEO who made this comment then went on to discuss the importance of being able to reflect and critically examine "one's own strengths and weaknesses":

So it was quite tough. It sounds gentle, but it was quite a rough process in some ways, to go through. Because you really had to look hard at yourself and what the things were that held you back.

People who had participated in these "tough" constructive feedback sessions described them as fundamental to enhancing their ability to rationalise the personal nature of many of the negative messages, tensions and paradoxes they experienced. Rather than viewing tensions as constraints, they had become an indispensable feature of their development process, and they were viewed as a challenge to be relished. 
Just as maturity and self-awareness are considered important to the effective enactment of CEO leadership, so are tenacity, confidence, and commitment. The CEO participants who had benefited from developmental experiences, such as those outlined spoke of how their commitment to the role was enhanced as a result. The reflective practices and feedback were deemed to build the individual's commitment, a love of the role, and to develop an excitement for business. The notion of balance, again, surfaced as a concept and it was deemed important that the drive, commitment and self-schema were all in balance. As described by one CEO: “And for me that was about confidence, building my confidence and my understanding so I could be tough and warm at the same time”.

There was a consensus that effective chief executives should have strong personalities, and that an individual should not be appointed to a CEO role if they did not. The CEOs taking part in this study acknowledged the need for this attribute to be present within him or her self. However, for the CEO to be effective in their role, it was recognised that all of their personal characteristics had to be in balance so that their drive or self-interest did not dominate. This applied also to their relationships with others. Explaining how this balance manifested itself, one non-CEO participant observed:

I think of these people, and he [a prominent CEO] never came across to me as the sort of a person who was there only for ego or power or position; it was just that he wanted to make a difference.

The desire to make a difference was approached with zeal and all the participants referred to it at some point in the study. For an individual "to make a difference" it was 
acknowledged they should possess high levels of business acumen, and be motivated and committed:

Self-motivation, you've got to have that. But if you think about it, if you're motivated to learn, then you have the right attitude. The most important thing in any outfit is to have people with the right attitude. You lead the world doing that.

The desire to make a difference developed from commitment, a positive, can-do attitude, and high levels of self-esteem. The participants were emphatic that this did not imply an individual was "feeding the ego" or arrogant. Feeding the ego was seen as a manifestation of pride and the desire for self-aggrandisement, rather than a commitment to the CEO role.

The desire to make a difference also extended to activities outside their organisation, perhaps spending time in voluntary activities or using their skills for charitable purposes, for example, board membership of non-profit organisations or community boards. Others were involved in mentoring young people, both in the business arena, and in the community. It is noteworthy to state that every person involved in the study utilised their skills and expertise to assist community organisations and charitable causes. While they all expressed a desire to have a greater level of involvement in activities of this nature, there was an acceptance that time constraints precluded it. The sense of responsibility and desire to "give something back" was considered to have sprung from an understanding of how fortunate they were being able to contribute in this manner. Much of this effort was unseen, and was undertaken without fanfare or public acknowledgement. Whilst there was recognition the high-profile activities of some 
CEOs were appropriately acknowledged, there was awareness that other CEOs were doing "equally good work", albeit in a less visible manner.

The CEOs spoke of how vital community links and commitments were and that they had to be maintained in spite of how busy a person was. The relationships that developed from such activities were considered to be highly reciprocal as the CEO was able to "give something back", and the ongoing positive feedback and learning experiences provided the incentive for the CEO "to keep going" when the "going got rough". One comment made by an executive team member about their CEO during an informal interview was:

I mean he's been quite open with his family's interests and people can sort of identify with him as he seems very much a family man that cares about people in New Zealand. He's very passionate about New Zealand, that's another key thing with him. Very, very keen in the community, so supportive of anything that is happening in New Zealand.

It was deemed important that the enthusiasm for people, the commitment to their wellbeing and the sense of responsibility was not manifested in a negatively patronising manner. Rather, it was considered important that relationships materialized as supportive, team-focused adult relationships. All the CEOs spoke of how important people are to an organisation, as illustrated by the following comment:

My view is that the three greatest attributes a company has are people, people, and people. I think that depending on your people is the best way to achieve the goals; I mean it's a case of "we" rather than "me". 
The first line of this quote alludes to a Māori proverb (it is people, people people). This was not the only time that a study participant used this phrase in their quest to explain how important people are to their success ${ }^{2}$

The importance of people and the awareness of the role they play, and of their abilities, was considered an essential factor in every CEO role as stated by all the respondents. One statement made by a CEO when she was reflecting on her role, the importance of people, and the need for the CEO to have a visionary perspective, was as follows:

The biggest thing I learnt is that I don't actually know much at all and as the CEO I'm really just conducting the orchestra. As a leader I provide a vision and I conduct the orchestra and all of these people playing the instruments are the experts, not me. I couldn't do a lot of these jobs, I just couldn't do them and I wouldn't even try to. But I can ask them the questions and look at the results and say "You're sure you are going to get the right outcomes from this, given that?

All the CEOs professed a strong commitment to their organisations, their employees, the wider environment, their family, and most importantly to his or her own integrity. Commitment was viewed as a fundamental attribute if the CEO is to meet and overcome the challenges that the role presents. The love of challenge was identified during the analysis as evolving from the theme, the development of confidence and commitment. The next section of this chapter provides a discussion of the theme the love of challenge. 


\section{The CEO role and the passion for challenge}

The elements of this theme are embedded in the simple statement that the CEO must love challenge. The strength of conviction conveyed in the emphatic expressions of the participants' about the importance of challenge. If challenge is defined as "a demanding task or situation" (Pearsall, 1999), then it is evident from the comments made throughout the research that everyone flourished in challenging situations, and these resulted in a high sense of achievement and levels of activity. The grounded theory analysis process known as theoretical coding identified that if, there was neither a passion for, nor an ability to rise and meet a challenge, the individual became conflicted and did not thrive within the CEO role. The passion for challenge was equated with the ability to engage in calculated risk oriented behaviour, summarised as follows: "I always say to them you need to take risks, take risks in your jobs, and the organisation should take risks and in fact a leader will do that".

To be able to drive the organisation forward, and to identify and assess challenging situations and meet them "head on" was considered fundamental. Inherent in this theme was the combination of the love of challenge and the desire and ability to drive change. There was an acknowledgement by the CEOs that sometimes the resultant decisions may lead to a degree of unpopularity for them, but that despite this, they had to ensure the long-term viability of the organisation:

Leaders aren't perfect. They won't always be people who can tie up all the ends and so they might piss some people off, but in the end they'll be up there moving the organisation forward and you've got to find the sorts of people who have got the ability to do that. 
When combined with the characteristics discussed earlier in this chapter, the CEO's love of challenge supported his or her ability to take the risks required by the role. The ability to translate these characteristics into behaviours that met the expectations of all the role senders and move the organisation forward was expressed by one CEO as:

Freeing up the organisation ... that is a key skill for a CEO and I think that is what is so critically important in this environment ... managing the board, managing the external stakeholders, that whole quality of communication, ability to sell the organisation.

It was recognised that the challenges resulting from complexity and change required high energy levels and a spirit of "can do". This was regarded as essential for success in the CEO role. However, the importance of managing the response to challenge for the individual not to appear to be aggressive or overbearing was also deemed to be important. The notion of balance again appeared as a key concept. In order to achieve such balance, it was stated again that appropriate developmental activities, constructive feedback, and appropriate role models and mentors had to be available to the CEO on an ongoing basis.

One example of the importance of challenge and challenging tasks was to the CEO was expressed in terms of the individual's ability to communicate in a multiplicity of situations. The challenge was to develop their interpersonal skills to an exceptionally high level, to understand their audience and to modify their inherent behaviours, as and when required. While enthusiasm and the ability to communicate are viewed as important, so is the ability to moderate one's behaviour in such a manner that people are able to work together for organisational success. 
A good CEO can free up a culture to become a 'can do' culture, and that's not easy, because people are basically cynics and they say "Show me and I'll believe you", and so you have to show a consistency of approach, but at the same time ensure everyone hears the same message.

The challenge to communicate effectively, and to develop strong interpersonal relationships, was another attribute that was perceived as essential for an individual to be effective in the role. The passion for challenge manifested itself in a variety of ways, including CEOs using their skills to mentor and guide young, talented, prospective CEOs:

I am working with a young fellow at the moment ... this guy has got energy to burn ...he obviously comes from a very strong family ... he's comfortable about that ... we have this idea of what it's like to be young and aggressive and he's right in your face, yet he's got an empathetic and caring feel about him ... bring that out ... make him less aggressive, having more empathy, learning, that on the way through becomes very powerful.

The ability to gain and maintain trust was considered fundamental to sustaining effective relationships, a challenge that was relished by all those involved in the study. The interviewees were aware that trusting, reciprocal relationships will only develop if the CEO demonstrates behaviours that engender trust. That is, the CEO must possess and display ethical and moral behaviour in a manner that enhances the reputational capital of the organisation. However, these expectations are not only applicable to individual relationships; they also include the varied networks that the CEO is part of. The next section of this chapter examines the properties of the theme, the importance of reputational capital. 


\section{The importance of reputational capital}

It has been claimed that the reputational capital of an organisation can be enhanced or diminished by the behaviour of the CEO and how they exhibit and respond to the need for behavioural complexity (Petrick, Scherer, Brodzinski, Quinn, \& Ainina, 1999). The ability of a leader to balance complex and competing demands at consistently high levels has been proven to enhance organisational success (Hart \& Quinn, 1993). Building on and complementing the discussion in other themes, this subsection discusses the importance of reputational capital, in particular, the importance of the CEO displaying ethical and values-based behaviours relevant to both the local and global contexts. The data analysis identified that the personal values of a CEO must be clear, consistent, unambiguous, and perceived as being of the highest standard. Uncompromising statements were made about the importance of values-based frameworks being evident in all aspects of the CEOs life, not just in business, this extended to their family and community life. There were equally adamant views expressed relating to the CEO's aversion to encountering situations where they were expected to lower their ethical standards. If an organisation or industry sector was perceived not to possess a high level ethical reputation or to exhibit appropriate ethical standards of behaviour, then a consequence, as stated by the participants, would be an inability to attract and retain capable people within the CEO role. At an individual level, such situations would include the CEO having demands made of them by shareholders, or government agencies or the board, that they felt compromised their integrity.

It was noted with some pride that New Zealand, as a country and as a business community, has a reputation for being one of the least corrupt in the world, a reputation 
that has acted to enhance the motivation and commitment of the CEOs who took part in this study and how they conducted themselves in the role. This consciousness was evident throughout the study. One CEO described it as follows:

I think that clarity about objectives and having an internal framework or an ethical framework or a business model that can underpin decision making .... What is your framework for dealing with people in an organisation or in a business sense?

The presence of values-based behaviours was deemed relevant to the effective discharge of the governance and CEO functions. A common view was that the reputation of an organisation should not be subject to compromise, by anyone at any level of the organisation. This uncompromising view was voiced throughout the study. It was acknowledged that historical actions, especially those prior to and during the 1987 share market crash, have resulted in considerable "bad press". There was a sense of bemusement on the part of some of the CEOs about the long memories of different groups. This was identified as one of the negative features of operating in a small business environment. In response to questions designed to ascertain if the situation had changed, and if not, why not, the following comment, by an individual who was an exCEO and now a board-chair, outlined the changes that have transpired as a result of this bad press:

Well, we have transparency now and I think the situation is as good as it could be ... and the work being done in this area should be applauded. Boards in New Zealand the good thing about them compared with, say, the American model, is that generally the CEO is not the chair of the board and that's a model the Americans have found hasn't worked for them, of course, with the scandals they have had. 
The current model or perspectives for governance is believed to have enhanced the transparency and accountability of boards and CEOs in large organisations. Whilst it is recognised that when operating in a small environment, an advantage of the de-facto scrutiny is that it can serve to keep "people honest", an intense dislike of personal scrutiny and its destructive effects was expressed. The participants hold a view that the scrutiny must focus on governance, business and business operations and not degenerate to being a vehicle for personal attacks.

The analysis identified the view that a superior reputation enhances an organisation's ability to attract people to that organisation. Reputations, both bad and good, were considered to travel "a long way" and that a negative reputation could be detrimental to the long term health of the organisation. Reputational capital was stated as being fundamental to the ability to recruit staff, a view expressed by an HR executive in the following manner:

So the organisation has a great deal of mana ${ }^{3}$, people want to come and work for us, people also want to come and work for (the CEO), so we've gone out to the market several times for fairly senior roles ... and we got emails, a lot of them saying how they'd read so much of what (the CEO) had done, they'd heard so much about him and they really wanted to work for him.

A CEO with mana was identified as one of the key factors in an organisation's ability to attract and retain competent staff, as the following statement indicates:

3 "Mana" is a Māori word difficult to translate directly into English but is a means of conveying notions of integrity, charisma and prestige. 
Even recruiting a new executive assistant for him recently we had people lining up saying they'd done a great deal of digging and found out what sort of person he was and they wanted to work for him as a person, as well as the organisation, so that's very important.

Reputational capital at both the personal and organisational levels was deemed a positive feature, not only during recruitment campaigns and selection processes, it was also identified as assisting in the retention of skilled employees. The opportunity to work for a company with a high level of mana was identified as an attractor that could be used by New Zealand organisations to overcome the limitations imposed by the inability to remunerate CEOs at globally competitive levels. The word integrity was often used to describe an essential CEO attribute. High levels of integrity were deemed to be displayed by all those CEOs considered to be effective in their role. The comment made by one board chair explained it in the following manner:

If you look at $A A$ and you look at $B B$, for me they would absolutely fall into the integrity camp ... it is about the authenticity of what they're doing. I think that's another interesting word. And they're very authentic with themselves ... and with what's happening around them. They're not interested in whether people like them or like what they're doing, so image isn't a driver, it may well be present, but it's not driving them.

Authenticity was also fundamental to the development of strong, trusting interpersonal relationships that are deemed important for effective leadership. If the individual was not authentic, then establishing trusting interpersonal relationship were not supposed possible. As discussed earlier in this chapter, the notion of balance is considered critical. Authenticity and persona had to be balanced. One HR Executive spoke of their organisation's purported high reputation in both New Zealand and internationally and referred to it as brand management: 
Even HR is responsible for brand management and I say that to a lot of HR people and they look at me blankly. So how do you see brand management as an HR function? What sort of people do we want to recruit? What sort of people do our customers want to do business with, and people often miss that link.

The need for all peoples and areas of the organisation to actively take responsibility for the ethical reputation of the organisation was commonly recognised by the participants. However, it was accepted that if the CEO did not lead the quest for "sound ethical leadership", then the likelihood of any such quest permeating further through the organisation was negligible. Reflecting on those organisations that received "mixed reviews" about their reputation, the participants identified situations where the CEO had not ensured that the importance of integrity, and where values-based ethical behaviour had not been accepted throughout all areas of the organisation. There was a common view expressed amongst the interviewees that the failure to act appropriately, for example, during product recalls, or crisis situations would ultimately rebound on the organisation. A CEO's behaviour and his or her expectations of their staff were thought to underpin all aspects of an organisation's reputation. However, organisational reputation was also considered to be closely linked to country reputation. It was a common view that the smallness of the New Zealand business environment would not only give rise to a higher degree of scrutiny but would also make more readily visible any inappropriate behaviour. The CEOs spoke of the importance of everyone taking responsibility to ensure their organisation's and the country's reputations were not compromised. This was a priority even if:

... it does jeopardise the profitability of New Zealand business. It is important because New Zealand is a very ethical country. There is no corruption here and we want to make sure that remains. So in this environment it's really important that the world sees that 
public accountability ... So I wouldn't count it as extremism on either side in this particular area because I think it's important that you safeguard your national ethics and reputation.

It was accepted that behaving ethically and appropriately may result in a less than desirable profit in the short-term. However, a "catch-22" situation was identified. The perception being that if a CEO seeks to maximise profit, (in line with stakeholder expectations), then this may mean they must behave in a manner that compromises their own personal ethical standards. Furthermore, if it is discovered they have acted unethically to ensure profitability, the CEO faces the possibility of criticism, fines and possibly even imprisonment. Yet if the organisation's profitability is less than that expected by the stakeholders, the CEO's tenure may be very short. Indeed, one comment suggested that pressures facing boards were readily transferred to senior managers: "lowered profitability, even if there is a valid reason and the board is having political pressure put on it", implying that it was important that profitability standards were maintained. It is believed that such dilemmas necessitate the CEO possesses high levels of maturity, self-awareness, commitment if he or she is to be effective. The ability to manage stakeholder expectations and to rise above such forces and engage people, create visions and sustain relationships was considered crucial to maintaining long-term corporate success. Successful CEOs were deemed to be those:

... who can engage people, engage in a vision, understand what their role is in the organisation, their objectives in the organisation ... give them the autonomy and empowerment, so they can achieve their potential. 


\section{Conclusion}

This chapter has provided an examination and discussion of the collective notions comprising the sub-themes that to contribute to understanding an individual's motivation to take on or acquire the role of the CEO. In the chapter, the sub-themes are drawn together in a manner that makes it possible to identify their contributions to synthesising the major theme that has been labelled the acquisition of leadership constructs. Figure Eleven provides a diagrammatic summary of the identified themes discussed in this chapter. Here, the researcher notes the following findings as significant aspects of the themes contributing to the acquisition of leadership constructs. It is restated that that the CEO should possess a high level of maturity and self-esteem. In addition, the CEO should have developed self-awareness, self-confidence and have a balanced ego that does not override other facets of the CEO's persona. It is important that all these factors are in balance and are not utilised in a negative sense, but in a positive manner that engenders mana and credibility. In doing so, the CEO would continue to build confidence and knowledge of "who they are as a person", who they are as a CEO, and also the impact of their behaviour on others. Within this major theme, the ability to create visions and be perceived to act in ethical manner while at the same time ensuring the long-term viability of the organisation is considered to be of overriding importance. The enactment of leadership behaviours within the $\mathrm{CEO}$ role is viewed as necessitating high levels of commitment, combined with a love of challenge and the will to succeed. In addition to the sub-themes contained within this chapter, a set of sub-themes that contribute to the formation of institutionalised expectations were identified. The next chapter discusses the sub- themes that comprise the major theme, confronting institutionalised expectations 
Figure 11: A diagrammatic representation of the themes discussed in Chapter Five

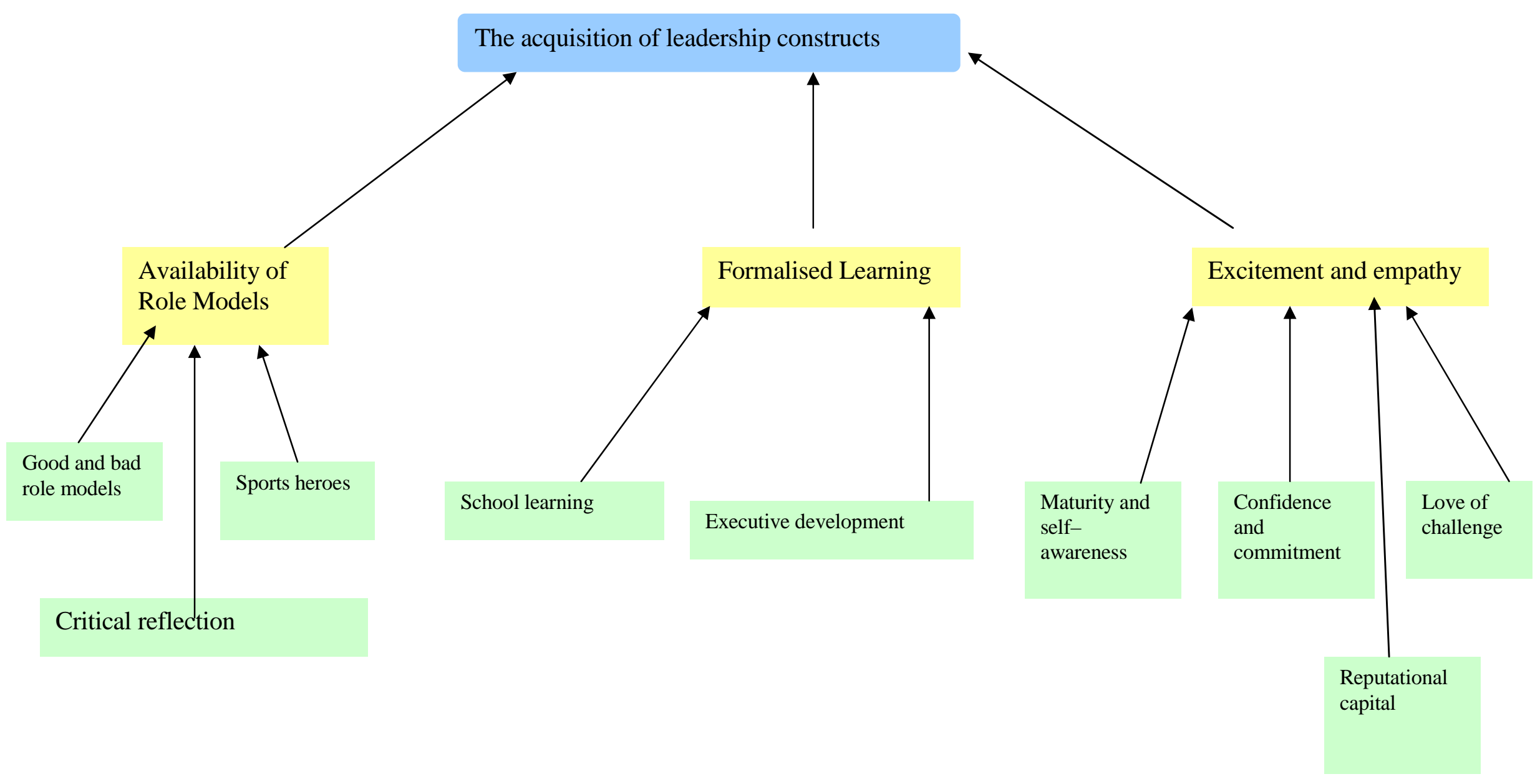




\section{Chapter 6: Confronting institutionalised expectations}

I spent months dealing with our select committee and related matters ... it did not warrant it ... and so there is a huge cost to people within the organisation ... and money has to be diverted to the wrong areas.

A CEO reflection

\section{Introduction}

The purpose of this chapter is to examine the elements that constitute the major theme of confronting institutionalised expectations. Within the context of this study, the word institutionalised is defined "as something that is established as a convention within an organisation or society" (Pearsall, 1999). The research participants perceived the institutionalised expectations as being deeply embedded within New Zealand society and extending beyond the boundaries of the business community. One example provided is the influence of New Zealand's colonial heritage, in particular egalitarianism. This heritage was referred to by the interviewees as having an integral role in forming the perceptions of the CEO role.

The chapter offers an explanation about why a CEO's leadership potential was not always maximised or an individual did not perceive the role of a CEO as a valid career option, or subsequently left the role. The iterative grounded theory coding processes identified three different reactions to the institutionalised expectations. These are as follows:

- The repression of leadership: This theme describes and explains the social structural process that explains the repression of leadership within the CEOs external context. 
- The restriction of leadership: This theme relates to the social structural processes that were identified as placing a restriction on the recognition and development of CEO leadership within the organisation.

- The rejecting of the role by the individual: In contrast to the prior two themes, this rejecting the role is a social psychological process. This describes the reaction of both capable executives and CEOs to the processes, paradoxes and tensions within their context that results in the CEO proactively choosing an alternative career option.

The chapter commences with a discussion of the research participants' perceptions of the role of New Zealand's colonial heritage in structuring the institutionalised expectations of the CEO role. 


\section{The role of New Zealand's colonial heritage}

As the interviews progressed, the researcher sought to ascertain the reasons for the tensions that were spoken of. The semi-structured interview format permitted the researcher to return to topics spoken of previously and use questions designed to elicit more comprehensive explanations. When asked why these tensions occurred, the respondents tended to focus on New Zealand's European colonial history, specifically the egalitarianism and how many of the perceptions of business and executive leadership have their genesis in this period of time. Participants were of the opinion that these historical origins have fashioned the traditions and beliefs that influence the defining of the CEO role and its subsequent enactment even in the twenty-first century. It was considered that this focus has been sustained and further embedded by groups external to the business community, for example, political and media factions. One comment that typified these responses was:

I mean I'm not a historian but if you go back to why people came here. They came to get away from huge differentials in wealth and the class system and it was the land of opportunity, egalitarianism. You know the stories of our child-hood, the perceived belief that if you are making money you are making it at the expense of other people.

The frequency with which the European colonial history was spoken of led me to the comments of Gergen and Gergen (1991, p. 206) who contend that:

"We enter the present with a sack of history slung over our shoulders and this weight shapes our posture ... each of us bring a host of preferences, interests and values that shape the way the present is understood". 
"The sack of history" within the context of this study was identified by the participants as New Zealand's European colonisation process. It was the perception of all participants that a considerable number of the tensions and paradoxes confronting the CEO emanated from this period. The participants were of the opinion that the forces that create these tensions are unique to New Zealand and have a bearing on how organisations are led and business is conducted.

To provide a framework for exploring and describing these perceptions, and using the literature as a guide and mentor (see Chapter Two), Garrison's (1998) “ice-berg model” was utilised to assist in the portrayal of the hidden influences of a business culture. The "ice-berg" model (see Figure 12) is conceptualised in terms of sections labelled as the superstructure, waterline and bedrock. It is the bedrock that has significance for this study. Garrison (1998) argues that the bedrock is developed from the historical, political, economic and religious forces that exist in a society, forces ${ }^{4}$ that are often indiscernible, yet have a deep impact upon a society and its business culture.

4 For the purposes of this study, forces are defined as where a person or thing exerts influence on somebody or something (Pearsall, 1999). 


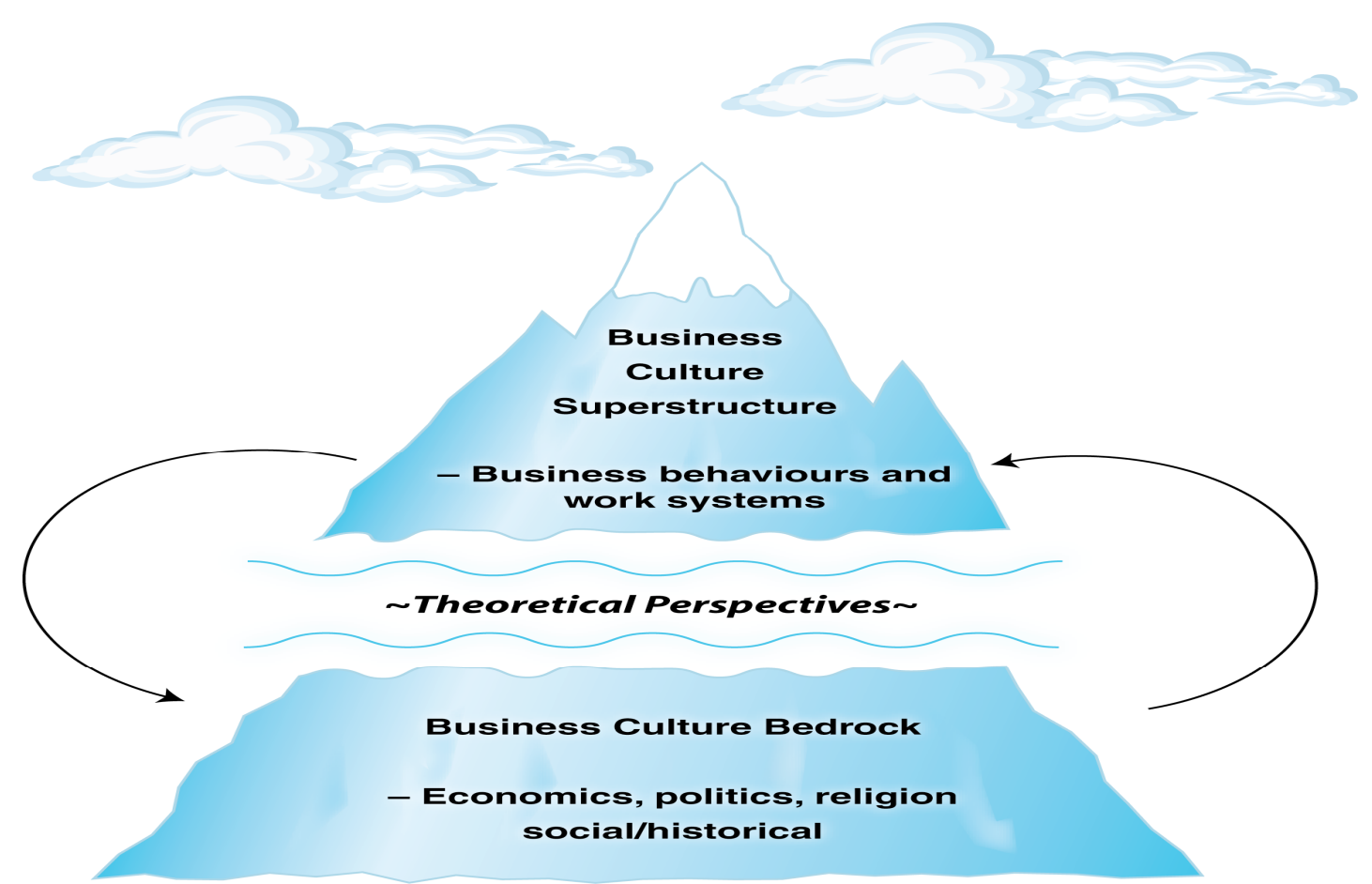

Source: Adapted from Garrison (1998)

Garrison (1998) suggests that the forces contained with the bedrock provide the foundation for a specific role within a specific context, for example that of the CEO. It is the confluence and release of such forces that contributes to the institutionalised expectations that inform the definition and enactment of the CEO role and the acquisition and retention of talented people to the role. Colonialism was not the only identified influence on New Zealand's business culture. However, there was an overwhelming consensus on the part of participants that its legacy is one of the primary forces that shapes the preferences, interests and values of the current business environment. 
Statements made by the more experienced CEOs (10 years plus in the role) highlighted their concern about how negative the perceptions were towards business, wealth and power as a result of this colonial legacy:

The whole working class ethic that has pervaded New Zealand, the reasons why this place was settled during the colonial period, the equity of opportunity - the reasons why the early settlers saw it as a land of opportunity. If you are a self-made man then you have somehow achieved the kiwi dream

It was claimed that the tendency to create heroes and role models from outside the business community, especially the attention paid to sports people and 'self-made men or women', is one result of this. The value ascribed these groups by the media and general public was perceived by the interviewees to be higher than that placed on business leaders. The promoted reason for this is that sports heroes and the self-made individual are perceived to have achieved their wealth as a result of their own abilities, hard work, honest effort or good luck. On the other hand, business people are perceived to attain their wealth "off the backs of others", one participant bemoaning the lack of positive role models and heroes from the business world: "Where are they ... the business heroes. We have sports heroes but heaven help us if a business person makes money or stands out from the crowd". One stated outcome of this negativity was the inability to attract talented people to executive leadership roles. The analysis of the secondary data confirmed these perceptions. One statement headlined in the media as 'Lottery winners gain more respect than business people' was made by the ex-Governor of the Reserve Bank and the then newly opposition finance spokesperson who claimed that "we have no problem with someone winning a million dollars on the lottery". He went on to state that the country had great rugby or netball players but resent anyone earning $\$ 300,000$ before tax, running a 
large business employing hundreds of people (Watkins, 2003, p. B1). This was one of a number of media articles appearing during the period of this research project and was referred to by participants in interviews conducted during the research project.

One CEO spoke fervently about the significance of the negativity generated from these views describing the situation thus:

There is a deep-seated suspicion of business and business leaders in New Zealand. It has its origins in the historical traditions of Kiwi self-reliance. Therefore, there is a deepseated cultural perspective to how we understand the notion of business leadership in New Zealand.

This cultural perspective was stated to be so deeply embedded that despite efforts to portray CEOs in a positive light, a CEO in New Zealand is deemed to be something of a Shylock character, having attained his or her position of power and/or wealth through business activities in a manner that exploits others. One comment that illustrates those that were received during the research was as follows:

Supposedly, if you're making money you're making it at the expense of other people. My world view of this attitude is that it is not correct. I think that we have got an opportunity in New Zealand to generate more wealth.

When asked why these attitudes prevail, the responses identified that rather than dissipating with time, they have been sustained by the continuous waves of working class immigration to New Zealand that have occurred since the initial European colonisation. One example provided was that of the refugees from Europe (as occurred after World War II), and the Pacific Island peoples, who found work in unskilled occupations in urban 
areas contributed to "cementing the attitudes in place", the consensus being that there is little hope of these attitudes changing in the medium term, if ever.

However, the egalitarian preferences were accepted by the respondents as having positive features. It was also accepted that these positive features have to be retained as they did assist in ensuring the development of capable business people in what is deemed to be a resource poor context. One example continually provided throughout the study was access to education. In New Zealand, all sectors of society were perceived to have equity of access to educational opportunity, a situation that may not occur in more stratified societies. The egalitarian premise that underpins government policies is seen as a factor ensuring equal access to health, education and welfare services. One CEO who had international experience extending over some 20 years made the following comment:

It is not as easy for poor people to get to university; you know that from the statistics, but it's not impossible. When they do get there they are sitting right alongside the kids from the rich homes. If you get your qualifications and you're on the job market, then you get work etc ... you don't have to be fabulously wealthy ... you can get into decision-making channels in New Zealand which I think is good.

However, this equity of access was outweighed by other factors within New Zealand. Throughout the study, every interview, on at least one occasion, contained reference to the tensions imposed as a result of the tall poppy syndrome. The next section of this chapter provides a definition and discussion of this syndrome and its impact on the CEO role. 
The tall poppy syndrome

One theme that was identified as a result of the data analysis, early in the coding process, was reference to the tall poppy syndrome. The discussions centred on the powerful informal social tensions that this syndrome caused. The tall poppy syndrome is perceived as a uniquely Australian and New Zealand term (Feather, 1994a). A tall poppy is defined in the Oxford Dictionary of New Zealand as a "person who has achieved conspicuous success" (Mouly \& Sankaran, 2000).

The phrase to "cut down the tall poppy" means to criticise or publicly denigrate those who stand out from the crowd (Mouly \& Sankaran, 2000) ${ }^{5}$. While the tall poppy syndrome is circulated as a uniquely Australasian phenomenon, other cultures have their terms to define those who are highly visible, such as:

\section{The nail that sticks out must \\ be hammered flat}

\section{(Japanese proverb)}

\footnotetext{
5 A web search via the Google search engine revealed 24,700 sources of primarily anecdotal information; while a Proquest business database search at Victoria University of Wellington provided 14 citations. This list was reduced to only one citation when the search was confined to purely scholarly journals. These findings mirrored those of Mouly \& Sankaran (2000), whose search via the Expanded Social Sciences, Art \& Humanities database at the University of Auckland revealed only one relevant reference, an article published in a New Zealand practitioner magazine. The level of empirical research examining the topic is almost non-existent.
} 
The analysis identified that the term tall poppy syndrome had a wider application than solely to people who were high achievers or had achieved conspicuous success. Within the context of this research, the term was used by the interviewees to refer to a phenomenon deemed to be deeply embedded within New Zealand society. The participants perceived its manifestations to be a set of constraining forces not only impacting the acquisition of talented individuals to the CEO role but also on those individuals who ultimately enact the role.

Mouly \& Sankaran (2002) developed a 2 x 2 framework conceptualising the tall poppy syndrome, showing how it operates within organisations to influence performance appraisals and peer-rating systems, and also the role it plays in workplace envy. While Mouly \& Sankaran's (2002) work examined the role of the tall poppy syndrome within organisations, this thesis identified that participants recognize it occurring within their external context as well. The cutting down of the tall poppy was observed as one of the key constraints on high-profile risk-styled leadership behaviours. Individuals who achieved notoriety by raising their heads above the general populace were certain to attract scrutiny from groups, albeit of a negative nature, outside the organisation.

The New Zealand-born CEOs commented that they learnt at an early age that it is not appropriate to draw attention to oneself in a manner that may be construed as standing out from the crowd. Two recent migrant CEOs commented that one of the first things they noted was how deeply the egalitarian principles were embedded, and also their impact on all facets of New Zealand life. A similar but differently expressed comment from a New Zealand-born CEO, with top-level, diverse international experience, referred to New 
Zealand as being: a culture where it is NOT OK to stand out; it is important to be the same as everyone.

The tall poppy syndrome is perceived as creating a moderating and constraining influence upon CEO leadership behaviours, specifically high profile risk behaviours. However, it was recognised that it was not solely the tall poppy syndrome; there was something more pervasive as suggested by a CEO participant who had experienced negative publicity in the immediate past:

The tall poppy syndrome thing is an over simplistic way of describing what happens in New Zealand. It's not because the tall poppies are higher, there's quite a lot more involved. Yes, we do criticise and we do pull down but, there is more to it, much more.

When asked to explain further, he was unable to expand. Whilst this CEO could not provide further explanatory comment, when asked, nevertheless, support for this view was evident in the comments of others:

I think we have to somehow get over this tall poppy syndrome ... it's a real problem in New Zealand ... I think there is a cultural thing as well.

The participants spoke of forces, other than the tall poppy syndrome, that were present but remained at a loss to identify and explain exactly what these forces were. One comment made with a degree of irritation was: "There is something deeply embedded and inherent in society ... it is not just because of the tall poppy syndrome that a person is criticised or pulled down”. 
Paradoxically, whilst some interviewees complained about the tall poppy syndrome they were also critical of their colleagues whom they considered did not 'play the game' of avoiding attention. One $\mathrm{CEO}$, reflecting on the negative scrutiny being received by some of her colleagues, made the following comment: “Oh well, there's the tall poppy syndrome ... some of them have brought it on themselves", echoing similar comments made by others. The perception of the interviewees is that it was the responsibility of the CEO to manage the tensions within their context more effectively. Failure to do so was a result of: "standing out from the crowd... only having themselves to blame".

One CEO [A] spoke of his predecessor [B], who had deliberately maintained a high public profile, commenting "he has an element of ego and love of the limelight". These characteristics were acknowledged as integral to that individual's personality and manifested themselves in a positive manner. However, a major concern for A was that his personal life had come under public scrutiny as a result, something neither he nor his family wanted. Exploring this issue further, it became evident that a high level of maturity and self-awareness enabled A to cope with the situation. However, he acknowledged that 'coping' took considerable time and energy to manage effectively.

Reference to the tall poppy syndrome was evident across all the industry sectors in the study. However, the public sector CEOs considered they had less latitude for discretion (Finkelstein \& Hambrick, 1996) in becoming conspicuous or "standing above the crowd". They reported a greater degree of scrutiny and condemnation, should they not conform to the expectations of their stakeholder groups. The interviewees said the dynamics created by the tall poppy syndrome had the ability to adversely impact on an organisation's ability to conduct business, to recruit high potential executives, and to 
develop and nurture executive talent within those organisations. Capable individuals were often reluctant to acquire leadership roles, instead, choosing alternative career options. One CEO commented on the number of younger executives who preferred to remain in a third tier role: "They have decided that it is much less stressful and they can maintain a quality of life-style without putting their heads above the parapet”.

The long-term effect of the "tall poppy syndrome" was judged to be so insidious that the consensus view was that a major change in societal attitudes is necessary if talented people are to be accepted for whom they are and appropriately supported. The analysis identified a consensus that this was a pre-requisite if the nation as a whole, and the business community specifically, are to realise the potential of capable people and create a thriving business community. There was concern expressed by more experienced CEOs that New Zealand was "stuck in the middle", a situation that constrained the development of successful CEOs, as one participant explained:

I think we're beyond the egalitarian stage now and we can do one of two things. We can adopt “everyone's equal attitude', put up the trade barriers, and become an isolated little pocket in the Pacific Ocean, or we have to get real and embrace globalisation. We're sort of between the two of them at present.

When discussing the prevalence of the tall poppy syndrome, interviewees stated its presence was felt early in their lives and would never leave. They also acknowledged that it was an issue that was difficult to deal with. In addition to the tall poppy syndrome, a second phenomenon, identified early in the coding processes, was the relationship between $N o 8$ fencing wire and the CEO role. 


\section{The relationship between "No 8 fencing wire" and the $\mathrm{CEO}$ role}

Analysis employing the grounded theory theoretical coding processes identified the perception within New Zealand that there is an affinity for ingenuity and improvisation. It is a concept widely referred to as the No 8 fencing wire mentality. Having its origins in the colonial period, the No 8 fencing wire was used to construct fencing on New Zealand farms and then put to a multitude of other uses. In the twenty-first century, No 8 wire has become a catch phrase for ingenuity, self-sufficiency and adaptability (Jones, 2001). In a similar manner to the tall poppy syndrome, the No 8 fencing wire mentality has become a clichéd explanation for particular features of managerial behaviour: For example, "oh it's the No 8 wire mentality" was a line used frequently when the participants were asked a 'why' question' during this part of the interview process .

Within the business environment, the No 8 fencing wire mentality manifests itself as an emphasis being placed on the ability to improvise and use whatever resources are available to ensure a job is completed or a piece of machinery made to work. While this phenomenon was spoken of with fondness as the skills attributed to it are valued, concern was expressed that other qualities have to be developed and valued, too, if specialist CEO leadership potential is to be realised. This was succinctly summarised by one person as:

The other thing is recognising leadership. People aren't actually recognising leadership ... it is the management versus leadership debate that has been around for year., However, we also have the technical competence, like the No 8 fencing wire, and there is still a great deal of it in most organisations and there are a large number of people promoted on that No 8 fencing wire basis. 
It is the perception of the research participants that phenomena such as the No 8 fencing wire mentality and the tall poppy syndrome have strengthened the institutionalised expectations of the CEO role. Jones (2001) contends that the No 8 fencing wire, has taken on a somewhat mythological presence in different spheres of New Zealand life. The presence of the No 8 fencing wire mentality has grown to a level where it has even become the subject of art shows and competitions. There were emphatic cries/pleas to move away from this "colonial attitude" and "No 8 fencing wire mentality" and to "get serious' about developing specialist executive leadership skills.

However, a collective note of caution was sounded by the participants, who were of the opinion that the positive aspects of the No 8 fencing wire should still be treasured, especially those factors that allow people to use their ingenuity and find unique solutions to problems. Interviewees stated that there is a place for New Zealand idiosyncrasies. The interviewees also spoke of the related ability for "the Kiwis" to able to "fit in" easily, and improvise and adapt well when they worked in off-shore organisations. However, there was an equally strong view that there is a need, not only to develop these abilities, skills and competencies to an even higher level, but also to develop a broader perspective that values specialist executive leadership skills.

The prevailing view of those involved, as research participants, is that there has to be a change in conventional-thinking that is away from leadership being framed solely within a traditional managerial structure and by the No 8 fencing wire mentality. The comments identified the view that generalist managerial skills were "great" when we were a pioneering country and that it is also great now, in the sense that New Zealanders tend to be multifunctional. It was suggested that this is why New Zealanders always find work 
overseas; however, it was perceived that generalist skills were not always congruent with the development of specialist CEO leadership expertise:

It's the No. 8 fencing wire and "she'll be right" and I'll just get out there, I've done enough. I mean it's good to have it because it gives you a degree of confidence that you can approach problems, become problem solvers. But it's not sufficient to suddenly get stuck in and charge into problems. But at the same time I wouldn't want to see us get like some societies where everybody is so channelled that they are incapable of doing anything else. I think there is a happy medium.

The words "she'll be right" are stressed in the above quote, as these words were emphasised by the participants as being symptomatic of the constraint on the enactment of executive leadership, as affected by the No 8 fencing wire mentality. The words themselves were used throughout both formal and informal interviews. There was a perception that the quick fix, the "she'll be right" attitude, has evolved out of the No 8 fencing wire mentality, meaning that if an ingenious quick fix can be found, then "she'll be right”. In other words, the participants believed that improvisation, rather than innovation, generated a state of affairs that can obscure the requirement for specialist CEO development. Again the ability to find a balance is posed as paramount.

The participants expressed a degree of conviction that the pride in the No 8 fencing wire mentality had become so entrenched that it was difficult to conceive of a world without it. The images associated with these attitudes were comfortable and non-threatening. Yet, at the same time, it was the cause of considerable frustration. The opinion was that No 8 wire mentality was no longer appropriate, especially if a healthy business community is to be sustained: One CEO commented: 
... because it's a do-it-yourself [No8 fencing wire] mentality, anyone can do anything in New Zealand ... we don't have enough people ... and companies won't pay for expertise in different areas ... same drivers ... it's in the same box as a lot of the other things we've been talking about, it's the do-it-yourself mentality.

To the participants, such mindsets are thought to have a repressive influence on the enactment of CEO leadership and its identification and development. When discussing the power of these two phenomena throughout the interviews, it became apparent many of New Zealand's developmental experiences existed in the light of constraints on situated learning interactions. It is these interactions that support the diffusion of the forces of phenomena of the tall poppy syndrome and the No 8 fencing wire.

\section{The constraints on situated learning}

In contrast to formalised learning which is defined as "institutionally sponsored, classroom-based and highly structured" (Marsick \& Watkins, 2001), situated learning occurs as a result of interactions between an individual, an activity and the context and culture within which it occurs (Lave \& Wenger, 1991). Within the context of this study, situated learning occurred primarily as a result of on-the-job training. Jonassen (1994) defines on-the-job training as learning where an individual participates in genuine and realistic tasks that reflect the realities of their world. While the interviewees identified formal learning as a primary means by which the expectations of a CEO are transmitted, the data analysis suggested that situated learning was the primary means of CEO development. As a result, questions were included in the interviews in an effort to ascertain the level and effectiveness of these situated experiences. Two constraints were 
identified: first, the lack of resources available for intensive situated development programmes, and second, the limited effectiveness of these experiences when they did occur. One non-CEO participant, who was a board member and had been involved in executive leadership development, explained it as follows:

Well, in the corporate world you know the best learning happens on the job. Let's face it. What do they say? The 70/20/10: 70\% of learning happens on the job, 20\% with peers and $10 \%$ on courses ... So if you think about leadership learning on the job, there's a hang of a lot of that goes on. But the question is, the experience goes on but are we learning from it?

This comment sits in contrast with research literature that indicates situated learning is believed to be a highly effective and efficient way to provide contextualised learning experiences. However, as Densten and Gray (2001) contend, for situated learning to be effective, the participants have to practice critical reflection. They go on to state that only by doing so will a situated experience enable the CEO to gain a greater understanding of their environment and make it possible for them to meet the demands of their role. The non-CEO participants acknowledged that the challenge for the development of situated learning is to design learning experiences that support effective learning through critical reflection. However, the data analysis identified that on-the-job training was considered to be ad hoc and task specific as opposed to being role oriented.

An additional element deemed vital to effective situated learning was the ability to provide a diversity of experiences in order for the individual to gain an appreciation of what is appropriate and what is not, what is good and what is bad, with critical reflection being at the nucleus of effective situated learning (Densten \& Gray, 2001). Densten and Gray (2001) state that it is only by critically reflecting on a diversity of people and 
behaviours in an appropriate learning context that an individual can generate a depth of meaning to the situated experience. One CEO summarized this view as follows:

First, size of New Zealand businesses ... If you, as a young person, went in and had some mentors in a larger place and you watched somebody operating ... even if you think, "how bad is that", you tend to see how [it should be done]... The worst leader I ever ran into was my first manager; he did everything wrong. We used to actually sit around and be absolutely bemused about how bad he was. But that was a good lesson ... good and bad is valuable ... people in small businesses do not get an opportunity [to see both perspectives]. The only person they may have run into [encountered] is the owner.

The relative small size of New Zealand organisations was deemed responsible for some of the difficulty in providing sufficiently robust situated learning experiences, which would involve executive leaders being able to experience a diversity of leadership situations, so that their critical reflective practices could be enhanced. If the only form or style of behaviour that is observed is inappropriate, then this is the behaviour they will replicate. One CEO summarised it as follows: “...that is where they get their experiences on how real [inappropriate] leadership is operating ... it starts them off and some of them never recover from that".

One senior executive, who had undertaken roles both as an executive coach and as a board member, expressed the criticality of such modelling in the following manner:

Effective leadership is about those people who learn from experiences, who don't just have them ... they learn from them. Many of us have experiences and we repeat the same thing time and time again because we do not learn from it. Good leaders learn from their experiences, keep learning and keep stretching and keep dropping themselves into stretch environments. 
The consensus among participants was that while situated learning had the opportunity to provide challenging experiences, these experiences needed to be relevant to the context in which the role was situated, if learning is to be maximised. One comment that captured such views was:

So there's lots of experience and dropping you in the deep end, there's a hang of a lot of stretch going on given the external environment ... are we actually stopping and saying well what am I learning from this, what do I need to stop doing, to start doing, that kind of thing ...that tends to be an individual thing rather than a company kind of initiative.

The non-CEO participants spoke of the importance of situated learning experiences being planned, designed, evaluated and relevant to each individual who partakes of them. When reflecting on their own organisation, one executive felt that the organisation had relied too heavily on formalised development in preference to situated learning:

The fact was that we didn't move people fast enough. We didn't think we had to give them accelerated job experiences. We thought more about sending them on a training course. HR people were more involved in designing training courses than they were thinking about how you make job rotation work in a big company like this.

As discussed in the previous chapter, supportive mentors, and role models, are vital to learning the expectations associated with the CEO role. Such individuals and groups can act as a catalyst and stimulus for learning, critical reflection and evaluation. However, the study identified they were not used effectively, if at all. More commonly, people voiced that they were "dropped in at the deep end" and left to flounder, and that often, the enormity of the CEO's mistakes are realised only with the passage of time. The method most commonly used to learn the hows and whys of doing business was the just getting out there and doing it method: 
$A A$ started it first. He went overseas, and then he took BB. BB and I worked together and then I took one of the engineers with me. They sit and listen, and you debrief afterwards and they ask questions and that's how you learn ... it's particularly important in places like Japan that you don't put your foot in it. They give you a sort of second chance but you can't afford to make too many errors. I am not talking about making pricing errors but stepping over the boundaries culturally and understanding that when a Japanese person agrees with you, it might be that" I understand what you are saying, not I accept what you say".

As a result of the above comment, further questions were asked of the participants in an attempt to identify the issues arising from "just getting out and doing it". The view was that the learning period was long and many mistakes were made before, for example, successful contracts with international companies were signed. While the benefits of this experience were passed on to others, it was a slow process. When the researcher asked, how, with the benefit of hindsight, organisations could do things differently, one interviewee stated that the preferred means was an interweaving of situated and formalised learning. He went on to state that he believed that his organisation was no different from many others who were forced into just getting out and doing it as there was no other alternative.

Whereas formal learning experiences provided executives with the theoretical frameworks of executive leadership behaviour, it was considered that situated learning has the potential to provide the practical relevant role experiences. The grounded analysis identified a perception that the education of CEOs should be based on a series of proactive relationships between all parties with a stake in the effective enactment of the CEO role. However, this was not occurring at the level required to ensure future capable CEOs. A point made by one retired CEO in this regard was: 
Yes, absolutely, it's education. I don't think I can stand up there and teach somebody to be a bloody leader; we try ... but we don't educate him or her, nor do they educate themselves.

The concerns of the research participants could be summarised as follows. There is not a co-operative approach to managing the learning of the CEO role. In addition, the ability of some organisations to provide development opportunities for talented people was restricted. However, in co-operation with other groups, there is the potential to ensure an individual could be given opportunities that they normally would not receive. For others, it was ensuring that appropriate feedback and mentoring systems were in place. For one group, it was changing attitudes towards executive leadership, allowing it to be perceived in a more positive light. For yet another, it was ensuring support and constructive feedback. It was evident that success depended on the willingness of various parties to become involved with executive leadership, and to co-operate to provide support and to initiate action when required. A board chair described one situation where an applicant did not have the level of skill required for a CEO role at that time. However, the applicant had strong leadership qualities, and it was considered important that the organisation provide an opportunity for him to develop his skills so he could be effective in the future:

And we interviewed a guy the other day, and to the surprise of the head-hunter person, XXX and I said 'We'd employ him, this fellow; we wouldn't for this job, but we couldn't afford to let this guy go past the door because he had all these very good qualities. But he's a bit raw and would probably be a disaster, but he needs some tuition and mentoring for a couple or three years. 
Identifying and developing those with the potential to undertake a CEO role was deemed imperative. The relative size of the business environment and the resultant lack of resources were seen as constraints for the development of potential CEOs. Despite this:

When gaps open up ... then give them the opportunity, give them a job and they do it. And that's about seeing in people good qualities of intellect, and all that stuff. In many cases they are exhibiting very good leadership in the things they've done.

Indeed, despite the lack of resources, the interviewees believed organisations should be able to ensure that effective situated learning is provided. One strategy judged necessary to ensure an effective learning experience was through the implementation of constructive feedback. The next section of this chapter discusses the role of feedback in developing the institutionalised expectations of the CEO role.

\section{The role of feedback in creating perceptions}

When discussing critical reflective practices and how they can be encouraged, the participants stressed the importance of constructive feedback to the process. However, when the form and structure of feedback mechanisms were discussed more thoroughly, a somewhat pessimistic view of the process surfaced. Observations were made that there was an aversion to the giving and receiving of feedback, and when it was received it was primarily negative. The result of the ongoing negativity was confusion, role ambiguity and role conflict. Often the feedback focussed on personalities, rather than on issues, and it was given by groups and individuals who were judged to be uninformed about the true 
nature of the CEO role. These people often held unclear and contradictory expectations of the CEO as an individual and how they should enact the role.

As discussed in the literature review, there is limited empirical research focussing on the expectations that external role senders have of role incumbents (Bauer \& Simmons 2000). As this research progressed, this lack of knowledge about expectations became evident within the substantive research environment. Participants often spoke of the conflicting feedback they received. Each source of feedback had a seemingly different perspective and set of opinions regarding the enactment of the CEO role. This, in turn, constrained the formation of an effective feedback loop (see Figure 2). There was also comment about the nature of the upbringing of New Zealanders that created an inability and unwillingness to provide constructive feedback:

...in many ways, in that New Zealanders, because of our background, especially somebody like myself who had a balanced great family life, we do not have this ability to actually receive feedback. We were not tough-minded. We take things too personally.

Such factors were identified as creating a self-perpetuating cycle of ineffective feedback. This in turn, was deemed by the respondents, to have implications for all groups in the business environment, not only for CEOs. While the CEOs bemoaned the nature of the feedback received from broader stakeholder groups, they were even more perturbed at the apparent reluctance of those involved in the governance function to partake in productive two-way feedback situations. One such criticism was captured as follows: "Yes they are quite happy to comment about my performance, and I am not just thinking solely about my organisation, but they are not prepared to be part of any open and transparent process regarding performance especially their own”. 
Participants who had held board and CEO appointments expressed concern about the lack of transparency regarding the performance of company directors in New Zealand. The reluctance, and at times outright refusal, of some involved in the governance function to participate in effective performance and feedback systems troubled the CEOs. A CEO who led a large multinational organisation and had been involved in selection processes for board members expressed the view as follows: "I think most boards and, in some cases, CEOs within organisations [are reluctant] to review their own performance and it is almost an embarrassment factor [within this country]".

When feedback was received, it was perceived that the positive constructive elements were absent, effectively hindering the development of the executive competencies required. Formalised performance management systems featured in all the organisations that took part in this study. However, the effectiveness of such programmes was called into question, one ex-CEO and current board chair commenting thus:

They don't have a higher degree of awareness because they haven't had the feedback; they're not used to that sort of feedback. And many of the boards that they work for in this country are not used to working with feedback mechanisms and don't feel comfortable within themselves in giving feedback to CEOs in a constructive manner.

Within a role episode (see Figure 2), the feedback loop is a two-way process. For many CEOs, this process should be constructive and positive, but was perceived as being more critical than constructive, more negative than positive, and largely uni-directional. When reflecting on those CEOs who had experienced difficulties, one executive stated that it was the unwillingness of many senior people to become involved with constructive 
feedback mechanisms that had impeded their personal growth and overall effectiveness within a role:

The issue with many CEOs and senior executives is that they think that coaching and leadership is for somebody else other than him or herself. They believe they have reached their position because of their own brilliance.

The absence of robust feedback mechanisms, both formal and informal, was believed to be one of the major reasons that there was often tension and conflict around the role of the CEO. The CEO participants stated that this in turn created a set of differing expectations and a lack of clarity about CEO performance between the CEO and the board. One participant expressed their view about this lack of clarity in the following manner:

Very clear expectations on the board's part about what they expect of the chief executive, the senior team in the business, and that's consistent around the board table ... and the chief executive is clear about those expectations and the board is also clear about the support, the resources and the expectations that chief executives have of them. So it's about clarity of the relationship and the expectations they each have ... and I think that's where it often breaks down.

The inability of such groups to clearly communicate their expectations in an informed manner was a concern expressed throughout the interviews. Positive, constructive feedback is integral to any learning experience, and was considered to be especially important when executive leadership was involved. It was also recognised that without it, CEO effectiveness may not be maximised, which in turn may hinder organisational success. Within the context of this research study, the majority of the feedback received by CEOs was described as being received from non-stakeholder groups, for example the 
media. The next section of this chapter discusses the research participants' views with regard to the role of the media in the development of perceptions of the CEO role.

\section{Role of the media in developing perceptions}

Chen and Meindl (1991) contend that meaning is constructed through a number of different agents in society, one of these being the media. They go on to state that the mediated images of leadership, specifically those of CEOs, feature more prominently than other images. As a result, these mediated images of the CEO may become the reality for the viewer. Giddens (1991) argues that these socially constructed realities can be experienced by an individual in two ways: first, as external and remote, and second, by way of entering an individual's life and becoming part of the everyday activities of their

life. It is this latter experience that was identified as having relevance for this study. All the participants taking part in this research referred to the role of the media in constructing a set of realities pertaining to the CEO role. While the media is only one of the agents responsible for creating these realities, the participants were emphatic in their statements as to the significance of the role that it played. Of even greater concern to them was the ease with which these mediated constructions become the reality for influential groups, for example, politicians.

Giddens (1991) maintains that mediated experiences act to generate a familiarity that may result in the real object or events having a less concrete existence than its mediated representation. When watching or reading or listening to any form of media, the individual uses schematic thinking to provide a frame within which to situate the 
particular representation. Graber (1986) contends that media representations of CEOs will be interpreted by individuals, who draw upon their own personal schemas or frameworks of knowledge in a manner that will enable them to "fill in gaps" and create meaning from the mediated images they observe (p.250). The perceptions of these mediated images were identified, as a result of the data analysis, to as forming a set of collective constructions about the CEO role. One experienced CEO and board chair was scathing about these media representations, believing they often showed the business leader as dictatorial, as in The Apprentice, or bullying or weak, something of a fool, as in the television programme The Office:

Every time you see a policeman in those Brit things the chief chap is always the halfwit and a bully. The Army bloke's always a halfwit, the bloke running the business, now this is ageing me a bit, The Placemakers, years and years ago, which was the first git [a contemptible person], he was as tough as XXXX [a former well-known prime minister]. Yeah they do, they show them as idiots and there is always somebody below them who is obviously brighter. That is not reality, not reality at all.

The entertainment media were perceived to provide an even less accurate representation of the CEO role than the news media, and the research participants maintained that the objective of such media coverage was sales and revenue. There were frequent wry and cynical reflections that should the everyday reality of the CEO be portrayed, it would not be a profitable venture for the media companies. Reference was made to the situation being exacerbated by how CEOs were portrayed by media that originated in North America and to a lesser extent Europe, these portrayals not fitting comfortably in the New Zealand context. There were angry exclamations such as: "It is sensationalism that sells newspapers; therefore, it is the negative stuff that sells and that's what people want to read". The need to sell newspapers and to make good television contributed to the negative 
images of, for example, CEO leadership behaviour. The consequence of these inaccurate representations was that the mediated portrayal of CEO leadership has entered people's lives and became their reality as opposed to realistic views of the role. Thus, in the participants' view, the true character of the CEO role has been misunderstood, and the realities of the role have become confused and misrepresented.

Review of the secondary data showed conflicting views and representations of business and executive leadership being expressed on an ongoing basis. When positive statements did appear, they were often negated by sensational negative headlines. After the researcher's attention was drawn to these conflicting articles, newspaper archives were searched. As a result, these media reports were discussed during the informal interview process, and the interviewees expressed shared views held regarding the media. Specific mention was made of the public condemnation of executive remuneration, and how such condemnation was viewed as constraining on the recruitment of highly talented people.

The interviewees suggested that one of the consequences of these negative media representations was a lowered morale within the targeted organisation. One person, working in an organisation that had been acclaimed as a great success by the media, spoke of the after-effects of a lower-than-expected financial performance. While there were sound business reasons for the reduced profit, the plaudits very quickly gave way to intense and at times vitriolic scrutiny by the media:

It was hugely damaging in terms of morale. XXX had been held up as kind of a guiding light ... we were a typical university study on organisations that go through high growth, very successful, people are really excited, and then suddenly bang.... It's like being the golden child, then it's almost like being a spoilt brat that suddenly gets reprimanded and realises the world isn't always going to protect it. So all the emotions that went with 
that...we had staff that weren't even going out to parties or drinks or mixing socially, even to spouse's work functions ... because they were just sick to death of getting hammered about what a joke the company was. They got sick of it.

The analysis process conducted as part of the grounded theory method identified the presence of a professed long-term negative impact on the corporate health and ultimately the strategic options available to the organisation. Morale and retention of staff and the attractiveness of the organisation to prospective staff were all put under threat from the negative publicity. Often, the overall "brand image" of the organisation was considered to have suffered, and resources had to be diverted from core business activities to deal with both media attention and the subsequent morale problems within the organisation. This in turn reduced the resources available for organisational development. A typical comment [summarised] was:

When the adverse publicity confronts you, you have to commit a great deal of attention, energy and resources on the people. They get depressed and low morale can reach almost epidemic proportions. Phenomenal amounts of time and energy are needed to get people refocused and re-energised getting them to believe that the organisation can lift its performance again.

The lowered morale was claimed to have contributed to lower productivity, and ultimately to a lowering of business performance that had the potential to result in further negative scrutiny by the media. The manifestation of these forces was the creation of a downward spiral (see Figure 13 on the next page). This spiral was self-perpetuating. One point made by all those involved in the study was that the relative size of the New Zealand business community resulted in higher personal profile, no matter what area of endeavour, and this, in turn, led to increased media scrutiny. The respondents claimed that one consequence is that any anomalous behaviour on the part of a CEO, however 
unintentional or innocent, can result in intense scrutiny and comment, thereby maintaining the downward cycle many people spoke of.

Figure 13: The downward spiral in the media goldfish bowl

\section{Negative Scrutiny from media}

\section{Impacts negatively upon morale}

\section{Causes Negative Performance}

\section{Increases public scrutiny}

\section{Further lowers morale}

\section{Negatively impacts upon corporate performance}

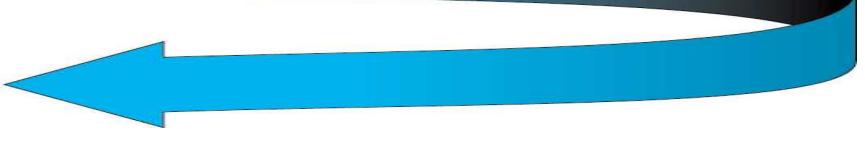


One group identified as being more willing to engage in negative criticism, thereby perpetuating this inward spiralling cycle, were those involved in the political sphere of society. The next section of this chapter examines the role of politicians in developing perceptions of the CEO role.

\section{The influence of political activity on the CEO role}

The ill-informed nature of the commentary received from the political sphere, and also the frequency with which it was received, was a concern expressed by all the participants and was referred to in less than glowing terms. There was an acceptance, on the part of all the public-sector participants, that a Minister of the Crown, who had a responsibility for a portfolio or industry sector, had the right to ask questions, and become involved in dialogue with the CEO, however, the participants' emphasis was on the word dialogue, rather than a public debate or condemnation. The ease with which any personal dialogue was perceived to be lost only to be replaced with public, vitriolic debate caused considerable disquiet. The most damaging consequences were considered to be the negative impact on staff morale and perceived development of constraints on the enactment of the CEO role. The outcome was the formation of a set of forces similar to those outlined in Figure 13 that acted to constrain leadership and suppress healthy business activity.

Comments were made throughout the study about the impact of negative political scrutiny on business and the CEOs personally. An almost symbiotic relationship between the politics and the media was believed to exist, and then to survive, because 
both groups required sensationalism in order to survive - the media to create news and, therefore, maintain revenue, the politicians to gain political profile and to be re-elected. Often, this sensationalism took the form of personal criticism of CEOs and other senior business leaders. The CEOs involved in this research were emphatic that it was virtually impossible for a CEO to become widely known, and/or enact calculated risk behaviours, without incurring some form of comment or attention from the political arena.

Comments focussed on the sensationalism arising from "rumour rather than fact", the small issues that are often "blown up" out of all proportion to their seriousness and "political interference" in business decisions, this in turn focussing unwarranted attention on the business itself. While it was accepted that other groups in society could also be targeted, when business activity was "in the gun", the CEO was the prime target, warranted or not. This created high levels of frustration, and the comments made by the participants were cynical and at times angry.

To the participants, one of the more troubling aspects of this situation was that "parliamentary privilege" was, on occasions, used to support the more vitriolic attacks. This left those named under its terms with no recourse. The CEO interviews suggested that, at times, there were displays of CEO anger at the willingness of parliamentarians to resort to personal attack during parliamentary debate. The view of the CEO participants was that there was a greater tendency for personal attacks during a pre-election period, a time when even the most innocent individuals, as one CEO stated, could become “cannon fodder".

The CEO participants considered that this situation was compounded by the three-year parliamentary term. One CEO complained that in every three year period, he would, if he 
were lucky, have eighteen months where he was not in danger of becoming a political football. His public relations team commenced dealing with issues arising from the political arena approximately 12-18 months out from each election. One participant expressed these concerns in the following manner:

The point is that the politician does not know whether there is definitely the smell of something wrong or there could be a perfectly understandable reason, and so they won't give anyone the benefit of the doubt for whatever reason.

Engaging in a public debate, especially with politicians, was considered inequitable by nature. The emphatic comment made by one person was: "If such a debate should occur, the CEO was bound to lose”. The foundation for the CEOs' belief was the marked difference between the styles of debate in the parliamentary and corporate contexts. This was compounded by the necessity for the CEO to maintain commercial and personal confidentiality, thereby, constraining the individual CEO from responding appropriately. The following comment from a public sector CEO was typical of those that were received: "A technical manager cannot debate with a politician, that's the be all and end all of it”. What he was referring to was the lack of equity in such a debate. He also expressed the feeling that it was inappropriate to air dirty linen in public. Again, he did not dispute the right of a Minister to ask questions, it was the engagement in public 'argy bargee' that he objected to.

Public sector participants spoke more fervently about political scrutiny than those in the private sector. However, the analysis during this phase of the research identified that all the CEOs spoke of experiencing some form of negative scrutiny. Whether it was a direct personal attack, or the media being used to focus on the business, it was believed to be in 
order "for a politician to score points"; in a number of cases criticism of their salary or perceived wealth was experienced. The primary concern expressed related to the overwhelming cost that an organisation was forced to incur in responding to these incidents. Such cost consisted of the following: compliance with freedom of information requests, legal expenses, specialist consultancy fees and associated costs associated in refuting allegations, public relations and communications. There was no way the organisation could avoid these costs. As a result, this restricted the resources available for strategic initiatives, including executive leadership development. When Figure 13 was shown to the participants as part of the theoretical sampling process it elicited the observation that this spiral accelerated when both the media and the political spheres "united as one", until it became "like a whirlpool".

The CEOs were adamant they were not denying the right of politicians to ask questions or to debate issues. It was that the debate had to be based on fact and not conducted for sensationalism, or to score political points. A CEO whose organisation had experienced considerable negative scrutiny, which he termed harassment, made the following comment:

When there are questions of accountability, there is an obligation to ask questions and inquire about it ... there were some questions about the business that had to be asked. And they were asked. So I think that's appropriate whether it's justifying after an event or whatever.

Creating the most concern amongst those taking part in the research was the inability of others to confine the debate to the relevant issue. Frequently, there was the failure "to take a wider view and a readiness to take a cheap shot for political gain". It was when these 
cheap shots were aimed at the CEO, or other senior executives on a personal level, that the most damage was done.

When asked why this happened in the manner it did, people referred to the disadvantages of being a "tall poppy" in a small business environment. "Standing out from the crowd" was deemed to place a CEO in "a glass cage", and thereby constrain how they enact their role. A public sector CEO said that they learned very quickly that it was inappropriate either to draw attention to oneself, or to take calculated risks to ensure a successful business operation. Private sector CEOs were also concerned about the level of personal attack. However, there was a sense of relief displayed and sympathy expressed for their public sector colleagues. The private sector CEOs found it difficult enough dealing with the political environment, let alone having to do it as a CEO from within the public sector. One private sector CEO stated: there is no way I would choose to be in their shoes. It is not about money, it's about the constant interference that stops you doing your job".

The CEOs also spoke of what, at times, was considered an immeasurable impact on their personal life and that of their families. Often their children suffered at school, partners and spouses in their social networks. Situations were identified where CEOs felt that they had no option but to withdraw from the role. Some CEOs spoke of situations where capable individuals who had the potential for executive leadership chose not to take on the role. All the CEOs taking part in the research spoke of instances when a highly talented individual had rejected a CEO or senior executive role. This was regarded as a direct result of the potential for scrutiny and attack. When the CEOs were asked how best to avoid such situations, the answer was to "keep quiet; keep your head down" in order to 
minimise fall-out when it does occur, "and it will". As a result, "keeping the head down" meant CEOs often became publicity-shy, reinforcing other earlier comments about the dearth of appropriate role models, and the conservative risk environment.

The relative smallness of the business environment was again held responsible. The higher level of political involvement in the economy had resulted in legislative changes that, in turn, created an increasingly litigious culture in New Zealand. One non-CEO participant bemoaned the fact that:

We are becoming more like the USA. Policy decisions have resulted in people becoming more litigious and results in businesses trying to address every contingency ... they become more risk-averse and more unwilling to take long-term risks.

The perceptions were that this situation had seemingly deteriorated over the previous 10 years, exacerbated by the short-term political cycle, and the mixed-member proportional (MMP) parliamentary representation system. Both were perceived to encourage shortterm thinking. Thus, it was difficult for a CEO to adopt a long-term perspective to ensure the viability of their organisation.

While both the board chairs and the CEOs agreed that there had to an increasingly speedy response to change, they considered adequate time to respond to and implement government policy to be vital. This was an opinion that was shared by both public and private sector participants. The most difficult challenges arose when organisations had to respond to policy changes that had retrospective elements. It was suggested that the CEOs can be confronted by an ethical dilemma, for example, if they acted to ensure the long-term health of the organisation, they may have to contravene government policy: 
"The rules, for example, all of a sudden, when you've been operating for many years under a set of conventions, they've changed and you struggle ... and it takes time to adapt”.

The CEO participants considered that a consequence of the close political involvement with business was that often a CEO was compelled to assess alternatives from two different political perspectives, and to have strategies in situ that would ensure a successful business, whatever the change in policy direction. For a CEO attempting to focus upon long-term strategic decisions, this was one of the more difficult issues to deal with, and it was often one of the most costly for the organisation. During discussions, a CEO dropped his shoulders and sighed, "I just want to get through the election intact". It was not that there was anything wrong with his organisation, rather that he was concerned that any issue, rumour or innuendo would be pounced upon, and used to make political capital. All those involved in the study stated, at some stage, that no one was immune from the point-scoring that occurs. The grounded theory analysis process identified three themes that explained the reactions to institutionalised expectations. The next section of this chapter provides a discussion of these themes.

\section{Reactions to the institutionalised pressures}

This section of the chapter discusses the social processes that explain the reaction to the forces that were identified as creating the institutionalised pressures. These themes are:

- the repression of leadership

- the restriction of leadership

- the rejecting of leadership. 
The repression and restriction of leadership themes explain the social structural processes present within the research context. The rejecting of leadership is the social psychological process that explains the CEO's response to the repression and restriction of leadership. These three themes are now dealt with in turn.

\section{The repression of leadership}

The analysis identified a set of social structural processes that impacted upon the repression of executive leadership, specifically that of the CEO role. Within the context of this study, repression is defined as "a force that restrains, prevents, inhibits, or suppresses (a thought, feeling or desire) so that it becomes or remains unconscious" (Pearsall, 1999).

When asked to reflect on the issues they had identified, and why they existed, the participants referred to New Zealand's geographic isolation as being partly responsible for this. The opinion was that while the geographic isolation has served the country well, in the past, preventing the country from experiencing the worst excesses of war, colonisation and modern globalisation and limiting migration (Kennedy, 2000), one of the major disadvantages has been the creation of a somewhat insular society. This, in turn, has aided in the creation of repressive social structural processes limiting the enactment of high profile leadership behaviours. One CEO, with extensive global experience, summarised it thus:

I think the huge fundamental is size and distance. We are a small and remote society and if we were in the middle of Europe it would be completely different. If we were in the 
middle of Asia it would be completely different. If we were 20 million people instead of 4 million people it would be different. There's even a difference between Australia and New Zealand and that is relative population, and they have had different migration patterns ... size and remoteness ... if it was one or the other it wouldn't matter but we've got both."

Some suggested this isolation has served to create a business environment that, at significant points in time, is deemed to be "out of touch" with the rest of the world. As one CEO lamented, "New Zealand wants to be part of the world, but it does not know the world". This CEO then went on to clarify his statement, stating that the geographic isolation does not allow 'a true' understanding of the realities and complexities of the global environment to develop.

The CEOs specifically spoke of the gap between the realities presented by a globalised world and the traditional "Kiwi dream" that existed in the "good old days". This world was one where the purpose of benevolent government policies was to ensure the wellbeing of New Zealand citizens and where the "kiwi dream" was made possible by high levels of government regulation and control. This situation is now no longer possible. The participants referred to the freeing up of monetary and trade policies that have resulted in the breaking down of many of the barriers created by distance and regulatory government controls. This rose tinted view of the past was still considered important for a large number of New Zealanders. So much so, that it was used as a focus for one political party's advertising during the 2005 election campaign. Views expressed by the CEO participants were that, at some point, the awareness of the shifting paradigms and the urgency for change had been lost. One succinct comment from a New Zealand born CEO was: 
At some point New Zealanders stopped communication with others in the rest of the world because they didn't like what they heard, so they stopped communicating and they just sort of kept thinking their own things in New Zealand.

There is a view that the geographic insularity has inhibited the development of effective responses to the need for leadership thinking. The danger is that the characteristics required of an effective CEO are not necessarily those that are valued nor developed by the different groups in New Zealand. An example provided by one CEO was how the insularity had imposed a restriction on the ability to listen to opposing viewpoints:

You know you've got to keep communicating and realise you won't always get your own things. So you can have these wonderful, strong, idiosyncratic (and I mean that in the nicest of ways), different, independent views, but you're not going to get it 100 per cent. And so what I don't see is the willingness to compromise and to get the best of both worlds.

Insularity, combined with a preference for egalitarianism (as opposed to meritocracy) is judged to have led to an embedded reluctance to recognise high achievement. One executive spoke of a business trip he had taken to Asia. While there, he had witnessed a very public celebration thanking the health workers who were involved with the SARS health crisis. He made a somewhat cynical observation that a similar event would be highly unlikely to occur in New Zealand, a statement endorsed by other participants in the research. The reluctance to acknowledge high performers was observed as being an embedded, endemic, and complex issue. Effecting change in this area would require a paradigm shift of some magnitude. This phenomenon was also deemed to extend to an ingrained lack of respect for authority, power and position. One CEO who had 
represented New Zealand in international forums on many occasions made the following comment:

The other side of that is that we actually don't acknowledge achievement, and it's interesting how we treat the Prime Minister. While someone may not like, or for that matter dislike, the Prime Minister as a person, the fact is when you're somewhere official the Prime Minister is the Prime Minister".

It was not only the repression of executive leadership behaviours that concerned the participants. The forces that generate this repression are believed to infiltrate many facets of business life. For example, long-term visionary behaviours were stressed as critical. However, the CEOs believed they were being thwarted in this by conflicting forces within their context. This extended to a disquiet regarding the lack of visionary direction at a national level:

At the moment I worry about New Zealand not having a vision. Lack of vision for this country ... if you do not have that vision and you haven't got leaders who consciously enunciate it, take a population with them about what we want to create, this is how we are going to do it ... it will never happen.

Having a short-term perspective was judged to be a hindrance to planning, not only in the business sector, but also, for example in the health and education sectors. A more cohesive relationship between business and the political spheres was deemed essential if long-term visionary thinking is to occur. The issue has its roots in the problem that: "there is no one thinking long term. The politicians and government policy are focusing on the next election in 3years, 18 months, or whenever". 
It was clear from the views that were voiced that the 'rose-tinted spectacles' have to be removed, and that it was time to commence long-term planning for the future. Creating a long-term focus would enhance the prospect for acquiring and retaining capable executive leadership. The social structural processes that create the repression of leadership were identified as being deeply embedded, and that for any improvement to occur, there had to be a dramatic change in the attitudes of all groups, not just the politicians and the media. As one CEO, with experience both in New Zealand and in the United Kingdom, explained:

Maybe it's linked to nineteenth century or even seventeenth century England, when if you were a businessman you were looked down upon basically. There is an element of that, like somehow if you are a businessman and you're making money you are ripping other people off. It's funny really, isn't it? We still don't value (business) people ... however, there's an extraordinary fixation on politicians and sportspeople".

The latter comment was typical of many received throughout the research. The low level of trust and value accorded to business in contrast to that placed on other sectors of the community, resulted in expressions of frustration on the part of the CEOs. When asked how the situation could change, the consensus was that: “... New Zealand culture ... I think we are generally an accommodating bunch and so accommodating someone else doesn't require activity, it requires passivity".

During the theoretical sampling processes, interviewees were asked to reflect on the tall poppy syndrome. These reflections elicited the view that passive and accommodating behaviours fitted more comfortably with the egalitarian mores that encourage people not to "stand out from the crowd". The desire to remain "low profile" was stated to result from an environment where the enactment of high-profile, risk-oriented leadership 
behaviours was actively discouraged. Again, there was mention of the preference for generalist, technical and professional managerial skills as opposed to specialist leadership characteristics. These preferences were considered to have their genesis in the phenomenon the No 8 Fencing wire, discussed earlier, with its emphasis on the individual's ability to use their ingenuity and adaptability to source innovative solutions to issues confronting them.

\section{The repression evolving from a small business environment}

Throughout the discussions, the relative smallness of the of the New Zealand business environment was acknowledged as having an impact on the forming of the perceptions of the CEO role. The consensus of all the participants was that an individual's actions are more easily scrutinised in a small environment and that gossip and innuendo can and do travel a long way rapidly and mistakes become public knowledge quickly and are not easily forgotten and that these events may hinder future career options. The more senior CEOs and all the board chairpersons spoke of how individuals can and will make mistakes in their career; and that they would not be human if they did not. However, it was believed that the New Zealand context has an unforgiving nature and this may result in an individual gaining a reputation that is difficult to "shake loose". The end result is that some individuals are precluded from being appointed to another CEO role. Even if they were successful in being appointed to a role, they were often unable to operate without intense scrutiny and the feeling that everyone was "waiting for you to make another mistake". 
During one interview, a non-CEO participant reported an interaction that they had with a visiting HR Director, from a USA subsidiary. The discussion centred on a possible recruit for an executive leadership role, an individual not personally known to either of them. During the conversation, the participant was able to highlight where this individual had worked, and for whom, and outlined the linkages to a variety of situations and organisations, essentially outlining a work history. The human resources director was bemused and commented that he had found this personal knowledge existed in New Zealand at a level unknown anywhere else in the world. He joked that, in New Zealand, it was not the "six degrees of Kevin Bacon", but rather the three degrees of anyone, anywhere in the country. The research participant's comment when recounting this was as follows:

You have people who have very strong views and because of the size of the country, people know people well. So you can have a polarised view of senior people. So that can be quite a barrier for some of these people to overcome.

Creating a supportive environment where an individual can grow and develop and to learn from mistakes is vital. The current situation creates an environment where even minor mistakes can haunt the CEO for the rest of their career. This has implications for the development of executive leadership talent, a task that was acknowledged as not being accorded a high priority. A comment typical of those received was:

We have done a very poor job in New Zealand on managing talent and succession planning and those related things. So for the country that is a real worry and I do worry because the thing we need more than anything is leadership. But once we get these people into these roles we have to be able to support them and help them to be successful. 
While respondents stated that there has been a recent renaissance in leadership and leadership development, they were firm in their view that this was too little too late to meet the immediate needs. The demands made by the global business environment, and created by technological advances, resulted in leadership development lagging behind the needs and demands for specialist executive leadership characteristics. A CEO who had worked in a diverse range of sectors, and had in-depth knowledge of both large and small organisations, described this as:

... an absolute disaster for New Zealand and comes from that cultural family, we're out here to better ourselves and get rid of the oppression and hostility of the class system. It was great when we were a pioneering country and it's also great now in the sense that New Zealanders tend to be very multifunctional which is why they are always snapped up overseas, but it's not good ... when you're running an organisation and you need expertise.

It was acknowledged by the participants that in every environment, there are issues of context that shape a role, and that every CEO has to work to ensure there is "fit" between them and the role requirements. There was concern expressed throughout this research about the inability of different role sender groups within the specific context to comprehend the diversity of the changes confronting the CEO, and to adapt their expectations accordingly. The result is a shortage of executive leaders, specifically capable CEOs. One CEO voiced it thus:

Yes, the elements of social issues ... there needs to be a broadening of the skill base ... and there aren't that many CEOs just found under trees and things, especially in New Zealand. 
There was an acknowledgement that in order to broaden the skill base, a move away from the strong emphasis on generalist technical skills, and the No. 8 fencing wire mentality, is required. It is suggested that New Zealand has to become more accepting of specialist leadership characteristics. There was no question in the participants' minds that if this fails to take place, a talent shortage is assured.

\section{The interrelationship between the CEO role and remuneration}

Everyone involved in this study spoke of the ongoing debate in the media and elsewhere that criticised the supposedly excessive levels of executive remuneration. Furthermore, analysis of the data identified that a symbolic significance was attached to the amount of $\$ 100,000$, and that anyone earning over this amount was believed to be excessively remunerated. This "magic number" was deemed to be fixated upon as a result of companies in New Zealand required by law to report employees earning $\$ 100,000$ or more in their annual reports.

For example, one front page newspaper article published during the time of the study focussed on the level of remuneration of a selection of New Zealand's top CEOs, and the impact of their salary increases on the return to shareholders and the cost of the company's products to the customer that is, the "person in the street" (Vaughan, 2005, p. A1). The article did attempt an unbiased view of the issues including a mention of how the tall poppy syndrome influences perceptions, and the "woeful inequities" when compared with salaries of CEOs in other countries. However, the attempt at an impartial discussion was countered by the strong opinions voiced in this and other publications 
ascribing to the view that the salary levels of CEOs are exorbitant. This article was used as a catalyst to generate discussion during the informal interviews. There was an immediate reaction to the graphic, which had the heads of prominent CEOs superimposed upon a New Zealand $\$ 100$ note as a symbol of the $\$ 100,000$ per annum salary. The CEOs taking part in this study acknowledged the article as factual and stated that such commentary is not helpful to the debate and does more harm than good.

Both CEO and non-CEO participants were of the view that newspaper commentary, such as this, demonstrated how "out of touch" the general public is with the true realities of the role. It was accepted that New Zealand organisations could not compete with the salaries paid internationally. However, remuneration packages still had to be sufficiently desirable to attract and retain capable CEOs. The participants were of the opinion that the negativity generated by such newspaper commentary acted to suppress salary levels which, in turn, hindered the recruitment and retention of CEOs. The CEOs themselves were comfortable with the challenges arising from leading a large organisation, and with the sense of satisfaction that can be achieved. However, it was believed that there came a point where the situation became unbalanced. A balance between the demands of the role and the level of remuneration was vital and should it not happen, then: "The salaries are not worth the hassle ... we cannot compete with salaries offered in other countries and this will impact on the recruitment of high potential people".

Some suggested that the lack of balance would negate the forces that act to reinforce the positive characteristics of the role. The potential to achieve a similar level of satisfaction, and less negativity in an alternative role or environment, acted to repress the acquisition 
of executive leadership. An executive search consultant spoke about the remuneration issues in the following way:

Remuneration is a huge issue in this country. It's a country of four million people and a small number of large companies; therefore the ability to pay is limited. But if you don't pay global salaries for talent then you're not going to get quality candidates.

The participants spoke of the paradoxical situation where, despite a deep-seated 'resentment' towards wealth and wealth creation which persist, "very contradictory situations exist in New Zealand ... everybody wants to make money, yet people that do make money get 'pulled down' or attacked". If the individual has inherited "old money" or "made it" from the land or through personal hard work, including small business, (for example, owner-operators and sportspeople), then they are only receiving what they deserve, while wealth generated by other means was a less acceptable means of wealth acquisition.

During one informal interview, the discussion focussed on how the situation regarding remuneration is exacerbated if a CEO has a salary level higher than the norm. When asked to expand on what they meant by "excessively high", they stated that when there are large salary differentials between levels in an organisation, then the egalitarian sensibilities come into play. The private sector CEOs were of the opinion that opportunity existed to create more wealth and prosperity for the country. However, these opportunities are repressed by misinformed, unfair and at times unnecessarily personal commentary on an individual's remuneration and/or supposed wealth. A participant, who had extensive contacts in the public sector, commented that: "You could cut CEO salaries in half and they would still be considered too high by the majority of people”. 
While there was a common viewpoint about the inappropriateness of these attitudes, there was no agreed view about the most appropriate way to deal with them. Some participants felt that it was better to ignore the issue and just "get on with the job". Others found it personally offensive, and moved to counter the effects upon them as individuals, and on their families, by proactively reducing their public profile in the hope of minimising criticism. A claimed consequence of reducing their public profile was that there were fewer role models for young capable individuals. Actions included leaving the country for executive roles in international companies. Ironically, this not only reduced the personal attacks, they usually obtained an increase in their remuneration. However, negative commentary is not seen as confined solely to CEOs; it is believed to include the remuneration of all those involved in executive leadership:

It is not just the top few executives who are suffering from the criticism, but I think that if they are doing well, if they are running the organisation really well, they deserve to get well rewarded because they are putting New Zealand on the line 24 hours a day, 7 days a week. It is their ultimate responsibility...

The verbatim interview transcriptions were accompanied by memos and notes made during and immediately after the interview. They indicate that the comments received were emotive and it was evident that a majority of participants had experienced the remuneration backlash to a greater or lesser degree. In addition to the repression of leadership the social structural process, restriction of leadership, was identified. The next section of this chapter discusses this theme and its impact on executive leadership and the CEO role. 


\section{The restriction of leadership}

Whereas the repression of leadership theme reflected the forces in the CEO's external context, the theme, restriction of leadership, explains the social structural processes that place a restriction on the recognition and development of executive leadership within the organisation. The definition of the word restrict is "to put a limit on, to keep under control. Restriction, then, is a limiting condition/s or measure/s (Pearsall, 1999).

As discussed previously, the view of the participants was that effective CEOs displayed adult behaviour in their interpersonal relationships. However, adult behaviour in organisations was not always evident. The following comment by a non-CEO participant aptly describes how the organisational systems and processes embed these structures in place:

When we go into the workplace there's a whole bunch of messages that say to us "You're not ready to be treated as an adult while you are here. You are required to clock in and clock out”.

A preference for conformity was spoken of as still existing in many organisations, and while there has been some movement away from the rigid conformity expected in the earlier part of the twentieth century, fully autonomous and empowered organisations were considered to be still some time away. Barriers that place restrictions on people within organisations were still very evident, and come in many different forms, with one of the respondent examples stated as: “We'll tell you how to dress; we'll give you a whole bunch of petty rules that eliminate your ability to make decisions". 
The non-CEO participants spoke of the organisational preference for formalised hierarchical structures that existed, despite moves to team structures. In contrast, the stated preference of the CEO participants was for team-based organisations. Bada (2003) provides the following examples of such changes, namely, features such as casual dress on Fridays, referring to people on a first-name basis, and social activities such as business sports games. The preference for hierarchical structures was judged to originate from the demands of the people within the organisation, as opposed to the wishes of CEOs. One person, when speaking of the tensions that have been generated, described the move to a less structured environment in the following manner: "It doesn't feel right ... yet it needs to be more team based. Somehow we are a team-based people and I think that influence will come through more as our ethnic mix changes".

This was one of the rare references to the potential for ethnicity to change the nature of workplace environments. Yet when queried, the person who made this comment had no real explanation for what they meant, other than to say "some cultures are more team focused". Despite the desire to operate within a less hierarchical framework, one that focuses on empowerment and autonomy, there was evidence of frustration on the part of the CEOs at the lack of willingness of people within their organisations to adapt to this.

When seeking an explanation for these tensions, again, the tall poppy syndrome was provided as a reason. The "petty rules" were used as a form of control, placing restrictions on high-profile, risk-oriented behaviours that may be perceived as alternative or different. Often, this is so entrenched within organisations that the CEOs were restricted in making the necessary changes: 
There's such a whole lot of organisational messages that you get that tell you to conform, and tell you not to stick your head out, and no doubt in most organisations there will be people who stuck their head out and had it lopped off and those legends travel a long way.

Participants expressed a sense of resignation, at times, about these restrictive forces as they were deemed difficult if not impossible to change. The grounded theory analysis processes identified a perceived partiality for high-level technical and professional skills as opposed to specialist leadership characteristics. The perception was that the CEO role has been, and still is assessed on the level of technical or professional expertise of the individual. One comment that summarised this view was:

And professional people who are very good at their job specialities, and you might find that lots of professional service type people, from accountants, lawyers, whatever, they're stunning at their speciality. In the past we've used that stunningness and said that's leadership potential and promoted accordingly.

The consequence of this has been the restriction on the development of specialist leadership talent. Recurring throughout the research was the concern that leadership behaviours are not always recognised as such and that this has created a restriction on the development of individuals from different ethnicities and backgrounds. Hence, the CEO population is essentially a homogenous one. Whilst there is awareness that the heterogeneity of the CEO population may/should reflect the heterogeneity of society, it is also acknowledged that this involves change, and change involves risk, and risk is not encouraged. One succinct statement identified the issue as: “...so we are definitely not highlighting leadership behaviours and measuring and assessing on those”. 
Both CEOs and non-CEO participants stated that the role sender groups have an influence beyond what could be considered appropriate within organisations. Their perceptions of whom, and what a CEO is, has played a significant part in the definition and enactment of the role. A sense of disquiet was expressed throughout the interviews, that if a CEO appointment did not "fit" the perceptions of what a CEO should be, critical commentary from role sender groups became even more likely and intense. The following comment summarising the concerns people had about the inappropriate perceptions of the CEO role:

I mean there is a real lack of leadership development ... we continue to promote, reward and recognise people who are functionally good but we're not yet making some of those decisions ... there aren't that many examples where people are being promoted based on what I would call leadership capability.

The non-CEO participants spoke of the need for CEO development to take a more longterm ongoing approach. Restricted developmental opportunities have left significant gaps in the available CEO capability, specifically those experiences that are believed to assist in developing maturity and self-esteem. One CEO described a worst case scenario as having a CEO who was:

Defensive, not taking risks, surrounding themselves with mediocre performers, playing a political game, and by that I mean going with the last person who came through the door or whatever or the best idea. It manifests itself in a kind of dysfunctional senior team, so you've got people competing rather than being part of a team.

The consequences of a dysfunctional senior team includes the creation of a negative culture and adverse business results, the respondents referring to the ironic situation where, often the severity of the situation was only identified subsequent to the CEO 
departing the role. Related to earlier comment about the absence of vision and a sense of direction, the non-CEO participants referred to the lack of cohesion that was likely to eventuate. One board chair making the following comment:

People going off doing their own thing, so you never actually harness a shared vision of the business, you're not all moving forward in the same direction. So it has a lot of cultural implications, as well as poorer results.

As discussed previously, the CEOs deemed formal learning as the most predominant means of leadership development. However, the lack of value attached to the informal and incidental learning experiences was judged to impact adversely on using such experiences. One HR executive spoke of the global contracts which their company were involved with. What concerned this individual was that people undertaking obligations within these contracts "did not see or acknowledge them as learning opportunities", and that this was wrong. When asked to expand on the reasons for this, the respondent spoke of the concept of role as very much a rank based ascribed construct, equated with positional power within an organisation. If the individual does not carry a title of "manager", then the situational, informal and incidental experiences are not recognised as leadership experiences, thereby restricting their value. The following comment typical of those received:

I mean I think they would say it's a very cool experience to go to off-shore, they say, "gee, it's hard communicating with people of different cultures, and my job was to train them how to use our system". I think that's the language they'd use. They wouldn't see it as a leadership exercise ... it's so tightly tied to rank. 
The ability to use informal and incidental experiences as learning opportunities has been identified as critical for effective leadership development (Black \& Gregersen, 2000; Kempster, 2006; Kotter, 1996). All those involved in the study expressed a view that there is a need for a change in attitudes if leadership talent is to be recognised and developed appropriately. Two key areas where a change in thinking would help the development of leadership were identified by participants. The first is the need for a higher value to be placed on individuals who have entered the business environment through non-traditional avenues. While it was acknowledged that, with time, this should resolve itself, there were comments to the effect that this issue had been active for a long time:

Some younger people who are a bit more lateral and women of course that haven't been in the workforce and they stayed home and minded the kids and come back in and are jolly good managers actually, and they are not recognised as such by some of the older more traditional managers.

The second area has evolved from the perceived emphasis or desirability for technical and professional skills, which when combined with a short-term orientation, has placed a restriction on the enactment of executive leadership. One CEO explained it thus:

And going back to the technocrats ... I think the most dangerous group to put in positions of authority are engineers, because a bit like lawyers, too, they have their backgrounds and training, they over-engineer things in case there's an accident. In the case of lawyers, they don't want to step outside the square in case the precedent is wrong and it is really very constraining on leadership, very constraining. 
The presence of these institutionalised expectations was considered by the participants to hamper the understanding of the CEO role. The consequence is that restrictions are placed on how the CEO role is enacted and developed.

I know I've said this; "What does it take to be successful as a leader in the New Zealand environment?" And we're not doing a lot of work around developing leadership because we don't know what it is. We're not doing a great job around developing the leadership side of things.

When asked to reflect on statements such as the one above, the participants used terms that were more aligned to the "heroic" descriptions of leadership (Ospina \& Schall, 2001). There was no evidence in the interviews that the exclusion of alternative views or forms of executive leadership were deliberate; they simply did not feature. Examination of both primary and secondary data identified that there was an espoused preference for hierarchical structures, and professional and technical expertise - which in turn, created a situation whereby the CEO role is defined by the frameworks of the traditional models as opposed to those purported to be the models more suited to the twenty-first century.

The non-CEO participants spoke of the tendency for people exhibiting high-profile or non-conformist behaviours in New Zealand not being selected for leadership roles. One participant, who had spent a number of years in senior executive roles, talked of the preference for passivity and conservative behaviour and how this imposed a restriction on the identification of talented executive leaders:

...as opposed to what they call high potential who are people who sometimes are pains in the neck in organisations, they ask lots of questions, they push the boundaries with what they say and do ... now sometimes those technical professionals who are very very good 
at what they do, but they like the tried and true ways of doing things, they like the comfort zones in the sense of having a resistance and ability to change.

No distinction was made between the private and public sector organisations. The restrictions were deemed to impact on all organisational sectors. There were ongoing comments about the inability of organisations to attract and develop a diversity of specialist leadership talent as opposed groups of individuals with generalist managerial characteristics. The dynamic global environment confronting CEOs means traditional attitudes and responses are believed to be no longer appropriate. Those CEO respondents who had extensive global experience commented on the inappropriateness of the expectations of the CEO role, and an inability to meet the demands for specialist executive leadership capabilities. One comment received from a retired CEO summarised the views of the participants:

You can't sit there and say I can do everything any longer. It's not the mentality of she'll be right and I'll just get out there and do it. I have done enough (learning and training). It is good to have some of that attitude so that the individual can go and get stuck into problems and find solutions for them. But at the same time it is not appropriate to get like some societies where everybody is so channelled (into a speciality) that they are incapable of doing anything else. I think there is a happy medium.

The institutionalised expectations, so described by the participants, were believed to constrain the required changes both in development and mindset from being made. Implicit leadership theory highlights the need for an individual's leadership style to be congruent with the collective expectations of others. When an individual's vision of a leadership role does not resemble how that person is perceived within a specific role or context, then a "lack of fit" exists (Markus \& Nurius, 1986). Within the context of this study, "fit" includes the ability to understand the expectations and requirements of what 
constitutes "good leadership within a role. The following comment typifies those made by the respondents about the importance of the individual within a role ensuring a ' $f i t$ ' within the organisation and nation culture:

So I guess that an organisation's cultural environment is important and the business culture in New Zealand within which an organisation fits also has an effect.

Indeed, the institutionalised expectations identified through the analysis process are deemed to be so deeply embedded that the CEO has minimal latitude of discretion (Finkelstein \& Hambrick, 1996) to change or modify how they enact the role. This can lead to what was described by one non-CEO participant as a self-perpetuating cycle. When striving for change, it was the combination of the external tensions and institutional inertia, as posited by Finkelstein and Hambrick (1996), which precluded the CEO from implementing the changes which they considered necessary. As a result, tensions resulting from cognitive dissonance, lack of clarity, and inconsistency of expectations were perceived to be the norm. The identified consequence was that the CEO role did not gain appeal as a potential career option. These factors lead to the individual making the decision to reject the role. The next section proceeds to examine the social psychological processes present within the context of the research that cause the rejecting of leadership. 


\section{The rejecting of the CEO role}

The theoretical coding and abstraction to higher order themes led to the identification of the social psychological process, the rejecting of the $C E O$ role. This theme describes the response of the individual to the presence of the social structural processes discussed in the themes, the repression of leadership and the restriction of leadership development.

Within the context of this study, the word rejecting is defined as "the failure to show due affection and concern for something or someone", and secondly, "to dismiss something as inadequate or faulty" (Pearsall, 1999). Rejecting was identified as occurring within two groups: first, those high-potential individuals who choose to reject the opportunity to take on executive roles and second, those holding CEO roles who decide they no longer wish to remain in the role. The tensions existing within their context prohibits or inhibits the individual from achieving the heightened levels of affection or excitement essential for the successful enactment of a CEO leadership role.

Negative perceptions of the CEO role were identified by the research participants as one of the primary reasons for the role not being perceived as a positive career option. As discussed in Chapter Two, Markus and Nurius (1986) state that the view of the possible self is an individual's future-oriented view of him or herself in a role. This view of the possible self provides an incentive for the individual to imagine themselves attaining a particular goal state, in this case, the role of the CEO. Markus and Nurius (1986) go on to state that the vision of the possible self needs to be validated by the individual for it to become part of their future goals. Then, for example, if the individual feels the compromise that they must make is too great, then they may choose to reject the role. 
Gergen and Gergen (1971) argue that in situations replete with inconsistencies and unwanted compromises, an individual may actively engage in actions that will free them from that situation. The more senior CEOs, in the sample, spoke of the predisposition of younger people to refuse to contemplate undertaking any executive leadership roles, let alone the CEO role. One comment, put rather more emphatically than others received, noted how the "last round of nonsense" resulted in the loss of some very capable people. The last round of nonsense being described was a media frenzy that attacked executive remuneration and as the supposed lack of ethical behaviour on the part of senior business people. One comment illustrating the sentiments of these participants is the following:

I guess what's concerning is some of these young ones coming through who are very capable, who are saying well there's more to life than this. I don't want the hassle; I actually want a balance in my life. I want to do a bit of this and a bit of that and have family time or whatever; they want more flexibility, the money is not actually worth it any more.

Markus and Nurius (1986) contend that when the individual is required to forsake those aspects of his or her self that they cherish and value, then there can be an adverse impact on the individual's self-esteem and self-worth. The interviewees identified that the stress and dissonance resulting from the tensions and compromises were deemed to be intolerable by those who chose to reject the role. The rejecting of the CEO role was one means by which an individual could avoid these tensions and compromises. One CEO, reflecting on his peers who had rejected the role, commented:

In my peer group, three groups of my really good friends have just opted out of this level of work and now are running a horticulture venture ... sailing around the world ... they are doing all these things because they've hit the wall. They say enough is enough ... there's more to life than having this level of stress. 
Although the more experienced CEOs commented on their younger colleagues, the analysis identified no difference in views that related to age groups, industry sector or gender. The comment "it's not worth it any more" was made on a number of occasions. One female participant spoke of stress, pressure, scrutiny and remuneration, and how the state of affairs had become one of "not being worth it any more". She also reflected on the tendency for women to reject senior roles in organisations more readily:

... people are saying, 'Well, I don't want to be the boss, it's too stressful, I want to choose a better lifestyle for myself, and I know a lot of women do that, in that they say 'Not worth it, it isn't worth it.

This comment was the only one specifically referring to a distinction based on gender. Consequently, this individual was asked to reflect on her comment, specifically gender as a determinant of the tendency to reject the role. While her initial reaction focused on women, she named male colleagues who had also taken this action:

No, it's the guys as well, if I think about those people who I mentioned earlier. Each of them, an issue that came up was their work/life balance and just the poor balance that there is. I saw the demands upon their ability to always be in action and thinking and onboard for enormously long hours, really long hours.

The pressures, both physical and mental, and lack of clarity regarding role expectations, eventually took their toll. The term, work/life balance issues, reflected the composite of reasons presented as the basis for the rejecting of the role. As a result, the interviewees were requested to explain what they meant by these statements. Their clarification identified that work/life balance was more than being solely family oriented. Rather, it 
was a generic phrase used in an effort to explain tensions that individuals may experience. Health and stress issues, dysfunctional relationships between the CEO and the board, the aversion to the levels of media and political commentary, the conflicting demands and negative perceptions responsible for creating high levels of disquiet, and internal conflict, were all identified as contributing to work/life balance issues. One participant with extensive experience, both in New Zealand and Europe, now mentoring senior business leaders, summarised these issues in the following manner:

And at the same time I'm dealing with a number of these people who have been CEO of New Zealand and Australian companies who are now sitting there saying " Well I don't want to do this anymore. I would rather be on a few boards, do a bit of this, do a bit of that, and play more golf.

When looking to the future needs of their organisations, it was acknowledged that there were concerns about the number of skilled individuals capable of undertaking a CEO role. The follow-on effect of the departure of capable CEOs from New Zealand (30\% of this sample), to pursue other opportunities, was expressed by one CEO as: "That's the problem; there is no one to fill the job because everyone has buggered off"'.

In many instances, as the interviews progressed, the participants' comments more clearly reflected an appreciation and understanding of why an individual would choose to leave the role and maybe, ultimately their country. One CEO, whilst reflecting on his prior experience in multinational corporations, talked of the differing expectations of executives in a relatively small business community, as opposed to those in a larger community. One comment illustrating this situation, made by one executive coach and board member, was as follows: 
There's another phenomenon that's been developing and I'm seeing it in the younger ones. They're developing the same feeling which I'm currently seeing in some of the 45 55 year-old CEO's, which is a growing reluctance to even want to be a CEO.

The comments of the participants identified the view that every mistake is visible in a small business community, and that they are not easily forgotten despite the passage of time. It was suggested that a price was paid for this scrutiny, and that it is "not worth it" for both the individual and their families. The 'cost' extends to include "comments about their children" and often older children "having a reputation to live up to". It was suggested that this caused stress for both parent and child. One CEO remarked that he was "asked without fail" by all prospective second and third tier managers during the recruitment process: "How strong are you and the board of this company to prevent 'that' happening to me and to protect me and my family from the damage?"

On one occasion, a CEO was discussing the public vitriolic reaction to some controversial decisions he had made. Unexpectedly, he began to display considerable emotion. This was one of the more difficult interviews that the researcher had to conduct and it took some time before he was able to continue the conversation. He declined an offer to turn off the tape recorder. After he had composed himself, he spoke of how the political attacks and resultant media scrutiny created a situation within his family whereby he felt he had no option but to leave the role. This interview was conducted in his last week with this particular company. When his peers were interviewed and asked to reflect on the personal cost of the role, similar emotions were discussed. One observation was made about the self-serving and abusive conduct of some sectors of society. One comment symbolising the strength of feelings was as follows: 
Yes, yes. I think the toll would be very heavy. And quite unimaginable, you look at XXX, (a fellow colleague undergoing intense public scrutiny) he's doing the work, they (the role senders) are all bullies in their personal lives as well and they can't imagine anything different.

When others were asked to reflect upon any similar experiences, the common view was that many of the mediated images of CEOs show them as aggressive and bullying. Therefore, any interaction with them as an individual must be of a similar standard of behaviour. This was a situation that the participants found highly offensive. One relationship that prompted a high level of discussion was the nature of the relationship between the CEO and their board of directors. The importance of constructive healthy relationships was stressed by the CEOs. However, there was a concern that healthy relationships were at times difficult to achieve. The next section of this chapter explores the features of the board-CEO relationship that were judged to have significance by the participants in this study. 


\section{Relationships between boards of directors, policy-makers and the CEO}

A healthy relationship between the board chairperson and the CEO was one of the more critical relationships spoken of throughout the study. Yet it was one relationship that was deemed most susceptible to becoming dysfunctional. The participants considered the dysfunctional nature of the relationships were exacerbated if there are tensions and conflicts between different board members, since this can result in the $\mathrm{CEO}$ being torn between the different factions. Within this study, tension created by different factions on the board was one of the "top-of-mind" issues for the majority of those being interviewed. While there were implications for all groups, the person most at risk if relationships did become dysfunctional, was the CEO. A failure to achieve a "meeting of the minds" was perceived as having far-reaching ramifications for both for the CEO and for the organisation. A lack of trust was cited as the primary reason for the poor relationships. The following comment was a response to a question about why some CEOs appear to be reluctant to make critical management decisions: "Some of that arises out of them having come out of unsatisfactory experiences and that comes back to a question around the board and expectations of the board".

The primary reasons provided for the cause of tensions was deemed to result from a lack of clarity of expectations between the board and the CEO. This was identified by the respondents as occurring as early as the recruitment process. Commonly, the desires and expectations expressed during the recruitment and selection processes were that the prospective CEO should be visionary, have a long-term strategic focus, and be innovative and creative. These were reinforced by executive search consultant participants who were conferred with during the informal interview process. A common claim related to 
the inconsistency and lack of clarity of expectations was manifest, and often subsequent to the individual having being appointed. One such comment made was as follows: "You know the number of companies that recruit for innovation ... that's what we want, but in reality they want those people who are more comfort zoned".

Explaining that being "comfort zoned", involved a preference for traditional, short-term, managerial styles of risk averse behaviour, it was acknowledged short-term profitability was normally the first priority. The CEO participants were of the impression that the long-term strategic viability of the organisation was accorded a lower priority. Repeatedly, the CEO was asked to make decisions that could compromise this: "the media grabbing at even one year of lowered profitability to make news". The lack of clarity of expectations between boards and CEOs were deemed responsible for many of CEOs' “bad experiences”. "They don't necessarily recruit for what the organisation needs, they may need different skills and competencies and experiences".

The participants, who had been involved with CEO appointment processes from a board perspective, were asked to reflect on these comments. Their responses referred to how, in addition to the formalised processes, there were also informal processes. The most important of these was the requirement to ensure clarity of expectations between all members of the board about the skills and abilities required of a CEO. Often, this did not take place. It was claimed that this disjunction was more evident when there were board members with political affiliations. One comment suggested that, repeatedly, the qualities ending up on a job specification would have evolved from a "wish list" of a subcommittee of the board. It was even said that these wish lists had their genesis in the leadership books that people may have read or the courses they attended, such that the job 
description created a mythological image of the perfect CEO, one that is somewhat removed from reality. One board member was emphatic when she stated:

It's about clarity of the relationship and the expectations they each have. And I think that's where it breaks down often. Very often the board will recruit someone who's got the capability for long-term growth, but in reality they want quick short-term results.

The desire to appoint a CEO who displays long-term strategic visionary thinking, and is responsive to the demands for change, was one of the primary requirements of a prospective CEO:

That's the frustration that chief executives have, on the one hand the board say "yes we want long-term growth, we've recruited you to grow this company into the future". In reality it's "let's get the share price up now, tomorrow". So it's around the expectations.

Comments received indicated that it was only subsequent to the CEO's appointment were the differing expectations exposed. Often this manifested itself as a dawning realisation. The priority was a focus on short-term profitability, risk avoidance, transactional leadership behaviours, and returns to the shareholder at the expense of reinvestment in the business; a situation quite different from that which was advertised.

The CEO participants were clear and unequivocal in their opinion that if this implicit and espoused inconsistency of expectations became untenable for the CEO, there were few options available to them. They could either continue in the role trying to minimise the inconsistencies and cognitive dissonance (Brehm \& Cohen, 1962; Festinger, 1957; Gergen, 1971), or reject the role and leave the organisation. There was a cynical observation on the part of one $\mathrm{CEO}$ about the apparent readiness to criticise every 
mistake of the CEO, however, there was not the same level of scrutiny pertaining to board members, or the processes that appointed board members. When asked to expand on this comment; he made specific relevance to board appointments of a political nature.

However, he was not prepared to be drawn any further on this issue. Other CEOs were more forthcoming, one making the following comment, with a degree of vehemence: “When lousy industries and good CEOs collide, it's always the industry that emerges with its reputation intact”.

This view was shared by other CEOs and appeared in modified forms in other interview transcripts. The respondents believed that the pressures to conform to short-term institutionalised expectations were often politically expedient and compromised the implementation of long-term strategic plans. A common belief expressed by CEOs was that no matter how effective you are as a CEO, there will be businesses in some industries that will never become outstanding and so, whether as result of political interference or policy changes or because the industry is reaching the end of its lifespan, eventually the CEO will exit the organisation.

One public sector CEO noted with concern that ensuring the long-term survival of the organisation could mean the CEO would have to disregard government policy. The tensions resulting from such situations were sometimes considered too difficult and complex to surmount, resulting in the rejecting of the role on the part of the CEO:

Well, I would say you'd just look at a number of the CEO's who have been exited from business in New Zealand and say that had there been clarity and honesty and a good process up front, that need not have happened. And I think of some of the people I've worked with who have come in [to an organisation] believing this was the agenda and this was the way the organisation was and this was how decisions would be made. Then 
when they get in there and find that it's quite different and they end up saying "it's all too hard, it's not right" and walk away from it.

The analysis of the interviews identified the view that this lack of clarity resulted in the reluctance on the part of capable executive leaders to take on a CEO role. The respondents stated that reputations, good or bad, valid or invalid, are acquired; these applied equally to boards of directors, Ministers of the Crown, organisations and associated groups. Some were marked "avoid at all costs". This, in turn, leads to a difficulty in recruiting capable CEOs and retaining them once they are appointed. One disparaging comment made was: "that rather than scrutinise themselves, they blame the poor old CEO".

\section{Conclusion}

This chapter has provided an examination and discussion of the collective notions comprising the sub-themes that contribute to understanding the features of the CEO's context that cause them to reject the opportunity to take on, or remain in, a CEO role. In this chapter, the sub-themes are drawn together in a manner that makes it possible to identify their contributions to synthesis of the major theme that has been labelled confronting the institutionalised expectations. The themes discussed in this chapter are represented diagrammatically on pages 251 and 252 . Here the researcher notes the following findings as significant aspects of the sub-themes contributing to the theme confronting the institutionalised expectations. Many of these expectations were perceived to have developed from New Zealand's colonial history and were deeply embedded, extending beyond the boundaries of the business community. These 
expectations included for example, a focus on short-term return to the shareholder orientation, a preference for technical and professional skills as opposed to specialist leadership capabilities. The manifestation of the tall poppy syndrome and the No 8 fencing wire mythology were discussed as examples that place constraints on the enactment of high profile role behaviours. The institutionalised expectations were deemed by the participants to be in opposition to the expectations of the CEO role as outlined in Chapter Five, the development of the leadership constructs of the CEO role. Two social structural processes were identified as overarching and as explaining these forces; these are the repression of leadership and the restriction of leadership development. The social psychological process, the rejecting of leadership, explains the response of executives to the presence of the two social structural processes. 
Figure 14: Diagrammatic outline of the themes discussed in Chapter Six (Part I)

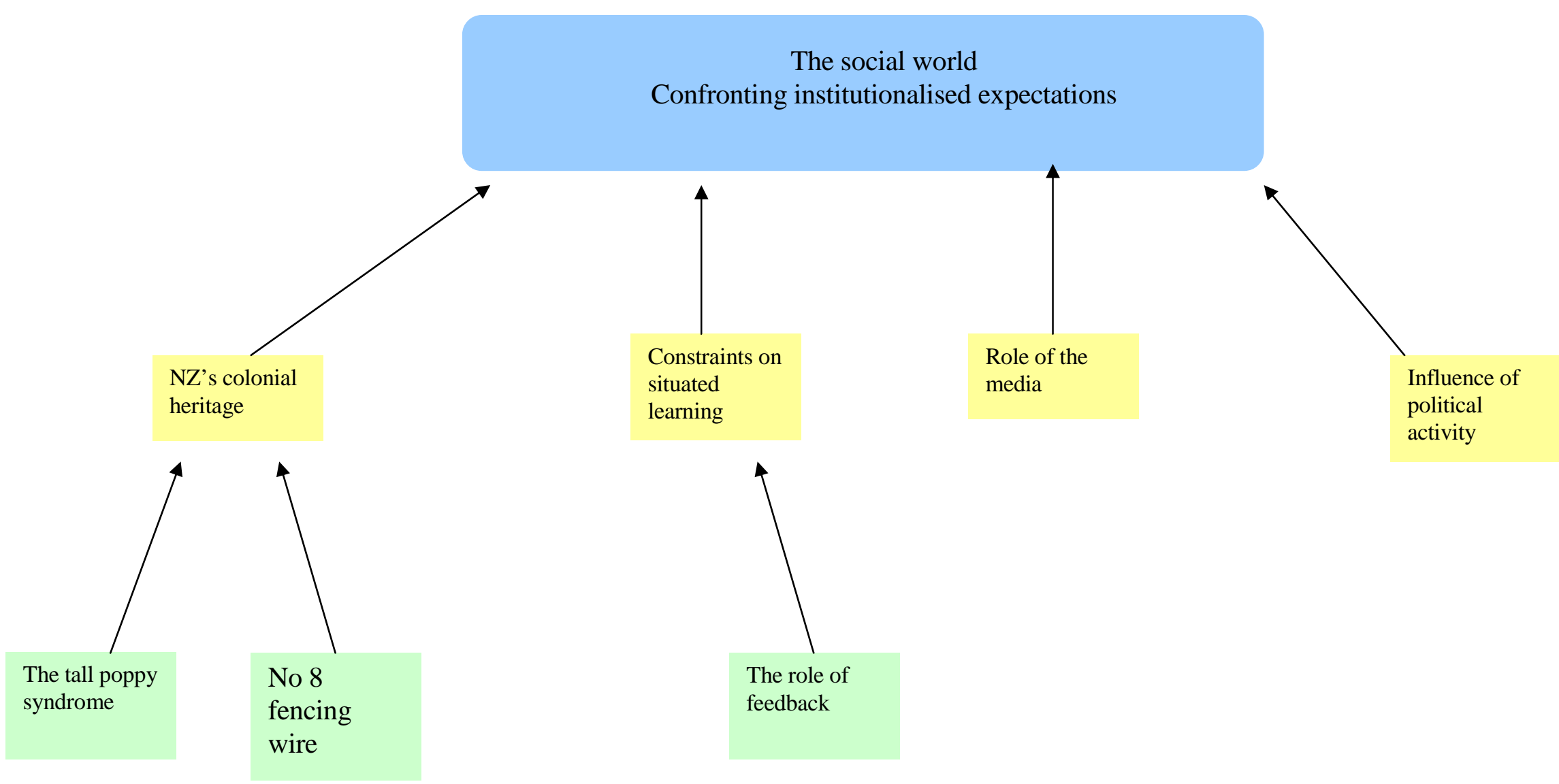


Figure 15: Diagrammatic outline of the themes discussed in Chapter Six (Part II)

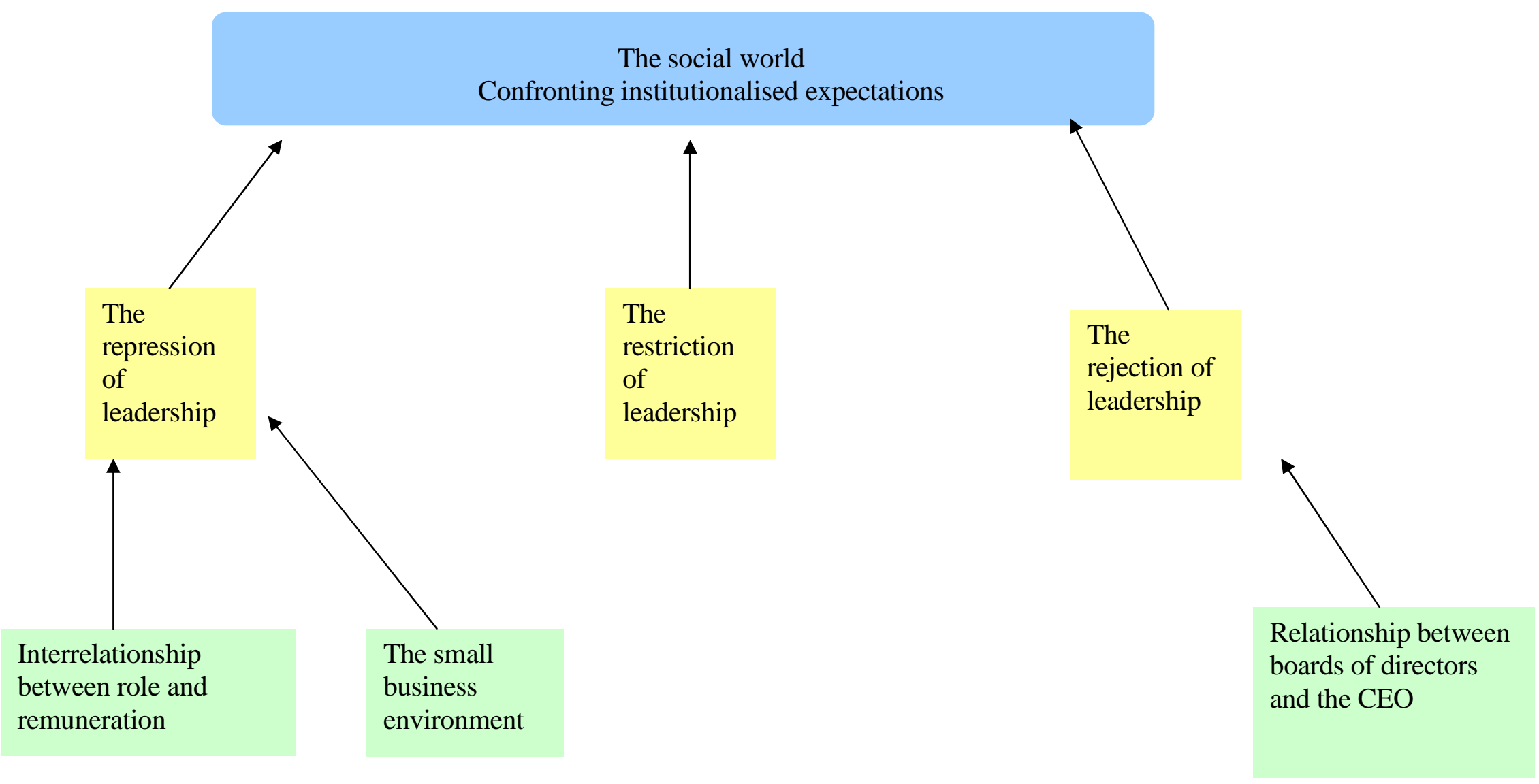




\section{Part III}

\section{Introduction}

Part III of this thesis comprises two chapters. Chapter Seven, Weaving the themes together, provides the discussion of the substantive theory of the CEO role. In this chapter, the identification of the two interpretative schemas is outlined and the learning experiences that contribute to their formation. The chapter then proceeds to discuss the overarching social structural process, the CEO role as a social institution and the social psychological process, balancing tensions and paradoxes.

Chapter Eight, Recapitulations, reflections and future directions, draws the thesis to a close. The recapitulation restates the premise for the thesis and restates the main themes. The reflections focus on the challenges faced and the contribution of the research to both the method and the literature. This includes a discussion of the implications for both academics and practitioners. Future directions posit opportunities for future research in both the method and the discipline.

Whereas, Chapters Seven and Eight focus on discussing the nature of data analysis, in what follows a brief note is provided on a facet of New Zealand that was identified as a gap in the data. 


\section{The CEO role as a mono-cultural construct}

Glaser (1998, p 200) has used the term "comebacks" to explain those themes that have emerged from the data and which 'have less relevance for the theory but provide an interest area on their own'. That is they provide an appeal for researchers to come back to these areas to study them in more depth. These comebacks can arise as emergent themes or from identified gaps, as is the case in this study. While the analysis focussed on what was present in data obtained from both primary and secondary sources, it also identified the absence of any reference to Māori leadership, in particular Māori CEOs or potential CEOs. The data analysis identified that there was no deliberate attempt to reject or minimise Māori leadership. It was simply that any style, other than that which fell within the frame of prior experience and prior discussions was not acknowledged. While there was a high level of awareness of the influence of European colonisation and its heritage, there was not the same level of awareness of the role of Māori in executive leadership and the forms of Māori businesses that existed prior to European colonisation. Nor was there any evidence of pre-European business having an influence on the perceptions of the CEO role. Within the context of this study the CEO role surfaced as a mono-cultural construct based on views of executive leadership situated in post-European, colonisation and industrial models.

Although identified late in the study, the theoretical sampling processes undertaken in this study permitted the researcher to return to ask specific questions relating to this situation. The specific question asked was: if you had the opportunity to draw a model of CEO leadership specific to New Zealand, what would that model encompass? It was then that comments such as the following were made: 
I think that again when we talked about the celebrating success stuff. What it is to celebrate success in a uniquely New Zealand way because I think it is important to acknowledge and recognise others and make it a New Zealand way. We haven't worked that out at all yet.

It was found that approximately one-third of the CEO participants and all of the non-CEO participants had given some thought to the formation of a uniquely New Zealand model of leadership. However, the frameworks and scripts informing the role are so tightly embedded within the institutionalised interpretative schema, the research participants appear constrained to work within or from deviating from such schema, or modes of thinking, or of making necessary changes. While the CEOs stated they would like to operate within the leadership schema it was obvious the frameworks and scripts did not include specifically New Zealand features. This was expressed as follows:

I think that's the appealing and the powerful parts of what it is to be Polynesian that somehow we haven't got our minds around. There's a huge amount to offer there because we've lost our sense of community, yet Polynesians have more of a sense of community than we do and I think, that it is a sense of belonging, and I think a lot of people don't have that in a company.

These specifically targeted questions allowed another layer of CEO role to be peeled back. This, in turn, identified the need for a deeper exploration of the other diverse aspects of leadership in New Zealand. An example of the responses received during this phase was:

We have these stereotypes around Maori leadership ... which is not necessarily wonderful. We need to understand more, and who these kids [bright young people] are ... there are some incredibly impressive [Māori] kids that are coming through. 
The following comment was one that appeared to explain the disquiet the researcher experienced amongst participants on occasions throughout the research when it was sensed there was something missing, but further questioning was not able to determine what exactly it was:

... taking a different view ... thinking about what it is that we want to be ... and it is obviously cultural issues, Māori, Pākehā, Asian, Pacific Island ....

It became evident from the analysis, at this phase of the research, that there are many different ways to lead and there is the potential to develop different more powerful models than those traditionally ascribed to. A uniquely New Zealand model would take account of the richness that is provided by the diverse groups in society:

Because if you get it right I think would be very powerful model but you won't find that one in a book on American leadership ...

Whereas it is not possible to analyse what is not present in the data, the identification of this gap does indicate that there is a need for more reflection and research about how indigenous factors influencing the CEO role can be identified. This issue is expanded on in Chapter Eight. 


\section{Chapter 7: Weaving the themes together}

Well you have to make a very fundamental decision at some stage because what the organisation is asking of you is inconsistent with your values or how you want your organisational life to fit in with your family life and you are going to have to make a call on the direction you want your career to take.

A CEO reflection

\section{Introduction}

The aim of this thesis is to develop a substantive theory that explains the CEO role as perceived by the research participants. As discussed in Chapter One, a substantive theory is one that can be described as having relevance to the area under investigation (Glaser, 1978). To reiterate, an important principle of grounded theory, both the objectivist and the modified forms, is for the theory to be developed freely from the data, as opposed to being forced by preconceived ideas. In this chapter, the themes discussed in Chapters Five and Six are woven together to form a substantive theory of the CEO role.

The chapter commences with a cogent discussion of the two interpretative schemas that were identified as a result of the theoretical coding processes. These schemas were identified as the leadership interpretative schema and the institutionalised interpretative schema. The chapter then weaves together the themes that led to the identification of the over arching social processes. As stated in Chapter Three, Glaser (1978, p. 102) contends:

"There is a logical relationship between the two forms of social processes. The overarching social structural process abets, facilitates or is the social structure within which the overarching social psychological process occurs". 
In this study, the basic social structural process reflects the $C E O$ role as a social institution. As a social institution, the CEO role is framed by a set of social norms that provide the "rules of the game" (Axelrod, 1986). Identified as a result of the iterative grounded theory analysis was the overarching basic social psychological process of balancing the tensions and paradoxes. Balancing the tensions and paradoxes is the social psychological response on the part of the CEOs to the dynamics created by the collisions of the two interpretative schemas. The chapter concludes with an overview of the theoretical perspectives of learning that contribute to the social structural process of the social institution of the CEO role and the social psychological process of balancing the tensions and paradoxes.

As outlined in Part II, in this thesis, the use of the literature is approached in three ways: first, providing a framework within which to situate the study; second, identifying signposts to aid in the clarification of specific elements of the research; and third, as a guide and "mentor" to the study. In this chapter, the literature assumes a mentoring role when intertwined with the findings, providing guidance and support throughout the discussion. 


\section{Schematic thinking and the CEO role}

The principles of schema theory illustrate how, in new situations, an individual constructs meaning by the testing of new ideas and experiences against prior knowledge, experience and learning. This new knowledge is then integrated with pre-existing intellectual constructs, thereby creating frameworks (schema) of meaning (Graber, 1986; Mento \& Larson, 2004). Therefore, a schema is a framework, plan, or script by which meaning and understanding of an event or interaction is constructed (Graber, 1986). This, in turn, provides a basis for understanding how a person's cognitive structures are used to identify the generic concepts stored in that individual's memory (Stein \& Trabasso, 1982).

The in-depth examination of the data and theoretical coding processes identified that the primary concern of those taking part in this research was the ability of the CEO to adhere to the expectations and requirements within their context. This was achieved by balancing the tensions and paradoxes confronting them. Analysis of the qualitative data provided evidence of two interpretative schemas that framed the requirements and expectations of the CEO role. Driscoll (1994) asserts that every individual creates meaning from their experiences according to their own perspective of the world, whether they are aware of it or not. This creation of meaning takes place both individually (Drath \& Palus, 1994) and socially (Berger \& Luckmann, 1966). However, it is important to recognize that if the construction of meaning is approached solely from the perspective of the individual, then there may be as many realities as there are minds to conceptualise them (Gergen, 2003). The theoretical coding processes inherent in the grounded theory method identified that certain individual perceptions were, in effect, a set of collective constructions. These collective constructions were categorised and assigned to one of the 
two schemas, either the leadership interpretative schema or the institutionalised interpretative schema.

Each of the two schemas possess its own differing shared mutual understandings or provinces of meaning (Ranson et al., 1980) which, in turn, explain the differing perceptions of the role. Ranson et al., (1980) contend that these provinces of meaning are a critical part of any interpretative schema, as they represent the values and interests of those individuals who hold a particular schema. Bartunek (1984) asserts that the provinces of meaning are then drawn upon to validate and legitimise the shared fundamental assumptions about why events happen as they do, and how people understand and are to act in different situations. A shared interpretative schema creates a background of collective understanding that represents implicit agreement between people and groups within a particular context. The consequence of this agreement is the orderly production of roles and rules (Brown, 1978, p. 374). Bartunek (1984) argues that understanding the basis for the existence of interpretative schemas and how they create order and rules for roles, permits a deeper appreciation and understanding of the intricate bonds that exist between roles, structure and actions. Within the context of this research, the different perceptions of the CEO role can be clustered together in either of the two interpretative schemas, their presence shaping the shared mutual understanding and rules (norms) informing the CEO role.

Driscoll (1994) contends that when constructing meaning from events and interactions, the individual places a priority on that construction. The level of priority is dependent on the value judgements which the individual creates about a particular schema and how the information they receive relates to it. As a result, any new situation creates a perception, 
which is then integrated with the pre-existing knowledge within the schema (Mento \& Larson, 2004). Bada (2003) maintains that, in addition to recognising the presence of different schemas, an understanding of their elements, and the willingness of people to adapt to them, is equally important. The theoretical abstraction undertaken as part of the grounded theory coding processes identified that, the more advanced the ability of a CEO to identify and adapt to the expectations and requirements created by the dominant schema, the more effective they were deemed to be in their role. The next section of this chapter examines the properties of the two interpretative schemas.

\section{The leadership interpretative schema}

The frameworks and scripts of the leadership interpretative schema presented in this thesis have developed from the demands for specialist leadership skills, the increasingly dynamic business conditions and the stated personal preferences of the CEO participants participating in all stages of this research. The schemas are also formed as a result of the formalised learning experiences of the CEOs. This includes attendance at specialist leadership programmes; information and learning received through books, magazines and professional associations; and the leadership theories and models emanating from

scholarly research. The characteristics of the frameworks of this schema were deemed by the interviewees as imperative for CEOs and executives to realize success and ensure the long-term viability of their organisations.

The behaviours identified as being enacted within this schema are those that are identified by the interviewees as specialist leadership capabilities. The CEO enacting leadership 
within this schema is perceived to display an excitement and deep-seated commitment to the role, and the desire and ability to respond to challenging situations. There were recurring comments by the CEOs expressing the desire to enact the CEO role that fell within the frameworks of the leadership interpretative schema. When asked to provide an example of the behaviours displayed by a person operating within the bounds of this schema, one individual commented:

Let's see... the key ones would be an ability to step back and see the big picture. There is a personal comfort about working with ambiguity. The individual has a capability of actually being able to guide teams or guide direct reports in coaching mentoring sense rather than a direct boss/employee relationship.

Participants suggested that a CEO has to possess high levels of maturity and have an ability to form and sustain "adult" interpersonal relationships. It was recognized that the CEO had to have high levels of self-confidence, and self-awareness. Successful CEOs were recognized as approaching both their business and personal life from a "balanced" perspective. As discussed in Chapter Five, humility, professionalism, commitment and values-based behaviours were also perceived to help shape the leadership component of the CEO role. Typical of the comments identified during the theoretical coding processes was the following: "They take an individual coaching focus rather than a strongly driven hierarchical focus. They are very comfortable with their own capability and with their own self and ego".

However, the examination of the data identified that these characteristics are not enough on their own. The ability to utilise them to create a people-centric organisation is regarded as imperative. Statements made by the interviewees were that as well as being able to take a long-term strategic view of the business, the CEOs had to have the power to 
break free from the traditional, hierarchical bureaucratic organisational models. This meant they would be able to structure their organisations in a form more suited to meet the requirements of the current business environment. While business experience and strategic thinking were deemed important, it is the "stronger than usual" level of interpersonal skills that are perceived a necessary priority for the CEO. Typical of the comments received was the following made by a CEO who had worked in variety of industry sectors:

There are some people who work at being managers, and then there are some people who really work at being a leader - there are some who are probably natural at it. However, all of the leaders [to me] have an affinity with people. I mean they are warm, cuddly people, they do understand what it takes, that you have got to work at developing people, work at mentoring and encouraging people.

The analysis identified evidence of the CEOs' awareness of the significance of the linkage between positive leadership behaviours and long-term business success. There were statements made about the importance of motivating people by allowing them the freedom to act autonomously, as opposed to coercive demands. In order to enact the CEO role within the leadership interpretative schema, it is advocated that the CEO should have the ability to operate from a long term "visionary" perspective. They also have to possess the ability to "drive through change and exhibit a personal leadership approach that demonstrates an appreciation of diversity". The perception of the CEO respondents was that their successful colleagues valued the contributions of others and were conscious that achievement of organisational goals was not possible without them. This was illustrated by the following comment: 
... Finding the direction and giving it to the people ... I find people who I would consider to be great leaders, they understand what it is to get people to perform ... and they know how to do this, not by fear and not by bullying ... they know how to develop and motivate people.

Evident throughout the research were expressions of frustration concerning the existing importance of technical or professional skills. These preferences were deemed by the participants to be deeply embedded and created a bias toward specialist technical and managerial expertise, as opposed to a desire for specialist leadership capability. Even CEOs who admitted that their own background was professionally or technically oriented were adamant about the need for CEOs to develop a greater appreciation of specialist leadership capabilities.

Within the leadership schema, value is accorded to those people who may think differently or "outside the box" and who may not be the type of person traditionally seen as being "CEO material". The analysis identified an affirmation on the part of the nonCEO participants that unless there is a change in perceptions about the CEO role, those individuals who think "outside the box" will never be truly accepted as leaders. This situation is compounded by the lack of understanding of exactly what the role encompasses; specifically the executive leadership component. While the CEOs in this study were clear in their views about the leadership capabilities suffused within their role, they were of the opinion, that, in general, there was a lack of understanding of the CEO role and its leadership connection. One of the CEO comments reflecting this view was:

... I think there is a real need to explain to people what leadership is about, and I don't mean in an academic sense, I mean in an absolutely practical sense ... when you come 
down to the fundamentals, it's getting those people to do something that they don't really want to do and do it with a smile.

The CEOs also referred to the need for an ability to keep people together during the tough times, and when tasks, for example, redundancies, had to be carried out that it was still possible to work as a team and to support each other. All the CEOs recognised the capacity to think in accordance with, and to operate within what has been identified as, the leadership interpretative schema, was fundamental to ensuring the long-term viability of their organisation. However, recurring throughout the study was a sense of disquiet on the part of the CEO respondents about the nature of the constraints that hindered them from leading in such a manner.

\section{The institutionalised interpretative schema}

The second of the two interpretative schemas within the substantive research environment is the institutionalised leadership schema. The term institutionalised is defined in this study as, a situation where a phenomenon is so deeply embedded within an organisation, society or a group, that it has become as a convention (Pearsall, 1999). The features or properties of this interpretative schema emphasise the importance of short-term profitability and the requirement for a high level of return to shareholders. A managerial orientation is the preferred style of role enactment, and if the individual has achieved a high level of technical or professional qualification, then that is deemed to reflect a strengthening of that orientation. A comment made by a non-CEO interviewee provided some insight into the mindsets that influence the definition, enactment and acquisition of the CEO role within this schema: 
I think there is a type of CEO that tends to get the CEO roles in New Zealand and this type is driven by short-term, quarterly reporting, focus on short term profits and all that sort of thing, as opposed to people who build organisations that have sustainability.

Interviewees were asked why opinions such as the above were expressed. In turn, they spoke of the influence of history, specifically New Zealand's colonial history. The historical, economic and social traditions originating from this colonisation process are considered to have influenced the formation of the many of the perceptions held within this schema. For example, one comment was as follows: “...a deep-seated suspicion of business and business leaders in New Zealand. It has its origins in the traditional Kiwi working class self reliance”.

Such a perception was deemed to constrain the CEO's latitude of discretion, precluding them from operating outside the institutionalised interpretative schema. This inability to "break away" restricts the CEO's capacity to implement the innovative changes they may consider essential -specifically, those changes required to address the competitive challenges presented by a globalised business environment. One non-CEO made the following comment when contemplating the dominance of the institutionalised interpretative schema:

It all rests on the fundamental premise of the rational economic man and I've never met one! And I'd be bloody frightened if I did, because he would be a soulless creature who I'd never want to employ...that is why I think this whole leadership thing in New Zealand culture is interesting.

When reflecting on the current situation, many spoke of the "very real gulf" between what "we say we want" and "what we will accept" from the CEO when they enact the 
role, in particular with regard to development of CEO capability. One individual reflected on how, even the most fundamental hows and whys of executive leadership are lacking, especially the long term focus:

So we say leadership, but we don't quite of know how to make it happen. As I was saying before, if I want to be an Olympic marathon runner, I have to get my shoes on today and tomorrow, and just one step at a time, to pound the pavement. Keep it happening, and just grinding away ... we were talking before of how senior management generally is quite short term.

This statement reflected similar comments made throughout the project. The notion of a short-term orientation was evidenced throughout the research and was judged by the respondents to impact on all features of business life, including planning and business strategy. The short-term focus was attributed directly to the constraints within the CEO's context. However, understanding precisely what the requirements and expectations of the CEO are was not a straightforward issue, as explained by one person:

The higher you get, the more filters there are in the system ... this means you can't rely on the same way of getting to the grass roots of understanding. I think we have really not done a lot around the need for leadership development either. We've put these people in roles because they've been successful functionally, and haven't done a lot to develop and support them.

The analysis described in Chapter Four as theoretical coding identified that the institutionalised schema was the dominant schema informing the CEO role. This includes how it is defined, acquired and enacted, and ultimately impacts the retention of capable people within the role. This resulted in a situation where the two schemas were identified as being in 'opposition' to each other. It was as if they were colliding. 


\section{The collisions of interpretative schema}

As per the prior discussion, the major elements comprising the two interpretative schemas are different. This in turn, leads to dissimilar perceptions of the CEO role, and different role expectations and requirements of the CEO. The views and behaviours could be described as if they were in collision. Collisions are then social processes that occur when elements that are significantly different come into opposition with each other (Pearsall, 1999). Using the work of Shaw (1990) as a base, the reasons for these collisions can be categorised as follows:

- The difference between the behavioural scripts held by the CEOs and the groups of role senders. This is evidenced by the expressed desire on the part of the CEOs to enact more calculated risk-oriented behaviours and the expectation for risk averse behaviour.

- The differences in the structure of the schemas, in particular the short term versus long term thinking, that was believed to constrain the decision-making ability of the CEOs.

- The difference in the extent to which individuals process information in an automatic or controlled manner.

The collisions were also identified as one source of the tensions that confronted the CEO. Continually throughout the research, there was evidence of a difficulty on the part of the CEO to reconcile these tensions, a situation that created expressions of anger and exasperation, resulting in elevated levels of dissonance for the CEO involved. As 
discussed previously, dissonance theory (Brehm \& Cohen, 1962; Festinger, 1957) explains how inconsistent cognitions or thoughts are intolerable for a human being and when they exist, the individual will go to great lengths to eliminate them (Gergen \& Gergen, 1971). Examples drawn from the data as evidence of these collisions are given below.

Situations were identified where a CEO had found his or her ethical standards were compromised by the demands of stakeholders, for example, expressed as requirements of the board:

... even if it does jeopardise New Zealand business [the level of profit]. It is important because New Zealand is a very ethical country. There is no corruption here and we want to make sure that remains. However, what occurs is that the CEO can be expected to compromise especially if there is "lowered profitability, even if there is a valid reason and the board is having political pressure put on it".

One participant who had been a CEO, and was now a board chair, spoke of the conflict between the short and the long-term and how this can and has compromised both the nature and level of executive leadership and the long-term viability of the organisation:

Quite clearly some boards have been captured at times ... a philosophy of short-term advancement for the current set of shareholders being the main game .... This has been at the expense of the well-being of the organisation ... and at the expense of the executive management ...

At the same time, there was an awareness of the importance of the CEO having high levels of people skills and being able to utilise these skills to ensure an effective organisation. 
I mean it is a case of we rather than me ... the CEO that can engage people, engage in a vision, understand what their role is in the organisation, their objectives in the organisation ... they should give them the power and be empowering so people can achieve their potential... however what happens more often ...

The individual making the above statement went on to express concern about the reality of the situation facing many of his colleagues:

The individual is forced into playing a political game whether it be the media, politicians, policy-makers or their shareholders ... then you watch them [the CEO] begin to lose - be unable to find support - the support of the board, so more questions are asked and people are 'climbing all over the place' - they start to lose confidence because they can't make things happen - the numbers come under scrutiny. The team kind of falls apart.

This participant spoke of how he had observed colleagues being forced into untenable situations where ability to utilise their skills to enact their role effectively was compromised or constrained.

\section{Constraining the ability of the CEO to act}

The conflicting nature of the expectations formed by the two interpretative schemas, and the need to reconcile such conflict, which often remained in an unarticulated form, created a sense of despair in the CEOs. They spoke of the desire and requirement to be able to lead their organisations within the frameworks of the leadership interpretative schema while at the same time managing the expectations embedded within the institutionalised schema, that is, working to ensure the future sustainability of their organisations. 
The memos, written at the time of data collection, were designed to capture aspects of tone of voice; body language etc and which accompany the verbatim record of the interview, used the word robust used to describe the opinions that were voiced concerning the future of executive leadership. There was an expressed desire on the part of the CEO interviewees to be able to move beyond the short-term thinking that has typified many organisations. This included the identification of a sense of powerlessness that the $\mathrm{CEO}$ respondents felt about being unable to accommodate the unwitting influence of the institutionalised schema. Some CEOs referred to colleagues:

...who have come in [to an organisation] believing this was the agenda and this was the way the organisation was and this was how decisions would be made. Then when they get in there and find that it's quite different, and they end up saying "it's all too hard, it's not right", and walk away from it.

When they were asked to expand on what he or she meant by "finding it is quite different", the disparity between the long-term and the short-term expectations and consequent implications were offered as the reason. Some CEOs spoke of a sense of disillusionment that they experienced when they open, what one CEO referred to as a 'Pandora's box'. While she stated that she would have still taken the job, she would have preferred a more 'up front and honest' process on the part of the board at the time of her recruitment. A similar disillusionment was spoken of by both CEO and non-CEO consultant respondents, and was identified as having a significant influence on the level of trust that may or may not exist between the board and the CEO.

The findings of the study were in accord with Hambrick \& Finkelstein's (1987) findings on the latitude of discretion available to CEOs. That is, the CEO is so affected by the perceived constraints existing within their context that the CEO perceives that he or she is 
not permitted to or able to choose to undertake certain important strategic actions. For example one CEO said:

Well, I would say you'd just look at a number of the CEO's who have been exited from business in New Zealand and say that had there been clarity and honesty and a good process up front, that need not have happened.

... and further added:

When there are misaligned expectations, not only between the CEO and the board chair, and it often exists between board members as well. When the perceptions that are created by the politicians and the media are added to the mix, then the disparity becomes greater and there is only one loser ... and that is the CEO

Bandura (2001) states that the power of an individual to act, in this case, the CEO, falls within the realms of personal agency. He goes on to argue that personal agency can not exist in isolation; rather it operates within a broad network of social structural configurations. As such the CEO, in order to operate effectively, must be mindful of these social structural influences. Bandura (1997) contends that if an individual can not [deliberately] act in isolation, then a collective agency is often created. He goes on to assert that people's shared belief in their collective power to produce desired results is the key ingredient for collective agency. Therefore, if the apparent dominance of the institutionalised interpretative schema is to be lessened then the shared belief of the CEOs, in their ability to achieve desired results, may be required if change is to occur.

Bandura (2001) further argues collective agency is developed from the broad network of social structures that represent authorised systems of rules, social practices and sanctions designed to regulate the social structural functions. Therefore, the CEO operates within 
these social structural functions by virtue of holding an ascribed or authorised role (Giddens, 1984). The constraints identified within this study's research context were experienced by the CEOs as a collective set of social structural processes.

Examples drawn from the discussions contained within the thesis to illustrate the level of agency afforded the CEO are as follows:

First, the potential exists for a less than healthy relationship to exist between the board/chair and the CEO, a situation created primarily from the misaligned expectations with regard to key performance indicators. These misaligned expectations can create a situation of conflict, and where and when board members had political affiliations, there was evidence of perceptions that CEOs were constrained even further from acting. As a result the $\mathrm{CEO}$ had limited latitude of discretion to initiate radical long-term strategic changes. An example of a comment received was:

There aren't well aligned performance expectations, there isn't a clearly articulated strategy that is shared by everybody so the CEO might be dancing to one tune and the Board think they are dancing to another. Sometimes it is incompatibility of agendas of various Board members that are not necessarily shared by the entire Board ... so you get factions and splits.

Second, one example is the seemingly higher level of scrutiny that results from the role being situated in a small business environment as opposed to that in a larger business environment. This is exacerbated by the scrutiny of the role by the media and by politicians. This, in turn, is perceived to have constrained CEO risk-taking behaviour, by heightening the fear of making the mistakes which could become 'cannon fodder' and 
possible destroy their career. A comment that summarises such concerns expressed during the research is:

The media haven't been very good at balanced views... I have no recollection of them seeking a comment about XXX situation ... in fact I don't believe the media have been very insightful they tend to deal with whoever the company puts up ... and of course the Chairman wants to be involved in announcing the good news and the CEO gets the bad news... and this colours people's views. It can actually make or break a CEO ... they haven't been very good at going behind (investigative reporting).

Third, the respondents referred, throughout the research, to facets of their context that were considered to have their foundation in New Zealand's colonial origins, for example, the creation of an egalitarian culture that values technical and professional skills, at the expense of specialist leadership capabilities. It is also deemed to restrain the enactment of high profile leadership behaviours. One consequence was a limited number of highprofile business role models for young executives. A comment received from one CEO suggested that:

It all stems from our colonial traditions and the working class ethic that has developed as a result ... that and the tall poppy syndrome and the No 8 fencing wire, the emphasis on egalitarianism and she'll be right ... all conspire to create an environment where it is better to keep your head down and not draw attention by conspicuous consumption or through the media...

This situation resulted in examination and further refinement of the conceptualisation of the CEO role within the substantive context of this research. The next section of this chapter offers an alternative to that provided at the beginning of the thesis. 


\section{Defining the CEO role}

As a result of the discussion contained in the earlier sections of this chapter, the researcher re-examined the definition of the CEO role provided in Chapters One and Two. At the forefront of the discussion throughout the thesis, the operational definition of the CEO has been the individual who has responsibility for the conduct and performance of an entire organisation, as opposed to a subunit of that organisation (Hambrick, 1998), and who has "the ability to influence others to make day to day decisions that enhance the long term viability of the organisation, while maintaining its short-term stability" (Rowe, 2001, p. 83). This definition included a consideration of the processual nature of executive leadership, whereby an executive guides, structures and facilitates activities and relationships, and influences the attitudes, behaviour and values of others (Daft, 2002; Vecchio, 1995; Yukl, 2002).

Comparing the properties of this definition and the frameworks contained within the two interpretative schemas, only one aspect of the definition as relating to the CEO role was identified. That is, the short-term stability of the organisation. This was emphasised over and above the long-term visionary leadership behaviours that are deemed to be essential to ensuring the long term viability of the organisation. Tensions experienced by the CEO stemmed from their desire to lead their organisation in a manner that ensures its longterm viability as well as maintaining it short-term profitability.

To aid in the confirmability of the findings, the researcher revisited a selection of the participants (theoretical sampling) in order to discuss the issues raised as a result of the emergent findings. There was a consensus that there was a need for a more apt definition 
or conceptualisation of the $\mathrm{CEO}$ role and how the role should be enacted. The emergent findings led me back to Pye's (2002) statement:

Conceptualising leadership presents a challenge which is akin to capturing the ethereal qualities of "the moon on the water"; you know it when you see it, but it defies capture. (p.2)

The CEO role is an interactive, multi-dimensional process (see Chapter Two) that extends beyond formal organisation and leadership boundaries (Northouse, 2004). This then leads to the individual's perceptions and feelings and responses to the interactions they experience in their context, becoming as important as their characteristics, abilities and traits (Barker, 2001). When synthesising these views with those of Pye's (2002), it became apparent the existing definitions of the CEO role and leadership have not fully captured the nuances of the role and its relationship with its context. The focus of definitions solely focusing on the traits and behaviours and the consequences of the CEO's actions have meant that other notions and dynamics, for example, context and the processual elements, have been excluded from consideration. However, as a result of the concurrent theoretical sampling and coding, a necessity to establish a more allencompassing conceptualisation of leadership that applies to CEOs was identified. Such a conceptualisation would have to take account of leadership as a multi-dimensional construct and as an integral part of the context within which it is situated. Further examination of the interviews and engagement with the iterative theoretical coding processes resulted in the identification of the overarching social structural process. That is the $C E O$ role is a social institution within the context in which it is situated. 


\section{The CEO role as a social institution}

As defined by Turner (1997) a social institution is the complexity of positions, roles, norms and values lodged in social structures. Summarising Martin's (2004) defining of a social institution, it is the contention of the researcher that the CEO role can be deemed a social institution because:

- The role consists of a collective of people who associate with each other

- The role endures across time and geographic boundaries.

- As a social institution, the CEO role entails distinct social practices that recur and are repeated over time by group members

- The CEO as a social institution has some behaviours constrained and others facilitated, this in turn forbids some alternatives and choices of actions.

- A social institution, in this case the CEO role, contains social positions and relationships that are characterised by particular expectations, rules/norms and procedures which 'make sense'

- A social institution is constituted and reconstituted by embodied agents, in this case the CEO, who enact practices to constitute the role in varying ways

- Social institutions are internalised by group members as identities and selves, and they are displayed as personalities. In this case, the CEO's experiences within, and, in the institution of the CEO role becomes incorporated into their identity and their personal self. This occurs as the CEO identify with their positions, the practices they enact and the positions they occupy

- Social institutions are inconsistent, contradictory and rife with conflict. Despite their apparent coherence, roles such as the CEOs are not highly coherent or 
integrated. The role entails many diverse practices, some of which conflict with each other.

Conceptualising the CEO role as a social institution facilitates a critical analysis of the role, for example, examining how perceptions of the role are formed within a specific context. This includes a discussion of the formation of the social norms and the forces that enhance or impede the individual's ability to carry out the role.

As a social institution, the CEO role is bounded and informed by a set of social norms. These norms are formed by the social structural processes having their genesis in the features of a society; for example, the historical, economic and religious traditions contained within the business bedrock (see Chapter Six, page 182). As discussed in the literature review (Chapter Two), every role comprises a set of behaviours that are enacted by an individual in that role. The behaviours are in turn framed by a set of rules (social norms) that guide the individual's behaviour in specific situation (Baron, Byrne, \& Branscombe, 2007). Baron et al., (2007) go on to argue that a number of social norms are explicitly stated and formal for example, role descriptions and contracts. Others are unspoken or implicit and may have been developed in an informal manner, their presence is often only identified when they are transgressed. Failure to adhere to these implicit social norms can result in punishments, the most feared of which is exclusion from the group (Baron et al., 2007).

Within the context of this research, the norms that had the greatest influence on the CEO construct were identified as the implicit social norms. Analysis of the interviews provided evidence whereby, if a CEO transgresses the implicit social norms, they may be 
excluded from the society of which they are a member. A comment that typifies those received was:

The CEO was good but his profile got too high for the sector and while there was a 'goes with the territory' mentality amongst his colleagues it didn't win him any friends ... he is working in North America now

The CEO participants contend that while it may not result in separation from your peers, it may result in exclusion from the New Zealand business community. For example, "he had to go off-shore, while the problems weren't really his fault he was labelled 'to hot to handle' for most New Zealand organisations.”

The likelihood of this happening in a small business environment was deemed by the participants to be greater than in larger environments. The reasoning of the participants is that in the smaller environment, the CEO is more visible and open to scrutiny. Baron et al., (2007) argue the adherence to the social norms has to be displayed frequently and with visibility. As discussed in Chapter Six, the analysis identified a set of forces within the business bedrock that create an array of perceptions regarding the status of the CEO role. One CEO's comment encapsulated the opinions expressed by some of the participants in this regard was:

The trouble is you are damned if you do and damned if you don't ... you have to interact with the media - And as a consequence you become the media property and that's fine when things are going well but when things turn they absolutely turn real frosty. Then the perceptions of the CEO become as if they are a lowlife... we become one of the great unwashed... 
As discussed previously, there has been a recurring concern expressed throughout the research about negative commentary pertaining to the CEO role. This, in turn, creates a set of negative perceptions about the status of the CEO role that helps generates the norms that determine how the role should be enacted, and subsequently the acquisition and retention of capable people to the role. Scheibe (1995) maintains that role status is an abstraction that is defined by the expectations of a relevant group or society within which a particular role is situated.

The analysis identified that the social status and the social norms that inform the CEO role are created, in part, as a result of the informal, incidental and situated theoretical perspectives of learning, and are conveyed by the role senders in both the external and internal contexts. As these learning processes occur they are refined by the personal values and expectations of the individual CEO. The next section of this chapter outlines the function of the various theoretical perspectives of learning that contribute to the formation of the social norms.

\section{The role of learning in creating social norms}

As discussed in Chapter Five, defining learning exclusively in terms of a literal dictionary definition, as the "knowledge and skills acquired through experience or study or by being taught" (Pearsall, 1999), would obscure many of the nuances contributing to the learning of the social norms that were identified throughout this thesis. Utilising an interpretivist perspective within the modified grounded theory method acknowledges learning as a social psychological process that is unable to be separated from the context in which it 
occurs. As a result an emphasis is placed on the beliefs and attitudes of the learner as opposed to those focusing solely on those of the teacher (Hein, 1991). The aim is for the learner to be able to construct new ideas and/or concepts based on their current or past knowledge (Bruner, 1966), thereby providing a guide for future action (Mezirow, 1994). Therefore, it is not just the interactions which the CEO experiences; it is also how they construct meaning from a specific learning experience that determines the effectiveness of the outcomes.

Hein (1991) goes on to argue that when an individual interprets their experiences in order to create meaning, they do so in a way that makes sense for them at a particular stage of his or her life. The learning experience is then placed within a particular interpretative schema that exists at that point of time. The data analysis indicated that the interactions pertaining to the CEO role commence early in an individual's life and those may be interpreted, fit or be placed within a schema appropriate for that period in his or her life. However, in the long-term, this schema may be inappropriate. The failure to encounter different learning experiences at a different age or stage in an individual's life may result in this inappropriate schema becoming institutionalised. The findings of this thesis suggest that unless concerted efforts are made to change the thinking patterns that are unwittingly influenced by the schema, then this or any schema can remain unchanged. There are implications also for the nature of executive development activities, ensuring they take account of schematic thinking and that they enable the CEO to achieve the ability to respond to the demands of changing contexts. This means that a life-long holistic approach to learning may be central to ensuring effective CEOs. The importance of life-long learning was expressed by one CEO of many years experience as follows: 
... and that to me is the mark of a good leader. You see these things about learning and, to me, smart people believe you never stop learning. It is part of the excitement of it all, if you stop learning you are probably dead or close to it.

Hein (1991) contends that as a social psychological process, learning is complex, and an integral part of an individual's life unable to be divorced from their prejudices and fears, ambitions and desires. The theoretical coding identified that the more advanced a CEO's ability to interpret, integrate and understand the expectations and requirements of the CEO role, the more effective they were perceived to be by role-sender groups. One consultant when reflecting on effective leadership in a CEO role commented:

...they would have felt a lot more comfortable personally and therefore if you think about the performances and the relationship to internal personal integration as being a factor here and then feeling comfortable about it and not anxious, then they would be as effective as they could be.

The ultimate outcome of any learning experience is that the learner, in this case the CEO, is able to gain mastery, autonomy and independence as a result of an interaction. This was identified by the respondents as an essential attribute for an effective CEO. Gaining mastery and autonomy empowers the individual to find their own solutions to the challenges they encounter. The CEO role, as a social institution, necessitates these solutions adhere to the social norms informing the role. Failure to do so would result in a less than effective enactment of the role. The next section of this chapter provides a discussion of the different forms of learning that were identified as a result of the data analysis. 


\section{Informal and incidental learning}

As identified in Chapter Five, the participants did not fully recognise the importance of informal and incidental experiences in contributing to the learning of the CEO role. Indeed, participants more likely attributed the primary means of learning to the formalised developmental experiences. However, the memos and coding notes accompanying the interview transcripts confirmed that the informal and incidental experiences were spoken of with a degree of passion on occasions.

Use of the theoretical sampling processes and the semi-structured interviewing techniques allowed the researcher to re-trace steps where necessary, resulting in participants reflecting more deeply on their responses. For example, in Chapter Five, the interviewees spoke initially of positive school experiences. They were then asked to reflect on both the good and the not so good. This then led to examples of both negative informal and incidental experiences being provided. One case in point was when a CEO spoke fondly of his childhood experiences. However, when asked to compare these experiences with some that were not so favourable, he began to speak of how his family upbringing had constrained his performance in an executive role later in his life:

We don't do it in a family situation, we don't do it in schools, and we sweep things under the carpet. I mean I grew up in a family where you know conflict was avoided and I had to learn to cope with that as I grew older. We don't do it, I can't think of any situation where you are taught some of those mechanisms.

The grounded theory analysis showed that informal and incidental learning experiences were identified as contributing to the development of the social norms that act to define 
the CEO role, and that act to influence its fulfilment. The informal and incidental experiences were also identified being present in the situated learning experiences (onthe-job training) undertaken by the CEOs. The next section outlines the role of situated learning in creating the social norms.

\section{Situated learning experiences and the development of a community of practice}

As discussed in Chapter Six, situated learning is one of the primary means of organisational learning in New Zealand. Lave and Wenger (1991) contend that situated learning focuses on the interplay between the function of an activity, and the context and culture within which it occurs. This is based on the supposition that all interactions are highly contextualised activities as opposed to the often decontextualised environment when formalised learning is undertaken (Wenger, 1997).

Situated learning, as a contextualised learning process, provides opportunities for informal and incidental interactions to happen. The majority of the participants spoke of positive situated experiences that had occurred throughout their career. These experiences, in turn, were noted to have contributed to the acquisition of business knowledge and achieving an awareness of the realities of the role, and the developmental processes involved in acquiring an executive leadership role. As one of the primary means of CEO development, situated learning was instrumental in the conveying and sustaining of the social norms. One CEO spoke of his first year as a graduate employee in a major international organisation stating that: 
I spent a year in New Zealand going round simply learning about the business and having a diary and having to produce the diary ... to the managers ... showing that I actually understood what the process was in the bloody XXX department of all things ... it's terrible to think about, but it's more like an apprenticeship and then I was given projects you know, to work with and I was given a mentor within the organisation.

An important principle of situated learning is that the individual works on genuine and realistic tasks reflecting the real world (Jonassen, 1994). The basic premise of the social experiences provided by this form of learning is that they are transferred from the classroom into the realm of practice, that is, the workplace. The removal of learning interactions from the classroom allows the learner to engage with the subject matter within the context of real world challenges (Stein, 1998). So while the social norms may be implicit and pervasive, they can also be familiar as a result of the interactions experienced by the individual in the situated contexts.

Awareness was expressed about the importance of situated learning having relevance to, and reflecting the true realities of the CEO role. In doing so, the effectiveness of the situated learning experience was perceived to be maximised. One HR executive, with 20 years experience in two of New Zealand's largest companies, commented that:

... we focussed on being clear on what we wanted to be more concise about how we developed people towards that end gain. We focus much more now on job experience, job rotation and work experience and we attribute $90 \%$ of the success of an executive to amount of on-the-job experience [situated learning] they gain.

The formation of the social relationships created from these experiences support the creation of what has become known as a community of practice (Lave \& Wenger, 1991), that is, a group of people who are informally bound together by shared expertise and 
enthusiasm for joint enterprise (Wenger \& Snyder, 2000), and according to Wenger (1998), they are a integral part of life. The concept of a community of practice, as theorised by Wenger $(1997,1998)$, provides an explanation of how role incumbents, for example, CEOs, are informally bound together as a group or unit. As the CEOs move through their career, it is the situated, informal and incidental learning interactions that actively engage them within their community of practice. Their lived experiences were identified as a major determinant in the learning of the CEO role. This is in keeping with the findings of Kempster (2006) who established that executive leadership is learned primarily through socialisation.

As discussed in Chapter Six, concern has been expressed by the non-CEO participants about the relevance of the situated learning that is being provided. The findings of this study suggest that situated learning must be applicable to the specific context and to the perceived future needs of the role and the organisation. The non-CEO participants stated that partaking in learning experiences that do not provide for the future may compromise the long-term viability of an organisation and a business community. Relevance to the social context is vital

This thesis argues that while the CEO may be part of a community of practice and ascribes to the social norms of that community, for example, those embodied within the leadership interpretative schema, that this is only one community that the CEO is part of. The CEO is also part of a wider community, that which is formed by their wider external context. They are bound to this wider community, just as they are to the CEO community of practice and their peers. The analysis identified that the CEOs perceive they are expected to heed the social norms created by this external environment just as they do 
those of their own group. When the social norms of the different groups are in opposition to each other, then tensions and paradoxes transpire. This, then, led to the identification of the overarching social psychological process, balancing the tensions and the paradoxes.

\section{Balancing the tensions and paradoxes}

This section of the chapter discusses the social psychological process identified as balancing the tensions and the paradoxes. Throughout the study, the participants used the term balance to explain how the CEO attempts to cope with the demands of their role and their personal lives. The balancing of two opposing, apparently contradictory forms of behaviour led to a conclusion that the CEO role could be paradoxical in and of itself. Paradox has been defined as a phenomenon that denotes contradictory yet interrelated elements, elements that seem logical in isolation but absurd and irrational when appearing simultaneously (Cameron \& Quinn, 1988; Lewis, 2000, p. 760). These elements, in turn, create the tensions and paradoxes confronting the CEOs taking part in this study.

The CEOs spoke of the balancing act that they had to perform as they carried out their role. Some of them described it as if they were on a tight-rope (See Figure 16). Such a tightrope is formed by the sociological, psychological, philosophical, economic, historical forces within the research context. These forces create the frameworks and scripts that define the CEO construct, its enactment, acquisition and retention. The narrowness of the tightrope and the need to achieve self-assurance on it, provides what Finkelstein and Hambrick (1996) term latitude of discretion. In this study, this latitude of discretion was 
considered by the CEOs to be very slender. Suggestions of the participants were that the individual has to balance these forces, while at the same time heeding the demands of the different role sender groups within their context. These demands act as an unbalancing mechanism, limiting the choices available to the individual. If the CEO made a decision outside their latitude of discretion and breached the social norms, they could become unbalanced and be tipped off the tightrope. There are two identified outcomes of this balancing act. The first is that an executive leader acquires the capabilities to operate within a small business community and the pressures inherent within that community. As a result the decision is made to acquire or remain in the role. The second is when an unbalancing occurs, and that when this transpires the CEO or potential CEO decides to the leave the role. Within this study the word leave is defined as, "to go away from or to abandon, or cause to be in a particular state or position. When the plural leavings is used this applies to things that have been left as worthless" (Pearsall, 1999) 


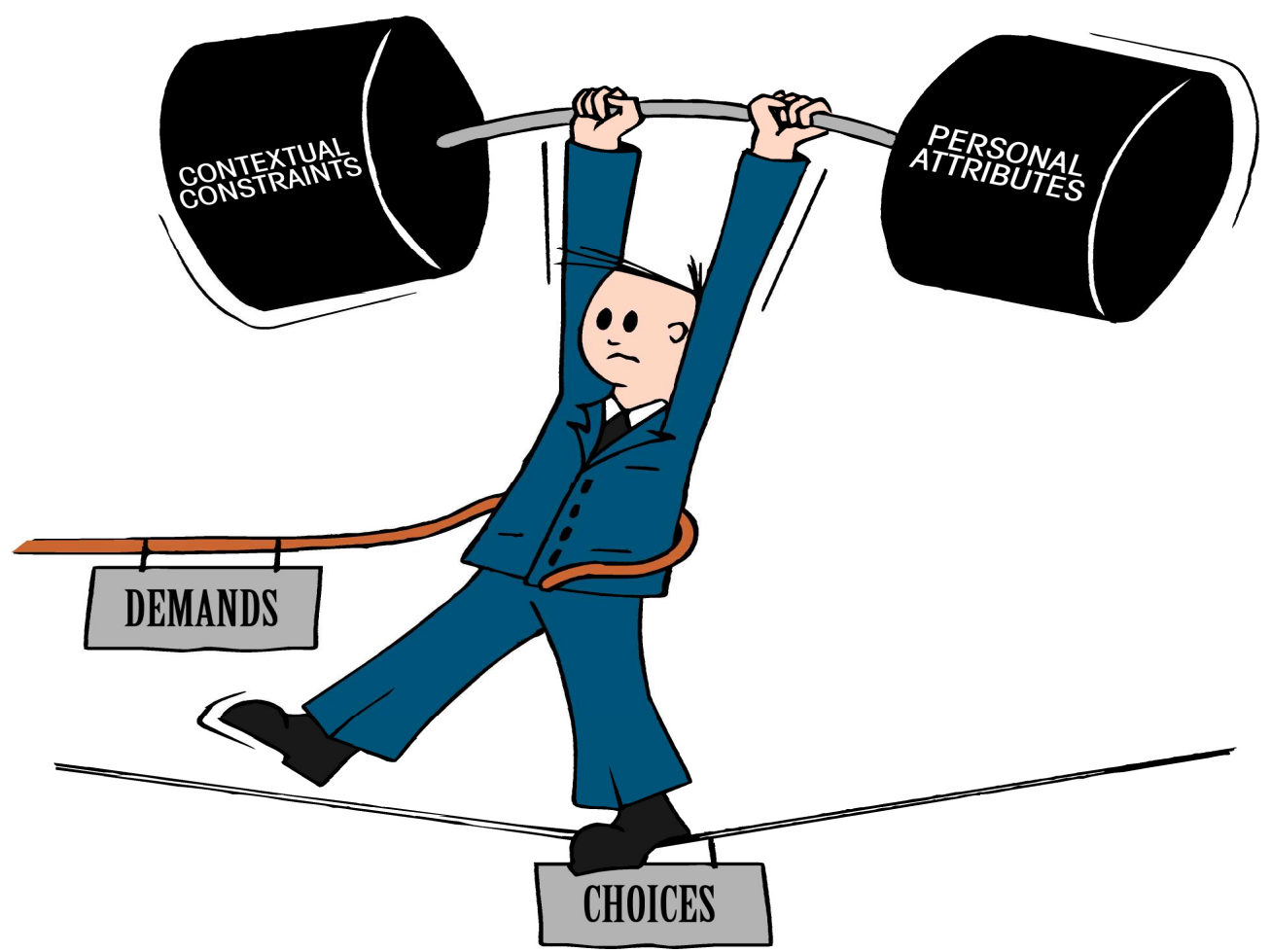

When discussing the above diagram as part of the confirmability process with those participating in the research, there was an immediate reaction and recognition, both humorous and cynical. Those consulted agreed that it was a fair representation of the situation that CEOs frequently found themselves in. Therefore, the figure remains as a mark of that sense of recognition, and the damned if you do and damned if you don't situations they stated they frequently experienced.

In this study, the tensions that necessitated this act of balancing required a deeper explanation to ensure that the concept of paradox was not offered as a superficial explanation. Lewis (2000) maintains that the labelling of a situation as paradoxical does not necessarily promote an understanding of how or why it is a paradox. However, the use of how and why research questions in this thesis enabled the researcher to provide a 
deeper explanation of the paradoxes and tensions and of why they occur. The modified grounded theory approach as posited by Charmaz (2000) avoided the study becoming one of simply identifying and discussing paradox. The decision to acknowledge the presence of paradoxical situations and focus the research on seeking an explanation for the perceptions of their existence permitted the identification of the forces that precipitate them, their consequences and implications. For example, it is evident in discussion of the origins of the mythology of the No 8 fencing wire and the perceived stated preference for technical and professional skills as opposed to leadership skills:

The other thing is recognising leadership. People aren't actually recognising leadership ... it is the management versus leadership debate that has been around for year., However, we also have the technical competence, like the No 8 fencing wire, and there is still a great deal of it in most organisations and there are a large number of people promoted on that No 8 fencing wire basis.

The CEO who successfully managed to retain their balance was judged to have developed a holistic approach to their life, both professional and personal:

When I say successful, truly successful, they have this quite holistic approach to their particular job, their organisation, their role, their life.

The conduct of those CEOs, who were identified as successful, was perceived by the interviewees to have achieved equilibrium. This, in turn, allowed them to meet the challenges of the role and balance the competing demands that confront them.

And for me that was about confidence, building my confidence and my understanding so I could be tough and warm at the same time. 
The CEOs taking part in this study expressed an awareness of the need to balance the contradictory demands of the role and stated that they wished this was not such a demanding task. However, inherent in conceptualising the role as a social institution was an expectation that they achieved the balancing of the tensions and paradoxes within the bounds of the social norms that inform the role. Within the context of this study, the analysis identified the counterbalancing forces as constraints existing within the context of the CEO that can be explained in the sub-themes, the repression, and restriction and rejecting of the role.

While the CEOs implicitly expressed the desire to be able to work within the bounds of both interpretative schemas, and not to have to choose between the two, a level of conflict was accepted as a reality. The analysis indicated that if a CEO was perceived as unable to balance the tensions and paradoxes, they had little option but to leave the role. It was apparent from the participants' comments that capable executives walked away from the opportunity to acquire a CEO role and those already in the role may decide to leave a small business environment for the opportunities of a larger environment. Alternatively, it was apparent to the CEO participants that some of their colleagues chose to remain in New Zealand. However, they decided to leave the business community for an alternative lifestyle or career direction. The ability to achieve equilibrium was vital. It was accepted by the CEO participants that, in some cases, potential CEOs recognised that they would not be able to achieve this equilibrium and therefore would not be able to develop the level of commitment required to meet the challenges of the role and to be successful. The research participants spoke of how the possible view of the future self, for these individuals, was flawed. 
I guess what's concerning is some of these young ones coming through who are very capable, who are saying well there's more to life than this. I don't want the hassle; I actually want a balance in my life. I want to do a bit of this and a bit of that and have family time or whatever; they want more flexibility, the money is not actually worth it any more.

As a social institution, the CEO role is bound by a set of social norms. The analysis identified that the social norms, specifically the implicit social norms, can make the balancing of the tensions and paradoxes seem virtually impossible. This was identified, by the CEO participant, as exposing him or her to criticism from role sender groups, for example, the media, or boards of directors. As discussed in Chapter Six, the CEOs expressed concern about the number of times they had to compromise their ability to act within the bounds of both the interpretative schemas. Comments such as: "the media grabbing at even one year of lowered profitability to make news" were indicative of this situation. Discord between boards of directors and the CEO, with regard to conflicting expectations of the role, were supposed as responsible for many CEOs " $b a d$ experiences":

They don't necessarily recruit for what the organisation needs, they may need different skills and competencies and experiences. That comes back to the long-term versus shortterm debate again.

An understanding how and why the tensions and paradoxes are perceived to exist is required in order to inform choices and add value to organisational decisions and actions (Clegg, da Cunha \& e Cunha, 2002; Weick, 1987). Clegg et al., (2002) go on to argue that as a day-to-day reality, the role of paradox within organisations is to keep the CEO on their toes and in a state of continuous awareness of its own contradictions. Rather than 
paradox being thought of as a constraint, they say that it should be embraced and treated as a challenge to be resolved. There was evidence that the CEOs in this study sought to construct meaning of the tensions and paradoxes. Examples of this were when they turned to New Zealand's historical traditions for explanations, or when they commented on the influence that the media has in a small business environment, or on the role that social forces, for example, the tall poppy syndrome and the No 8 fencing wire, has on the role. There was awareness that their ability to maintain their balance resulted just as much from forces in their external context, as those in the internal organisation and their own personal values.

In Chapter One, this thesis opened with the following quote by Max DePree (1998):

"When a chief executive officer departs an organisation, they should leave behind them both assets and a legacy" (p.130).

The perceptions of the participants in this study are that it is much more difficult for a CEO to leave both assets and a legacy, if they are unable to balance the tensions and paradoxes effectively.

\section{Conclusion}

This chapter outlines the frameworks and scripts of the two interpretative schemas that inform the CEO role. The analysis identified that the dominant schema informing the CEO role was the institutionalised interpretative schema in contrast to the frameworks 
and scripts of the leadership interpretative schema. In order to accommodate the expectations of role sender groups, risk averse, short-term, cost focussed behaviour was perceived as the overriding requirement. The opposing nature of the two schemas shaped the tensions that were identified as responsible for many of the paradoxical situations that CEOs tend to face on a daily basis as they carry out their role. These tensions have implications for the way in which perceptions are shaped regarding the desirability of the role of the CEO as a career option and, the ability to attract and develop the best possible recruits for CEO roles.

The contention of this thesis is that the CEO role in New Zealand should be conceptualised as a social institution. It is a role having its own set of social norms that create and sustain a social order governing the behaviour of the CEO. Conceptualising the role in this manner acknowledges the multi-dimensional nature of the role, embracing and celebrating the context in which it is situated.

Studying the research participants' perceptions of the CEO role using a qualitative perspective provided a voice for those who participated in this research, thereby enabling them to articulate their views about the issues they perceive that influence the definition of their role, the subsequent enactment of that role and the acquisition and retention of talented people within that role. Traditionally, the concept of being able to have or express a voice has been ascribed to the weak, to minorities, the disadvantaged and dispossessed (Baez, 2002). The perception, both within society and within organisations, is that CEOs have considerable power and status and therefore have the ability to voice their 'true feelings' (Finkelstein \& Hambrick, 1996). 
Paradoxically, this research identified executive leaders as perceiving that they have very little voice. That is, the analysis identified they perceive to be constrained and silenced with regard to certain aspects of their role, their feelings and how they construct meaning regarding their role. As discussed previously, Hambrick \& Finkelstein (1987) referred to this concept as latitude of discretion. Latitude of discretion is a notion that gives meaning to situations when the CEO is so confined by external constraints, institutional pressures and internal inertia, that he or she perceives to be not permitted, or chooses not to undertake certain major strategic actions. The theoretical coding revealed that the expectations of the role-sender groups control how the role is defined and enacted. This, in turn, influences the acquisition and retention of talented people. This resulted in the CEO identified as a role-taker (Cast, 2004), as such accepting the requirements and expectations of the role, as opposed a role-maker (Cast, 2004), where they create themselves in the role. The frameworks of the institutionalised interpretative schema create limited latitude of discretion for the CEO in all facets of their role.

As discussed in Chapter Three, there are elements of all grounded theory studies that contribute to their achievement of academic rigour (Glaser, 1978). In this study, the emergent concepts and theory were considered to have:

- Grab: In the sense that grounded theories have grab and they are interesting. People remember them and they use them. This was evidenced as a result of feedback received from seminar presentations made throughout the study. Interest has also been generated by fellow researchers with regard to collaboration in future research projects based on the findings of the study. Even in practitioner environments, people have expressed interest in the concepts being developed, in 
particular the presence of historical influences and the presence of the two interpretative schemas.

- Fit: In the sense that the theory, or categories of the theory must fit the data. Data should not be forced to fit pre-conceived or pre-existent categories or discarded in favour of keeping an extant theory intact. This was achieved by using the modified approach in preference to the traditional Glaserian or Straussian methods. This was designed to ensure the fit between data and theory, and to allow the findings in all their depth and richness to emerge.

- Work: In the sense that a theory should be able to explain what happened, predict what will happen and interpret what is happening in an area of substantive or formal inquiry. The study provides a lens through which to view the construct of CEO leadership in contemporary New Zealand. It provides a view of the foundations of CEO leadership, how it is learnt, why some individuals come to love the role and the challenges it presents, and why others decide to leave the role. Using the concept of interpretative schemas to frame the discussion provides a means by which the multi-faceted dimensions of the construct can be systematically interpreted and studied.

- Relevance: In the sense that grounded theory arrives at relevance because it allows core problems and processes to be identified. In a time when there is predicted to be a talent shortage of CEOs, especially leadership talent, this study gains its relevance by being situated in contemporary New Zealand. It gains relevance by the sample size and nature of CEOs interviewed, the inclusion of 
participants close to the CEO role and the sample being drawn from across a range of industry sectors.

- Modifiability: In the sense that the generation of the theory is an ever modifying process and nothing is sacred if the researcher is dedicated to giving priority to the data. The journey from the purist grounded theory method of Glaser through consideration of the Straussian approach, to the modified approach used in this study was a justifiable response to the context of the research, the concerns expressed by the participants and the issues that were raised in ongoing discussions. While the individual datum was an important part of the research process, so were the environments and the life-world of the participants themselves. The use of a modified grounded theory approach allowed these features to be acknowledged and included in the findings. In doing so the study provides the means for the findings to be used by others when developing their own research. This contributes to the criteria for modifiability.

The following comment was one that provided an appropriate ending for this chapter.

It's not knowing what you don't know is the problem and it is the same in politics, management or sports leadership ... Leaders have to be prepared to be quite humble about what they don't know. 


\section{Chapter 8: Recapitulation, reflections, and future directions}

The major one is trust and then a unified purpose so that there are no hidden agendas and no hierarchical battle. So you need the trust, you need single mindedness, you need unity on the vision and you need equality and an approach that is not a point scoring ... or an ego situation.

A CEO reflection

\section{Introduction}

The core purpose of this study is to investigate the perceptions of the CEO role within large New Zealand business organisations from the perspective of the CEO and those closely involved with the role. The primary research objective of the study was:

To identify the CEOs'perceptions of their role and the interpretative schemas informing that role

The primary research questions arising from the research problem identified in Chapter One are:

1. How does the context in which the CEO role is situated influence the perceptions of the research participants as to the definition and enactment of that role?

2. Why is an individual attracted to the CEO role and why do they choose to remain or leave the role?

In this chapter, summary and concluding comments are provided, thereby completing the frame that forms the boundaries of the thesis. This chapter has four objectives, first, it 
provides a recapitulation for the basis of the thesis, and second, it reflects on the contributions that this thesis has made to the literature on this issue. Thirdly, it outlines the limitations of the research, and fourthly, it discusses the implications of the findings for practitioners and poses possibilities for future research opportunities.

\section{A recapitulation of the premise for the thesis}

A recapitulation in music is where the main ideas of the exposition are restated (Pearsall, 1999). Therefore, this section restates the main arguments that provided the premise for this thesis. As discussed, the inspiration for this thesis arose from a desire to understand more fully the "how and why" of the CEOs' perceptions of their role, and the identification of the social processes that inform the role. As discussed in the literature review, the CEO encompasses an executive leadership role. The desire to learn more about the role was heightened by the paucity of research available examining executive leadership, for example, less than $5 \%$ of the leadership literature has focused on executive leadership (Storey, 2005) (see Chapter One).

This thesis responded to the call to move studies away from the, who, what and when of the CEO role, for example, how an individual and their actions may have saved a company. In doing so, the researcher answered the call made by Tsui (2004) (referred to in Chapter Two) who contends that there is a need for more quality, theory generating, context-bound and context-specific research, to add to the body of knowledge of roles such as that of the CEO. The modified grounded theory approach utilised in this study is particularly appropriate for exploratory research of this nature as it allows the theory to 
build and flow from the data. This relevance is enhanced when the researcher acknowledges their participation in the research and develops a participatory consciousness as part of the research process (Bishop, 2005; Heshusius, 1994). Further, the nature of the research design combined with the reciprocal relationships that were developed with the participants, enabled the researcher to unravel and weave, to fold in and unmask the various layers of the participants' experiences (Smith, 2005, p. 103).

Concern has also been expressed about the relative volume of research emanating from North America and Europe in comparison to other contexts (Adler, 2002; De Cieri \& Dowling, 1997; Muczyk \& Adler, 2002). Further, despite the evolution of leadership theory from trait through to supra-leadership and self-leadership, it is stated that the leadership component of the CEO's role is still not sufficiently researched (Grint, 2005; Jackson, 2001; Kan, 2002; Parry, 1998). One reason given for this situation is that the literature and theories remain firmly situated in industrial models of organising, which models have provided the values and assumptions that have dominated the twentieth century field of executive leadership research (Ospina \& Schall, 2001; Rost, 1993). Thus, mental models have formed that are more suited to the industrial era, especially those pertaining to the CEO; furthermore, they have been formed from a narrow set of voices (Ospina \& Schall, 2001).

There is a need (see Chapter One) for more research examining how a CEO constructs meaning from the context in which he or she enacts their role. To address this issue, this research has expanded the range of voices commenting on the role of the CEO, by including the voices of the CEOs themselves and others closely involved with the CEO role. 
The grounded theory approach as proposed by Charmaz (2000) provides an alternative perspective of the CEO role and of the individuals who are appointed to it, whereas, the objectivist orientation to grounded theory assumes an external but discernable world, unbiased observers, and discovered theory emphasising logic, analytic procedures, comparative methods and conceptual development when the research is carried out (Charmaz, 2003). The modified grounded approach emphasises a focus on the studied phenomena (Charmaz, 2005, pp. 508-509). It was this latter approach that allowed the theory to be drawn and identified from the data rather than being forced into pre-ordained categories. This approach supports the integration of the participants' subjective experiences within the findings, thus, giving voice to the desires, concerns and excitement of those involved in the research (Charmaz, 2000, 2003, 2005; Mills, et al., 2006a, 2006b).

\section{Reflections on the significance of this thesis and its contribution}

This study claims significance arising from and for its context-specific nature. As a result, the multi-dimensional nature of the CEO role came more clearly to the forefront allowing the processual nature of the role to be identified. The context is not marginalised; rather it is embraced and celebrated as a means for allowing a deeper appreciation of the CEO role. Establishing context as a primary factor within the study resulted in the contextual features, which enhanced or inhibited the enactment of the CEO role, being captured by the study rather than be marginalised or minimised by it. 
By re-conceptualising the CEO role as the CEO role as a social institution, this study contributes to the literature by providing a conceptual framework that acknowledges the CEO role is bound by social norms contained within a specific context. This, in turn, provides an opportunity to commence a dialogue about the appropriateness of the social norms informing the role. Social norms sustain a social order that governs the behaviour of the CEO. Conceptualising the CEO role as a social institution has provided a view of the role that is more aligned with its multi-dimensional nature.

This thesis supplements the work of Wordon (2003) who examined the ability of an individual to mediate tensions between the executive role and integrity and reputational capital. The study develops this understanding by identifying the overarching social psychological process as: the balancing of the tensions and paradoxes. The study identified that CEOs perceive the need to be able to identify and then balance the tensions and paradoxes within their context if they are to enact their role effectively. In other words, the perceptions are that the CEO has to act as a mediator. That is, the CEO has to successfully mediate between the dualities created by the conflicting expectations of the two interpretative schemas. This, in turn, enhances their effectiveness in the CEO role. However, for the balancing to be effective, the CEO has to have developed high levels of commitment or enthusiasm for the role, a passion for challenge and displays of commitment and perceived ethical behaviour (See Chapter Five). As discussed in Chapter Six, the CEO's inability to mediate and reconcile the conflicting dualities, are perceived as grounds for the individual rejecting the role. Further, the study contributes to the literature through explaining the social processes that lead to the repression of the 
CEO role by forces in the external context, and to the restriction of the CEO role within the organisation.

The research contributes to the literature through the identification of the two interpretative schemas that inform the role. The institutionalised interpretative schema was identified as the dominant schema informing the role of the CEO. However, the analysis showed that the leadership interpretative schema was the dominant schema within which the CEOs enacted their role. By identifying the frameworks of the two interpretative schemas, this study, has offered an explanation for the limited latitude of discretion that the CEOs perceived they possess (Finkelstein \& Hambrick, 1996). In other words, the interpretative schemas have historical collective features that impact on the latitude of discretion afforded the CEO to act independently.

In keeping with the argument of Cannella and Monroe (1997), who state that any theory concerning executive leaders should be drawn from different perspectives, it is the researcher's contention that the research design of this study allowed diverse perspectives and traditions to play a role in forming the substantive theory of the CEO role. This study responds to the calls of (Bryman \& Stephens, 1996; Bryman, 2004; Conger \& Kanungo, 1998; Yukl, 2004) for executive leadership and CEO research to give a priority to studies conducted within the qualitative paradigm. The research design combined with the context-specific nature of the study permitted the economic, philosophical, sociological, historical and psychological features to be identified. This, in turn, highlighted important challenges that should be addressed if capable executives are to be attracted and retained in the CEO role. 
In contrast to other studies of the CEO role undertaken in New Zealand, this study guaranteed the anonymity of the participants. Prior studies have focused on a specific individual, naming the individual playing the lead role, see Jackson and Parry (2001) and Janson and McQueen (2003). Some are unauthorised biographies, for example, Michael Bassett's (2008) examination of a previous Prime Minister, David Lange; some are eulogies and some auto-ethnographies, completed with different levels of rigour. It is suggested that this lack of anonymity may not only lead to a "sugar-coating" of the views expressed, it can also silence voices, causing some perceptions to remain implicit and beliefs to remain hidden. In addition, it can also lead to what Darth and Palus (1994) and Ospina and Schall (2001) assert is an issue of concern with the majority of executive leadership studies. That is, they produce a view of reality that is portrayed as undebatable and unrelated to establishing an in-depth, holistic view of the role. Ensuring the participants' anonymity was vital in allowing personal insights to emerge; insights that otherwise may have remained hidden.

The research complements the work of Guthey and Jackson (2005) who examined the "images" of top executive and CEOs as represented both in the media and also via corporate portraiture. Guthey and Jackson (2005) focus on interpreting these images, for example in terms of how they offer a visual construction of corporate identity and can create an authenticity paradox. In contrast, this study investigates the research participants' perceptions of these mediated representations of the CEO role, thereby adding to the literature examining the public persona of the CEO.

The research has also made a contribution to the literature by extending the work of Feather (1994a, 1994b), Jones (2001), and Mouly and Sankaran (2000), through 
identifying some of the stories, customs and beliefs that contribute to the formation of the social norms that inform the CEO role. In the New Zealand context, such norms are expressed as the tall poppy syndrome and No 8 fencing wire and she'll be right thinking and are perceived as impacting on the enactment of the CEO role. While Feather (1994a, 1994b) and Jones (2001) discuss these phenomena within the broader context and Mouly and Sankaran (2000) from a specific organisational perspective, this study focuses on a specific role, the CEO, in a variety of organisational settings. Within this thesis, the customs and beliefs are perceived to have their origins in the colonial, religious, economic and historical traditions of New Zealand's European colonialism. Building on the work of Cheng (1994), it is the contention of the researcher that the context-specific focus of this thesis was responsible for allowing these social, cultural, historical, political and economic forces to contribute to the building of knowledge of the phenomena under study.

This study expands on the related work of Kempster's (2006), who recommended that future research should attempt a cross-sectoral investigation of leadership learning. This study, by including participants from a diversity of industry sectors, has assisted in providing those high-level causal or theoretical explanations for leadership learning amongst CEOs that Kempster (2006) believed would emerge from such a study. Such explanation or theory includes the seemingly unrecognised role of situated, incidental and informal learning on the learning of the CEO role, as opposed to the espoused importance of formal learning experiences.

This study has also responded to the work of Parry (1998) and Yukl (1994) who contend that when examining the CEO role, aspects of the role, for example, executive leadership 
needs to be researched as a process rather than through the study of a specific individual. In fact, in his 1998 work, Parry states that one of the few studies offering a sociological interpretation was conducted by Selznick (1957) who asserted that in understanding roles, for example, the CEO's role, a greater appreciation of the wider social context is required. This research, by providing an emphasis on both context and process, has expanded the knowledge base pertaining to the CEO role.

Martin (1986, p. 15) contends that when different conceptualisations are used to chart the same territory, the results and findings will differ and each conceptualisation will provide an alternative view of the realities of the phenomenon. The use of the modified grounded approach utilised in this study facilitated a change in how the CEO role is viewed, thereby altering what is seen. By altering the lens through which a phenomenon is viewed, then how it is conceptualised will also be modified. This study contends that as social beings, we construct our world via series of interactions and therefore this study focussed on these interactions and relationships, and how meaning was created from them. This approach enabled the researcher to move away from the industrial models that have informed executive leadership research, and from the objectivist stance of traditional grounded theory. Utilising tools that support a more comprehensive view of the CEO role, as perceived by CEOs, enabled the development of a substantive theory of the role more suited to a small business economy, for example, New Zealand. 


\section{Limitations of the research}

Throughout the thesis, the researcher has provided critical commentary on aspects of the research design and the objectivist and modified forms of grounded theory that have placed limitations on various aspects of the study. This commentary has included a discussion of the use of the literature provided in Part I. For example, if the literature is not used appropriately then it is possible that the researcher may be unable to attain the required level of theoretical sensitivity. In addition, an outline of the strengths and weaknesses of the grounded theory method is contained in Chapter Three, drawing attention to the role of the researcher in data collection, analysis and interpretation. For example, the limitations that may be placed on research that involves in-depth interviews if interviewer skills are not of the highest standards. Limitations relating to analysis and the nature of findings have also been discussed. For example in Part III, a particular comeback theme Glaser (1998) was identified, 'the CEO as a monocultural construct'. This, in turn, is judged to be a limitation resulting arising from the sampling procedures that are discussed in Chapter Four and again here. In addition to such prior commentary, the following limitations have been identified.

The researcher acknowledges that time constraints have limited the opportunity to follow up on some of the emergent findings of the study. For example, the latitude of discretion exercised by CEOs, that is, the seeming lack of exercise of discretion - thus limiting the opportunities to research and understand why CEOs appear to be passive or accepting of situations that they perceive to be constraining them. Another such theme is the perceived role of egalitarianism in constraining the CEO's actions and the part that narratives contained with the CEO's context play in defining the role, and in influencing 
the subsequent enactment of the role. These factors are also identified as comeback themes, Glaser (1992), where there is also an opportunity for further research in these areas.

\section{The role of the researcher}

In qualitative research, the researcher plays an integral and personal role throughout the study (Denzin \& Lincoln, 1994; Rose \& Webb, 1998). The researcher's own background, gender, social class, ethnicity, values and beliefs can affect the participants' construction of reality and vice versa (Sword, 1999, p. 270). This is in contrast to the positivist paradigm where the perspective of the researcher remains covert within a study rather than being acknowledged and an open-minded and curious attitude being recognised (Chenail, 2000). An over familiarity with the study area can create a threat to the researcher's theoretical sensitivity (Backman \& Kyngas, 1999; Skodol-Wilson \& Ambler-Hutchinson, 1996). (See Chapter Three). It is important that the researcher maintain an appropriate level of theoretical sensitivity.

As a qualitative study, it was essential the researcher be aware of his/her own biases, values, experiences and judgements (Locke, Spirduso, \& Silverman, 1987). At the start of the project, numerous conversations were held with colleagues and those involved in the CEO role and executive leadership in order to clarify the directions the research could take. My prior business experiences, business networks and my involvement with executive development programmes might have produced biases and they needed to be identified prior to my commencing the research. The researcher was aware that there 
was a danger that that undue influence could be placed on the outcomes of the interviews, or attributed to her background in influencing the constructions of the participants with regard to their perceptions. This awareness led to the researcher spending time with colleagues working in this area to ensure this was minimised throughout the research process. The interviews were checked immediately after they were completed for any questions that may have influenced the nature of the responses. Interpretations of the interviews were checked throughout the analysis process by paraphrasing the interviewees' responses back to them to confirm the interpretation of responses and by discussing issues that arose with colleagues.

The researcher's interest in the CEO role and CEO leadership has always been grounded in her desire to be able to work with people in a positive manner enhancing growth opportunities for all those involved. My own experiences in a variety of leadership roles have instilled in me a desire to understand more fully the processes involved in the leadership act. The researcher's awareness of her role in the research process was a critical component of the study. This awareness was necessary if the required level theoretical sensitivity, for the successful completion of the study, was achieved.

The following comments are typical of those received throughout the study and was made by a senior CEO during one of the first interviews conducted: "You are making me very reflective and it is good to be able to sit and think about such things". Similar comments were made throughout the research; for example, the following was received during one of the final interviews, "It was good to stop and think about these kinds of issues ... it doesn't happen very often". These comments were made in direct response to openended questions such as: "Why do you think that is?" or, "What do you think caused that 
to happen?" It was statements such as these that made me aware of the significance of my presence and my role in the interview process.

\section{Limitations imposed by the methodology}

The grounded theory approach utilised in this study has recognised methodological strengths and weaknesses that impose limitations on the research conducted. For example, Charmaz (1990) states that if the researcher does not adhere to the grounded theory processes then there is a danger that the researcher can become more descriptive than theoretical, and an overarching social process may not be identified or derived. A discussion of the strengths and weaknesses is contained in Chapter Three. In addition the following limitations have been identified.

There is a limitation in that the findings of the research are applicable only to the substantive setting under investigation. Further work is required before the transferability of the findings to other settings or environments can be demonstrated. An example of such work could include examining the relevance of the findings for owner-operator organisations, or CEOs operating in the not-for-profit sector. In the same way, an international comparative study may highlight cross-cultural differences or similarities. Foddy (1993) asserts that the conversational interactions that occur in semi-structured interviewing is problematic. This is because both the interviewer and interviewee are processing and coding each other's questions and responses on their own presumptions about each other. This can influence the nature of the responses to questions that were asked. In research of this type, the researcher plays a key role in the interactions that 
occur and the interpretations of those interactions, and their experience impacts on the effectiveness of that interaction. For example, researchers with limited experience may not have the same degree of comfort in interviewing CEOs, or other researchers may have differing perceptions of the CEO role, thereby revealing different constructions.

An additional limitation of this study was that I was not able to fully capture the nature, and therefore analyse the effect of social cues in the data analysis. The interviews were not videotaped because of privacy concerns on the part of the participants. Therefore, the researcher was not able to capture all such cues. However, it was considered that the verbal data and the memos and notes captured a sufficient level of data that would ensure robust findings.

There is a limitation resulting from the use of a convenience (non-probability) sampling strategy. Sample members were approached as a result of the personal networks of both the researcher and her colleagues. While efforts were made to ensure an appropriate cross-section of people based on gender and ethnicity, the sample was mono-cultural. Such representation may be a result of the sampling process or it could be a true reflection of the demographics of the target population. A much larger sample would be required to cater for smaller minority groupings. Any attempt to extend the results of this study to other groups in society may be problematic, unless supported by further research.

In addition, a limitation results from much of the early research conducted in New Zealand has been informed by "western" models and researchers; and some of that research has been described as perceiving "indigenous" models as second class (Smith, 
2005). Furthermore, Pfeifer (2005) contends that where studies have been conducted in NZ, for example, Hines (1973), Kennedy (2000) and Parry and Proctor-Thomson (2000), they have categorised or incorporated all members of the sample into one cultural grouping. An attempt to gain an ethnic representation in the sample of this study was not successful. In addition, no participants in this study identified themselves as nonEuropean. While an awareness of the applicability/non-applicability of North American and European theories to other parts of the world is increasing (Adler, 1982, 2002; Hessling, 1971; Hofstede, 1980; Hofstede \& Kassem, 1980; Maruyama, 1974; Muczyk \& Adler, 2002), there is still a need for research on the leadership dimensions of the CEO role to be placed within the specific, institutional, situational and societal contexts applicable to the role being studied (Alvesson, 1996; Biggart \& Hamilton, 1987; Bryman \& Stephens, 1996; Muczyk \& Adler, 2002).

Glaser (1998, p.199) argues there is a limit to how far any one researcher can go with a study. Often, it is resource constraints that dictate the boundaries of the substantive research environment, for example, the extent of theoretical sampling. This was the case in this research. However, such limitations, plus the exploratory elements of the study, have provided further opportunities for research, both for the method and for the topic, which will be outlined in the following section. 


\section{The implications of the research for practitioners}

Because the results of any grounded theory are drawn from or emerge from the experience of the research participants, the conclusions of any grounded theory study must provide a discussion of the implications of such theory for those we may describe as practitioners (Glaser, 1978), and for others. These groups may include those involved in the governance function, policy-makers, and those having responsibility for the development of individuals to fill the CEO role. This study identifies the following areas of possible interest and concern for practitioners.

This study identified implications for a wide sector of New Zealand society who come into contact with the CEO role. Some of these people could be deemed to be role observers and others as role senders. The literature review (Chapter Two) discusses the presence of role senders as part of role episodes involving CEOs, and surfaces the concern expressed by Bauer \& Simmon's (2000) at the lack of empirical research focussing upon this group. It is important to distinguish between those role senders who provide feedback to the role incumbent (the CEO) and have a stake in the organisation, and those groups who do not. This study identified role senders (stakeholders) as those individuals or groups of individuals who have a formalised role as part of the organisation, for example, employees, board members, clients and shareholders. The term role observer is used to refer to a group of people who do not have a stake in an organisation, such as the media, politicians and lobby groups. An example of the difference between a role sender and role observer is where the role sender is the Minister of the Crown with responsibility for a particular department, ministry or industry sector as part of their portfolio, and the role observer is a member of parliament from an 
opposition party or a person who represents a lobby group and who is providing commentary on a particular organisation, industry or individual. Within the private sector, role observer groups could include environmental lobby groups, educationalists or academics. These groups were identified as having considerable influence in shaping the expectations and requirements of the CEO role, including establishing a set of expectations about the characteristics of the individual who acquires the role and how the role is subsequently enacted. There are implications for these individuals as their perceptions, commentary and expectations have a marked impact on the ability of the CEO to balance the tensions, paradoxes or dualities confronting them in their role.

As discussed earlier, a recurring theme throughout the study was that CEOs perceive they have greater potential to contribute to the economic and social well-being of the country than is currently expressed in practice. This potential was considered by the respondents to be repressed by the social processes that exist within the substantive research context. This study does not offer a means for addressing this issue; however, it does identify the underlying challenges and causes of the challenges identified by the CEOs taking part in this study. Knowing the reasons for, and consequences of these issues, can act as a catalyst for further discussion regarding the future form the role may take.

However, the lack of clarity about the nature of the relationships impacting the CEO role has implications for all groups. For example, there is a need for greater clarity of expectations for all those involved in, say, mentoring and coaching chief executive officers. Further work is recommended to establish the most appropriate means by which to develop such clarity and expectations of relationships the CEO is involved in, especially those between the CEO and the Board. 
There are implications for those practitioners who are involved in the recruitment and selection of CEOs. The preference for expected behaviours enacted or emphasised within the institutionalised interpretative schema influences decisions made about CEO selection. While there may be reported preferences for charisma, long-term strategic thinking and visionary behaviour, as evidence in job-advertisements and competency profiles, the perceptions of the CEO role in this study are very different.

There are implications for those involved in executive leadership development. These include identifying prospective CEO candidates early in their career and ensuring they receive the appropriate developmental experiences; for example, recognising the nature and importance personal qualities such as maturity and self-awareness as well as business and strategic skills. There needs to be a more creative and innovative approach to the delivery of executive leadership to overcome the constraints imposed by scarce resources and a small business environment. This includes recognition of the value of situated, informal and incidental learning experiences that an individual experiences. Providing opportunities for critical reflection will enhance the value of such learning interactions.

There are implications for policy-makers and advisors. For example, whilst changes in policy direction may be politically expedient in the short-term, in the long-term these changes may compromise the long-term viability of an organisation. The short-term political cycle and its constraining forces were considered by the participants to be the primary contributor to a one-dimensional view of CEO leadership as opposed to a acknowledging it as a multi-dimensional construct. 


\section{Future opportunities for research}

Arising from the prior discussions, research opportunities have been identified that related to both the method and the CEO role itself.

There are methodological implications that arise from the use of a modified grounded theory. At the start of this project, the work of Charmaz $(2000,2003)$ and the responses of Glaser (2002) and Bryant (2003) were the major works available in this area. An examination of the literature conducted by Mills (2006a) identified few peer-reviewed studies or papers of a theoretical nature. Latterly, the work of Mills et al., (2006a, 2006b) has led to further discussion on the processes involved in a modified grounded theory approach. Additional benefit would be achieved from research aimed at clarifying still further the key philosophical and methodological differences between the objectivist and modified grounded theory methods. At a practical level, guidelines founded on a solid philosophical and methodological base would be particularly useful for researchers entering this field of inquiry for the first time.

As discussed earlier in this thesis, there is an ongoing methodological debate about how literature should be used within grounded theory. Further research and discussion in this area would be useful, not only for the grounded theory method, also for other forms of qualitative inquiry. As the various domains of inquiry and the information made available via computerised and information technology increases, it is becoming less likely that a researcher would be able remain totally divorced from the literature in a particular field of inquiry. Further research investigating the role and use of the literature 
in such studies would enhance the understanding of its role in both objective and modified grounded studies.

As mentioned previously, the objectivist approach to grounded theory can be described as hierarchical, where those involved in the research are subordinate to the researcher (Charmaz, 2005), the researcher needing to remain objective and removed from the research process (Glaser \& Strauss, 1967). This study, by breaking out of the traditional hierarchical power-based relationship (Mills, et al., 2006a), has acknowledged the active role of the researcher in the research process. Further work examining the role of the researcher and the interactions that result from the inter-relationships between the researcher and the researched would contribute to the literature, especially in providing guidelines for naming those relationships, for those involved similar context-specific and context-bound studies.

Glaser (1978) believes that one of the key implications for future research in substantive studies is elevation to formal theory status. Formal theory is defined as having a broader application beyond the boundaries of a single area of inquiry and depends on carrying out further comparisons, developing theories from different contexts and studies. There are three areas of research that could support the elevation from substantive to formal theory:

- The first is where CEO research could move still further from the quantitative and who, what, where leanings (as outlined in Chapter One and Two) that typify much of the existing body of knowledge. In doing so, the use of a variety of approaches, for example, discourse analysis, ethnography and action research, would provide alternative perspectives on the CEO role. In making this 
recommendation, the researcher echoes the calls of Ospina and Schall (2001) for more executive leadership research to be conducted across a wider range of ontologies, epistemologies and methodologies.

- The second is the recommendation for researchers to explore the presence and efficacy of diverse forms of executive leadership within the corporate environment, specifically, research that examines indigenous and ethnic influences on the enactment of the CEO role. However, it is important to note that conducting high quality research in this area may not necessarily involve testing the applicability of western models (Tsui, 2004), nor does it necessarily require western-trained researchers (Bishop, 2005; Smith, 2005). Rather, this form of research may require researchers who are able to move beyond the boundaries existing between business, society and cultural groups that use theory-generating research methods (Tsui, 2004). Failure to approach the study of executive leadership from this broader perspective may lead to the invisibility of different forms of executive leadership and leadership behaviour. An example of such a study could involve a comparison of the results of this study with those of a similar independent study undertaken in Māori organisations, or one comparing the styles of Māori and Päkehä CEOs, within and across Māori and "European" organisations.

- Third, there is the opportunity for international comparisons to be conducted of the CEO role. Such a study would provide another dimension to the CEO construct. Conducting similar comparative work in another country would add to the body of knowledge in the discipline, for example, facilitating a comparison between two formal colonial and island states such as New Zealand and 
Singapore. Singapore is an island nation with British colonial experiences occurring at a similar point in history to New Zealand's. This suggestion is a response to the challenge laid down by Ospina and Schall (2001) for researchers to expand the range of voices commenting on executive leadership.

Further research is required to explore more fully the conceptualisation of the CEO role as a social institution and the frameworks and structures of the interpretative schema that inform this definition. It is also recommended that further exploration of the actions of the CEOs, as they attempt to mediate or balance the tensions and paradoxes confronting them in the day-to-day enactment of their role, is undertaken. This recommendation also includes the possibility of research examining still further the consequences of the failure to achieve a balance which leads to the individual leaving the role.

As discussed in Chapter Five and Six, comments were received relating to the validity of the view that if an individual had been an effective CEO in one context then they could be an equally effective CEO in another. This belief was rejected by the majority of the participants. Examples were provided of situations where individuals were not successful in moving from one context to another. Self-awareness and the ability to sense and adapt to the new context were identified by the interviewees as critical success factors. Future research could include a study of those factors that inhibit or enhance the successful transference of a CEO between different contexts.

As discussed previously in this chapter and in Chapter One and Three, the contextspecific nature of the study allowed the social, cultural, legal and economic themes existing within this environment to be used as factors in building knowledge about the 
phenomena of the CEO role (Cheng, 1994). There are opportunities for further explanatory research examining these predictors, thereby adding to the body of knowledge. One example, where further study could prove of value, relates to those norms which have become embedded in New Zealand culture as aphorisms or metaphors such as tall poppy syndrome, No 8 fencing wire and she'll be right in describing "the New Zealand way". The identified lack of empirical research in this field, one that is perceived to have such a high impact on CEO behaviours, is disquieting. There is an urgent need for more research into what could be called folkloric stories, customs and practices that are deemed to have an influence on the CEO role.

This study identified the part played by role senders, in contexts external to that of the $\mathrm{CEO}$, as being perceived to have considerable influence on the CEO role, for example, the media and politicians and the general public. Research designed to achieve a deeper and more holistic understanding of the influence of role-senders embedded in the external context is critical. This will answer the call of Bauer and Simmons (2001) for a greater understanding of the influence of the role-sender groups. 


\section{Some last words ...}

In the last two chapters, I have summarised the findings of the study and discussed the implications and future directions arising from them. The search for an understanding of the how and why research questions were instrumental in this study providing a more comprehensive view of the CEO role in New Zealand. This study identified that the CEO role is multi-dimensional, encompassing a social influence process, as well as an assigned strategic function. CEO perceptions suggest that fundamental to the role was the quality and form of the contextual relationships that were present. These relationships led to the identification of the social structural process that defines the CEO role as a social institution and a social psychological process involved in balancing the tensions and paradoxes. By situating the study within the qualitative paradigm, the researcher was able to attend to the complexities, subtleties and nuances that were identified from the study of a dynamic construct such as CEO role.

There was a recurring belief among the participants that CEOs have a greater potential to contribute to the economic and social well-being of New Zealand society than they do at present. Realising the personal desire to lead in a long-term visionary manner, to have a greater influence and to create more wealth, thereby making an even greater contribution to society, was deemed to be inhibited on many occasions by the identified social processes contained within the CEOs context.

The research has allowed the voices of the participants to be brought forward and be heard Traditionally, the concept of voice has been ascribed to the weak, minorities, and disadvantaged (Baez, 2002). The paradoxical situation identified by this research was 
that CEOs perceive themselves as having little voice, despite a more widespread perception, both within society and within organisations, that CEOs have considerable power and status and therefore have the ability to voice their 'true feelings'. This research identified that that in reality, silencing and constraints are manifest with regard to certain aspects of the CEO role.

In reflecting on the research process in which I have been enmeshed, I recognise that it is the people I have met who have taught me so much, recognising their passion and commitment and their importance to all aspects of my life. As I look forward, I realise there is still much work to do; the ending of this project is only the beginning of a longer research journey. There are still more stories to be told, more people to meet and more lenses to look through. With this in mind, I leave the last words to one of the participants:

Being a CEO is one of the loneliest jobs that you can have. Because you're put up there on a pedestal, because you are a CEO, people think you should behave and act in certain ways and therefore there is an immediate distance. And it's tough because at the end of the day we are just capable normal people who are trying to our job. 


\section{References}

Adler, N. J. (1982). Understanding the ways of understanding: Cross-cultural management methodology reviewed. In R. N. Farmer (Ed.), Comparative Management: Essays in contemporary thought (pp. 31-67). Greenwich, CT: JAI Press.

Adler, N. J. (2002). International dimensions of organisational behaviour. Cincinnati, OH.: South-Western.

Adler, P. S., \& Kwon, S.-W. (2002). Social capital: Prospects for a new concept. Academy of Management Review, 27, 17-40.

Akin, G. (1987). Varieties of managerial learning. Organisational Dynamics, Autumn, 36-48.

Alvesson, M. (1996). Leadership studies: From procedure to abstraction to reflexivity and situation. Leadership Quarterly, 7(4), 455-486.

Anderson, C., \& Paine, J. (1975). Managerial perceptions and strategic behaviour. Academy of Management Journal, 18, 811 - 823.

Ashworth, P., \& Lucas, U. (2000). Achieving empathy and engagement: A practical approach to the design, conduct and reporting of phenomenographic research. Studies in Higher Education, 25(3), 295-308.

Axelrod, R. (1986). An evolutionary approach to norms. American Political Science Review, 80(4), 1095-1111.

Backman, K., \& Kyngas, H. (1999). Challenges of the grounded theory approach to a novice researcher. Nursing and Health Sciences, 1, 147-153.

Bada, M. (2003, 25 February - 1 March). Culture and social structures. Paper presented at the International Studies Association Convention, Portland, Oregon.

Baez, B. (2002). Confidentiality in qualitative research: Reflections on secrets, power and agency. Qualitative Research, 2(1), 35-58.

Bandura, A. (1997). Self-efficacy: The exercise of control. New York: Feeman.

Bandura, A. (2001). Social cognition: A agentic perspective. Annual Review of Psychology, 52, 126.

Banton, M. (1965). Roles: An introduction to the study of social relations. New York: Basic Books.

Barker, C., Wuest, J., \& Stern, P. N. (1992). Method slurring: The grounded theory/phenomenology example. Journal of Advanced Nursing, 17(11), 1355-1360.

Barker, R. A. (1997). How can we train leaders if we do not know what leadership is? Human Relations, 50(4), 343 - 362. 
Barker, R. A. (2001). The nature of leadership. Human Relations, 54(4), 469 - 494.

Barnard, C. E. (1948). The nature of leadership. Boston.: HBR Press.

Baron, R. A., Byrne, D., \& Branscombe, N. R. (2007). Mastering social psychology. New York: Pearson

Bartlett, C. A., \& Ghoshal, S. (1989). Managing across borders: The transnational solution. Boston: Harvard Business School Press.

Bartlett, C. A., \& Ghoshal, S. (2000). Transnational Management: Test cases and readings in cross-border management. London: McGraw Hill.

Bartlett, F. C. (1932). Remembering. London: Cambridge University Press.

Bartunek, J. M. (1984). Changing interpretive schemes and organisational restructuring: The example of a religious order. Administrative Science Quarterly, 29, 356-372.

Belich, J. (1996). Making peoples: A history of the New Zealanders. Auckland, NZ: The Penguin Press.

Bennis, W., \& Nanus, B. (1985). Leadership: The strategies for taking charge. New York: Harper Row.

Berger, P. L., \& Luckmann, T. (1966). The social construction of reality: A treatise in the sociology of knowledge. Baltimore, Maryland: Penguin.

Berger, P. L., \& Luckmann, T. (1971). The social construction of reality: A treatise in the sociology of knowledge. Baltimore, MD: Penguin.

Biggart, N., \& Hamilton, G. (1987). An institutional theory of leadership. Journal of Applied Behavioural Science, 23(4), 429-441.

Bishop, R. (2005). Freeing ourselves from neo-colonial domination in research. In N. K. Denzin \& Y. S. Lincoln (Eds.), The Sage Handbook of Qualitative Research (3 ed., pp. 109-138). Thousand Oaks, CA: Sage.

Black, J. S., \& Gregersen, H. (2000). High impact training: Forging leaders for the global frontier. Human Resource Management, 39(2-3), 173 -184.

Bonoma, T. V. (1985). Case study research in marketing opportunities problems and process. Journal of Marketing Research, 32(4), 419-441.

Brehm, J. W., \& Cohen, A. R. (1962). Explorations in cognitive dissonance. New York: Wiley.

Brown, A. D. (2000). Making sense of inquiry sensemaking. Journal of Management Studies, 37(1), 45-75.

Brown, R. H. (1978). Bureaucracy as praxis: Toward a political phenomenology of formal organisations. Administrative Science Quarterly, 6, 257-281.

Bruner, J. (1966). Toward a theory of instruction. Cambridge, MA: Harvard University.

Bryant, A. (2003, January). A constructivist response to Glaser Retrieved 06/042004, 2004, from http://www.qualitative-research.net/fqs-texte/1-03brayant-e.htm 
Bryman, A. (1987). The generalisability of implicit leadership theory. Journal of Social Psychology, 127(2), 129-141.

Bryman, A. (2001). Social research methods. New York: Oxford University Press.

Bryman, A., Gillingwater, D., \& McGuinness, I. (1996). Leadership and organisational transformation. International Journal of Public Administration, 19(6), 849-872.

Bryman, A., \& Stephens, M. (1996). The importance of context: Qualitative research and the study of leadership. Leadership Quarterly, 7(3), 353-371.

Bryman, A. S. (2004). Qualitative research on leadership: A critical but appreciative view. Leadership Quarterly, 7(3), 353-370.

Burns, J. M. (1978). Leadership. New York: Harper \& Row.

Byrd, R. E. (1987). Corporate leadership skills: A new synthesis. Organisational Dynamics, 16(1), 34-43.

Calder, B. J. (1977). An attribution theory of leadership. In B. M. Staw \& G. R. Slanick (Eds.), New Directions in Organisational Leadership. Chicago: St Clair.

Caldwell, C., Bischoff, S. J., \& Karri, R. (2002). The four umpires: A paradigm for ethical leadership. Journal of Business Ethics, 36(1-2), 153-163.

Cameron, K. S., \& Quinn, R. E. (1988). Organisational paradox and transformation. In K. S. Cameron \& R. E. Quinn (Eds.), Paradox and transformation: Toward a theory of change in organisation and management. Cambridge: Ballinger.

Cannella, A. A., \& Monroe, M. J. (1997). Contrasting perspectives on strategic leaders: Toward a more realistic view of top managers. Journal of Management 23(3), 213-237.

Carr, L. (1994). The strengths and weaknesses of quantitative and qualitative research: What method for nursing. Journal of Advanced Nursing, 20, 716-721.

Cast, A. D. (2004). Role taking and interaction. Social Psychology Quarterly, 67(3), 296-309.

Charmaz, K. (1990). Discovering chronic illness: Using grounded theory. Social Science and Medicine, 30, 1161-1172.

Charmaz, K. (2000). Grounded theory; Objectivist and constructivist methods. In N. K. Denzin \& Y. S. Lincoln (Eds.), Handbook of qualitative research (2nd ed., pp. 509-535). Thousand Oaks, CA: Sage.

Charmaz, K. (2003). Grounded theory: Objectivist and constructivist methods. In N. K. Denzin \& Y. S. Lincoln (Eds.), Strategies of qualitative inquiry (2nd ed., pp. 249-291). Thousand Oaks, CA: Sage.

Charmaz, K. (2005). Grounded theory for the 21st century: Applications for advancing social justice. In N. K. Denzin \& Y. S. Lincoln (Eds.), The Sage handbook of qualitative research (3rd ed., pp. 507-535). Thousand Oaks, CA: Sage. 
Chen, C. C., \& Meindl, J. R. (1991). The construction of leadership images in the popular press: The case of Donald Burr and People Express. Administrative Science Quarterly, 36, 521551.

Chenail, R. (2000). Navigating the 7 c's: Curiosity, confirmation, comparison, changing, collaborating, critiquing and combinations. The Qualitative Report, 4(3,4). Retrieved from http://www.nova.edu/ssss/QR/QR4-3/sevencs.html

Cheng, J. L. C. (1994). On the concept of universal knowledge in organisation science: Implications for cross-national research. Management Science, 40, 162-168.

Chenitz, W. C., \& Swanson, J. M. (1986). From practice to grounded theory: Qualitative research in nursing. Menlo Park, CA: Addison-Wesley

Chetty, S. (1996). The case study method for research in small and medium sized firms. International Small Business Journal, 15(1), 73-86.

Chetty, S. (2001). Internationalisation. In C. Campbell-Hunt (Ed.), World famous in New Zealand: How New Zealand's leading firms became world class. Auckland, New Zealand: Auckland University Press.

Clark, K. E., \& Clark, M. B. (1990). Measures of leadership. West Orange, NJ: Leadership Library of America.

Clarke, A. (2005). Situational analysis: Grounded theory after the post-modern turn. Thousand Oaks, CA: Sage.

Clegg, S. R., da Cunha, J. V., \& e Cunha, M. P. (2002). Management paradoxes: A relational view. Human Relations, 55(5), 483-503.

Col, J.-M. (1993). Managing softly in turbulent times: Corazon C. Aquino, President of the Philippines. In M. A. Genovese (Ed.), Women as national leaders (pp. 13-40). Newbury Park, CA: Sage.

Conger, J. A., \& Kanungo, R. N. (1998). Charismatic leadership in organisations. Thousand Oaks: CA: Sage.

Cresswell, J. W. (1994). Research design: Qualitative and quantitative approaches. Thousand Oaks, CA: Sage.

Crotty, M. (1998). The foundations of social research: Meaning and perspective in the research process. Thousand Oaks, CA: Sage.

Daft, R. L. (1999). Leadership: theory and practice. Fort worth, TX: Dryden Press.

Daft, R. L. (2002). The leadership experience. Fort Worth, TX: Dryden Press.

De Cieri, H., \& Dowling, P. J. (1997). Strategic international human resource management: An Asia Pacific perspective. Management International Review., 37(1), 21-43.

Densten, I., \& Gray, J. (2001). Leadership development and reflection: What is the connection? The International Journal of Educational Management, 15(3), 119-124. 
Denzin, N. K. (1994). The art and politics of interpretation. In N. K. Denzin \& Y. S. Lincoln (Eds.), Handbook of qualitative research (pp. 500-515). Thousand Oaks, CA: Sage.

Denzin, N. K., \& Lincoln, Y. S. (1994). Handbook of qualitative research. Thousand Oaks, CA: Sage.

Denzin, N. K., \& Lincoln, Y. S. (2000). Introduction: The discipline and practice of qualitative research. In N. K. Denzin \& Y. S. Lincoln (Eds.), Handbook of qualitative research. Thousand Oaks, CA: Sage.

DePree, M. (1998). What is leadership? In G. R. Hickman (Ed.), Leading organisations: Perspectives for a new era. Thousand Oaks, CA: Sage.

Drath, W., \& Palus, C. (1994). Making common sense: Leadership as meaning making in a community of practice. Greensboro, NC: Centre for Creative Leadership.

Driscoll, M. P. (1994). Psychology of learning for instruction. Needham Heights, MA: Allyn \& Bacon.

DuBrin, A. J. (2000). Leadership. London: Houghton Mifflin.

Dunnette, M. D. (1966). Fad, fashions, and folderol in psychology. American Psychologist, 21, 343-352.

Ebbs, C. A. (1989). Qualitative research inquiry: issues of power and ethics. Education, 117(2), 217-222.

Eichelberger, R. T. (1989). Disciplined inquiry; Understanding and doing educational research. White Plains, NY: Longman.

Eisenhardt, K. M. (1989). Building theories from case study research. Academy of Management Review, 14(4), 532-550.

Fagerhaugh, S. Y. (1986). Analysing data for basic social processes. In W. C. Chenitz \& J. M. Swanson (Eds.), From practice to grounded theory; Qualitative research in nursing. Menlo Park, CA: Addison-Wesley.

Feather, N. T. (1994a). Attitudes toward high achievers and reactions to their fall: Theory and research concerning tall poppies. In M. P. Zanna (Ed.), Advances in social psychology. New York: Academic Press.

Feather, N. T. (1994b). Values and national identification: Australian evidence. Australian Journal of Psychology, 46, 35-40.

Festinger, L. (1957). A theory of cognitive dissonance. Stanford, CA: Stanford University Press.

Finkelstein, S., \& Hambrick, D. (1996). Strategic leadership: Top executives and their effects on organisations. St Paul, MN: West.

Finnemore, M., \& Sikkink, K. (2001). Taking stock: The constructivist research programme in international relations and comparative politics. Annual Review of Political Science, 4, 391-416. 
Fisher, C. D., Schonfeldt, L. F., \& Shaw, J. B. (1999). Human resource management. Boston: Houghton Mifflin.

Foddy, W. (1993). Constructing questions for interviews and questionnaires: theory and practice in social research. Cambridge: Cambridge University Press.

Fondas, N. (1997). The origins of feminization. Academy of Management Review, 22, 257-282.

Fraser, D. (1999). QSR NUD*IST Vivo: Reference guide. Melbourne, Australia: Qualitative Solutions and Research Pty.

Frederick, H. H., \& Carswell, P. J. (2001). Global entrepreneurship monitor: New Zealand, 2001. Auckland: New Zealand Centre for Innovation \& Entrepreneurship. UNITEC.

Fujita, M. (1994). Small and medium-sized transnational corporations: Role impact and policy implications. New York: United Nations.

Geertz, C. (1973). Thick description: Toward an interpretative theory of culture. In C. Geertz (Ed.), The interpretation of cultures. New York: Basic Books.

Geletkanycz, M. A., \& Hambrick, D. (1997). The external ties of top executives: Implications for strategic choice and performance. Administrative Science Quarterly, 42(4), 654-681.

Gemmill, G., \& Oakley, J. (1992). Leadership: An alienating social myth. Human Relations, 45(2), 113-129.

Ger, G. (1999). Localising in the global village: Local firms competing in global markets. California Management Review, 41(4), 64-83.

Gergen, K. J. (1971). The concept of self. New York: Holt, Rinehart \& Winston.

Gergen, K. J. (1991). The saturated self. New York: Basic Books.

Gergen, K. J. (2003). An invitation to social constructionism. London: Sage.

Gerstner, C. R., \& Day, D. V. (1994). Cross-cultural comparison of leadership prototypes. Leadership Quarterly, 2, 121-134.

Gibson, D. E. (2004). Role models in career development: New directions for theory and research. Journal of Vocational Behaviour, 65, 134-156.

Giddens, A. (1984). The constitution of society. Cambrdige: Polity Press.

Giddens, A. (1991). Modernity and self identity: Self and society in the late modern age. Cambridge, England: Polity Press.

Gilbert, N. (2008). Research,theory and method. In N. Gilbert (Ed.), Researching social life. London: Sage Publications.

Gilmore, A., \& Carson, D. (1996). Integrative qualitative researching: A service context. Marketing Intelligence and Planning, 14(6), 21-26.

Gioa, D. A., \& Chittipeddi, K. (1991). Sensemaking and sensegiving in strategic change initiation. Strategic Management Journal, 12, 433-448.

Gioia, D. A., \& Chittipeddi, K. (1991). Sensemaking and sensegiving in strategic change initiation. Strategic Management Journal, 12, 433-448. 
Glaser, B. (1978). Theoretical sensitivity. Mill Valley, CA: Sociology Press.

Glaser, B. (1992). Basics of grounded theory analysis. Mill Valley, CA: Sociology Press.

Glaser, B. (1998). Doing grounded theory: Issues and discussion. Mill Valley, CA.: Sociology Press.

Glaser, B., \& Strauss, A. (1967). The discovery of grounded theory. Chicago: Aldine Press.

Gordon, R. D. (2008, 2-5 December). Dispersed leadership, power and change: An empirical study using a critical management framework. Paper presented at the Australian/New Zealand Academy of Management, University of Auckland, New Zealand.

Goulding, C. (1999). Grounded theory: Some reflections on paradigm, procedures (Working Paper). Wolverhampton, England: Management Research Centre, University of Wolverhampton.

Goulding, C. (2002a). Grounded Theory: A practical guide for management, business and market researchers. London: Sage.

Goulding, C. (2002b). Grounded theory: A practical guide for management, business and market researchers. London: Sage Publications.

Graber, D. (1986). Processing the news: How people tame the information tide. New York: Longman.

Graen, G. B., \& Hui, C. (1999). Transcultural leadership in the twenty-first century. In W. H. Mobley, M. J. Gessner \& V. Arnold (Eds.), Advances in global leadership (Vol. 1, pp. 926). Stamford, CT: JAI Press.

Gregersen, H., Morrison, A. J., \& Black, J. S. (1998). Developing leaders for the global frontier. Sloan Management Review, 40(1), 21-32.

Grint, K. (2005). Leadership: Limits and possibilities. Basingstoke, England: Palgrave MacMillian.

Grover, R., \& Glazier, J. (1986). A conceptual framework for building theory in library and information science. Library \& Information Science Research, 8(3), 227-242.

Guba, E. G. (1990). The paradigm dialog. Newbury Park: Sage Publications.

Guba, E. G., \& Lincoln, Y. S. (1994). Competing paradigms in qualitative research. In N. K. Denzin \& Y. S. Lincoln (Eds.), Handbook of qualitative research. Thousand Oaks, CA: Sage.

Guba, E. G., \& Lincoln, Y. S. (1998). Competing paradigms in qualitative research. In N. K. Denzin \& Y. S. Lincoln (Eds.), The landscape of qualitative research. Thousand Oaks, CA: Sage

Gulati, R., Nohria, N., \& Zaheer, A. (2000). Strategic networks. Strategic Management Journal, 21, 203-215.

Guthey, E., \& Jackson, B. (2005). CEO Portraits and the Authenticity Paradox. Journal of Management Studies, 42(5), 1057-1082. 
Hackman, M. Z., \& Johnson, C. E. (1996). Leadership: A communication perspective (2nd ed.). Long Grove, IL: Waveland Press.

Hagen, A. F., Hassan, M. T., \& Amin, S. G. (1998). Critical strategic leadership components: An empirical investigation. S.A.M Advanced Management Journal, 63(3), 39-44.

Hambrick, D. (1998). Blackwell encyclopaedia dictionary of organisational behaviour. In N. Nicholson (Ed.): Blackwell.

Harrison, E. F., \& Pelletier, M. A. (1997). CEO perceptions of strategic leadership. Journal of Managerial Issues, 9(3), 299 -317.

Hart, S., \& Quinn, R. (1993). Roles executives play: CEO's behavioural complexity and firm performance. Human Relations, 46, 543-575.

Hein, G. E. (1991, October). Constructivist learning theory. Paper presented at the CECA (International Committee of Museum Educators), Jerusalem, Israel.

Heshusius (1994). Freeing ourselves from objectivity: Managing subjectivity or turning toward a participatory mode of consciousness? Educational Researcher, 23(3), 15-22.

Hessling, P. (1971). Organisational behaviour and culture: The case of the multinational enterprise. Quarterly Journal of Management Development, 2, 1-23.

Hitt, M. A., \& Ireland, D. R. (2002). The essence of strategic leadership. Journal of Leadership and Organisational Studies, 9(1).

Hitt, M. A., Keats, B. W., \& Yucel, E. (2003). Strategic leadership in global business organisations: Building trust and social capital. In W. H. Mobley \& P. W. Dorfman (Eds.), Advances in global leadership (pp. 9-35). Oxford, England: Elsevier Science.

Hitt, M. A., Lee, H., \& Yucel, E. (2002). The importance of social capital to the mangement of multinational enterprises: Relational capital among Asian and Western firms. Asia Pacific Journal of Management, 19(2-3, August), 353-372.

Hitt, M. A., Lee, H., \& Yucel, E. (2003). The importance of social capital to the management of multinational enterprises: Relational capital among Asian and western firms. Asia Pacific Journal Management, (In press).

Hitt, W. (1996). A global ethic: The leadership challenge. Columbus, OH: Battelle Press.

Hofstede, G. (1980). Motivation, leadership and organisation: Do American theories apply abroad. Organisational Dynamics, 9(1), 42-63.

Hofstede, G., \& Kassem, S. (1980). European contributions to organisation theory. Amsterdam: Van Gorcum.

Howell, J. M., \& Avolio, B. J. (1992). The ethics of charismatic leadership. Academy of Management Executive, 6(2), 43-55.

Hunt, J. G. (1984). Organisational leadership: The contingency paradigm and its challenges. In B. Kellerman (Ed.), Leadership: Multidisciplinary perspectives. Englewood Cliffs, N.J.: Prentice-Hall. 
Hunt, J. G., \& Dodge, G. E. (2000). Leadership deja vu all over again. Leadership Quarterly, $11(4), 435-458$.

Hutchinson, S. (1986). Creating meaning: Grounded theory of NICU nurses. In W. C. Chenitz \& J. M. Swanson (Eds.), From practice to grounded theory. Menlo Park: Addison Wesley. Industry-Regional-Development (2001). SMEs in New Zealand. Wellington: Ministry of Economic Development.

Ireland, D. R., \& Hitt, M. A. (1999). Achieving and maintaining strategic competitiveness in the 21st century: The role of strategic leadership. Academy of Management Executive, 13, 4357.

Irurita, V. F. (1990). Optimising as a leadership process: A grounded theory study of nurse leaders in Western Australia. Unpublished Doctoral dissertation, University of Western Australia, Perth.

Irurita, V. F. (1996). Optimising: A leadership process for transforming mediocrity to excellence. In K. W. Parry (Ed.), Leadership research and practice: Emerging themes and new challenges. Warriewood, Australia: Business and Professional Publishing.

Jonassen, D. H. (1994). Learning with media: Restructuring the debate. Educational Technology Research and Development, 42(2), 31-39.

Jones, D. (2001). Managing with a piece of No 8 wire: National culture as competitive advantage. In C. Campbell-Hunt (Ed.), World famous in New Zealand: How New Zealand's leading firms became world-class competitors. Auckland, New Zealand: Auckland University Press.

Kahn, R. L., Wolfe, D. M., Quinn, R. P., \& Snoek, J. D. (1964). Organisational stress. New York: John Wiley \& Sons.

Kan, M. (2002). Identifying paradox: A grounded theory of leadership in overcoming resistance to change. Unpublished Doctoral dissertation, Victoria University of Wellington, Wellington, New Zealand.

Kanter, R. M. (1985). Managing the human side of change. Management Review., April, 52-56.

Kanter, R. M. (1992). The change masters: Corporate entrepreneurs at work.

Keller, T. (1999). Images of the familiar: Individual differences and implicit leadership theories. Leadership Quarterly, 10, 589-627.

Kelsey, K., Weeks, W., \& Terry, R. (2002). Important issues facing agriculture in Oklahoma: An analysis of agricultural leaders perspectives. Journal of Southern Agricultural Research, 52(1), 52-61. Retrieved from http://pubs.aged.tamu.edu/jsaer/Vol52Whole.pdf

Kempster, S. (2006). Leadership learning through lived experience: A process of apprrenticeship? Journal of Management and Organisation, 12(1), 4-22.

Kennedy, J. (2000). Leadership in New Zealand: Findings of the globe study. International Journal of Organisational Behaviour, 2(4), 45-52. 
King, M. (2004). The Penguin History of New Zealand. Auckland, New Zealand: Penguin.

Klenke, K. (2008). Qualitative research in the study of leadership. Bingley, UK: Emerald Group.

Kotter, J. (1982). The general managers. New York: Free Press.

Kotter, J. (1990). A force for change: how leadership differs from management. New York: The Free Press.

Kotter, J. (1996). Leading change. Boston: Harvard Business School Press.

Labour-Market-Policy-Group (2001). Workforce 2010 (Discussion Document). Wellington: Department of Labour.

Lave, J., \& Wenger, E. (1991). Situated learning: Legitimate peripheral participation. Cambridge, England: University of Cambridge Press.

Le Compte, M., \& Goetz, J. (1982). Problems of reliability and validity in ethnographic research. Review of Educational Research, 52(1), 31-60.

Lee, T. W. (1999). Using qualitative methods in organisational research. Thousand Oaks, CA: Sage.

Leininger, M. M. (1985). Qualitative research methods in nursing. Orlando, FL: Grune \& Stratton.

Lewis, M., W. (2000). Exploring paradox: Toward a more comprehensive guide. Academy of Management Review, 25(4), 760-776.

Lincoln, Y. S., \& Guba, E. G. (1985). Naturalistic inquiry. Newbury Park, CA: Sage.

Lincoln, Y. S., \& Guba, E. G. (2000). Paradigmatic controversies, contradictions and emerging confluences. In N. K. Denzin \& Y. S. Lincoln (Eds.), Handbook of Qualitative Research. Thousand Oaks, CA: Sage.

Locke, K. (2001). Grounded theory in management research. London: Sage.

Locke, L., Spirduso, W. W., \& Silverman, S. J. (1987). Proposals that work: A guide for planning dissertations and grant proposals. Newbury Park, CA: Sage.

Lord, R. G., \& Aditya, R. N. (1997). The social scientific study of leadership: Quo Vadis? Journal of Management, 23(3), 409-473.

Lord, R. G., Binning, J. F., Rush, M. C., \& Thomas, J. C. (1978). The effects of performance cues and leader behaviour on questionaire ratings of leadership behaviour. Organisational Behaviour and Human Performance, 21(1), 27-39.

Lord, R. G., Brown, D. J., Harvey, J. L., \& Hall, R. J. (2001). Contextual constraints on prototype generation and their multilevel consequences for leadership perceptions. The Leadership Quarterly, 12, 311-338.

Lord, R. G., \& Smith, W. G. (1999). Leadership and the changing nature of work performance. In D. R. ILgen \& E. D. Pulakos (Eds.), The changing nature of performance: Implications for staffing motivation and development (pp. 192-239). San Francisco: Jossey-Bass. 
Louis, M. R. (1980). Surprise and sensemaking: What newcomers experience in entering unfamiliar organisational settings. Administrative Science Quarterly, 25, 226-251.

MacDonald, M., \& Schreiber, R. S. (2001). Constructing and deconstructing: Grounded theory in a post-modern world. In R. S. Schreiber \& P. N. Stern (Eds.), Using grounded theory in nursing (pp. 35-53). New York: Springer.

Manolova, T. S., Brush, C. G., Edelman, L. F., \& Greene, P. G. (2002). Internationalization of small firms. International Small Business Journal, 20(1), 9-31.

Markus, H. (1977). Self-schemata and processing information about the self. Journal of Personality and Social Psychology, 35, 63-78.

Markus, H., \& Nurius, P. (1986). Possible selves. American Psychologist, 41, 954-969.

Marsick, V. J., \& Watkins, K. E. (2001). Informal and incidental learning. New Directions for Adult and Continuing Education, 89(Spring), 25-34.

Martin, P., Y. (2004). Gender as a social instiution. Social Forces, 82(4), 1249-1273.

Martin, W. (1986). Recent theories of narrative. Ithaca, NY: Cornell University Press.

Marton, F. (1994). Phenomenography. In T. Husen \& T. N. Postlethwaite (Eds.), The international encyclopaedia of education (2nd ed., Vol. 8, pp. 4424-4429). London: Pergamon.

Maruyama, M. (1974). Paradigmotology and its applications to cross-disciplinary, cross professional and cross-cultural communication. Dialectica, 28(3-4), 135-194.

Massey, A. (1996). Using the literature: 3 x 4 analogies. The Qualitative Report, 2(4).

Maynard, M. (1994). Methods, practice and epistemology: The debate about feminism and research. In M. Maynard \& J. Purvis (Eds.), Researching women's lives from a feminist perspective (pp. 10-26). London: Taylor \& Francis.

Mead, G. (1934). Mind, self and society. Chicago: University of Chicago Press.

Mento, A. J., \& Larson, J. C. (2004). Epiphany: A story of improving teaching effectiveness in an Executive MBA economics course. Journal of Executive Education, 3(1), 17-36.

Mezirow, J. (1994). Understanding transformation theory. Adult Education Quarterly, 4, 222-232.

Michaels, E., Handfield-Jones, H., \& Axelrod, B. (2001). The war for talent. Boston: Harvard Business School Press.

Miles, M. M. (1979). Qualitative data as an attractive nuisance: The problem of analysis. Administrative Science Quarterly, 24(4), 590-601.

Millett, B. (1994). Identifying a model of institutional change: The transition college of advanced education to university. Unpublished Doctoral dissertation, Griffith University, Brisbane, Australia.

Milliken, P. J., \& Schreiber, R. S. (2001). Grounded theory and symbolic interactionism. In R. S. Schreiber \& P. N. Stern (Eds.), Using grounded theory in nursing. New York: Springer. 
Mills, J., Bonner, A., \& Francis, K. (2006a). Adopting a constructivist approach to grounded theory: Implications for research design. International Journal of Nursing Practice, 12, 813.

Mills, J., Bonner, A., \& Francis, K. (2006b). The development of constructivist grounded theory. International Journal of Qualitative Methods, 5(1). Retrieved from http://www.ualberta.ca/ iiqm/backissues/5 1/pdf/mills.pdf

Mingers, J. (2003). A classification of the philosophical assumptions of management science methods. Journal of Operational Research Society, 54, 559-570.

Mingers, J., \& Brocklesby, J. (1997). Multimethodolgy: Towards a framework for mixing methodologies Omega International Journal of Management Science, 25(5), 489-509.

Morse, J. M. (2001). Situating grounded theory within qualitative inquiry. In R. S. Schreiber \& P. N. Stern (Eds.), Using grounded theory in nursing. New York: Springer.

Mouly, S., \& Sankaran, J. K. (2000, September). The tall poppy syndrome in New Zealand: An exploratory investigation. Paper presented at the 2nd annual conference of the International Association of Insight and Action, Brisbane, Australia.

Muczyk, J. P., \& Adler, T. (2002). An attempt at a consentience regarding formal leadership. Journal of Leadership and Organisational Studies, 9(2), 2-17.

Mullins, L. J. (1993). Management and organisational behaviour. London: Pitman.

Munhall, P. (1989). Philosophical ponderings on qualitative research methods in nursing. Nursing Science Quarterly, 2(1), 20-28.

Munhall, P., \& Boyd, C. (1993). Nursing research: A qualitative perspective. New York: National League for Nursing Press.

Nadler, D. A., Shaw, R. B., \& Walton, A. E. (Eds.). (1995). Discontinuous change: Leading organisational transformation. San Francisco: Jossey-Bass.

Norburn, D. (1989). The chief executive: A breed apart. Strategic Management Journal, 10(1), 115.

Northouse, P. G. (2004). Leadership: Theory and practice. Thousand Oaks: Sage.

Orb, A., Eishauer, L., \& Wynaden, D. (2001). Ethics in qualitative research. Journal of Nursing Scholarship, 33(1), 93-96.

Ospina, S., \& Schall, E. (2001). Perspectives on leadership: Our approach to research and documentation for the leadership for a changing world programme Retrieved October 2, 2004, from http://leadershipforchange.org/research/papers/perspectives.php3

Parry, J. (2003). Making sense of executive sensemaking. Journal of Health Organisation and Management, 17(4), 240-263.

Parry, K. (2001). Introduction. In P. K.W. (Ed.), Leadership in the antipodes: Findings, implications and a leader profile. Wellington: Institute of Policy Studies and the Centre for the Study of Leadership 
Parry, K. W. (1997). Enhancing adaptability: A grounded theory of organisational leadership as a social process. Unpublished Doctoral dissertation, Monash University, Australia, Melbourne.

Parry, K. W. (1998). Grounded theory and social process: A new direction for leadership research. Leadership Quarterly, 9(1), 85-105.

Patton, M. Q. (1990). Qualitative evaluation and research methods. Newbury Park, CA: Sage.

Patton, M. Q. (2002). Qualitative research and evaluation methods. Thousand Oaks, CA: Sage.

Pearsall, J. (Ed.). (1999). Concise Oxford dictionary. Oxford, England: Oxford University Press.

Perkins, S. J. (2000). The people dimension: A European perspective on globalisation. Workspan, 43(10), 16-20.

Perry, C., Riege, A., \& Brown, L. (1999). Realism's role among scientific paradigms in marketing research. Irish Marketing Review, 12(2), 16-23.

Petrick, J. A., Scherer, R. F., Brodzinski, J. D., Quinn, J. F., \& Ainina, M. F. (1999). Global leadership skills and reputational capital: Intangible resources for sustainable competitive advantage. Academy of Management Executive, 13(1), 58-69.

Pettigrew, A., \& Whipp, R. (1991). Managing change for competitive success. Oxford, England: Blackwell.

Pfeifer, D. M. (2005). Leadership in Aotearoa New Zealand: Maori and Pakeha perceptions of outstanding leadership. Unpublished Masters of Management Thesis, Massey University, Wellington.

Phillips, J., \& Hearn, T. (2008). Settlers, New Zealand immigrants from England, Ireland and Scotland : 1800-1945. Auckland: Auckland University Press.

Pye, A. (2002). Leadership in organising: Sensemaking in action. Paper presented at the EIASM Workshop, Oxford.

Ranson, S., Hinings, B., \& Greenwood, R. (1980). The structuring of organisational structures. Administrative Science Quarterly, 25, 1-17.

Richards, L., \& Richards, T. (1997). QSR NUD*IST: Software for qualitative data analysis. Melbourne, Australia: Scolari Sage.

Ritchie, J., \& Lewis, J. (2003). Qualitative research practice: A guide for social science students and researchers. Thousand Oaks: Sage.

Ritter, B. A., \& Lord, R. G. (2004). Schemata, scripts and mental models. In G. R. Goethals, G. J. Sorenson \& J. Burns (Eds.), Encyclopaedia of leadership (Vol. 4). Thousand Oaks, CA: Sage.

Robbins, S. P., Millett, B., Cacioppe, R., \& Waters-Marsh, T. (1999). Organisational Behaviour: Leading and Managing in Australia and New Zealand. Sydney.

Rose, K., \& Webb, C. (1998). Benefits and limitations of professional-family interactions: The family perspective. Archives of Psychiatric Nursing, 12(3), 556-562. 
Rost, J. C. (1991). Leadership and management. In G. R. Hickman (Ed.), Leading organisations: Perspectives for a new era (pp. 97-114). Thousand Oaks, CA: Sage.

Rost, J. C. (1993). Leadership for the 21 st century. Westport, CT: Praeger.

Rowe, G. W. (2001). Creating wealth in organisations: The role of strategic leadership. The Academy of Management Executive, 15(1), 81-94.

Scheibe, K. E. (1995). Self studies: The psychology of self and identity. Westport, CT: Praeger.

Schein, E. H. (1992). Organisational culture and leadership. San Francisco: Jossey Bass

Schneider, S., \& De Meyer, A. (1991). Interpreting and responding to strategic issues: The impact of national culture. Strategic Management Journal, 12(4), 307-320.

Schreiber, R. S. (2001). The "how to" of grounded theory: Avoiding the pitfalls. In R. S. Schreiber \& P. N. Stern (Eds.), Using grounded theory in nursing. New York: Springer.

Schreiber, R. S., \& Stern, P. N. (Eds.). (2001). Using grounded theory in nursing. New York: Springer.

Schwandt, T. A. (1994). Constructivist, interpretivist approaches to human inquiry. In N. K.

Denzin \& Y. S. Lincoln (Eds.), Handbook of qualitative research (pp. 118-137). Thousand Oaks, CA: Sage.

Selznick, P. (1957). Leadership in administration: A sociological interpretation. Evanston, IL: Row Peterson.

Shaw, J. B. (1990). A cognitive categorisation model for the study of intercultural management. The Academy of Management Review, 15(4), 626-645.

Skodol-Wilson, H., \& Ambler-Hutchinson, S. (1996). Methodological mistakes in grounded theory. Health Research, 45(2), 122-124.

Smircich, L., \& Morgan, G. (1982). Leadership: The making of meaning. Journal of Applied Behavioural Science, 18(3), 257-273.

Smith, L. T. (2005). On tricky ground: Researching the native in the age of uncertainty. In N. K. Denzin \& Y. S. Lincoln (Eds.), The Sage handbook of qualitative research (3 ed., pp. 85107). Thousand Oaks, CA: Sage.

Sorcher, M., \& Brant, J. (2002). Are you picking the right leaders? Harvard Business Review, 80(2), 78-85.

Speziali, H. S., \& Carpenter, D. R. (2003). Qualitative research in nursing: Advancing the humanistic imperative (3 ed.). Philadelphia, PA: Lippincott Williams \& Wilkins.

Statistics-New-Zealand (2002). New Zealand stories Retrieved 12 March, 2002, from http://www.stats.govt.nz

Steel, G. (1997, August). Global leadership in a mature multinational enterprise: Symposium on global leadership in the 21st century. Paper presented at the Academy of Management, Boston, MA. 
Stein, D. (1998). Situated learning in adult education: Retrieved September, 1, 2005, from http://www.ericdigests.org/1998-3/adult-education.html

Stein, N. L., \& Trabasso, T. (1982). What's in a story? An approach to comprehension and instruction. In R. Glaser (Ed.), Advances in instructional psychology (Vol. 2, pp. 213267). Hillsdale, NJ: Erlbaum.

Stern, P. N. (1994). Eroding grounded theory. In J. M. Morse (Ed.), Critical issues in qualitative research methods (pp. 212-223). Thousand Oaks, CA: Sage.

Stogdill, R. (1974). Handbook of leadership. New York: Free Press.

Storey, J. (2005). What next for strategic-level leadership research. Leadership, 1(1), 89-104.

Strauss, A. (1987). Qualitative data analysis for social scientists. Cambridge, England: Cambridge University Press.

Strauss, A., \& Corbin, J. (1990). Basics of qualitative research: Grounded theory procedures and techniques. Newbury Park, CA: Sage Publications.

Strauss, A., \& Corbin, J. (1994). Grounded theory methodology: An overview. In N. K. Denzin \& Y. S. Lincoln (Eds.), Handbook of qualitative research: Sage Publications.

Strauss, A., \& Corbin, J. (1998). Basics of qualitative research: Techniques and procedures for developing grounded theory. Thousand Oaks, CA: Sage.

Streubert, H., \& Carpenter, D. R. (1999). Qualitative research in nursing: Advancing the humanistic imperative. Philadelphia, PA: Lippincott.

Stryker, S. (1962). Conditions of accurate role-taking. In M. Arnold (Ed.), Human behaviour and social processes. Boston: Houghton Mifflin.

Svensson, L., \& Theman, J. (1983). The relation between categories of description and interview protocol in a case of phenomenographic research. Goteborg, Sweden: Department of Education, University of Goteborg.

Sword, W. (1999). Accounting for the presence of self: Reflections on doing qualitative research. Qualitative Health Research, 9(2), 270-278.

Talkington, A. (2001). Global leadership: What chemical industry CEO's think about managing the global enterprise. 2002(March). Retrieved from http://www.chemexpo.com/cmronline/login.cfm

Tellis, W. (1997a). Application of case study methodology. The Qualitative Report, 3(3).

Tellis, W. (1997b). Introduction to case study. The Qualitative Report, 3(2).

Thomas, J. B., Clark, S. M., \& Gioa, D. A. (1993). Strategic sensemaking and organisational performance: Linkage among scanning, interpretation, action and outcomes. Academy of Management Journal, 36(2), 239 - 270.

Tregoe, B. B., \& Tobia, P. M. (1990). Assessing the strategic health of your organisation. Management Review, 79(8), 10-15. 
Tsui, A. S. (2004). Contributing to global management knowledge: A case for high quality indigenous research. Asia Pacific Journal of Management, 21, 491-513.

Turner, B. A. (1983). The use of grounded theory for the qualitative analysis of organisational behaviour. Journal of Management Studies, 20(3), 333-348.

Turner, J. (1997). The institutional order. New York: Longman.

Vakkari, P., \& Kuokkanen, M. (1997). Theory growth in information science: Applications of a theory of science to a theory of information seeking. Journal of Documentation, 53(5), 497-519.

Vaughan (2005, October 8). The (big) buck stops here. Dominion Post.

Vecchio, R. P. (1995). Organisational behaviour. Orlando, FL.: Harcourt Brace.

Vrasidas, C. (2001). Interpretivism and symbolic interactionism: Making and familiar strange and interesting again in educational technology and research. In W. Heinecke \& J. Willis (Eds.), Research methods in educational technology (pp. 81-99). Greenwich, CT.: Information Age.

Watkins, T. (2003, July 14). Compared to lotto winners: Business people less respected. Dominion Post.

Weick, K. E. (1987). Substitutes for strategy. In D. J. Teece (Ed.), Competitive challenge. Cambridge. MA: Ballinger.

Wenger, E. (1997). Practice, learning, meaning, identity. Training, 34(2), 38-39.

Wenger, E. (1998). Communities of practice: Learning as a social system. Systems Thinker, June.

Wenger, E. C., \& Snyder, W. M. (2000). Communities of practices: The organisational frontier. Harvard Business Reviw, Jan-Feb, 139-145.

Wright, L. L., Lane, H. W., \& Beamish, P. W. (1988). International management research: Lessons from the field. International Studies of Management \& Organisation, 18(3), 5571.

Wright, P. L. (1996). Managerial leadership. London: Routledge.

Yin, R. K. (1994). Case study research; Design and methods (2nd ed. Vol. 5). Newbury Park, CA: Sage.

Yukl, G. (2002). Leadership in organisations (5th ed.). Englewood, NJ: Prentice Hall.

Yukl, G. (2004). Leadership in organisations (6th ed.). Englewood New Jersey: Prentice Hall.

Zaccaro, S. J., \& Banks, D. J. (2001). Leadership, vision, and organisational effectiveness. In S. J. Zaccaro \& R. J. Klimoski (Eds.), The nature of organisational leadership. San Francisco: Jossey-Bass.

Zaccaro, S. J., \& Horn, Z. (2003). Leadership theory and practice: Fostering an effective symbiosis. Leadership Quarterly, 14, 769-806.

Zaleznik, A. (1977). Managers and leaders: Are they different? Harvard Business Review(MayJune), 67-78. 
Zikmund, W. (2000). Business Research Methods (6 ed.). Orlando, FL: Dryden Press. 


\section{Appendices}

\section{Appendix A: Received Ethics Approval}

\section{VICTORIA UNIVERSITY OF WELLINGTON}

Te Whare Wananga. o te Upoko o te Ika a Maui

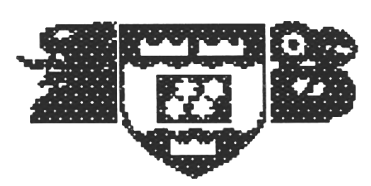

Dr Sally Davenport

Associate Dean, Graduate Studies \& Research

Faculty of Commerce \& Administration

P.O. Box 600

Wellington, New Zealand
Telephone: (04) 4635144

(If no reply): (04) 4635943

International: + 6444635777

Facsimile: (04)495-5076

E-mail:

Sally.Davenport@vuw.ac.nz

$\boldsymbol{R E F}: 2002-109$

To : Beverley McNally

On behalf of: Sally Davenport, Associate Dean, Graduate Studies and Research

Please note that the Human Ethics Committee has reviewed and approved your application for the project "The Global Managers: An analysis of the impact of the global environment on the acquisition of executive business leadership and the implications for HR policies and processes ".

Date: $5^{\text {th }}$ March 2003

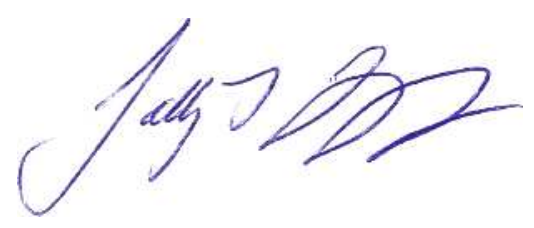

Dr Sally Davenport 


\title{
Appendix B: Information sheet for participants
}

\author{
VICTORIA UNIVERSITY OF WELLINGTON \\ Te Whare Wananga o te Upoko o te Ika a Maui
}

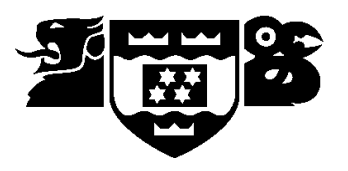

\section{RESEARCH PROJECT:}

\section{CEO Research Project}

\section{INFORMATION SHEET}

This aim of this research project is to explore a number of issues impacting on Boards, CEOs and Senior Executives relating to their development in the New Zealand context. I am aiming to explore the existence and nature of these issues, and identify any interrelationships that may exist, in particular the impact and relevance of the global business environment on business leadership. The interview will cover issues regarding the competencies required of board members and CEOs and the development of the knowledge, skills and abilities that are required in leadership roles now and in the future.

For this project, I will conduct a semi-structured interview with you that will last no longer than two hours. I may also require a maximum of one hour with you some weeks later to ask clarifying and outstanding questions. To ensure accuracy in our data collection, I would like to be able to tape the interviews. However, you will have the opportunity to decline the taping. I will provide you with an opportunity to review correct and edit the transcript of the interviews.

With respect to matters of confidentiality, I will take the following steps to ensure that the information will not be disclosed or used in any way except to complete this research project. Your name will not be disclosed at any time. Names of people and organisations discussed in the interview will not be disclosed to anyone. All write-ups will be anonymous with regard to the identity of all people and organisations. The findings will be written in such a way that no links can be made between people and organisations. All information will be stored securely so that it cannot be accessed by anyone other than the two researchers named below. Once the project has been completed, all drafts, notes, documents, recordings and computer files containing interview data will be destroyed. 
This project is being conducted as part of my $\mathrm{PhD}$ research project. The project being conducted under the auspices of the Centre for the Study of Leadership at Victoria University of Wellington and is supervised by Dr Ken Parry.

The intent of the attached consent form is to make sure that you have been adequately informed about the purpose of this study, what it means for you, and the steps that will be taken to ensure confidentiality. Informed consent is a standard requirement of the Victoria University of Wellington Human Ethics Committee, which reviews the procedures being used whenever individuals are interviewed in a research study.

\section{CONTACT INFORMATION}

Dr. Ken Parry

Director of the Centre for the Study of Leadership

Victoria University of Wellington

P.O Box 600

Wellington

Tel: +64-4-463-5126

e-mail: ken.parry@vuw.ac.nz
Beverley McNally

Doctoral Researcher

Victoria University of Wellington

P.O. Box 600

Wellington

Tel +64-4-5730

e-mai:beverley.mcnally@vuw.ac.nz 


\title{
Appendix C: Informed consent form
}

\author{
VICTORIA UNIVERSITY OF WELLINGTON \\ Te Whare Wananga o te Upoko o te Ika a Maui
}

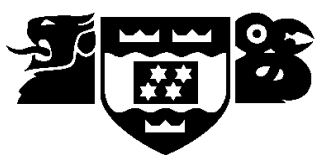

\section{RESEARCH PROJECT:}

CEO Project

INFORMED CONSENT FORM

The purpose of this form is to make sure that you have been adequately informed about the purpose of this study, what it means for you, and the steps that will be taken to ensure confidentiality.

I have been given a copy of the information sheet which describes the research project and I have had an opportunity to ask questions and have them answered to my satisfaction.

I understand that my participation is voluntary and that I may withdraw myself (or any information that I have provided) from this study without having to give reasons of any sort. I can decide if I want the interview to be taped or have the researcher take notes. I can see the transcripts if I want to. No one other than the researchers will have access to the tapes or notes. These will be securely stored and destroyed once the project is completed. I understand that no remarks made in the interviews will be attributed to me.

The researcher will supply preliminary general information about the research project, and any further information about the research project that I request, as long as this does not breach confidentiality for other participants.

Any other specific conditions for agreement:

I agree to take part in this research. I agree to have the interview taped

\section{Participant:}

Name: Title: Organization:....

Signature:

Date:

\section{Researcher:}

Signature:

Date: 


\title{
Appendix D: Preliminary research questions
}

\author{
CEO Project \\ Preliminary INTERVIEW SCHEDULE*
}

These are indicative questions only. They were used at the start of the project, the consequent direction of the interview and the responses of interviewees determine the exact wording of these questions, and the wording of intervening and supplementary questions. No matter how the interview progressed there was always an effort to introduce a 'counter question' - that is a question designed to cause the participant to reflect on the difference or opposite to their response

What are the major challenges confronting you in your role at the current time?

How are you responding to these challenges?

What is working well?

What is working not so well?

What challenges do your foresee in the future?

Why are these deemed to be challenges?

What could you do to meet these challenges?

What are the key experiences a successful executive in your organisation would have had to operate effectively until 10 years ago?

Are there any key experiences that are needed now that were not needed 10 years ago?

What about in 10 years time?

Why is this good or bad?

Think of CEOs (talented people) you know - what makes them effective?

What makes them less than effective?

What makes them stand out from the crowd?

What causes someone not to be perceived as a CEO leader?

Reflect on a challenging situation you have been confronted with recently - why did this occur?

How effective do you believe your response is?

What worked well?

What did not work so well?

* Note: In addition to these generic questions, in accordance with the process of theoretical sampling, the researchers plan to answer subsidiary, case-specific questions that emerge from the interview and from the analysis of the interview data.

I asked the interviewee to reflect on a CEO whom they considered to be effective in his or her role. I then asked them to reflect on what characteristics of an individual contributed to their effectiveness. I then asked them to think about a less than successful CEO. Then to identify the characteristics that contributed to their lack of success. 